\title{
Metal containing peptides as specific DNA binders
}

\author{
DISSERTATION
}

\author{
zur Erlangung \\ des mathematisch-naturwissenschaftlichen Doktorgrades \\ "Doctor rerum naturalium" \\ der Georg-August-Universität Göttingen \\ im Promotionsprogramm: IRTG 1422 \\ der Georg- August University School of Science (GAUSS)
}

vorgelegt von

Harita Rao

aus Kota, India

Göttingen 2015 


\section{Thesis Committee Members:}

Prof. Dr. Ulf Diederichsen

(Referent)

Prof. Dr. Franc Meyer

Prof. Dr. Sofi Elmroth

(Co-Referent)
Institut für Organische und Biomolekulare Chemie Georg-August- Universität Göttingen

Institut für Anorganische Chemie (Co-Referent) Georg-August- Universität Göttingen

Center for Molecular Protein Science

Lund Universitet, Lund, Sweden

\section{Members of the examination board:}

Prof. Dr. Ulf Diederichsen

Prof. Dr. Franc Meyer

Prof. Dr. Ivo Feußner

Prof. Dr. Claudia Höbartner

Prof. Dr. Kai Tittmann

Dr. Franziska Thomas

Date for thesis disputation:
Institut für Organische und Biomolekulare Chemie, Georg-August- Universität Göttingen

Institut für Anorganische Chemie, Georg-AugustUniversität Göttingen

Department of Plant Biochemistry, Georg-August- Universität Göttingen

Institut für Organische und Biomolekulare Chemie Georg-August- Universität Göttingen

Department of Molecular Enzymology, Georg-August- Universität Göttingen

Institut für Organische und Biomolekulare Chemie, Georg-August- Universität Göttingen

$9^{\text {th }}$ November, 2015 
This work was supported by the Deutsche Forschungsgemeinschaft via the International Research Training Group 1422 - Metal Sites in Biomolecules - Structures, Regulations \& Mechanisms and has been carried out under the supervision of Prof. Dr. Ulf Diederichsen at the Institut für Organische und Biomolekulare Chemie of the Georg-August-Universität Göttingen between September 2011 and September 2015.

I sincerely thank Prof. UIf Diederichsen for giving me an opportunity to work on various interdisciplinary and scientifically stimulating research topics within his group. I am also grateful for his generous support, guidance and for providing freedom of research during the course of this work. 



\section{Metal Containing Peptides as Specific DNA Binders}





\section{Table of Contents}

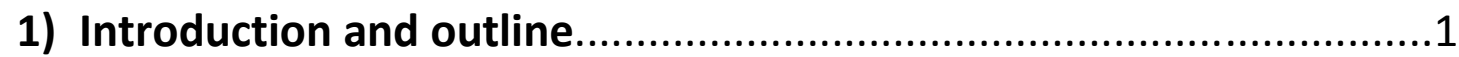

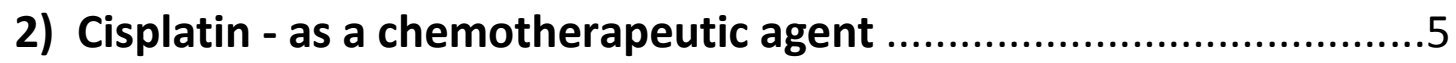

2.1 Platinum based chemotherapeutics..............................................

2.2 How does cisplatin function as an anticancer agent?......................

2.2.1 Entry and activation of cisplatin in the cells...................... 7

2.2.2 Covalent modification of DNA by cisplatin........................9

2.2.3 DNA distortion by cisplatin..........................................10

2.3 Proteins that recognize cisplatin-DNA adducts............................11

2.3.1 Repair Proteins.........................................................11

2.3.2 High mobility group (HMG) proteins............................12

2.3.3 Induction of apoptosis by binding of HMG domains .......13

2.3.4 Various other DNA binding and bending proteins............14

\section{3) Synthesis and DNA interaction of Pt complex/peptide chimera} mimicking Integration Host Factor..................................................17

3.1 A brief overview of chimeric platinum drugs..............................17

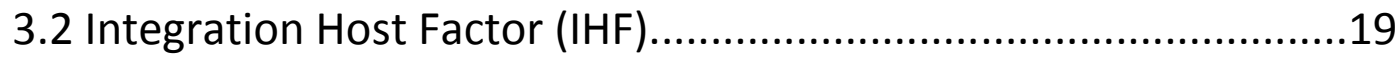

3.2.1 The consensus sequence of IHF...................................19

3.2.2 Structural features of IHF facilitating DNA interaction.....20

3.3 Design of the model peptide mimicking IHF................................22

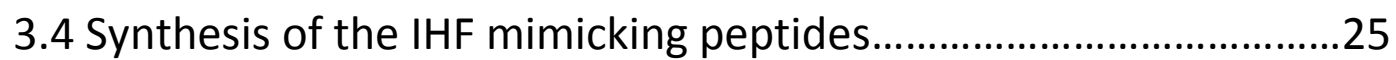

3.4.1 Synthesis of the amino acid building blocks......................26

3.4.2 Synthesis of the dendrimeric units................................28

3.4.3 Synthesis of the cyclic minor groove recognition units....29

3.4.4 Synthesis of the unplatinated IHF mimic..........................31

3.4.5 Synthesis of the Pt complex/peptide chimera..................32

3.5 DNA binding studies of the IHF mimicking peptides.....................33

3.5.1 Plasmid DNA unwinding studies.....................................33

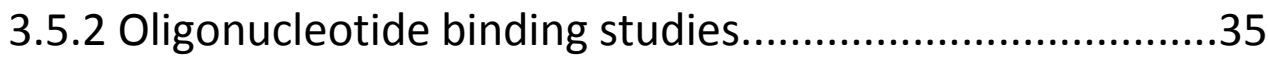

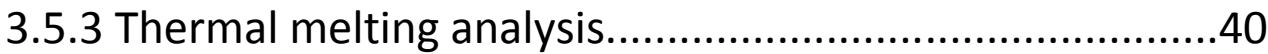


4) The Zif268 zinc finger domain- as a model nuclease. .45

4.1 The zinc finger domains.

4.2 Interaction of the $\mathrm{Cys}_{2} \mathrm{His}_{2}$ type of zinc finger domain Zif268 with the consensus DNA binding site. .46

4.3 Engineering zinc finger domains .50

4.3.1 Sequence selection 51

4.3.2 Zinc finger nuclease technology. .52

4.4 Hydrolytic cleavage of DNA phosphodiester linkage by multinuclear metal complexes..................................................54

4.4.1 Biomimetic systems as artificial nucleases. .56

4.4.2 Design of site specific model nucleases utilizing DNA recognition motifs

\section{5) Synthesis and DNA interaction of a modified Zif268 domain} containing an allosteric metal binding site.

5.1 Synthesis of artificial amino acid mimicking histidine. .60

5.2 Preparation of the synthetic Zf3 domain. .62

5.3 Expressed protein ligation 63

5.3.1 Protein expression in E. coli for the preparation of the Zf12 domain.

5.3.2 Preparation of $\mathrm{Zf13}$ domains by native chemical ligation 65

5.4 Determination of the structure and DNA recognition of the modified zinc finger domains..........................................................67



5.6 Plasmid DNA Cleavage Experiments..........................................72

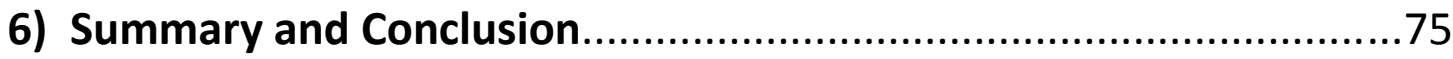

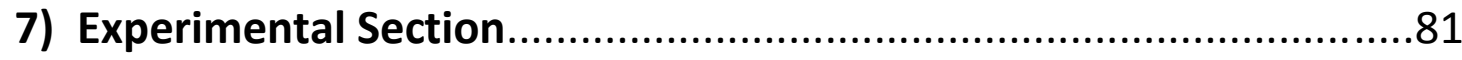

7.1 Materials and general methods applied for synthesis..................81

7.2 Materials and general methods applied in biochemistry..............87 


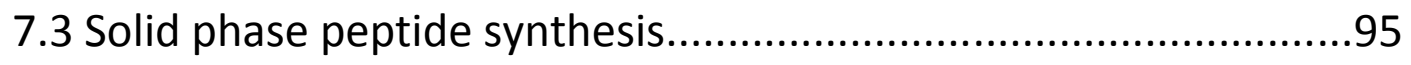

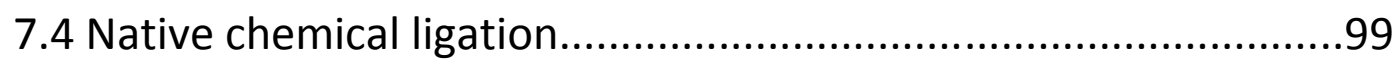

7.5 Synthesis of artificial building blocks contained in IHF mimicking

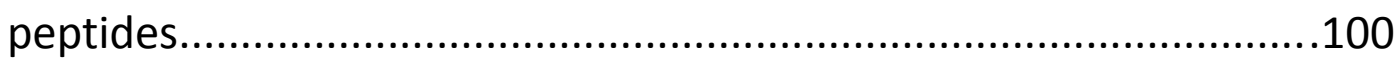

7.5.1 Synthesis of platinum chelating unit.............................100

7.5.2 Synthesis of the dendrimeric building block..................110

7.5.3 Synthesis of the linking unit between the dendrimeric and the cyclic peptide..................................................................111

7.6 Synthesis of the IHF mimicking peptides...................................114

7.6.1 Synthesis of the cyclic peptide..........................................114



7.6.3 Synthesis of IHF-2 .........................................................121

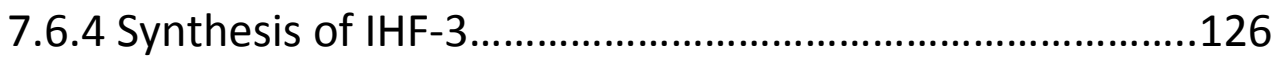

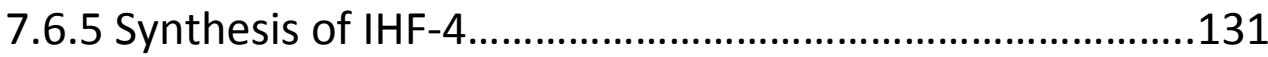

7.6.6 Synthesis of the platinated lysine dendrimer...................137

7.7 Synthesis of binuclear Histidine mimicking amino acid................140

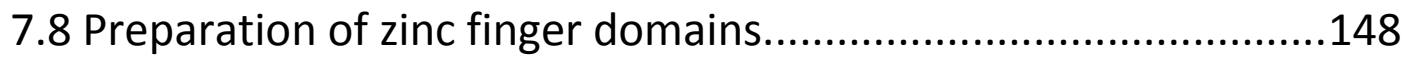

7.8.1 Solid phase synthesis of Zf3 domains............................148

7.8.2 Expression of Zf12 domain............................................155

7.8.3 Preparation of $\mathrm{Zf13}$ domain by native chemical ligation between Zf3 and Zf12 peptide sequences..............................156

Appendix

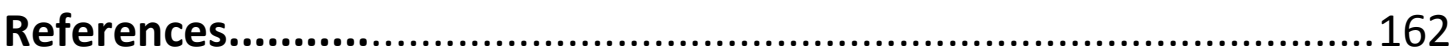

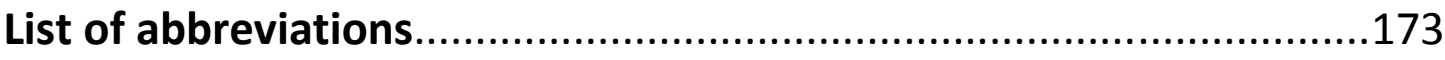

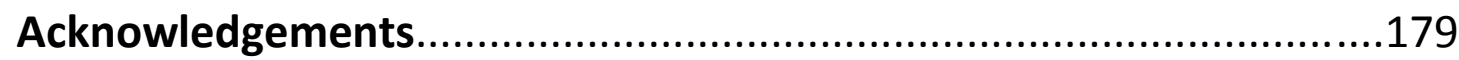

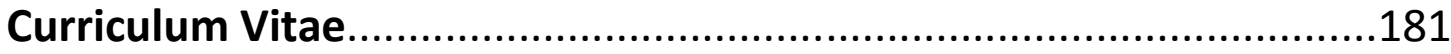





\section{Introduction and outline}

Deoxyribonucleic acid (DNA) as a genetic information carrier plays an essential role in the development and functioning of every living organism. The information stored in the DNA sequences is transcribed into an intermediary molecule called messenger ribonucleic acid (mRNA). ${ }^{[1]}$ The mRNA guides the biosynthesis of proteins, which in turn interact with other biomolecules such as DNA scaffolds and assist in various cellular events such as replication, repair, regulation of gene expression as well as in the structuring of DNA itself. ${ }^{[2]}$ In most cases, metal ions play an important role in providing a basic biologically active structure and cellular functions to most of the enzymes. ${ }^{[3]}$ Understanding the significance of protein-DNA interactions and its correlation to genetic disorders has played a crucial role in the development of novel therapeutics in past few decades. Mimicking the active site of protein domains and studying their interactions with their consensus DNA sequences might assist in probing the binding pocket and furthermore, corroborates the understanding of their structural aspects, binding mode and binding parameters. Additionally, since metal ions are not only essential for the biological activity of most of the proteins but also have electrostatic affinity for the polyanionic nucleic acid targets (DNA/RNA) in the cell, incorporation of metal binding sites in such peptide sequences might render it with unique biochemical properties. In this line of thought, the following two projects were pursued during the course of this doctoral thesis.

Metal ions interact with DNA in numerous ways forming both covalent and non-covalent linkages. The cis- $\left(\mathrm{NH}_{3}\right)_{2} \mathrm{Pt}-\mathrm{dGpG}$ site is an example of a covalent modification of DNA by cisplatin, ${ }^{[4]}$ a widely used chemotherapeutic agent. Herein, the cis-diammineplatinum centre coordinates with two adjacent guanine residues at the N7 position forming an intrastrand crosslinked DNA. The resulting kinked DNA duplex is stabilized by the binding of a class of proteins called the high mobility group proteins, which inhibit the binding of 
cellular repair proteins and lead to cell death. In the first project, platinum complex/peptide chimeras mimicking the integration host factor (IHF) were synthesized and tested for their DNA binding abilities. IHF is a DNA architectural protein which sequence specifically binds to DNA and induces a bend $>160^{\circ}$ in dsDNA through minor grove intercalation (Figure $1.1 \mathrm{~A}) .^{[5]}$ The motivation behind the synthesis of such chimerical peptides is to enhance site specific targeting of cisplatin by means of peptideDNA recognition. Additionally, since IHF induces a drastic bend in the DNA double helix, tethering a platinum chelating unit to the IHF mimicking peptide might have a synergistic effect of the two on their DNA binding and bending abilities.

The design of the chimerical peptide is based on a model peptide proposed by E. K. Liebler that mimics IHF. ${ }^{[6]}$ The IHF mimicking peptide contains a small lysine dendrimer, a cyclic peptide core and a glycine oligomer (Figure $1.1 \mathrm{~B}$ ). The lysine dendrimer resembles the positively charged globular body of IHF whereas the cyclic peptide resembles the recognition unit that interacts with the minor groove of DNA. The glycine oligomer not only contains the platinum chelating unit but also tethers to the dendrimer with the cyclic recognition unit. The DNA binding of the platinum containing IHF mimicking peptides in comparison with the anticancer drug cisplatin was tested by gel mobility shift assay and thermal melting analysis.
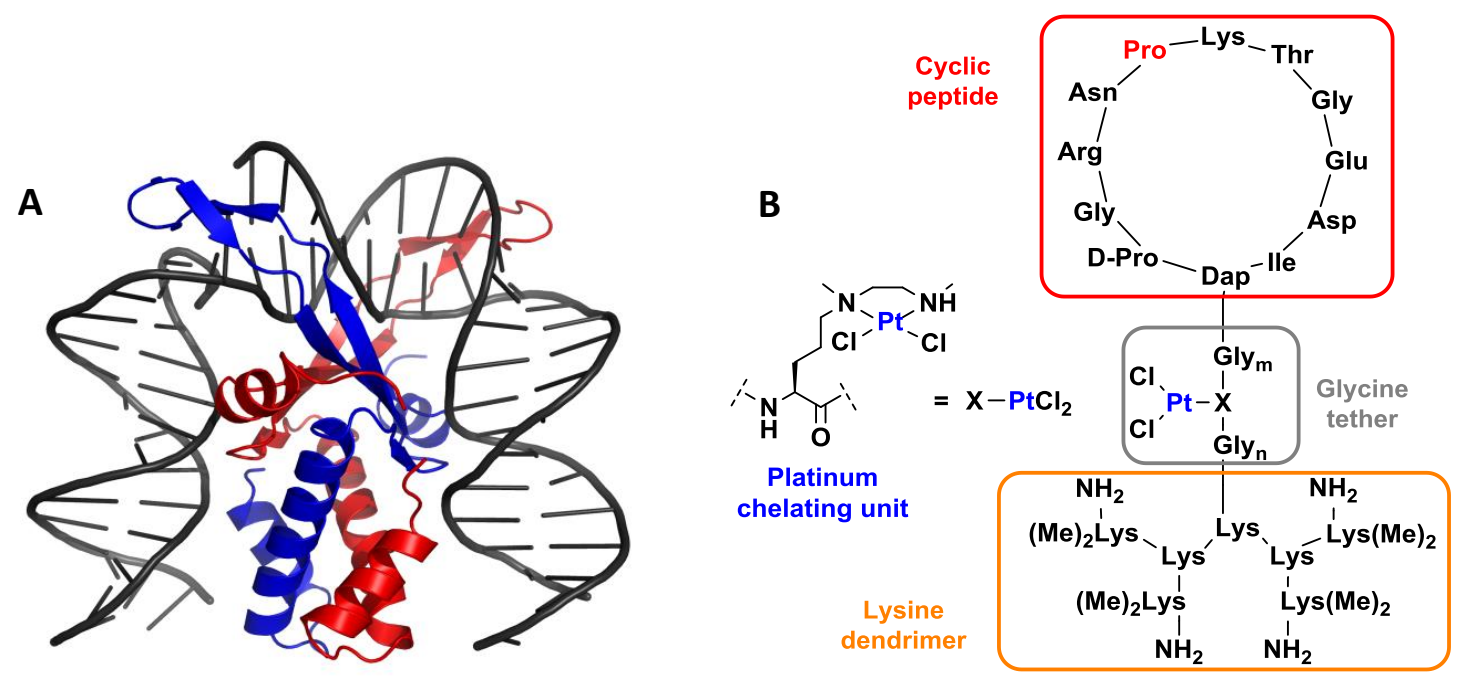

Figure 1.1: (A) IHF cocrystallized with its consensus DNA binding site. The image has been reproduced using PyMOL (PDB entry: $1 \mathrm{IHF}$ ). ${ }^{[5]}$ (B) The IHF mimicking model peptide consisting of a minor grove binding cyclic unit, a positively charged lysine dendrimer and a glycine linker including the platinum chelating unit. 
In a second project, a semi-synthetic method was utilized for the preparation of a zinc finger domain consisting of a tandem repeat of three zinc fingers. The Zif268, a Cys $\mathrm{His}_{2}$ type of zinc finger domain is one of the most abundant selective DNA binding proteins in the human organism and plays an important role in the regulation of transcriptional processes (Figure 1.2 A). ${ }^{[7,8]}$ Single fingers fold into a characteristic $\beta \beta \alpha$ structure which is induced by the coordination of a zinc ion. ${ }^{[9]}$ The $\alpha$-helix formed thereby serves as a recognition unit and binds to three consecutive base pairs in the DNA sequence. It is known that in nature for having better selectivity for target DNA sequences a tandem repeat of at least two zinc fingers is necessary while in most domains three or more zinc fingers are present.

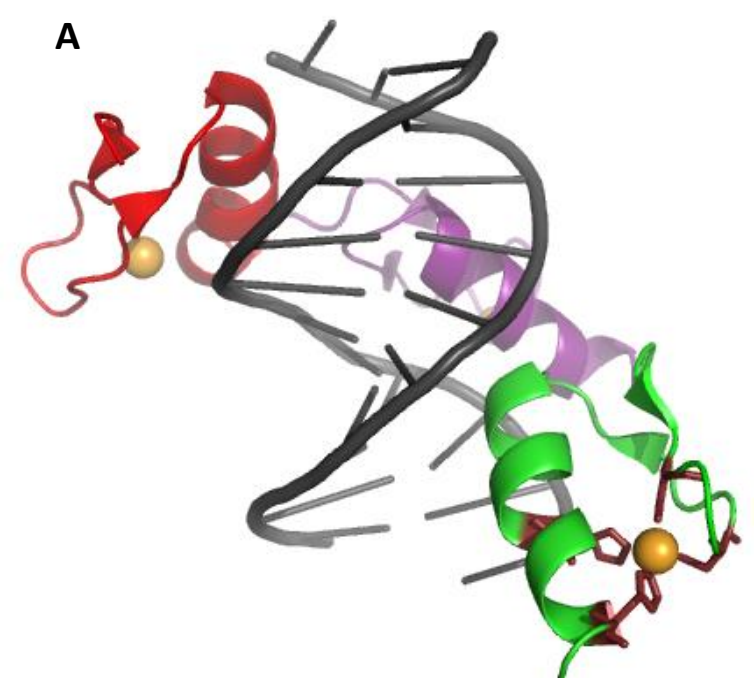

\section{B}

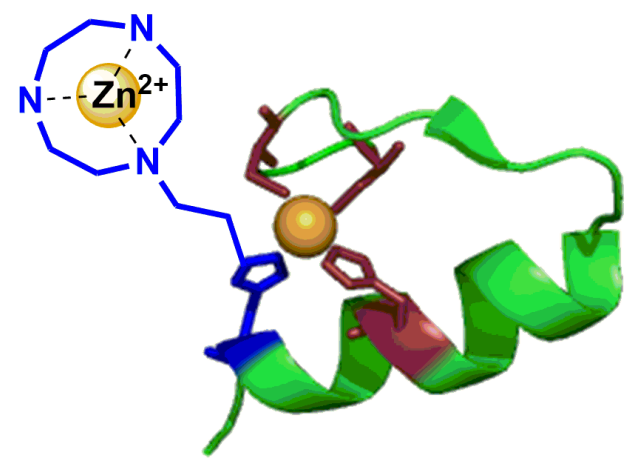

Figure 1.2: (A) Zif268 containing a tandem repeat of three zinc fingers wrapped around its consensus DNA binding site. (B) The $\mathrm{Zf3}$ domain modified to contain a triazacyclononane ligand as an additional $\mathrm{Zn}^{2+}$ coordination site. (pdb code: $1 \mathrm{AAY}) .{ }^{[9]}$ Image genetrated by PyMOL.

Following a semi-synthetic strategy, proposed by F. Fehr, ${ }^{[10]}$ the modified Zif268 domain containing a tandem repeat of three zinc fingers (Zf13) was constructed. The approach utilizes expressed protein ligation in which the zinc fingers 1 and 2 (Zf12) need to be expressed in E. coli whereas the zinc finger 3 (zf3) can be synthesized using conventional solid phase peptide synthesis (SPPS). A 1,2,3-triazole based histidine mimic reported by A. Nadler, ${ }^{[11]}$ containing an additional zinc binding site, was incorporated into the 
synthetic domain ( $\mathrm{Zf3}$ ) using SPPS (Figure 1.2 B). The two peptide fragments Zf12 and Zf3 were then linked together by applying native chemical ligation leading to the formation of the modified $\mathrm{Zf13}$ sequence. The introduction of the artificial amino acid within the Zf13 domain positions will place the metal centre in close proximity to DNA and might assist in sequence specific cleavage of DNA by hydrolyzing the phosphodiester bond. The modified zinc finger constructs were characterized using mass spectroscopy and their secondary structures were elucidated by utilizing CD spectroscopy. The preliminary experiments to test DNA binding and cleavage ability of the modified zinc finger were performed using CD spectroscopy and gel electrophoresis.

The ultimate goal of the work done in this $\mathrm{PhD}$ thesis is to mimic protein domains that have specific recognition and interaction with their corresponding DNA binding sites. The design and synthesis of metal containing peptides mimicking such appended protein domains offer a possibility to exploit their recognition properties to direct the peptide towards a particular DNA sequence and additionally, to modulate their biochemical reactivity with the target DNA. The novel library of peptides with enhanced cell penetrating, target directing and recognition properties generated henceforth has the potential to be developed as sequence specific therapeutic targets, artificial model nucleases as well as structure diagnostic probes. 


\section{Cisplatin - as a chemotherapeutic agent}

Metals play an important role in the regulation of numerous biochemical transformations in all living cells and as a consequence an excess or deficit of metal ions is associated with pathological disorders. ${ }^{[3]}$ Since almost 5000 years, medicinal inorganic chemistry has been applied for the treatment of various ailments such as diabetes, cancer, rheumatoid arthritis and cardiovascular diseases. ${ }^{[12]}$ The unique properties of metal complexes such as Lewis acidity, electrophilicity, redox activity, variable coordination modes and more importantly their ability to interact with the electron rich biomolecules such as DNA, RNA and proteins have made them interesting targets for the development of novel metallopharmaceuticals. ${ }^{[13,14]}$ In recent years, the importance of inorganic complexes in medicine as both therapeutic and diagnostic agents has enormously increased. ${ }^{[15]}$

\subsection{Platinum based chemotherapeutics}

Platinum based metal coordination complexes have found clinical value through their therapeutic efficacy against cancer. ${ }^{[16-19]}$ The first and one of the most famous examples of a platinum containing chemotherapeutic agent cisplatin, ${ }^{[20]}$ serendipitously discovered by Rosenberg in $1965^{[21]}$ was a stepping stone in the field of medicinal inorganic chemistry. Since the discovery of the biological activity of the drug, ${ }^{[22]}$ significant interest has been aroused amongst researchers to understand its mode of action against cancer. While several analogues of cisplatin have been synthesized for evaluating their anti-cancer potential, only a few of them have been registered as marketed chemotherapeutics ${ }^{[23,24,30]}$ (Figure 2.1) and till date cisplatin is the most effective drug for the treatment of ovarian, testicular, head, neck and bladder cancer. ${ }^{[25-28]}$ Currently, apart from cisplatin only two drugs, carboplatin and oxaliplatin, 
have received approval from the FDA and are in clinical use worldwide for the treatment of ovarian and colorectal cancer, respectively. ${ }^{[29,30]}$

$$
\begin{aligned}
& \mathrm{H}_{3} \mathrm{~N}^{-}-\mathrm{Pt}^{-}-\mathrm{Cl} \\
& \mathrm{H}_{3} \mathrm{~N}^{-}-\mathrm{Cl}
\end{aligned}
$$

Cisplatin<smiles>N[P+]1(N)OCC(=O)O1</smiles>

Nedaplatin<smiles>N[P+]1(N)OC(=O)C2(CCC2)C(=O)O1</smiles>

Carboplatin<smiles>CC(C)C1C[C@H]2CN[PH]3(NC[C@@H]2C1)OC(=O)CC(=O)O3</smiles>

Heptaplatin<smiles>O=C1CC(=O)O[P]2(N1)N[C@@H]1CCCC[C@H]1N2</smiles>

Oxaliplatin<smiles>C[C@@H]1CC(=O)O[P]2(NCC3CCC3CN2)O1</smiles>

Loboplatin

Figure 2.1: Chemical structures of platinum based drugs clinically approved for chemotherapy in at least one nation, of which only cisplatin, carboplatin and oxaliplatin have been approved worldwide. ${ }^{[30]}$

However, the usage of these commonly prescribed drugs owing to their poor solubility, poor oral bioavailability and lack of selectivity is associated with severe dose limiting side effects which include nephrotoxicity, neurotoxicity, ototoxicity and emetogenesis. ${ }^{[20]}$ In addition to these issues, another major drawback compromising their therapeutic utility is the presence of intrinsic resistance or onset of resistance followed by chemotherapy. ${ }^{[28]}$ The key to expanding the scope of platinum based chemotherapy lies in development of novel therapeutic targets that are able to minimize the toxic side effects and are more efficient in combating drug resistance. 


\subsection{How does cisplatin function as an anticancer agent?}

A thorough understanding of the mode of action of platinum based drugs against cancer is very important in order to develop novel anticancer drugs with improved properties as well as to enhance the chemotherapeutic efficacy of the existing class of drugs. This section sequentially sheds light on the string of complex cellular events that are responsible for the anticancer activity of cisplatin which include its cellular uptake and transport to the nuclear DNA, covalent modification of DNA in the chromatin, interaction of various cellular proteins with platinum-DNA adduct and inhibition of cellular repair machinery ultimately triggering cell death.

\subsubsection{Entry and activation of cisplatin in the cells}

Cisplatin is usually administered as an intravenous injection into the blood stream. In order to ensure a successful chemotherapy, the drug must be efficiently imported from the extracellular medium into the cell followed by formation of active species readily available for reaction with various cellular components. The cellular uptake of cisplatin occurs either by passive diffusion or by an active transport mechanism. ${ }^{[31,32]}$ Passive diffusion is an energy independent process and results from a concentration gradient of the drug molecules across the cell membrane. On the contrary, in an active transport mechanism a particular carrier molecule is responsible for the transport of a specific kind of cargo into the cells (Figure 2.2). The plasma membrane copper transporters, involved in the influx (Ctr1) and efflux (ATP7A and ATP7B) of copper have also shown to directly influence the accumulation and removal of platinum based metal complexes from the cell. ${ }^{[33-35]}$

In the blood stream, where the chloride concentration is much higher ( 100 mM) compared to the intracellular environment cisplatin exists in the relatively stable neutral form. The lower chloride concentration ( $3-20 \mathrm{mM})$ inside the cells leads to replacement of either one or both the chloride ions with water molecules. ${ }^{[36]}$ The resulting mono-aqua species $\left[\mathrm{Pt}\left(\mathrm{NH}_{3}\right)_{2} \mathrm{Cl}\left(\mathrm{OH}_{2}\right)\right]^{+}$and di-aqua species $\left[\mathrm{Pt}\left(\mathrm{NH}_{3}\right)_{2}\left(\mathrm{OH}_{2}\right)_{2}\right]^{2+}$ are the active form of 
the drug which can potentially react with various cellular constituents including cellular phospholipids, DNA, RNA, proteins, thiol containing molecules and cytoskeletal microfilaments. ${ }^{[37-39]}$.



Figure 2.2: Schematic representation of the mechanism of cisplatin influx and efflux across the cell membrane including formation of the more reactive aquated complex. ${ }^{[39]}$

There is also evidence supporting the formation of the hydroxo species, $\left[\mathrm{Pt}\left(\mathrm{NH}_{3}\right)_{2} \mathrm{Cl}(\mathrm{OH})\right]$ and $\left[\mathrm{Pt}\left(\mathrm{NH}_{3}\right)_{2}(\mathrm{OH})_{2}\right]^{+},{ }^{[40,41]}$ resulting from the loss of protons from the aqua complexes. However, the hydroxo species are rather inert towards substitution whereas the cationic mono-aqua species $\left[\mathrm{Pt}\left(\mathrm{NH}_{3}\right)_{2} \mathrm{Cl}\left(\mathrm{OH}_{2}\right)\right]^{+}$are readily available for reaction with the polyanionic DNA by means of electrostatic interactions. Side reaction of these species with cellular thiols is known to reduce the formation of cisplatin adducts with DNA and is considered to be one of the reasons for resistance development reducing the potency of the drug. 


\subsubsection{Covalent modification of DNA by cisplatin}

The cytotoxic effect of cisplatin predominantly arises from the binding of the mono-aqua complex $\left[\mathrm{Pt}\left(\mathrm{NH}_{3}\right)_{2} \mathrm{Cl}\left(\mathrm{OH}_{2}\right)\right]^{+}$with the $\mathrm{N} 7$ atoms of the purine bases resulting in the formation of covalent adducts with nuclear DNA. ${ }^{[42-47]}$ At first, the mono-functional adduct is formed by replacement of the water ligand with a guanine residue followed by aquation of the second chloride ion. Subsequent ring closure by nucleophilic attack of another neighboring N7 atom of a guanine or an adenine base pair leads to the formation of the bi-functional adduct with the same strand (intrastrand adduct) or opposite strands (interstrand adduct) of the DNA duplex. The various modes of cisplatin binding to DNA have been identified and structurally well characterized by performing enzymatic digestion of cisplatin modified DNA followed by chromatographic purification and NMR analysis of individual components. ${ }^{[48]}$ These studies reveal that the major components of adducts include 60-65\% 1,2-d(GpG), 20-25\% 1,2-d(GpA), 5-10\% $1,3-d(G p X p G)(X$ is an additional base pair between two guanines) intrastrand crosslinks and a small amount of interstrand $d(G p G)$ crosslinks (Figure 2.3).
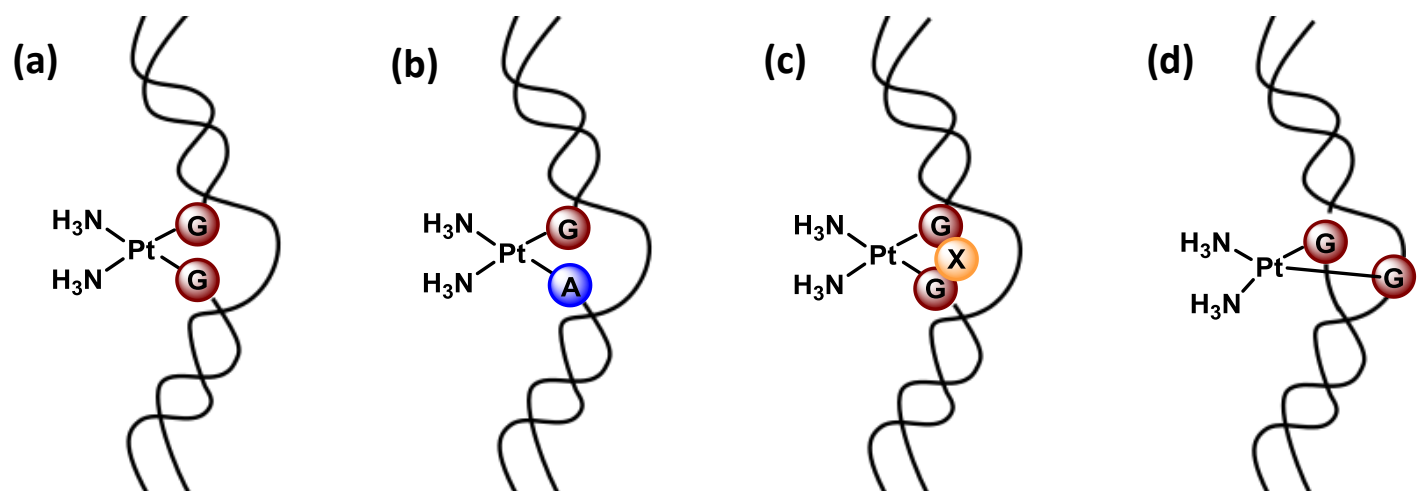

Figure 2.3: Representation of various kinds of adducts formed by binding of cisplatin to DNA. (a) Intrastrand 1,2-d(GpG) adduct; (b) intrastrand 1,2-d(GpA) adduct; (c) intrastrand 1,3-d(GpXpG) adduct and (d) interstrand $d(G p G)$ adduct. ${ }^{[48]}$ 


\subsubsection{DNA distortion by cisplatin}

X-ray crystallography and NMR studies have provided further insight into the structure of cisplatin-DNA adducts (Figure 2.4). ${ }^{[49-52]}$ The major adduct cis-[1,2- $\left.\left\{\mathrm{Pt}\left(\mathrm{NH}_{3}\right)_{2}\right\}^{2+} \mathrm{d}(\mathrm{GpG})\right]$ (Figure $2.4 \mathrm{a}$ ), formed by crosslinking between adjacent guanine residues on same strand of DNA distorts the duplex by inducing a bend of around $34^{\circ}$ towards the major groove as well as by local unwinding of about $13^{\circ}$ near the platination site. ${ }^{[33]}$ The intrastrand adduct cis-[1,3-\{Pt( $\left.\left.\left.\mathrm{NH}_{3}\right)_{2}\right\}^{2+} \mathrm{d}(\mathrm{GpTpG})\right]$ contains an additional nucleotide in between the crosslinked guanine residues (Figure $2.4 \mathrm{~b}$ ). The 1,3-intrastand adduct despite of exhibiting a more pronounced distortion in the proximity of the platination site has a much lower impact on the global structure of DNA compared to the 1,2-intrastrand crosslink. Contrary to the effect of intrastrand crosslinking, the interstrand crosslinking between guanine residues on opposite strands of the duplex induces a bend towards the minor groove of DNA (Figure $2.4 \mathrm{c}$ ). ${ }^{[51]}$ The formation of 1,2-intrastrand crosslinks is considered to be crucial for the chemotherapeutic efficacy of the cisplatin as experiments indicate that the therapeutically inactive trans isomer of cisplatin, transplatin, is unable to form them. ${ }^{[54,55]}$

(a)



(b)

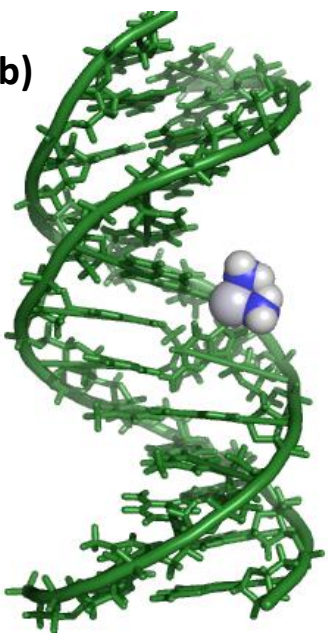

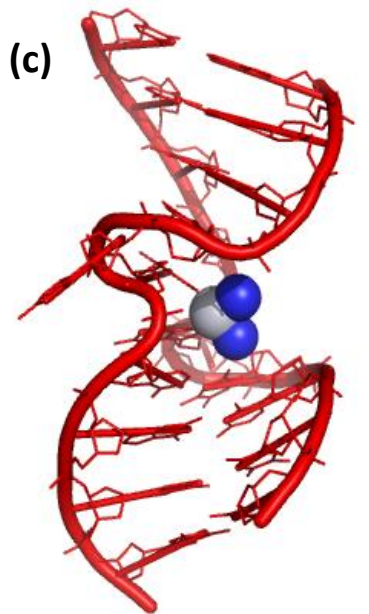

Figure 2.4: Structures of cisplatin-DNA adducts formed by covalent crosslinking between cisplatin and DNA. (a) cis-[1,2- $\left.\left\{\mathrm{Pt}\left(\mathrm{NH}_{3}\right)_{2}\right\}^{2+} \mathrm{d}(\mathrm{GpG})\right]$, pdb code: $1 \mathrm{AlO}{ }^{[49]}$ (b) cis-[1,3-\{Pt($\left.\left.\left(\mathrm{NH}_{3}\right)_{2}\right\}^{2+} \mathrm{d}(\mathrm{GpTpG})\right]$, pdb code: $1 \mathrm{DA} 4 ; ;^{[50]}$ and (c) interstrand $\mathrm{d}(\mathrm{GpG})$ adduct, pdb code: $1 \mathrm{~A} 2 \mathrm{E} .{ }^{[51]}$ Images generated by PyMOL. 


\subsection{Proteins that recognize cisplatin-DNA adducts}

The distorted DNA resulting from covalent crosslinking with cisplatin is recognized by mainly two classes of proteins. The first class consists of repair proteins which upon binding trigger a cellular mechanism to repair the damaged DNA. Resistance development in platinum based chemotherapy has been found to be more explicit in cells with increased repair of the damaged DNA. ${ }^{[56-58]}$ This indicates a direct correlation between cellular repair and the mode of action of platinum containing chemotherapeutics. The second class consists of architectural proteins belonging to the family of high mobility group (HMG) proteins which bind to the kinked structure of DNA and further stabilize the bend. This inhibits the repair process of the damaged DNA and thus, interferes with various cellular responses including DNA replication and transcription. ${ }^{[59]} \mathrm{A}$ thorough understanding of the binding interactions of these proteins with cisplatin-DNA lesions is essential to study their influence on the cytotoxicity and molecular mechanism of the drug.

\subsubsection{Repair proteins}

Various repair proteins recognize a different kind of DNA damage, for instance, that resulting from UV radiation, chemical agents or cisplatin-DNA lesions. Upon recognition, they prompt a damage repair pathway. The major pathways for repairing cisplatin induced DNA damage include nucleotide excision repair (NER) ${ }^{[59]}$ or the mismatch repair pathway $(M M R)^{[60]}$. In the NER pathway an assembly of repair proteins such as TFIIH, XPA, RPA function together to specifically recognize and repair the intrastrand crosslinked DNA. ${ }^{[61]}$ Cell lines with deficient NER were found to exhibit greater sensitivity towards cisplatin. ${ }^{[62,63]}$ In the MMR pathway in human cell lines, the MMR protein hMutS $\alpha$ and its subunit hMSH2 bind to cisplatin-DNA lesions with rather high specificity considering it as a mismatch. ${ }^{[64-66]}$ The mismatch repair in the unplatinated nascent strand is not possible as long as the cisplatin-DNA lesion is still present in the template strand. ${ }^{[64]}$ Several futile attempts of MMR could ultimately trigger a signal for apoptosis and result in cell death. 


\subsubsection{High mobility group (HMG) proteins}

The high mobility group (HMG) domains are non-histone proteins involved in the structuring of DNA or proteins present in the nucleus or chromatin of the cells in order to form higher order protein-DNA and protein-protein complexes. ${ }^{[61,67-69]}$ Depending on the specificity of the HMG proteins to recognize a target DNA sequence, they are sub-divided into two categories. The first consists of proteins such as HMG1, HMG2, the mitochondrial transcription factor (mtTFA) and the upper binding factor (UBF) that lack sequence specificity and are often referred to as structure specific HMG domains. The second category consists of sequence specific DNA binding proteins such as the sex determining factor (SRY) and the lymphoid enhancer factor (LEF-1). Upon binding, all HMG domain proteins predominantly act either by bending DNA or by stabilizing the prebent DNA, thereby facilitating its efficient recognition and interaction with other proteins required for performing essential nuclear processes. Structural analysis of complexes between HMG domains and their corresponding cognate DNA sequences reveal a sharply bent duplex with amino acid side chains of the protein inserted between the base pairs. ${ }^{[70,71]}$

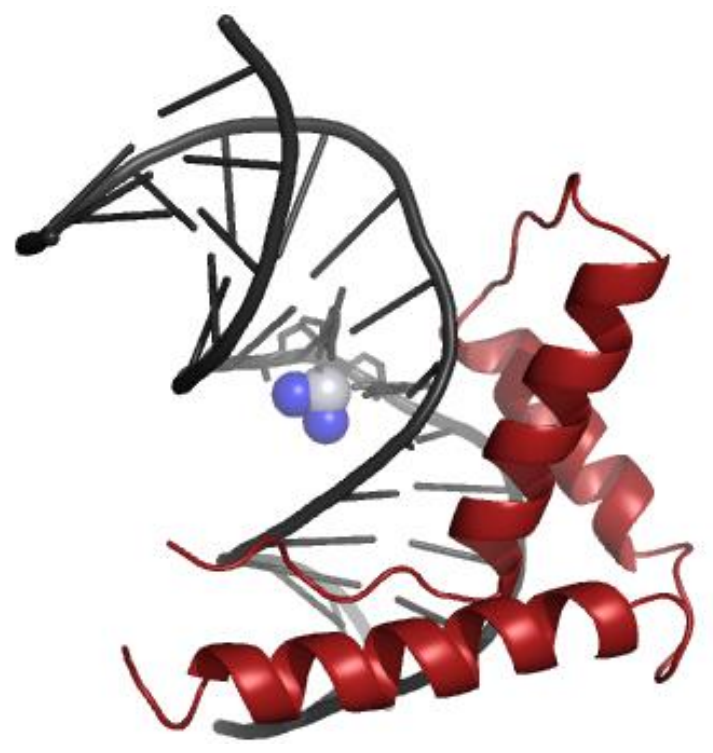

Figure 2.5: X-ray crystal structure of a complex between the rat HMG1 domain $A$ and a 16-mer DNA sequence containing a 1, 2-d(GpG) adduct with cisplatin, pdb code: $1 \mathrm{CKT} .^{[74]}$ Images generated by PyMOL. 
The HMG1 proteins consisting of two DNA binding domains, $A$ and $B$, were found to recognize the bent DNA containing cisplatin induced $1,2-d(G p G)$ and 1,2-d(ApG) intrastrand crosslinks more specifically compared to DNA modified by pharmacologically inactive platinum analogues. ${ }^{[72,73]}$ The HMG1 domain protein obtained from rat was cocrystallized with a 16 base pair DNA sequence with a single intrastrand 1,2-d(GpG) crosslink formed by cisplatin (Figure 2.5 ) and their interactions were studied in detail. ${ }^{[74]}$ The L-shaped protein consisting of three $\alpha$-helices binds to the minor groove of DNA while introducing a bend of $61^{\circ}$ towards the major groove. Additionally, the binding results in flattening of the major groove and broadening of the minor groove. The hydrophobic side chain of the Phe37 residue intercalates into the minor groove resulting in destacking of guanines at the 1,2-d(GpG) site. The mutation of this phenylalanine residue with an alanine drastically reduced the binding affinity of the protein domain for cisplatin damaged DNA. ${ }^{[75,76]}$

\subsubsection{Induction of apoptosis by binding of HMG domains}

One of the plausible mechanisms mediating cytotoxicity of cisplatin-DNA adducts is by formation of a complex with HMG box proteins which triggers a signal for apoptosis. ${ }^{[77]}$

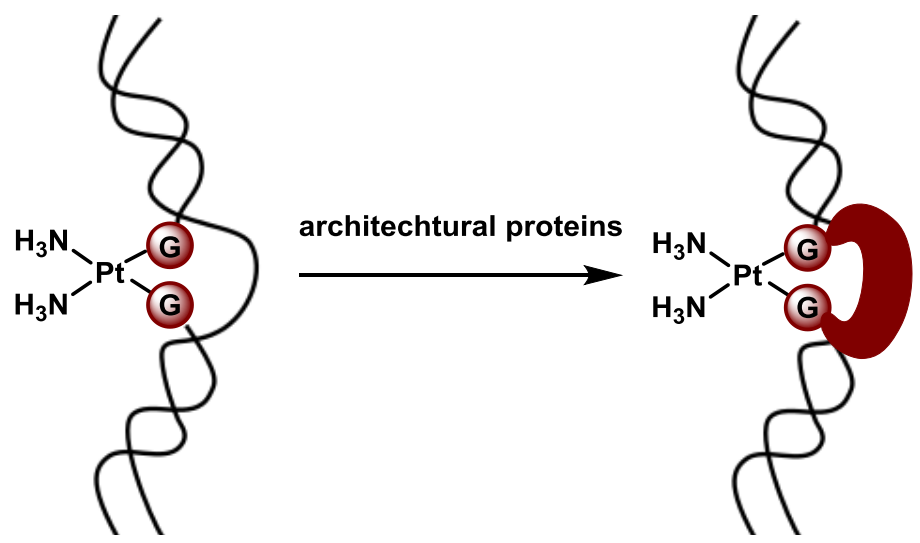

DNA Repair Complex

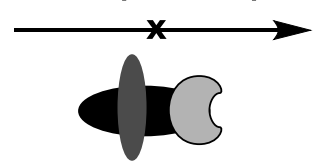

CELL DEATH

Figure 2.6: A schematic representation of the repair shield model in which binding of the architectural proteins to 1,2-intrastrand $d(G p G)$ cisplatin-DNA adduct inhibits the repair process by blocking the binding of repair proteins and ultimately leads to cell death. ${ }^{[78]}$ 
Several studies clearly indicate that the binding of architectural proteins such as HMG1, mTFA, tsHMG or SRY to the damaged 1,2-d(GpG) site shields its recognition from the cellular repair machinery, particularly blocking the nucleotide excision repair pathway and ultimately triggers cell death (Figure 2.6). ${ }^{[59,78,79]}$ Consistent with this model, termed as the repair shield model, cell extracts with deficient HMG1 and HMG2 expression exhibited an enhanced repair of cisplatin damaged DNA. ${ }^{[80]}$ Additionally, steroid induced overexpression of HMG1 in breast cancer cells sensitizes them towards cisplatin treatment. ${ }^{[81]}$ Apart from this model, the "transcription factor hijacking" model also justifies the role of HMG domain proteins in cancer treatment. ${ }^{[61]}$ Transcription factors such as hUBF bind to cisplatin damaged DNA with a high affinity and as a result, there is a competition between the promoter sequence and the cisplatin-DNA lesions. ${ }^{\left[{ }^{82]}\right.}$ In this way cisplatin treatment inhibits the transcription process and endangers the cell survival. ${ }^{[83]}$ The crucial role of DNA architectural proteins such as HMG domains in cancer treatment make them an interesting pharmacological target.

\subsubsection{Various other DNA binding and bending proteins}

Eukaryotic histones are another important class of the chromatin architectural proteins that allow condensation of genomic DNA by functioning as spools to wrap the enormously long DNA around them. ${ }^{\left[{ }^{84]}\right.}$ Additionally, they assist in structural pre-organization of DNA to enable the binding of various proteins necessary for processes such as replication, transcription and recombination. Similar to the HMG1/2 proteins the linker histone $\mathrm{H} 1$ has a propensity to bind to bent and cruciform DNA as well as to cisplatin modified DNA. ${ }^{\left[{ }^{85]}\right.}$ In fact, the linker histones have 20 times greater binding affinity towards such distorted DNA sequences as well as occur in 10 fold higher nuclear concentration. The stronger binding affinity of linker histones to the cisplatin modified DNA hints towards its importance in mediating the toxicity of the drug by affecting DNA transcription and repair.

The integration host factor (IHF) and HU proteins, prokaryotic analogues of histones, termed as "histone-like", share a functional similarity to the eukaryotic HMG1 domains 
such that in some situations they have been found to be functionally interchangeable. ${ }^{[86]}$ Irrespective of their origin both the prokaryotic as well as eukaryotic architectural proteins, upon binding to the DNA minor groove result in bending and unwinding of the DNA. However, a distinguishing feature of IHF is its ability to bind to DNA in a sequence specific manner and induce a drastic U-turn in duplex, thus, taking the DNA bending phenomenon to a new extreme. The structural features of IHF responsible for its DNA interaction, DNA binding and bending abilities are described elaborately in the next chapter. The design of a model peptide mimicking such protein domains that not only stabilize the cisplatin induced DNA distortion but also assist in further bending the distorted DNA seems to be a promising approach for developing novel chemotherapeutic agents. 



\section{Synthesis and DNA interaction studies of the platinum complex/peptide chimera mimicking Integration Host Factor}

Development of novel chemotherapeutic agents with enhanced pharmacological properties is of utmost importance. As discussed in the earlier chapter 2, a thorough optimization of the drug design is necessary at various levels including enhancement of cellular as well as nuclear accumulation, efficient DNA targeting, minimizing resistance development and dose limiting toxic side effects. Taking all these requirements into consideration several attempts are being made to develop novel therapeutic candidates. Varying the coordination sphere of the Pt metal centre modulates its interaction with DNA as well as other cellular targets and hence, determines the overall cellular response of the drug. ${ }^{[87]}$ Attachment of metal complexes with suitable carrier molecules possessing cell penetrating, target directing and recognition properties seems to be a promising approach. $^{[88]}$

\subsection{A brief overview of chimeric platinum drugs}

The first and foremost challenge posed on the drug is to be able to cross the biological barrier i.e. cell membranes. Hyperpermeability ${ }^{[89]}$ and enhanced cellular retention of macromolecules in tumour cells can be exploited to target the tumour tissue either by attachment or by encapsulation of the drug with a carrier nanostructure. In contrast to small molecules, which rapidly enter the cells by passive diffusion the cellular uptake of macromolecules occurs by a kinetically slow process of endocytosis. ${ }^{[90]}$ Supramolecular assemblies such as liposomes, miscelles, polymerosomes, polymer conjugates and nanoparticles have found utility in biomedical field as nanovehicles for delivering therapeutic agents. ${ }^{[91,92]}$ Remarkably, highly branched dendrimeric peptides due to their 
well defined architectures, mono-dispersity, abundant terminal groups and multivalent surface, are attractive candidates to develop delivery nanoplatforms. ${ }^{[93,}{ }^{94]}$ Another exploitable aspect allowing specific targeting of cancerous cells and facilitating the passage of the active drug through the cell membrane is over expression of membrane bound receptors in certain kinds of tumours. Effective receptor mediated cellular internalization of platinum based drugs has been achieved by tethering the platinum moiety to a suitable carrier ligand having a high affinity for the receptor such as the antibody against it. ${ }^{[95,96]}$

Nuclear DNA is known to be one of the major targets of anti-cancer drugs. Therefore, apart from effective cellular internationalization of the chemotherapeutic, enhancing its nuclear localization and interaction with DNA also plays a crucial role in determining its clinical success. Attachment of the Pt complex to a carrier molecule which is known to be efficient in delivering cargo to the cellular nucleus for e.g., the nuclear localization peptide $(\mathrm{NLS})^{[97,98]}$ has shown enhanced nuclear accumulation of the chimeric drug. ${ }^{[99]}$ Numerous DNA targeting agents have been prepared by conjugation of the Pt complex with various DNA ligands including intercalators, groove binders, peptides, polyamides, PNA, DNA and amino acid residues. ${ }^{[88]}$ In a previous attempt in the Diederichsen group, ${ }^{[100]} \mathrm{Pt}$ complexes tethered to positively charged peptides demonstrated enhanced interaction with nucleic acid sequences by means of rather non-specific electrostatic attraction. Despite being able to efficiently target DNA most of chimeric drugs had little or no cytotoxic effect. However, the approach offers tremendous versatility in choosing the design of the carrier ligand and the field is yet to be explored to its complete potential. With optimization of the design it provides a scope to develop a whole new library of target oriented compounds applicable as potential chemotherapeutic agents.

Peptide based ligands possess several advantages as drug candidates due to their high bioavailability, reduced toxicity and moreover, due to their specific interactions with DNA. ${ }^{[101-104]}$ In this work, a model peptide mimicking the integration host factor (IHF) has been chosen as the platinum complex carrier to target DNA by exploiting its interaction with the minor groove as well as its ability to introduce an overwhelming bend in the duplex. The Pt complex/peptide chimera is expected to exhibit a synergistic effect of 
both the platinum chelating unit as well as the body of the IHF mimicking peptide with respect to their DNA bending and binding properties.

\subsection{Integration Host Factor (IHF)}

As discussed in the earlier chapter 2, the condensation of enormously long genome as well as formation of higher order nucleoprotein complexes is essential to regulate various cellular activities. Analogous to the eukaryotic histones, in prokaryotic organisms this task is achieved by two of the most abundant DNA binding proteins, namely, integration host factor (IHF) and histone-like (HU) proteins. ${ }^{[105-107]}$ Together they fall under the category of type II DNA binding proteins (DNAB II) and share a peculiar sequence homology, particularly in the DNA binding domain. Despite these similarities IHF binds to the cognate sequence with a high degree of specificity whereas the HU proteins are rather non-specific DNA binders. ${ }^{[108]}$ On the other hand, the evolutionarily unrelated eukaryotic HMG-box domains regardless of having fewer structural aspects in common with the HU and IHF proteins have been found to be functionally equivalent to them under certain conditions. ${ }^{[86]}$

\subsubsection{The consensus sequence of IHF}

Apart from regulation of cellular processes, one of the best identified roles of IHF is for site-specific recombination in bacteriophage lambda. ${ }^{[109]} \mathrm{IHF}$ specifically binds to one of the three different core recognition sequences, $\mathrm{H}^{\prime}, \mathrm{H} 1$ and $\mathrm{H} 2$ sites within the attP phage attachment region and assists in integration of phage DNA into the genome of the host chromosome. ${ }^{[110]}$ Out of these three, the $\mathrm{H}^{\prime}$ site is one of the strongest and most well characterized binding site. The binding affinity of IHF towards this site lies in the order of $1 \mathrm{nM}$ and that towards any random sequence has been found to be $10^{3}-10^{4}$ times lower. ${ }^{[111,112]}$ Though the binding of IHF protects more than 25 bp only as few as 9 bp located at the $3^{\prime}$ downstream end remain conserved in the binding sites of IHF. ${ }^{[113]}$ The degenerate core consensus sequence for specific recognition of IHF consists of a 
5'-WATCARNNNNTTR-3' element in which W stands for A or T, R stands for A or G and N strands any nucleotide. A relatively non-conserved part of the binding site consists of an A/T rich tract extending over 4-5 bp positioned around 8-9 bp upstream of the conserved domain. ${ }^{[114]}$ The presence of this $A / T$ rich track results in the formation of a narrow minor groove occupied by a well ordered string of water molecules, allowing only water mediated hydrogen bonding with the conserved nucleobases. The interaction of IHF with such an element hints towards recognition of sequence dependent structure of the cognate DNA instead of base pair recognition by IHF. The following section highlights the unique structural features of IHF that not just assist in specifically recognizing the consensus sequence and but also lead to drastic conformational changes in the DNA upon binding.

\subsubsection{Structural aspects of IHF facilitating DNA interaction}

The functional utility of IHF arises from its ability to induce a sharp bend of $>160^{\circ}$ in the cognate sequence by binding to the minor groove of DNA. An interesting feature of IHF domains is that it employs an indirect readout mechanism for binding and wrapping around DNA. In case of indirect readout the basis of protein-DNA recognition relies on a shape readout wherein the structural aspects of DNA dominate over actual hydrogen bonding interactions between the two. Detailed X-ray crystallographic analyses of the IHF-DNA co-crystal with a 35-mer DNA fragment including the $\mathrm{H}^{\prime}$-site of bacteriophage $\lambda$ was performed in order to understand the structure, DNA binding and bending mechanism of IHF (Figure 3.1). 

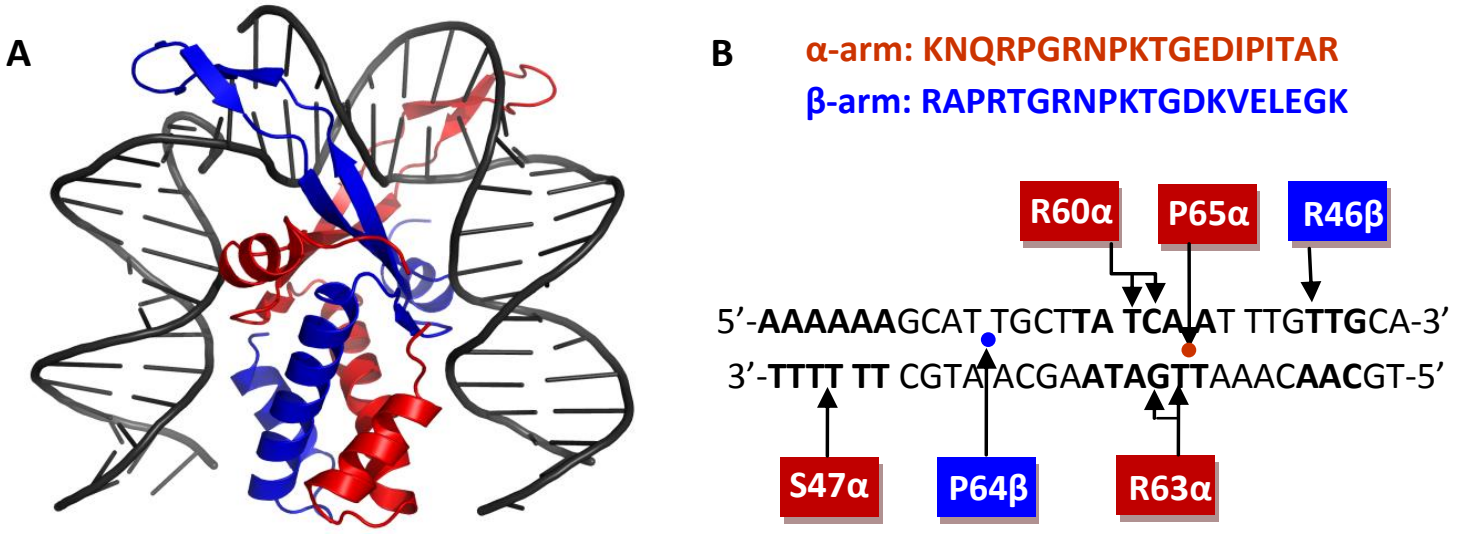

Figure 3.1 : (A) Co-crystal structure of IHF bound to a 35 bp ds DNA fragment consisting of the $\mathrm{H}^{\prime}$-site of phage $\lambda$, wherein, the $\alpha$-subunit is shown in red and $\beta$-unit is shown in blue. The image has been reproduced using PyMOL (PDB entry: 1IHF). ${ }^{[5]}$ (B) An illustration of the sequence of amino acids and oligonucleotide involved in the structure wherein the arrows point towards the interaction sites between them. The core consensus sequence and the A/T-rich 5' element are marked in bold.

The general structure of IHF is heterodimeric formed by two intertwining subunits, an $\alpha$-subunit and a $\beta$-subunit, having $30 \%$ sequence similarity. ${ }^{[5,115]}$ Each subunit approximately is $10 \mathrm{kDa}$ in size, consisting of $3 \alpha$ helices and $5 \beta$ sheets structures. In the IHF-DNA complex, ${ }^{[5]}$ the two long flexible ribbon like arms each made up of two anti-parallel $\beta$-sheets extend from the globular body of the protein embracing the DNA minor groove. A proline residue present at the tip of each arm (Pro ${ }^{65}$ of the $\alpha$-subunit and Pro $^{64}$ of the $\beta$-subunit) intercalates between the DNA base pairs, thereby disrupting the stacking interactions and broadening of the minor groove. The binding of the protein to the widened DNA drives drastic conformational changes leading to the formation of two sharp kinks separated by a sequence of $9 \mathrm{bp}$ within the duplex. The repulsive forces in the bent polyanionic DNA back bone are compensated by its interaction with an overall positively charged surface of the protein due the presence of the basic amino acids in the large $\alpha$-helical part ${ }^{[116]}$ (Figure 3.2 ) as well as with the $\mathrm{N}$-termini of the helices. $^{[5,117,118]}$ 

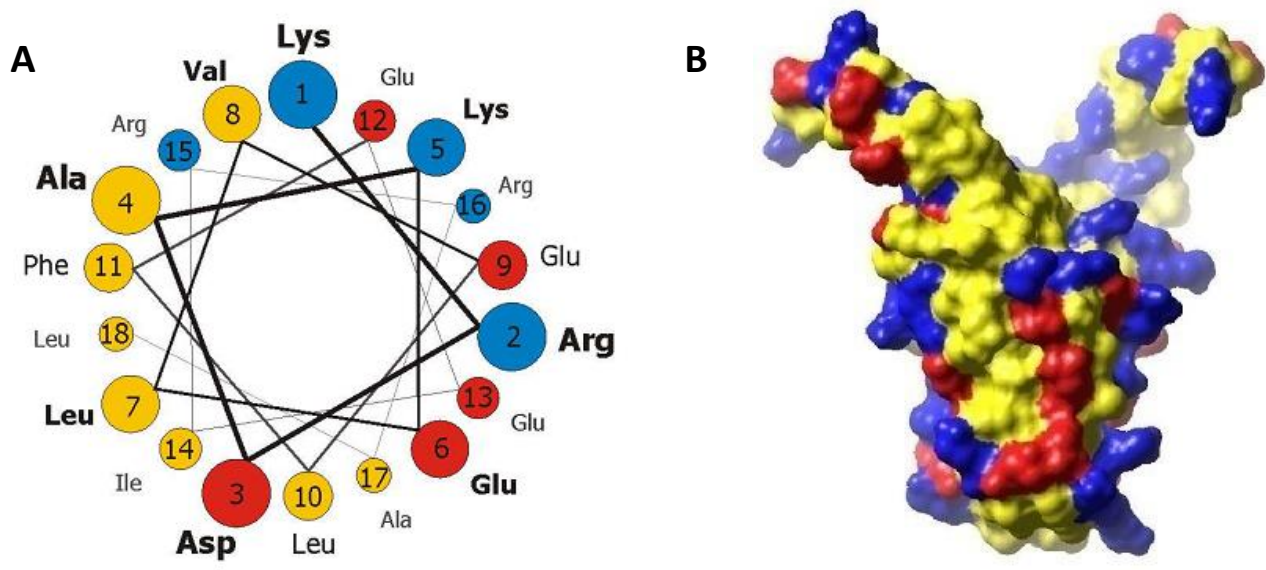

Figure 3.2: Representation of amino acid residues on the surface of IHF protein wherein the acidic amino acids are depicted in red, basic amino acids in blue and neutral in yellow. ${ }^{[116]}$ (A) a helix wheel diagram representing the $\alpha$-helical domain of IHF. (B) The distribution of amino acids on the overall surface of IHF (PDB entry: $1 \mathrm{IHF}) .^{[5]}$

In total, there are as few as $4 \mathrm{bp}$ in the minor groove of the DNA sequence involved in hydrogen bonding interactions with IHF. These include interactions between the side chains of two arginine residues ( $\mathrm{Arg}^{60}$ and $\mathrm{Arg}^{63}$ ) within the minor groove interacting arm of the $\alpha$-subunit of IHF and the conserved DNA base pairs, each having similar hydrogen bond acceptors. On the contrary, analogous arginine residues of the $\beta$-subunit have no direct contact with the DNA bases but with the phosphate backbone through bridging water molecules. These observations hint towards a higher contribution of the $\alpha$-subunit towards sequence specific recognition of IHF in comparison to the $\beta$-subunit.

\subsection{Design of the model peptide mimicking IHF}

Our motivation to design the IHF mimicking peptides is to establish elements necessary for enhanced DNA interaction of the platinum metal complexes. The IHF mimicking model peptide reported earlier in the Diederichsen group, ${ }^{[6,116,119]}$ is based on the deeper penetrating $\beta$-arm of the $\alpha$-subunit owning to its greater role in specific recognition of the IHF consensus sequence. The model is designed taking into account 
various interactions from individual sub-domains for optimum interaction with DNA and hence can be divided into three parts (Figure 3.3). Firstly, it consists of a cyclic peptide resembling the minor groove binding arm of the $\alpha$-subunit and containing amino acid residues surrounding the intercalating proline. Secondly, it consists of a positively charged lysine dendrimer that mimics the globular $\alpha$-helical body of IHF for facilitating electrostatic interactions with the negatively charged DNA. Thirdly, it consists of a glycine linker that tethers the cyclic peptide with the dendrimer peptide and additionally, contains the platinum chelating unit. The suitable length of the glycine linker was determined by Macro Model calculations, by estimating the distance between the minor groove binding domain of the $\alpha$-subunit and the compact body of IHF. The $\mathrm{C}_{\alpha}$ atoms of $\mathrm{Leu}^{54}$ and $\mathrm{Arg}^{60}$ were found to be $17.7 \AA$ apart and therefore, a flexible hepta glycine linker spanning a range of $22.2 \AA$ was chosen. A norvaline derivative containing a dimethylethylenediamine as a side chain functionality was employed as an artificial amino acid to replace one of the glycine residues within the linker region for platinum coordination.

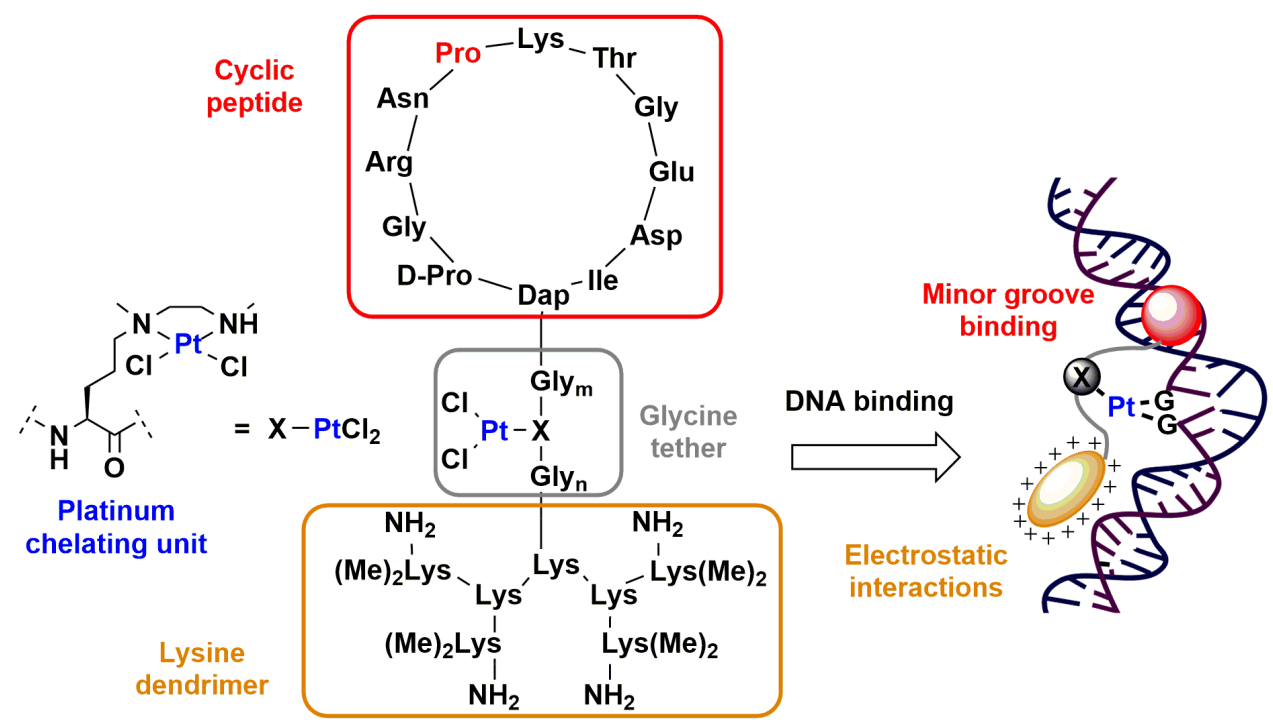

Figure 3.3: The model of the IHF mimicking Pt complex/peptide chimera for enhanced DNA targeting. The minor groove binding cyclic peptide and the intercalating Pro residue are depicted in red, the positively lysine dendrimer in orange, the glycine linker in gray and the Pt metal centre in blue. 
The sequence of the cyclic peptide, in addition to an appended domain of the minor groove binding loop containing 10 amino acid residues (GRNPKTGEDI), was extended by two more amino acids, a D-proline and a diaminopropionic acid residue. The D-proline offers conformational rigidity assisting in induction of a $\beta$-turn in the loop like structure $^{[120]}$ and furthermore, in the cyclization of the linear peptide. The diaminopropionic acid residue carries two amine functionalities, one of which is utilized for the cyclization reaction and the second one is available for subsequent connection of the cyclized peptide with the glycine linker.

Some of the previous designs of the cyclic peptide in the Diederichsen group, included cysteine or histidine residues for providing a stable conformation as well as assisting in structural pre-organization either by formation of disulfide bridges or by complexation with metal ions, respectively. ${ }^{[121]}$ Additionally, the intercalating proline residue was exchanged with analogous species to study the influence of different size of the side chain functionality, ring conformation and aromaticity on DNA interaction of the IHF mimicking peptides. ${ }^{[122]} \mathrm{A}$ more recent approach involved synthesis of an IHF mimic containing two cyclic recognition units extending from the central compact body, resembling the native heterodimeric IHF protein, in order to enhance the DNA binding and bending ability of the mimic. ${ }^{[123]}$ 


\subsection{Synthesis of the IHF mimicking peptides}

The main motivation behind the synthesis of the IHF mimicking Pt complex/peptide chimeras is to enhance sequence specific DNA targeting as well as to observe a combined effect of the Pt complex and the IHF mimic with respect to DNA bending properties. We have synthesized an artificial amino acid building block for tethering with the platinum chelating unit and incorporated it into the peptide domain. Our approach for the synthesis of the IHF mimicking peptides involves both solid phase and solution phase peptide chemistry based on the Fmoc coupling protocol. The various peptide mimics IHF-1/2/3/4, P1 and P2 synthesized henceforth in this study were applied for DNA interaction experiments (Figure 3.4). The IHF-2, IHF-3 and IHF-4 are the platinated IHF mimicking peptides prepared by placing the platinum chelating unit at different positions within the glycine linker. Additionally, the unplatinated mimic IHF-1, the platinated lysine dendrimer $\mathbf{P} \mathbf{1}$ and the cyclic peptide $\mathbf{P} \mathbf{2}$ were prepared for control experiments.



Figure 3.4: Representation of the various IHF mimicking peptides synthesized for the current study. The IHF-2/3/4 are the platinated mimics, IHF-1 is unplatinated mimic, $\mathbf{P 1}$ is the platinated lysine dendrimer and $\mathbf{P 2}$ is the cyclic peptide. 


\subsubsection{Synthesis of the artificial amino acid building blocks}

A norvaline based modified amino acid residue was synthesized to suit the Fmoc based SPPS protocol for incorporation into the chimeric peptide sequences. A dimethylethylenediamine was introduced into the side chain of the amino acid as a platinum chelating unit. The allyloxycarbonyl (Alloc) protection of $N, N^{\prime}$ dimethylethylenediamine $\mathbf{1}$ yielded $N$-allyloxycarbonyl- $N, N^{\prime}$-dimethylethylenediamine 2. Following a literature known procedure, ${ }^{[124]}$ the commercially available $\mathrm{N}$-Boc glutamic acid benzyl ester $\mathbf{3}$ was first reduced to the corresponding alcohol $\mathbf{4}$ by using sodium borohyride and subsequently, brominated under Appel reaction conditions to yield $\mathbf{5}$. The attachment of the platinum chelating ligand to the amino acid is achieved by nucleophilic substitution of the bromine residue in compound $\mathbf{5}$ with $\mathbf{2}$. The Boc and benzyl group of the resulting amino acid 6 were removed and the free $\mathrm{N}$-terminus was further protected with the Fmoc group yielding the amino acid 7, to be introduced into the Fmoc SPPS cycle.<smiles>CNCCNC</smiles>

1

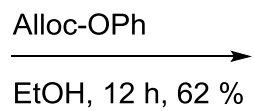

$\mathrm{EtOH}, 12$ h, $62 \%$



2

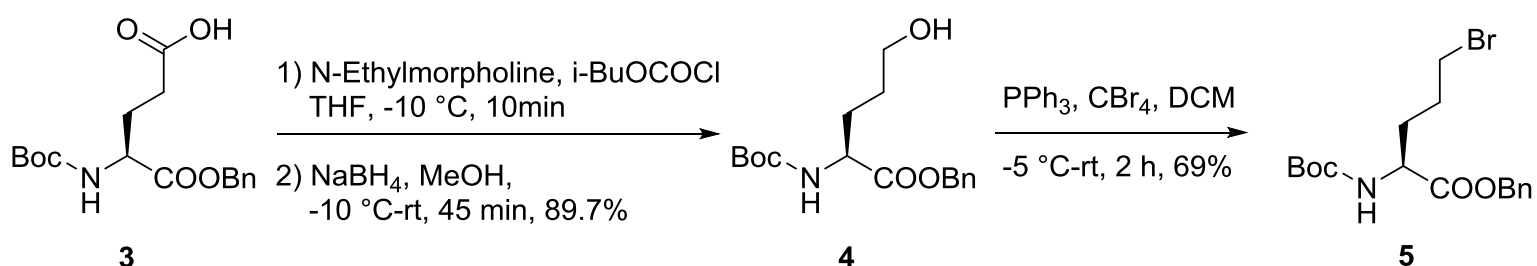

3

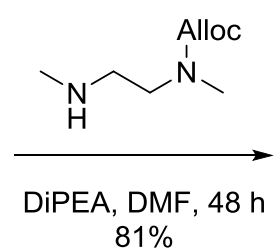

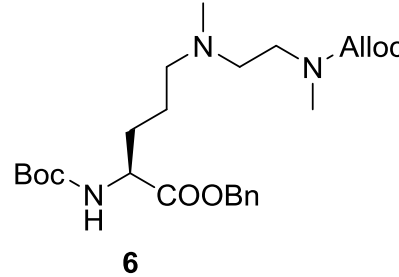

6
1) $1 \mathrm{~N} \mathrm{NaOH}, 6 \mathrm{~h}$

2) $95 \%$ TFA, $6 \mathrm{~h}$

3) Fmoc-OSu, $10 \% \mathrm{Na}_{2} \mathrm{CO}_{3}$, dioxane, 4 h, 65\%<smiles>CN(C)CCN(C)CCCC(NC(F)F)C(=O)O</smiles>

Scheme 3.1: Synthesis of the norvaline based artificial amino acid 7 for platinum coordination. 
<smiles>CC(C)(C)OC(=O)N[C@@H](CCCCN)C(=O)O</smiles>

8 $\underset{\text { r.t., } 24 \text { h, } 82 \%}{\stackrel{37 \% \mathrm{CH}_{2} \mathrm{O}, \mathrm{H}_{2} / \mathrm{Pd} / \mathrm{C}}{\longrightarrow}}$

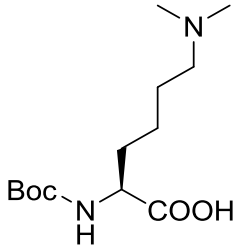

9

Scheme 3.2: Synthesis of Boc- $\mathrm{Lys}(\mathrm{Me})_{2}-\mathrm{OH} 9$ to be incorporated into the lysine dendrimer. ${ }^{[125]}$

The synthesis of the lysine dendrimer was accomplished by introduction of Boc-Lys(Me) ${ }_{2}-\mathrm{OH} 8$ as a terminal residue in Fmoc SPPS cycle. The synthesis of the $\mathrm{N}$-bismethyl lysine was achieved by reductive amination of Boc-(Lys)-OH applying a literature reported procedure analogous to an ornithine based transformation. ${ }^{[125]}$

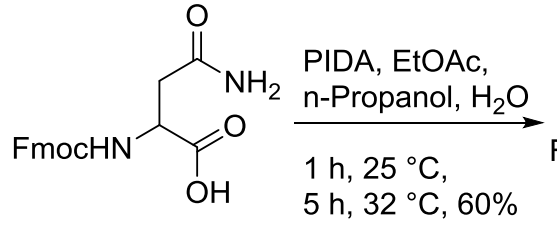

10<smiles>NCC(NC(F)F)C(=O)O</smiles>

11

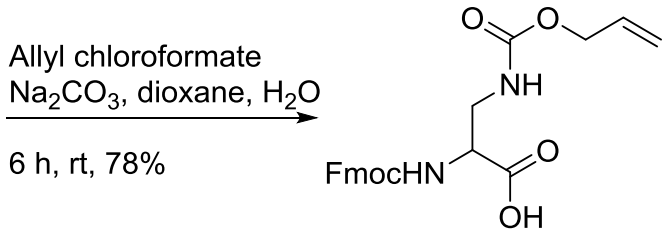

12

Scheme 3.3: Synthesis of Fmoc-Dap(Alloc)-OH 12 to be incorporated into the cyclic peptide. ${ }^{[126]}$

A terminal diaminopropionic acid residue was introduced as Fmoc-Dap(Alloc)-OH 12 into the sequence of the cyclic peptide domain by Fmoc SPPS strategy. The tandem removal of the Fmoc and the Alloc (compatible with Fmoc protocol) group facilitated cyclization and coupling with the glycine linker, respectively. The synthesis of Fmoc-Dap(Alloc)-OH 12 was accomplished in two steps, ${ }^{[126]}$ by Hoffmann rearrangement of the commercially available Fmoc-Asn-OH 10 with iodobenzenediacetate (PIDA) yielding Fmoc-Dap-OH 11 followed by Alloc protection of the newly generated free amine in the side chain of 11 . 


\subsubsection{Synthesis of the cyclic minor groove recognition units}

The sequence of the linear precursor of the cyclic peptide in total contained 12 amino acid residues including those from $\mathrm{Gly}^{62}$ to $\mathrm{Ileu}^{71}$ mimicking the minor groove binding arm of the IHF $\alpha$-subunit, a D-proline and a diaminopropionic acid. The synthesis was accomplished by Fmoc SPPS protocol starting from a 2-chlorotrityl (2-ClTrt) resin preloaded with isoleucine. Standard coupling conditions using HBTU/HOBt as activators and DIPEA as base were applied. The deprotection of the Fmoc group was achieved in $20 \%$ piperidine. The cleavage of the peptide from the resin under mild conditions utilizing $30 \%$ HFIP in DCM yielded the protected peptide $13 .{ }^{[127]}$ Subsequently, cyclization of the linear peptide was performed with DIC/HOAt and NMM in DCM/DMF $(9 / 1, v / v)$ yielding 14. Alloc deprotection of the diaminopropionic acid employing $\mathrm{Pd}\left(\mathrm{PPh}_{3}\right)_{4}$ and $\mathrm{Me}_{2} \mathrm{NH} . \mathrm{BH}_{3}$ rendered peptide $\mathbf{1 5}$ with all the other amino acid side chain protecting groups still intact. ${ }^{[128,129]}$ This allows minimal side reactions during the connection of the free amine of the cyclic peptide with the carboxylic acid of the glycine linker. Furthermore, complete cleavage of the side chain protecting groups is achieved by treatment of $\mathbf{1 5}$ in 95\% TFA in water yielding the cyclic peptide $\mathbf{P 2}$, used later in control experiments.
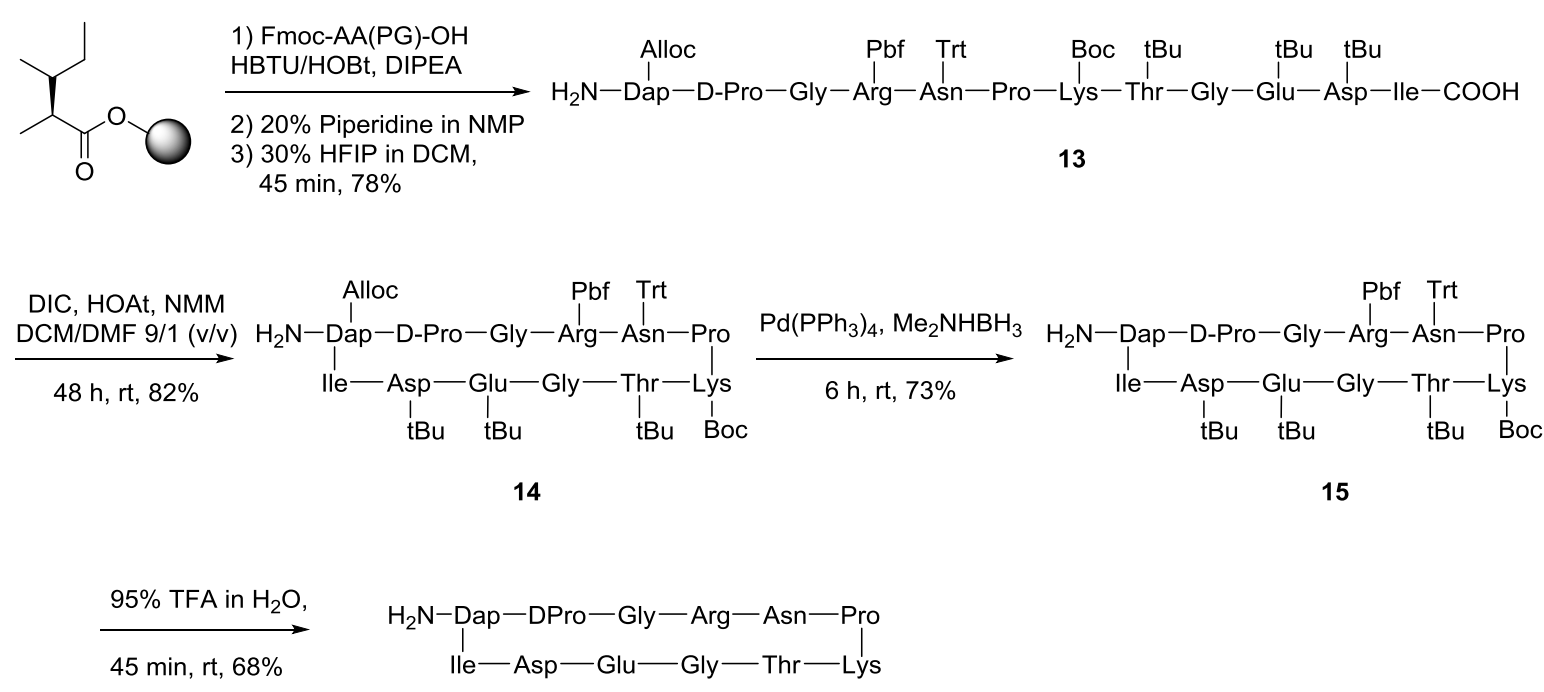

P2

Scheme 3.4: Synthesis of the cyclic peptides $\mathbf{1 5}$ and $\mathbf{P 2}$ for connection with the glycine linker and for control experiments, respectively. 


\subsubsection{Synthesis of the dendrimeric units}

The synthesis of the three generation lysine dendrimer along with the glycine linker was performed on a NovaSyn ${ }^{\circledR}$ TGT resin preloaded with a glycine residue. The lysine dendrimer, positively charged under physiological conditions, provides electrostatic interaction with the DNA backbone. While the glycine linker places the cyclic recognition unit and the dendrimer at appropriate distance to each other as well as holds the platinum chelating unit. All amino acids within the glycine linker both including and excluding the platinum chelating unit were coupled by standard Fmoc protocol using HOBt/HBTU/DIPEA for coupling and $20 \%$ piperidine in NMP for deprotection. The first and the second generation dendrimer were prepared by coupling of Fmoc-Lys(Fmoc)-OH onto the glycine linker sequence whereas the third generation dendrimer was obtained by coupling of Boc-Lys $(\mathrm{Me})_{2}-\mathrm{OH}$. The use of $\mathrm{N}$-bismethyl lysine for the synthesis of the third generation dendrimer offered better solubility to the dendrimeric peptides in organic solvents, necessary for solution phase conjugation with the cyclic peptide 15. Cleavage of the peptide from the resin applying mild conditions of $30 \%$ HFIP in DCM yielded the side chain protected peptide dendrimers, 16 without the Pt chelating and 17a-c containing the platinum chelating unit. The dendrimer 16 was further employed for the synthesis of the unplatinated mimic IHF-1 whereas 17a-c were utilized for the synthesis of the platinated mimics IHF-2/3/4.


Scheme 3.4: Synthesis of the dendrimeric peptides 16 and $17 a-c$ excluding and containing the Pt chelating unit, respectively. 
The $\mathrm{N}$-termini of lysine dendrimer as well as the $\mathrm{N}$-bismethylated residue are protonated at $\mathrm{pH} 7$ and have the ability to neutralize the negative charge on the DNA phosphate backbone. The platinated lysine dendrimer P1 lacking the minor groove binding cyclic recognition unit was synthesized for control experiments in order to test the effect of solely electrostatic interactions upon the binding of Pt complex to DNA. The synthesis was done in three simple steps starting from deprotection of the Alloc group of the Pt chelating unit in $17 \mathrm{c}$ with $\mathrm{Pd}$ catalyst in the presence of a scavenger $\mathrm{Me}_{2} \mathrm{NH} . \mathrm{BH}_{3}$ yielding peptide 18. Subsequent, platination reaction was performed under exclusion of light yielding 19, which was further treated with 95\% TFA in water to remove all the amino side chain protecting groups furnishing the peptide $\mathbf{P} 1$.
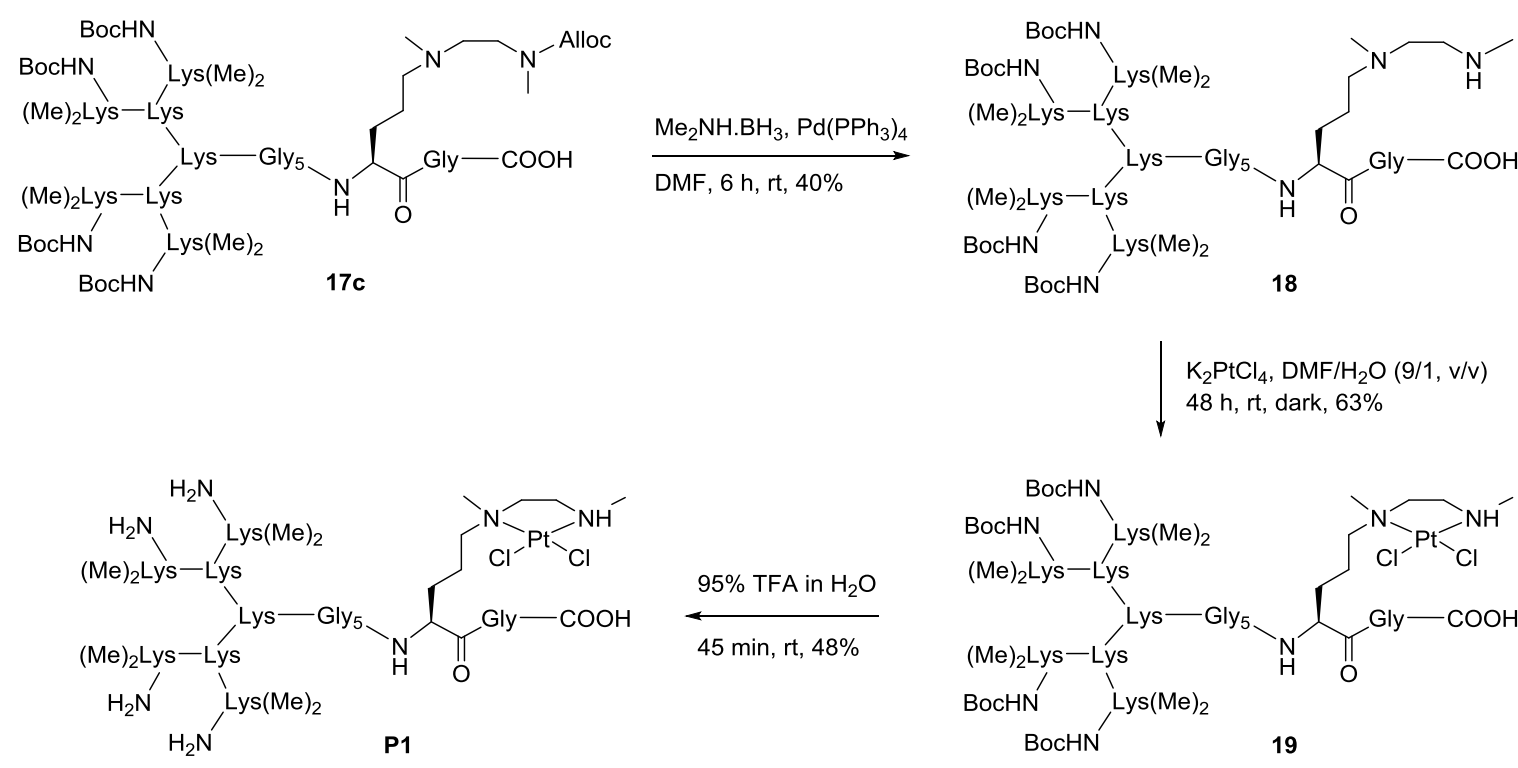

$\underset{45 \text { min, rt, } 48 \%}{95 \% \text { TFA in } \mathrm{H}_{2} \mathrm{O}}$

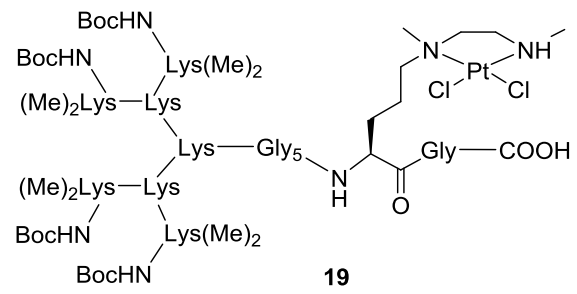

Scheme 3.5: Synthesis of the platinated lysine dendrimer P1. 


\subsubsection{Synthesis of the unplatinated IHF mimic}

In the absence of the platinum metal centre, the IHF mimicking peptides lack the ability to covalently modify DNA. Hence, an unplatinated IHF mimic IHF-1 was prepared for control experiments to monitor the DNA interaction of the peptide backbone by non-covalent interactions which include electrostatic interactions of the dendrimeric peptide and minor groove binding of the cyclic peptide. The cyclic peptide $\mathbf{1 5}$ was connected to the dendrimeric peptide 16 utilizing activators DIC/HOAt and NMM as base in DMF. Subsequently, treatment of the resulting conjugated peptide $\mathbf{2 0}$ with 95\% TFA removed the amino acid side chain protecting groups yielded IHF-1.



Scheme 3.5: Synthesis of the unplatinated IHF mimicking peptide IHF-1. 


\subsubsection{Synthesis of the Pt complex/peptide chimeras}

The IHF mimicking platinum complex/peptide chimera IHF-2, IHF-3 and IHF-4 were prepared by placing the platinum chelating unit in proximity to the dendrimeric peptide, in between the dendrimer and the cyclic peptide, and towards the cyclic peptide. The synthesis of the chimeric peptides was accomplished by a following series of solution phase peptide modifications. The dendrimeric peptides 17a-c were connected with the cyclic peptide 15 utilizing coupling agents DIC/HOAT and NMM in DMF. The resulting conjugated peptides 21a-c upon treatment with palladium catalyst undergo deprotection of the Alloc group, orthogonal to Fmoc chemistry, yielding peptides 22a-c. Subsequently, platination reaction with $\mathrm{K}_{2} \mathrm{PtCl}_{4}$ in $\mathrm{DMF} / \mathrm{H}_{2} \mathrm{O}$ was performed under exclusion of light. Deprotection of the side chain protection groups of the resulting platinated peptides 23a-c yielded the platinated IHF mimics IHF-2/3/4 with yields in the range of $45-55 \%$.

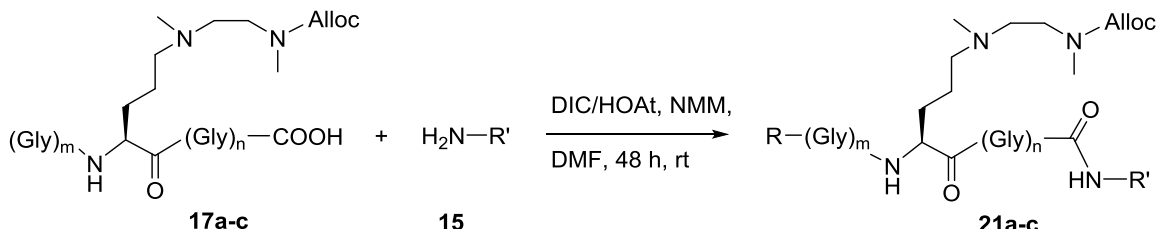

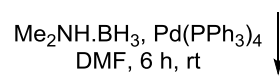

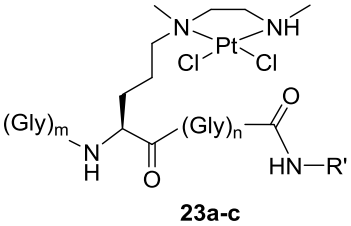

95\% TFA in $\mathrm{H}_{2} \mathrm{O}$ $45 \mathrm{~min}, \mathrm{rt}$
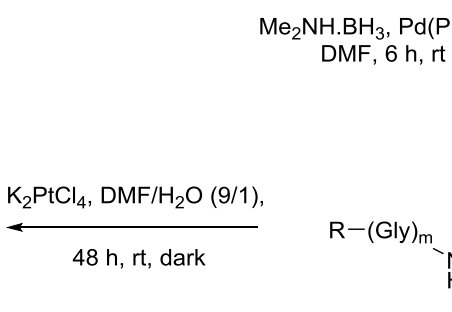

$17,21-23 a(m=1, n=5)$

$17,21-23 b(m=3, n=3)$

$17,21-23 \mathrm{c}(\mathrm{m}=5, \mathrm{n}=1)$



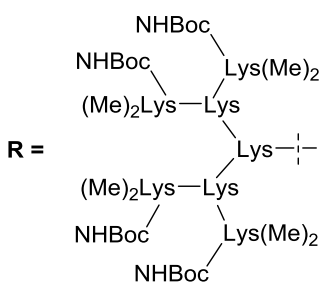

22a-c

Scheme 3.6: Synthetic route for the platinated IHF mimicking peptides IHF-2/3/4 with yields varying in the range of $45-55 \%$. 


\subsection{DNA binding studies of the IHF mimicking peptides}

The DNA interaction of the IHF mimicking peptides was studied by means of various biochemical assays: 1) Agarose gel electrophoresis to study their influence on binding and unwinding of supercoiled plasmid DNA. 2) Native and non-denaturing polyacrylamide gel electrophoresis to test their binding with IHF consensus DNA sequence either including or excluding adjacent guanine residues, the preferred site for platination. The former assists in monitoring binding events resulting from both covalent and non-covalent interactions whereas the latter assists in exclusively monitoring covalent linkages. 3) Thermal melting analysis to test their influence on the stability of the DNA duplex containing the GG site. The interactions of the platinated IHF mimics, IHF-2/3/4, were compared with the control peptides IHF-1, P1 and P2.

\subsubsection{Agarose gel electrophoresis with plasmid DNA}

Native agarose gel electrophoresis was utilized to investigate changes induced in the circular plasmid DNA upon interaction with various synthetic peptides (Figure 3.5). Platinum based compounds are known to induce local structural perturbation in DNA and result in unwinding of the double helix by means of covalent modification. ${ }^{[130]}$ The agarose gel migration pattern of plasmid DNA is affected by such DNA conformational changes. Typically, the unwinding of DNA resulting from platination is evident from the emergence of a slower migrating band. ${ }^{[131]}$ The interaction of the IHF mimicking peptides with the DNA is governed by various forces acting simultaneously. Firstly, via electrostatic attraction between the lysine dendrimer, positively charged under physiological conditions, and negatively charged phosphates group of the DNA backbone. Secondly, by minor groove binding of the cyclic peptide that can interrupt structural organization of DNA and induce bending. Thirdly, the IHF mimics containing a platinum chelating unit can further enhance the DNA distortion due to their ability to covalently crosslink DNA. The interactions of the negatively supercoiled pUC18 plasmid DNA were studied with various IHF mimicking peptides including the unplatinated mimic IHF-1, the platinated mimics IHF-2/3/4, the platinated peptide dendrimer $\mathbf{P 1}$ and the unplatinated cyclic peptide $\mathbf{P 2}$. 
Due to a more condensed structure the supercoiled plasmid DNA has comparatively a faster gel migration than the relaxed form. Monitoring the difference in the migration properties of plasmid DNA upon interaction with the IHF mimicking peptides can provide information on their DNA binding and unwinding abilities. Prior to electrophoresis the peptides were incubated with the plasmid DNA for $2 \mathrm{~h}$ at $37{ }^{\circ} \mathrm{C}$ in $10 \mathrm{mM}$ phosphate buffer, $\mathrm{pH}=5.8$ wherein the ratio of the nucleotide concentration $\left(C_{\mathrm{DNA}}\right)$ to that of the peptide concentration $\left(C_{\text {peptide }}\right)\left(r_{\mathrm{f}}=C_{\text {peptide }} / C_{\mathrm{DNA}}\right)$ was varied in a range of 0-0.15.

The platinum containing IHF mimicking peptides IHF-2/3/4 induce a gel shift in the migration of the plasmid DNA within $2 \mathrm{~h}$ reaction time at an $r_{\mathrm{f}}$ value of 0.05 whereas for the unplatinated mimic IHF-1 the effect is observed starting at a later $r_{f}$ value of 0.1 . Therefore, the platinated IHF mimics IHF-2/3/4 have a greater unwinding effect compared to the unplatinated mimic IHF-1. The reason behind the enhanced unwinding of the platinated mimics IHF-2/3/4 could be attributed to the presence of the platinum metal centre as an additional functional unit forming covalent linkages with DNA, whereas IHF-1 can interact with DNA only through electrostatic interactions. The positively charged platinated peptide $\mathbf{P 1}$ which lacks the cyclic unit seems to cause perturbation in DNA conformation starting at an $r_{f}$ value of 0.075 . On the other hand, the minor groove intercalating cyclic peptide $\mathbf{P 2}$ alone is not sufficient to induce a change in the migration pattern of the plasmid DNA. One of the plausible reasons could be, the cyclic peptide in the absence of the positively charged lysine dendrimer is insufficient to have electrostatic attraction with negatively charged DNA phosphate backbone. The effect is more prominent when comparing the cyclic peptide P2 with the unplatinated IHF mimicking peptide IHF-1. Moreover, the platinated lysine dendrimer P1 lacking the cyclic peptide domain is not as efficient as the platinated IHF mimics IHF-2/3/4 with respect to their DNA binding and unwinding properties. Hence, electrostatic interactions of the dendrimeric peptide with the plasmid DNA exclusively are also not sufficient enough to assist in maximizing distortion of its structure.

Therefore, the IHF mimicking peptides IHF-2/3/4 formed by the connection of the cyclic minor groove recognition unit with the positively charged dendrimeric unit was conformed to be better in terms of their ability to induce gel shifts in the plasmid DNA migration pattern. Additionally, the presence of the platinum chelating unit in the IHF 
mimics leads to enhanced binding and unwinding of the DNA by means of covalent modification.


P1

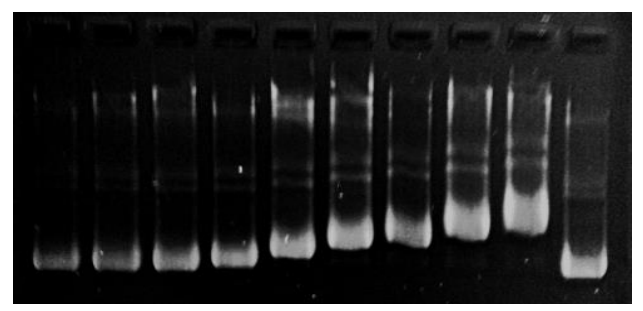

$\begin{array}{llllllllllll}r_{\mathrm{f}} & 0 & 0.005 & 0.01 & 0.025 & 0.05 & 0.075 & 0.1 & 0.125 & 0.15 & 0\end{array}$



$\begin{array}{llllllllllllllll}r_{f} & 0 & 0.005 & 0.01 & 0.025 & 0.05 & 0.075 & 0.1 & 0.125 & 0.15 & 0\end{array}$

Figure 3.5: Agarose gel electrophoresis to study the interaction of the IHF mimicking peptides IHF-1/2/3/4, the platinated lysine dendrimer P1 and the cyclic peptide P2 with the negatively supercoiled pUC18 plasmid DNA (incubation time at $37{ }^{\circ} \mathrm{C}$ for $2 \mathrm{~h}$, with $r_{\mathrm{f}}$ varying from 0 to $0.15,10 \mathrm{mM} \mathrm{Na} 2 \mathrm{HPO}_{4} / \mathrm{NaH}_{2} \mathrm{PO}_{4}, \mathrm{pH}$ 5.8, $[$ pUC18] $=0.2 \mathrm{mM}$ nucleobases, $1 \%$ agarose) .

\subsubsection{Oligonucleotide binding studies}

Polyacrylamide gel electrophoresis was performed under native and denaturing conditions to study the binding interactions of the platinum complex/peptide chimeras with IHF consensus sequence contained within 34-mer DNA duplexes. The oligomers containing (3'ATTTTTTCGTAACGGATAGTTAAACAACGTTGCT5') or excluding the (3'ATTTTTTCGTAACGAATAGTTAAACAACGTTGCT5') the GG site, a preferred platination site. Each of the two oligonucleotides, consisting of a fluorescent 6-carboxyfluorescein 
label at the $5^{\prime}$ end for visualization under a fluorescence imager, were annealed with their corresponding complimentary DNA to form duplexes D1 and D2, respectively. Prior to electrophoresis the peptides were incubated with DNA for $17 \mathrm{~h}$ at $37{ }^{\circ} \mathrm{C}$ in $10 \mathrm{mM}$ $\mathrm{Na}_{2} \mathrm{HPO}_{4} / \mathrm{NaH}_{2} \mathrm{PO}_{4}, 100 \mathrm{mM} \mathrm{NaClO}$, $\mathrm{pH}=5.8$. Molecules larger in size tend to migrate slowly in the gel compared to smaller molecules. Therefore, monitoring the changes in the migration pattern of DNA upon interaction with the peptides can provide information on the DNA binding properties of the peptide. ${ }^{[132-134]}$ Visualization of a slower migrating DNA band in comparison to the band corresponding to the unbound DNA band clearly indicates the binding of the peptides to the DNA. While denaturing gels exclusively allow visualization of covalent peptide-DNA linkages, native gels provide additional information on the electrostatic interactions.

Both native and denaturing gels indicate a greater binding affinity of the platinated peptides towards duplex D1 containing a GG site (Figure 3.6a and 3.6b) in comparison to duplex D2 without a GG site (Figure 3.6c and 3.6d). Additionally, the inability of the unplatinated peptide IHF-1 (lane 2) to bind to either of the two duplexes emphasizes the importance of the platinum unit for optimal interaction with DNA.

A detailed study to test the DNA interaction of various IHF mimicking peptides with duplex D1 containing the platination site was performed in absence (lane 1-6) and in presence (lane 7-11) of cisplatin (Figure 3.6a and 3.6b, respectively). All peptides containing a platinum chelating unit led to retardation in the migration properties of the DNA duplex (lane 3-6 and lane 7-11). While excluding cisplatin in the DNA binding studies (lane 3-6), the mono-peptide DNA conjugate corresponds to the first highest intensity band with a slower migration than the unbound DNA. On the contrary, the other less intense bands accompanied with larger gel shifts indicate formation of multiple higher order peptide-DNA adducts. In the denaturing gel (Figure 3.6a), formation of the peptideDNA adduct with IHF-2/3/4 (lane 3-5, 40\%) was more efficient than the platinated dendrimeric peptide P1 (lane 6, 20\%). Additionally, the peptide P1 led to nearly complete disappearance of the unbound DNA band due to formation of several higher order adducts which were below detection limit. Interestingly, even with five times excess of cisplatin covalent binding of duplex D1 to IHF-2/3/4 (lane 7-10, 15\%) and dendrimeric peptide P1 (lane 11, 10\%) was observed. 
(a)

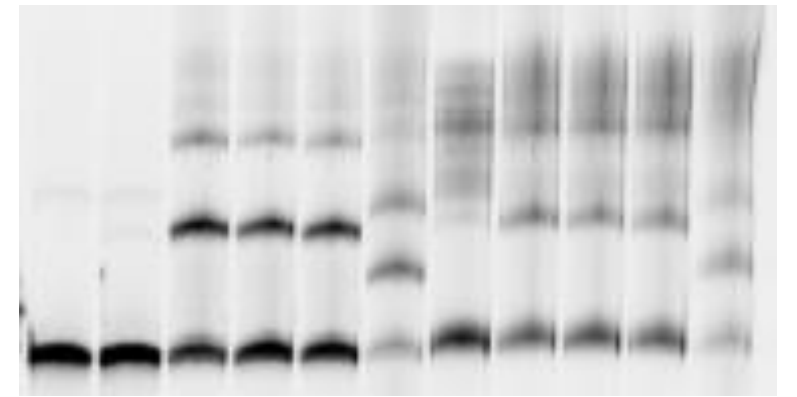

Control IHF-1 IHF-2 IHF-3 IHF-4 P1 IHF-1 IHF-2 IHF-3 IHF-4 P1 + Cisplatin

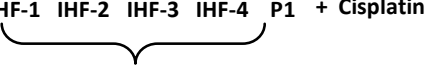

(b)

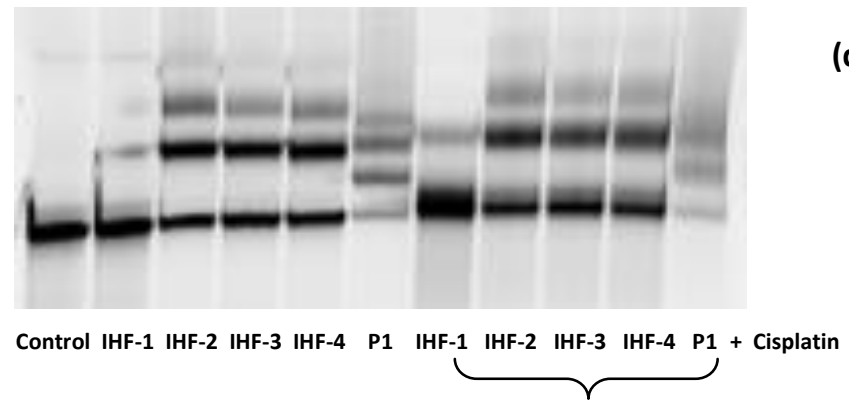

(c)

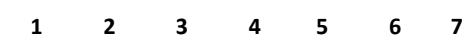
intate

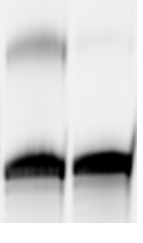

Control IHF-1 IHF-2 IHF-3 IHF-4 P1 P2

(d)


Control IHF-1 IHF-2 IHF-3 IHF-4 P1 P2

Figure 3.6: Gel electrophoresis to study the interaction of the IHF mimicking peptides with the 34 mer DNA duplex D1 consisting of a GG site and duplex D2 excluding the GG site. The samples were incubated for $17 \mathrm{~h}$ at $37^{\circ} \mathrm{C}$ in $10 \mathrm{mM} \mathrm{Na}_{2} \mathrm{HPO}_{4} / \mathrm{NaH}_{2} \mathrm{PO}_{4}, 100 \mathrm{mM} \mathrm{NaClO}$, pH 5.8. (a) (b) Lane 1-11 contain 0.5 $\mu \mathrm{M}$ DNA duplex D1. Lane 2-6 contain $10 \mu \mathrm{M}$ of IHF-1, IHF-2, IHF-3, IHF-4, dendrimeric peptide P1 respectively and lane 7-11 contain $50 \mu \mathrm{M}$ cisplatin in addition to IHF-1, IHF-2, IHF-3, IHF-4 and peptide P1 respectively. (c) (d) Lane 1-6 contain 0.5 $\mu \mathrm{M}$ DNA duplex D2. Lane 2-7 contain $10 \mu \mathrm{M}$ of IHF-1, IHF-2, IHF-3, IHF-4, dendrimeric peptide P1 and the cyclic peptide P2 respectively. (a) (c) Performed under denaturing conditions (20\% PAA, 7 M urea, 1x TBE). (b) (d) Performed under native conditions (20\% PAA, 1x TBE).

In the native gel (Figure 4b), both in absence and presence of cisplatin the peptide-DNA adduct formation with duplex D1 was much better with IHF-2/3/4 (lane 3-5, 50\% and lane $7-11,31 \%)$ compared to that in denaturing gel. These results indicate that the IHF mimicking platinum complex/peptide chimeras compete for the same site as cisplatin for covalent modification of DNA and at the same time they are also able to non-covalently interact with the cisplatin modified DNA. In conclusion, the overall design of the IHF mimicking peptides is once again verified to be optimal for maximizing DNA binding efficiency of the chimeric peptides. 


\subsubsection{Analysis of sequence specificity of IHF}

In order to test the sequence specificity of the platinated IHF mimicking peptides their binding interactions were tested with various DNA duplexes containing a GG site. The duplexes D1 and D3-D11 were employed in this study (Table 3.1). The duplexes D1 and D3-D10 contain a GG site at distinct positions within the IHF consensus sequence while the conserved bases remain intact whereas the duplex D11 is a GG site containing random DNA sequence. The peptides were incubated with each DNA duplex for $17 \mathrm{~h}$ at $37{ }^{\circ} \mathrm{C}$ in $10 \mathrm{mM} \mathrm{Na} 2 \mathrm{HPO}_{4} / \mathrm{NaH}_{2} \mathrm{PO}_{4}, \mathrm{pH}=5.8$ prior to electrophoresis under native and denaturing conditions. All three platinated mimics IHF-2/3/4 seem to have identical interaction with every DNA duplex indicating a lack of sequence specificity of the IHF mimicking Pt complex/peptide chimera in recognizing the target DNA (Figure 3.7).

(a)

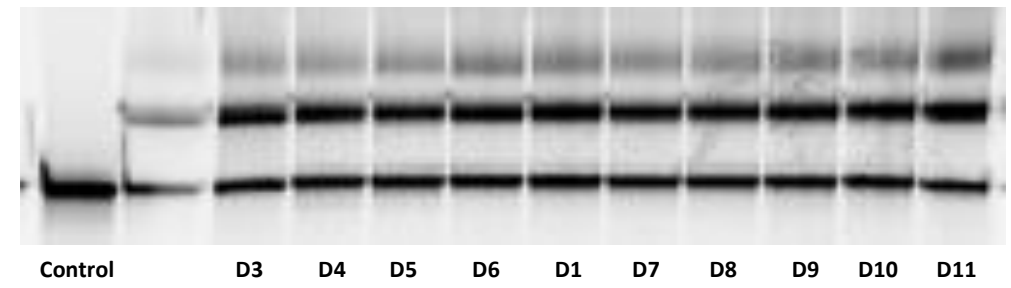

(b)

$\begin{array}{lllllllllll}1 & 2 & 3 & 4 & 5 & 6 & 7 & 8 & 9 & 10 & 11\end{array}$

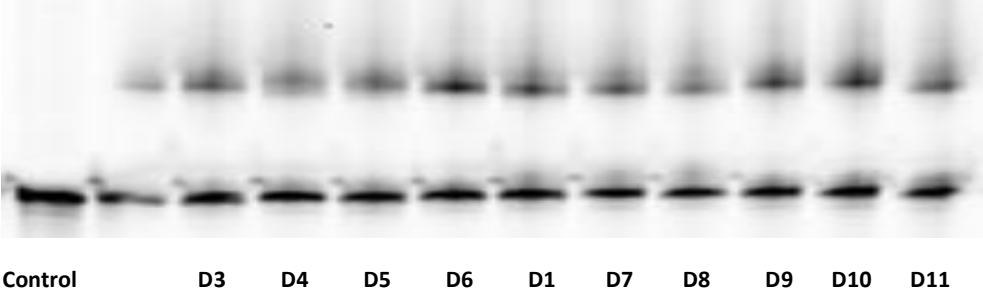

Figure 3.7: Gel electrophoresis assay to study the interaction of the IHF mimicking peptides with the 34 mer DNA duplex consisting of a GG site. The duplexes D1 and D3-D10 consist of the IHF consensus sequence whereas the duplex D11 is a random sequence. The samples were incubated for $17 \mathrm{~h}$ at $37^{\circ} \mathrm{C}$ in $10 \mathrm{mM} \mathrm{Na}_{2} \mathrm{HPO}_{4} / \mathrm{NaH}_{2} \mathrm{PO}_{4}, 100 \mathrm{mM} \mathrm{NaClO}$, $\mathrm{pH}$ 5.8. Lane 1-11 contain 0.5 $\mu \mathrm{M}$ DNA duplex with $10 \mu \mathrm{M}$ of IHF-4. (a) Performed under native conditions (20\% PAA, 1XTBE). (b) Performed under denaturing conditions (20\% PAA, 7 M urea, 1x TBE). 


\section{DNA sequences used in the study:}

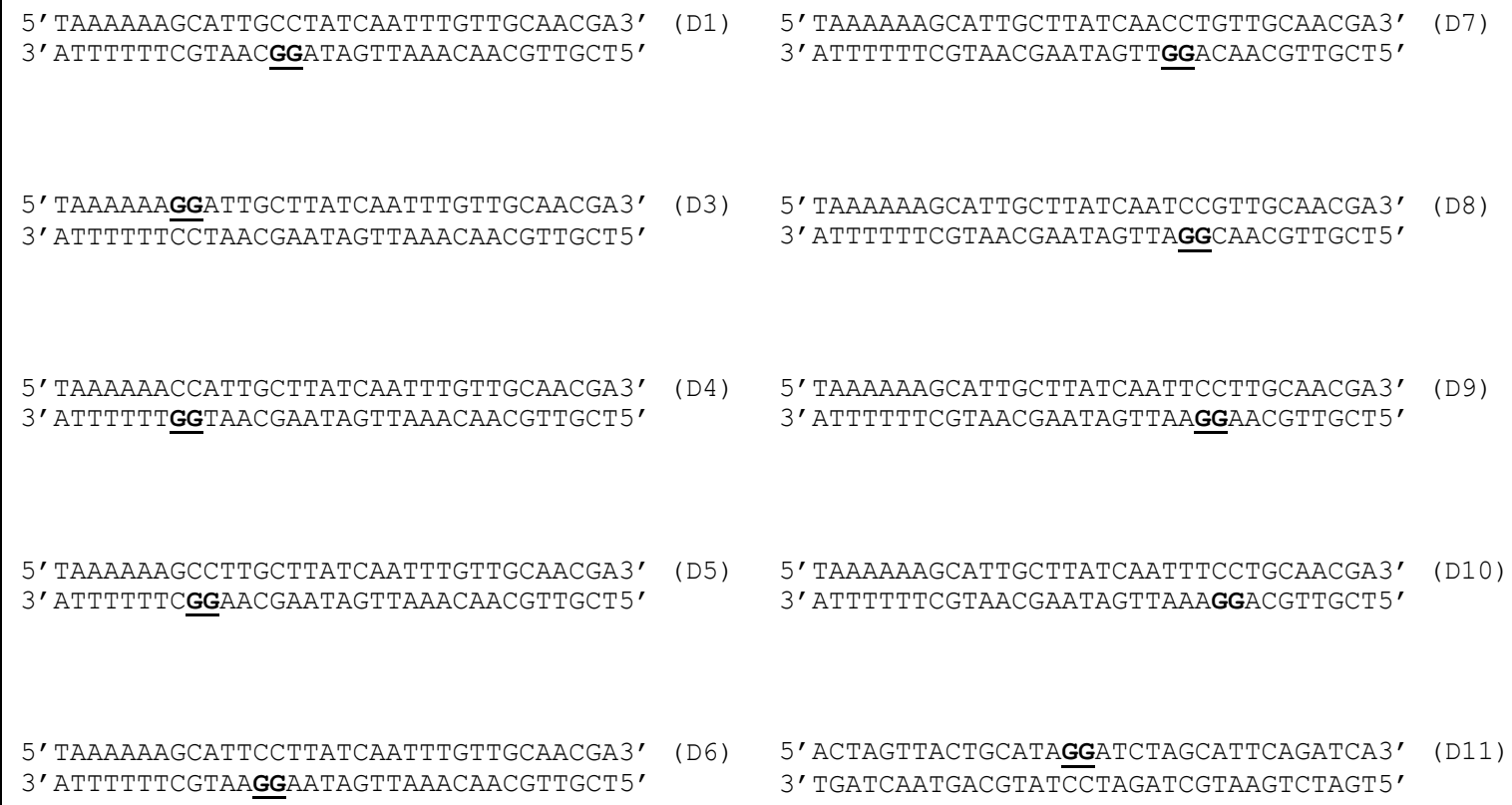

Table 3.1: Various GG site containing DNA sequences utilized in binding experiments for determining sequence specificity of the platinated IHF mimicking peptides. 


\subsubsection{Thermal melting analysis}

Temperature dependent UV spectroscopy was utilized in order to obtain further insight into the interactions of IHF mimicking with the 34-mer duplex D1, consisting of the IHF consensus sequence and including a GG site within (Figure 3.8). The platinated IHF mimicking peptides can influence the thermal stability of the duplex in the following two ways: 1) Firstly, they can enhance the duplex stability by binding of peptides utilizing minor groove recognition of the cyclic domain and electrostatic interactions of the positively charged dendrimeric domain. 2) Secondly, the covalent modification of DNA with the platinum chelating unit can either destabilize the duplex when intrastrand crosslinks are formed or stabilize the duplex when $d(G p G)$ interstrand crosslinks are formed. The melting profile is therefore visualized as a net result of the two counteracting effects. ${ }^{[135,136]}$ The peptides were pre-incubated with the DNA duplex D1 in $10 \mathrm{mM}$ phosphate buffer, $\mathrm{pH}=5.8$ for $17 \mathrm{~h}$ at $37^{\circ} \mathrm{C}$. Thermal denaturation process was measured by heating the sample from $20-95{ }^{\circ} \mathrm{C}$ whereas the renaturation process was measured by cooling from $95-10{ }^{\circ} \mathrm{C}$. The thermal melting temperatures $\left(T_{\mathrm{m}}\right)$ were determined for both heating and cooling cycle by calculating the maxima of the first derivative of the corresponding curve (Table 3.2).

Thermal denaturation and renaturation cycle for duplex D1 $(1 \mu \mathrm{M}, 10 \mathrm{mM}$ $\mathrm{Na}_{2} \mathrm{HPO}_{4} / \mathrm{NaH}_{2} \mathrm{PO}_{4}, \mathrm{pH}=5.8$ ) have the same melting temperature when measured alone as well as upon incubation with the unplatinated IHF mimics peptides, IHF-1 (Figure 3.8 A) and cyclic peptide P2 (Figure 3.8 B). The unplatinated IHF mimic IHF-1, on the one hand induced a drastic increase in duplex D1 melting temperature $\left(\Delta T_{\mathrm{m}} \geq 12{ }^{\circ} \mathrm{C}\right)$, the cyclic peptide $\mathbf{P} \mathbf{2}$ on the other hand induced a mild stabilization effect $\left(\Delta T_{\mathrm{m}} \sim 1{ }^{\circ} \mathrm{C}\right)$. This result points towards the ability of the unplatinated IHF mimic IHF-1 to interact with the duplex with the help of electrostatic interactions with negatively charged phosphate groups on the DNA backbone and hence, enhancing the duplex stability. On the contrary, the cyclic peptide P2 lacking the positively charged dendrimeric unit can only interact minimally with the DNA duplex. Moreover, the attachment of the dendrimeric unit is necessary to bring the cyclic peptide in close proximity to the DNA for facilitating its 
minor groove recognition. However, the melting profile of the platinated IHF mimics IHF-2/3/4 and the dendrimeric peptide P1 were not found to be reversible for the heating and the cooling cycle.

A

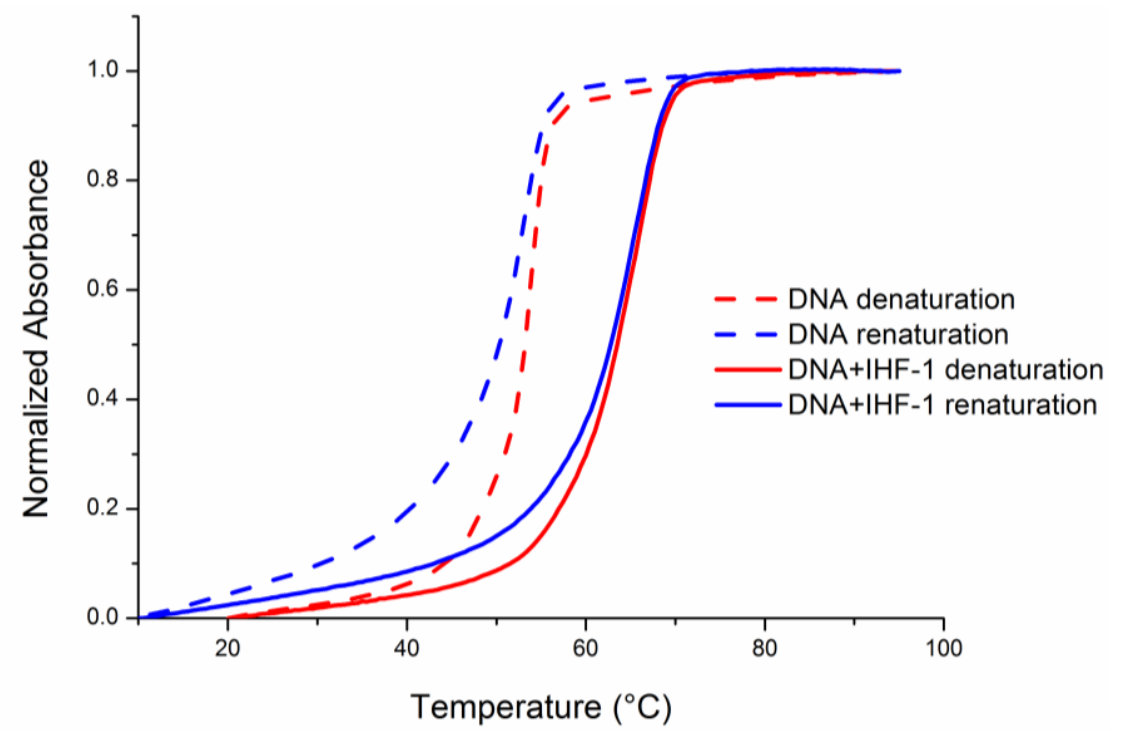

B



Figure 3.8: The thermal denaturation and renaturation profiles of duplex D1 studied after pre-incubation (A) with the unplatinated IHF mimicking peptide IHF-1 and (B) with the cyclic peptide P2 as well as DNA alone for $17 \mathrm{~h}$ at $37{ }^{\circ} \mathrm{C}\left(1 \mu \mathrm{M}\right.$ of DNA with $5 \mu \mathrm{M}$ of peptides) in $10 \mathrm{mM} \mathrm{Na}{ }_{2} \mathrm{HPO}_{4} / \mathrm{NaH}_{2} \mathrm{PO}_{4}, \mathrm{pH}=5.8$.

In the heating cycle, all three of the platinated IHF mimics IHF-2/3/4 $\left(\Delta T_{\mathrm{m}} \sim 6-8{ }^{\circ} \mathrm{C}\right)$ as well as the platinated dendrimeric peptide P1 $\left(\Delta T_{\mathrm{m}} \sim 4{ }^{\circ} \mathrm{C}\right)$ demonstrate a net increase in the duplex stability (Figure 3.9 A and Figure 3.9 B, respectively). However, the increase is comparatively less than that observed for the unplatinated mimic IHF-1. When the 
duplex DNA undergoes complete denaturation at elevated temperatures, the resulting single stranded DNA can readily react with the platinum complex/peptide chimera, thereby, facilitating covalent modification of DNA with the platinated peptides. As a result of this, the subsequent renaturation of the duplex gets disrupted and is accompanied with a net decrease in the melting temperature of the duplex.

A

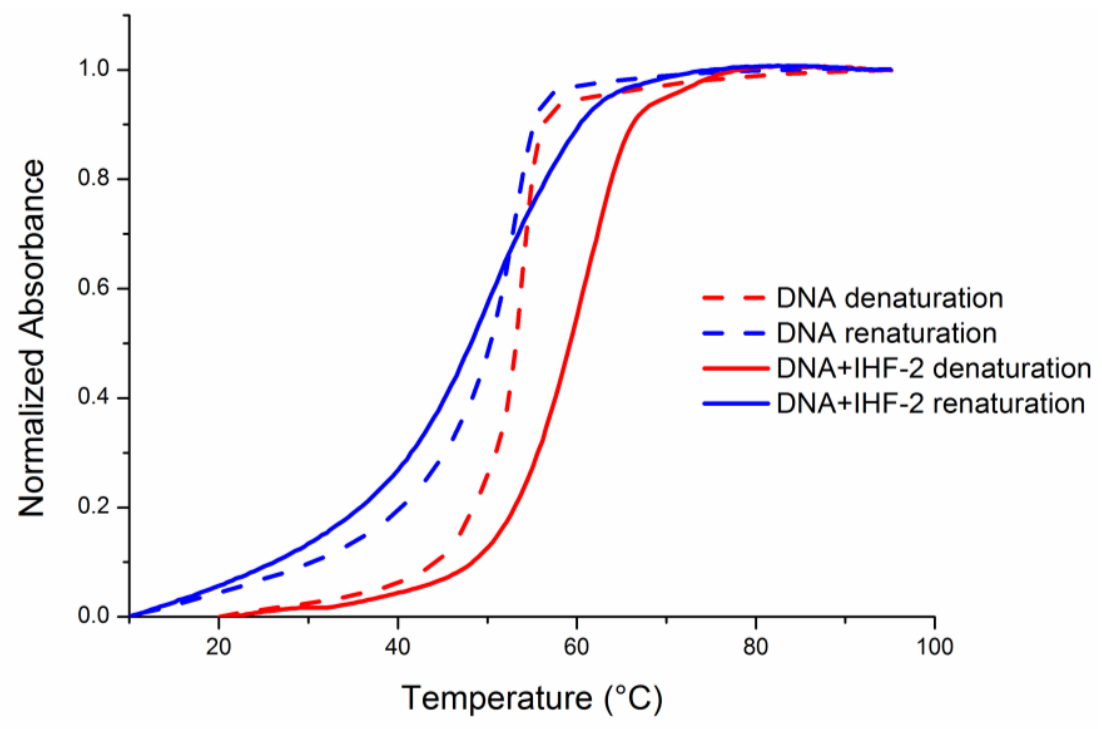

B

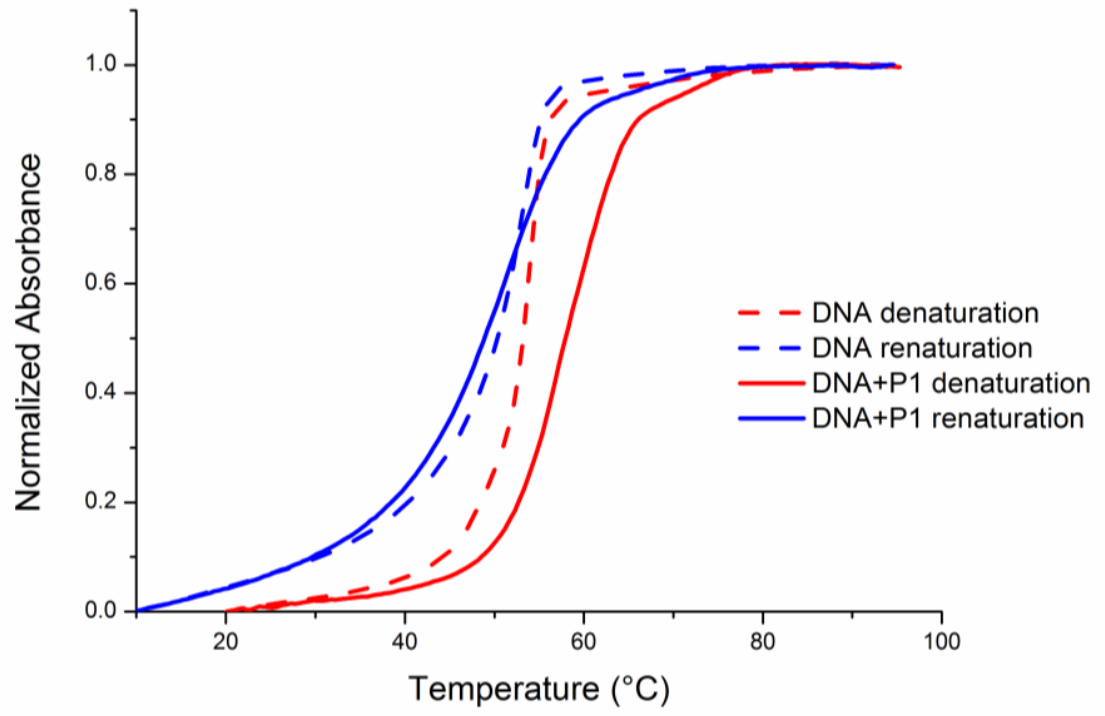

Figure 3.9: The thermal denaturation and renaturation profiles of duplex D1 studied after pre-incubation (A) with the platinated IHF mimicking peptide IHF-2/3/4 and (B) with the lysine dendrimer P1 as well as DNA alone for $17 \mathrm{~h}$ at $37^{\circ} \mathrm{C}\left(1 \mu \mathrm{M}\right.$ of DNA with $5 \mu \mathrm{M}$ of peptides) in $10 \mathrm{mM} \mathrm{Na} \mathrm{HPO}_{4} / \mathrm{NaH}_{2} \mathrm{PO}_{4}, \mathrm{pH}=5.8$. The melting profiles of IHF-2/3/4 were found to be similar and the profile for only IHF-2 has been used for representation. 
Denaturation $(20-95)^{\circ} \mathrm{C}$

\begin{tabular}{|c|c|c|c|c|}
\hline Peptide ${ }^{[\mathrm{a}]}$ & $T_{m}\left({ }^{\circ} \mathrm{C}\right)$ & $\Delta T_{m}{ }^{b}\left({ }^{\circ} \mathrm{C}\right)$ & $T_{m}\left({ }^{\circ} \mathrm{C}\right)$ & $\Delta T_{m}{ }^{\mathrm{C}}{ }^{\circ} \mathrm{C}$ \\
\hline Control & $53.6 \pm 0.5$ & - & $52.7 \pm 0.1$ & - \\
\hline IHF-1 & $65.6 \pm 0.1$ & +12 & $66.0 \pm 0.1$ & +13.3 \\
\hline IHF-2 & $61.5 \pm 1.5$ & +7.9 & $50.2 \pm 0.9$ & -2.5 \\
\hline IHF-3 & $62.1 \pm 0.9$ & +8.5 & $50.0 \pm 0.1$ & -2.7 \\
\hline IHF-4 & $59.6 \pm 0.6$ & +6.0 & $50.6 \pm 0.6$ & -2.1 \\
\hline P1 & $57.9 \pm 0.3$ & +4.3 & $51.1 \pm 0.7$ & -1.6 \\
\hline P2 & $54.1 \pm 0.1$ & +0.5 & $53.9 \pm 0.1$ & +1.2 \\
\hline
\end{tabular}

Renaturation $(95-10)^{\circ} \mathrm{C}$

Table 3.2: Summary of melting temperatures $\left(T_{m}\right)$ and changes in melting temperatures $\left(\Delta T_{m}\right)$ of a GG site containing duplex for two subsequent cycle, heating from $20-95{ }^{\circ} \mathrm{C}$ (denaturation) and cooling from $95-10$ ${ }^{\circ} \mathrm{C}$ (renaturation). [a] The peptides were pre-incubated with the duplex D1 for $17 \mathrm{~h}$ at $37{ }^{\circ} \mathrm{C}$ in $10 \mathrm{mM}$ phosphate buffer, $\mathrm{pH}=5.8$ wherein the concentration of the DNA was $1 \mu \mathrm{M}$ and the concentration of the peptide was $5 \mu \mathrm{M}$. [b] [c] $\Delta T_{\mathrm{m}}$ represents $T_{\mathrm{m}}$ (in the presence of peptide) - $T_{\mathrm{m}}$ (control DNA) for the heating and the cooling curve respectively. 



\section{The Zif268 zinc finger domain - as a model nuclease}

The design of bio-inspired metalloenzymes is an attractive approach to mimic the target specificity and activity of naturally occurring enzymes. Metal ions not only play a structural role by stabilizing the protein folds but also play a functional role by assisting in biochemical transformations. Moreover, metal complexes have tremendous potential to interact with nucleic acid sequences by means of electrostatic interactions between the cationic metal centre and the negatively charged DNA. The main targets of metal complexes within a DNA sequence include oxygen atoms of the phosphate groups, various atoms of the nucleobases as well as hydroxyl groups of the sugar unit. The previous section elaborated the ability of the platinum complex to covalently modify DNA by binding to guanine residues that results in a cytotoxic effect. Apart from this, it is also well known that certain metal complexes assist in hydrolytic cleavage of the phosphodiester bonds in DNA. The combination of such metal complexes possessing DNA cleaving ability with a biomolecular scaffold possessing DNA recognizing properties has the potential to develop novel sequence selective model nucleases. This section sheds light on the design of artificial zinc finger nucleases targeted towards the consensus DNA sequence of the native zinc finger domain.

\subsection{Zinc finger domains}

The zinc finger domain is one of the most widely occurring DNA binding motifs performing diverse functions in eukaryotic cells including regulation of gene expression and apoptosis, protein assembly, RNA packaging, lipid binding, etc. In nature the zinc finger domains usually occur as a tandem repeat of three or more single zinc fingers, each consisting of cysteine and/or histidine within the sequence. ${ }^{[137]}$ The zinc ion plays a 
structural role by inducing and stabilizing protein folds around itself. Based on the coordination sphere around the metal centre, the zinc fingers can be classified into different types such as $\mathrm{Cys}_{2} \mathrm{His}_{2}, \mathrm{Cys}_{4}$ and $\mathrm{Cys}_{6}$. The first zinc finger motif was discovered in the Xenopus laevis transcription factor IIIA which is a $\mathrm{Cys}_{2} \mathrm{His}_{2}$ type occurring as a tandem repeat of nine single zinc fingers. ${ }^{[138]}$ Adjacent fingers are stitched together by a linker sequence TGXKP ( $\mathrm{X}$ is any amino acid), highly conserved among the $\mathrm{Cys}_{2} \mathrm{His}_{2}$ type of zinc finger domains. These constructs play an essential structural role in facilitating DNA recognition by maintaining appropriate spacing between two consecutive domains. The wide occurrence of the $\mathrm{Cys}_{2} \mathrm{His}_{2}$ of zinc finger motifs, together with their ability to interact not just with DNA but also with RNA and some other proteins, makes them an interesting target for a detailed elucidation of structure and recognition properties. ${ }^{[139]}$

\subsection{Interaction of the $\mathrm{Cys}_{2} \mathrm{His}_{2}$ type of zinc finger domain Zif268 with the consensus DNA binding site}

The consensus sequence of the $\mathrm{Cys}_{2} \mathrm{His}_{2}$ type of zinc finger, consisting of nearly 30 amino acids, is of the form (F/Y)-X-Cys- $\mathrm{X}_{2-5}-\mathrm{Cys}-\mathrm{X}_{3}-(\mathrm{F} / \mathrm{Y})-\mathrm{X}_{5}-\psi-\mathrm{X}_{2}-\mathrm{His}-\mathrm{X}_{3-5}-\mathrm{His}$ in which $\psi$ is an amino acid residue with a hydrophobic side chain whereas $X$ can be any amino acid residue. ${ }^{[140]}$ The structural stability of the zinc finger domains is dependent solely on a small set of conserved amino acids. Coordination of the conserved cysteine and histidine residues with the zinc ion drives the folding process of individual zinc fingers to form a 3-dimensional compact globular domain consisting of an antiparallel $\beta$-sheet and an $\alpha$-helix (Figure 4.1a). Two of the conserved cysteine residues are located in the $\beta$-sheet fold while the other two conserved histidine residues are present in the $\alpha$-helix. The removal of the zinc ion leads to denaturation of the protein, ${ }^{[141]}$ and replacing either of the conserved histidine or cysteine ligands leads to inactivity of the protein. ${ }^{[142,143]}$ Additionally, the core of the zinc finger domain consisting of three conserved hydrophobic amino acids, Tyr5/Phe5, Phe16 and Leu22, plays a crucial role in determining its structural stability by holding the entire construct around the zinc coordination site. ${ }^{[144]}$ The invariable $\beta \beta \alpha$ fold among all Cys ${ }_{2} \mathrm{His}_{2}$ type of zinc fingers hints 
towards its role in mediating DNA binding. Furthermore, sequence specificity arises from base pair interaction with side chains of particular amino acid residues located at the surface or amino-terminus of the helical domain.

(a)

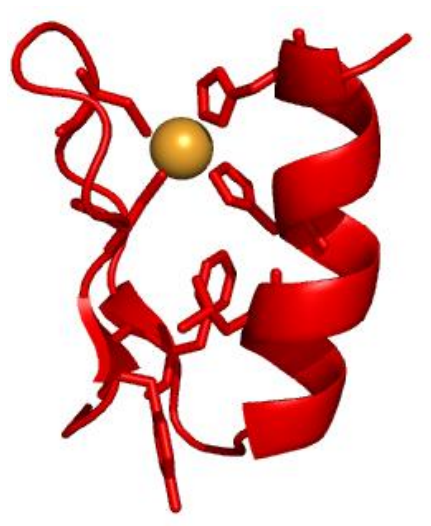



(b)

(c) Finger 1

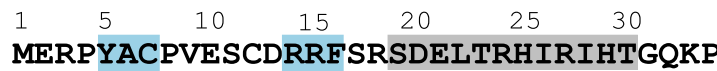

Finger 2

Finger 3
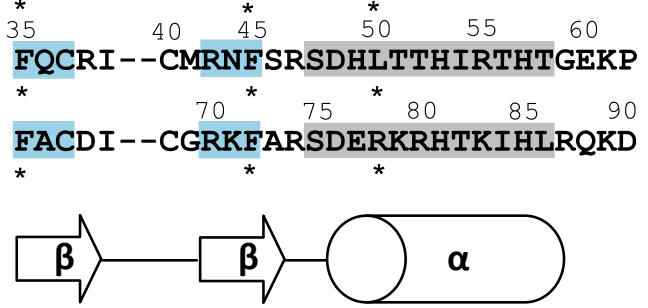

Figure 4.1: (a) Structure of single $\mathrm{Cys}_{2} \mathrm{His}_{2}$ type of zinc finger in Zif268 wherein binding of the $\mathrm{Zn}^{2+}$ to two of the cysteine and histidine residues along with a conserved hydrophobic core stabilizes the $\beta \beta \alpha$ fold. (b) Zif268 domain wrapped around the consensus DNA binding site (5'-GCGTGGGCGT-3')* (5'-ACGCCCACGC-3') as a tandem repeat of three zinc fingers shown in red, purple and green, respectively (pdb code: 1AAY). ${ }^{[9]}$ Images genetrated by PyMOL. (c) The amino acid sequence derived from the Zif268 domain utilized in this study, wherein the $\alpha$-helical domains are highlighted in grey, the anti-parallel $\beta$-sheets in blue and the conserved hydrophobic residues are star marked. ${ }^{[9]}$

X-ray crystallographic analyses were performed in order to understand the structural aspects of the zinc finger domains that facilitate site-specific recognition of DNA (Figure 4.1b). The polypeptide consisting of a tandem repeat of three zinc finger domains of the murine protein Zif268 was co-crystallized with its consensus binding site, 
$\left(5^{\prime}-\right.$ GCGTGGGCGT-3')*(5'-ACGCCCACGC-3'). ${ }^{[9]}$ The sequence of the polypeptide consisted of 90 amino acid residues (Figure 4.1c). The crystal structure of the Zif268 complex displays the protein wrapped around the major groove of DNA, making conserved base pair contacts with amino acid residues placed at positions $-1,2,3$ and 6 in the $\alpha$-helical domain. The position of the $\alpha$-helix of individual zinc finger domain in the major groove is slightly slanted such that the axis of the $\alpha$-helix is oriented at an angle of $45^{\circ}$ with the axis of the DNA duplex. The binding of the Zif268 is accompanied with widening of the major groove. ${ }^{[145]}$ The amino acid residues at positions $-1,3$ and 6 contact the three consecutive base pairs on the primary DNA strand whereas the residue at position 2 contacts the nucleobase in the complementary strand (Figure 4.2). ${ }^{[146]}$

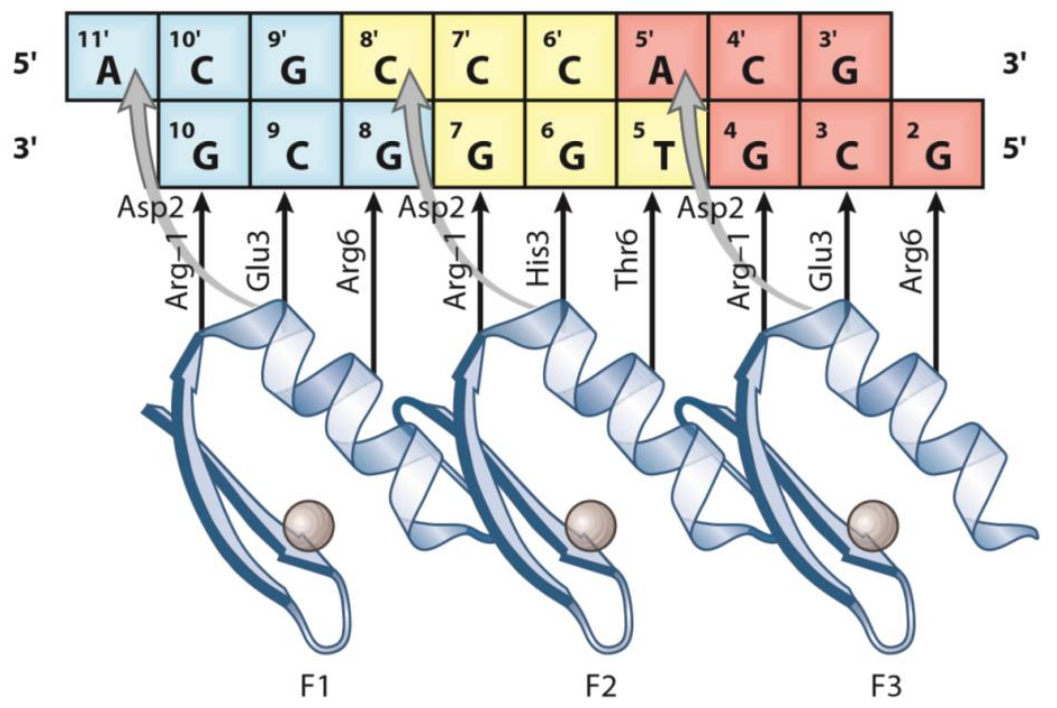

Figure 4.2: Representation of the interactions between various amino acid residues within the Zif268 domain and its consensus DNA binding sequence. ${ }^{[146]}$

It is interesting to note that among all three zinc fingers within Zif268 domain, the residues at -1 and 2 are identical. An arginine at position -1 exhibits hydrogen bonding interactions with a guanine whereas an aspartic acid at position 2 interacts with the exocyclic amine of an adenine/cytosine on the complementary DNA strand (Figure 4.3a). Furthermore, the residues interact with the phosphate backbone of DNA via bridging water molecules as well as with each other via hydrogen bonding between the aspartate and the guanidinium functionality. At position 3 , in zinc fingers 1 and 3 a glutamate 
residue forms a hydrophobic contact with cytosine whereas in finger 2 a histidine residue forms hydrogen bonding with a guanine residue in addition to van der Waals interaction with a neighbouring thymine (Figure $4.3 \mathrm{~b}$ ). Additional interactions are provided by an arginine residue at position 6 in fingers 1 and 3 which is involved in hydrogen bonding with a guanine (Figure 4.3c). Taking all these interactions into consideration it is apparent that the recognition of DNA by zinc finger domains is predominantly driven by the helical domain. ${ }^{[148,149]}$ Therefore, individual zinc fingers recognize a subsite of the DNA duplex consisting of four base pairs, three of which belong to the primary DNA strand and the fourth one lies on the complementary DNA strand interacting with the residue at position 2 in helical domain. The latter interaction causes adjacent zinc finger domains to have an overlap in the recognition subsite and plays an important role in determining the specificity of binding a particular DNA sequence. Moreover, a tandem repeat of three zinc fingers in the Zif268 motif substantially enhances the sequence specificity by making contacts with 9 consecutive base pairs on the primary DNA strand. Adopting this modular design of zinc fingers and applying a combinatorial approach offer the possibility to enhance the span of specifically recognizing a multitude of DNA sequences of a varying length.

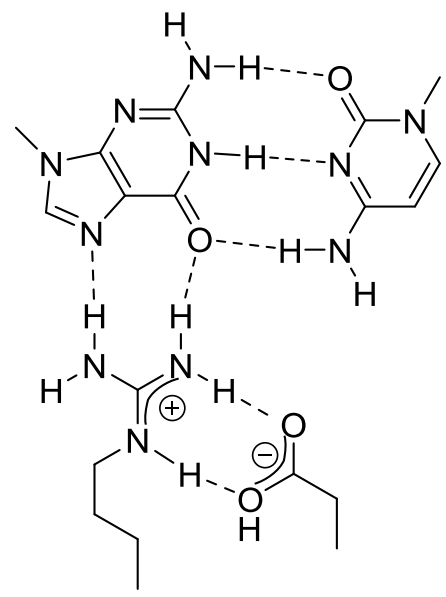

(a)

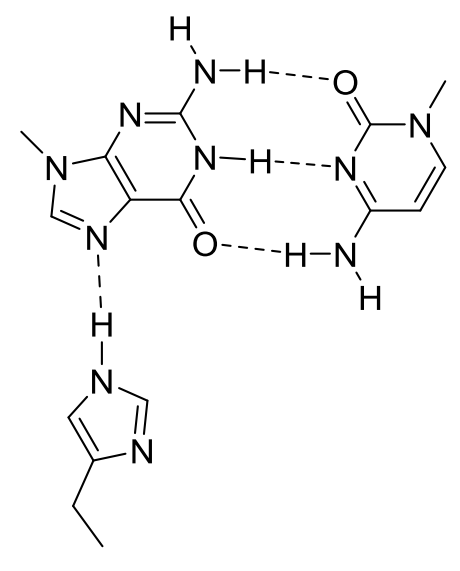

(b)

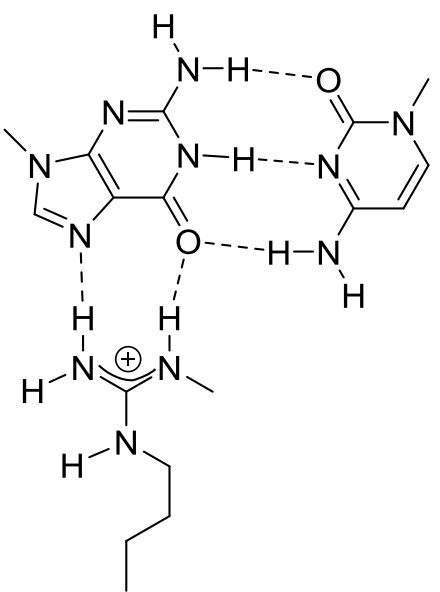

(c)

Figure 4.3: (a) Interaction of the conserved arginine at position -1 with the aspartic acid at position 2 within the $\alpha$-helical domain as well as with the guanine and cytosine on the primary and complementary DNA strand, respectively. (b) Interaction of the histidine at position 3 in finger 2 with a guanine on the primary strand. (c) Interaction of an arginine at position 6 in fingers 1 and 3 with a guanine on the primary strand. ${ }^{[9,146]}$ 


\subsection{Engineering zinc finger domains}

The unique framework of the $\mathrm{Cys}_{2} \mathrm{His}_{2}$ type of zinc finger domain in combination with the available selection strategies offers the possibility to engineer a specific DNA binding protein for targeting any given nucleic acid sequence. ${ }^{[146]}$ Chimeric protein domains can be prepared by the combination of such DNA binding modules in order to accommodate other domains known to perform certain biochemical transformations such as DNA cleavage, mutagenesis, transcription activation and repression, gene correction and silencing (Figure 4.4). ${ }^{[147]}$ The novel chimeric domains acquire enhanced recognition properties from the zinc finger DNA binding module and hence are able to target the specific gene of interest. In this section emphasis has been laid on the design of zinc finger nucleases for site specific DNA cleavage with the aim of developing artificial restriction endonucleases.
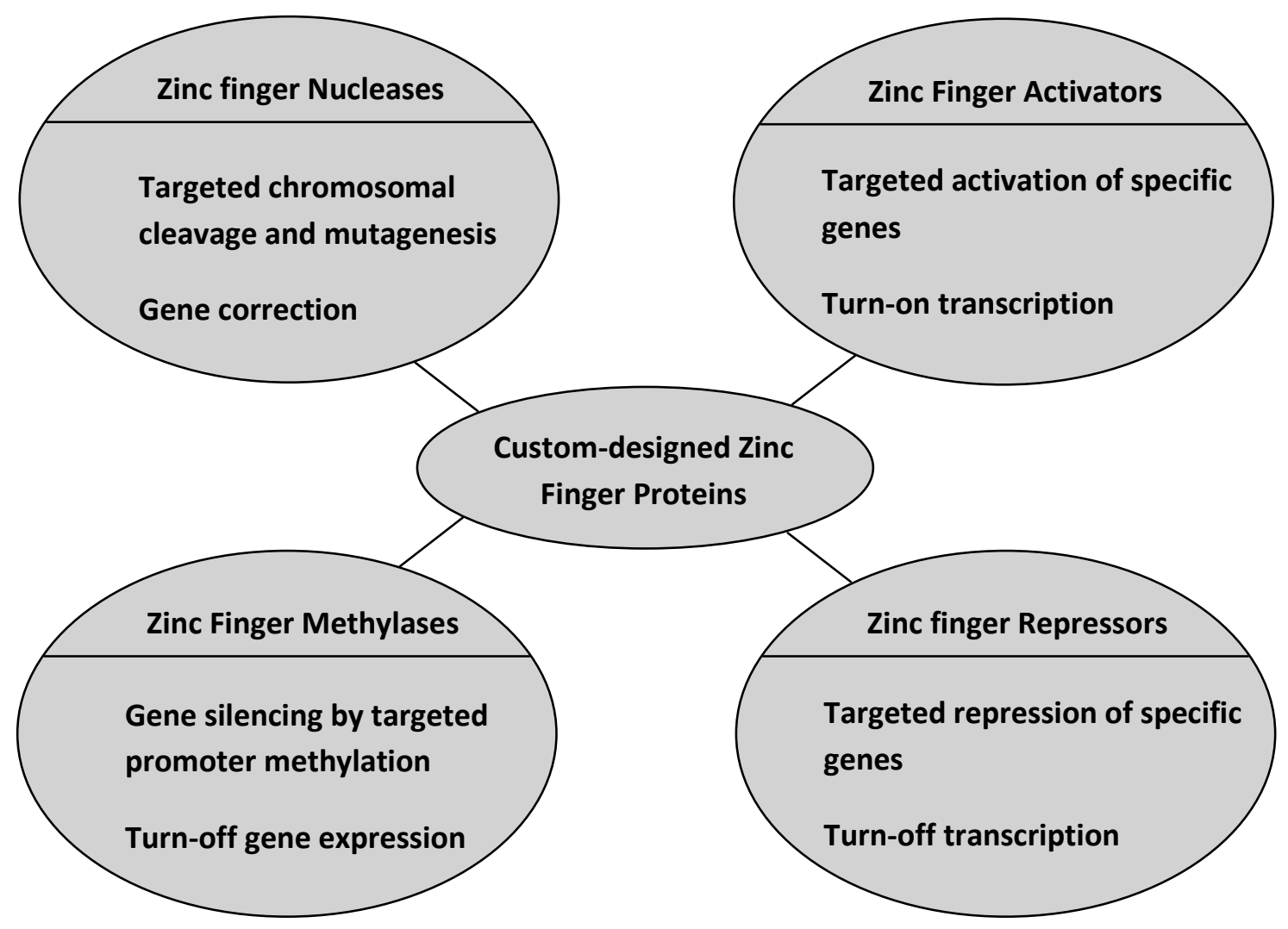

Finger Proteins

Figure 4.4: An overview of the diverse biochemical transformations performed by engineered zinc finger proteins prepared by combination of the zinc finger DNA binding module with various functional domains such nucleases, methylases, transcription activators and repressors. ${ }^{[147]}$ 


\subsubsection{Sequence selection}

In order to understand the aspects of sequence recognition by the zinc finger motifs several techniques have been employed including X-ray crystallography, NMR studies, site specific mutagenesis and phase display experiments. The cocrystal structure of the Zif268-DNA complex clearly indicates the importance of amino acid residues located at positions $-1,2,3$ and 6 in the recognition $\alpha$-helix for DNA binding. ${ }^{[9,150,151]}$ By means of interactions with the DNA major groove, these residues facilitate individual zinc finger domains to recognize a three base pair code. The specificity of binding towards a target DNA sequence can be altered by exchanging one or more amino acid residues at these key positions.

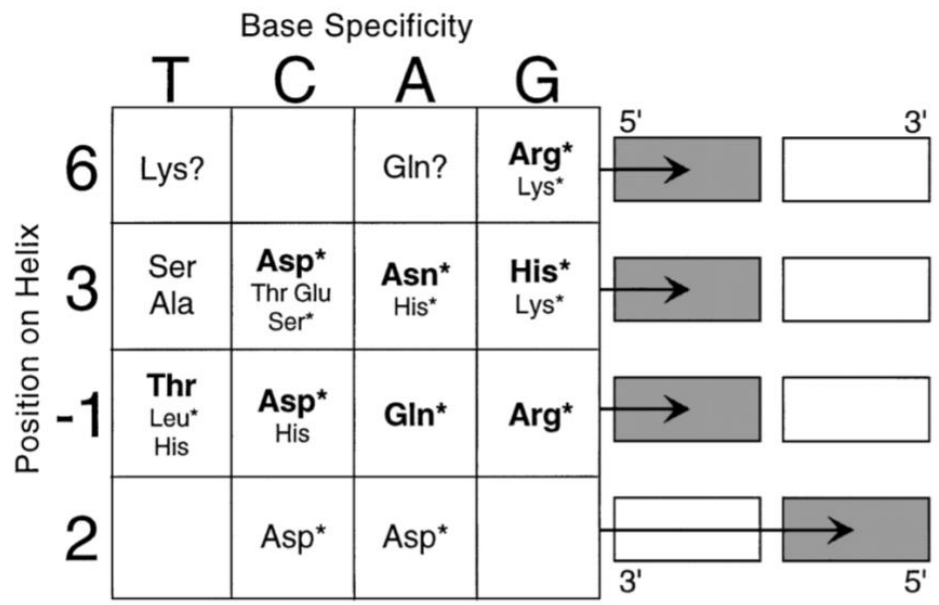

Figure 4.5: The interactions of amino acid side chains located at the key positions $(-1,2,3,6)$ in the recognition helix with a given 4 base pair subsite on the DNA duplex. The amino acids marked in bold are the most frequently observed in phage display assay for specificity towards a particular base pair interaction and those marked with an asterisk are frequently found in structural analysis. The interaction of the question marked amino acids is uncertain with the corresponding base pair whereas blank positions in the chart indicate undefined interactions. ${ }^{[149]}$

Phage display methods provide a more rational route to identify novel zinc finger motifs with distinct DNA binding specificities. ${ }^{[152-156]}$ The method relies on the selection of amino acid sequences for the zinc finger domain under consideration from a randomized library. Comparison of similarities in sequences that are capable of recognizing the same nucleotide triplet allows deduction of a recognition code, which can be visualized as a combined effect of individual amino acid side chain (at positions $-1,2,3,6$ ) and base pair 
interaction (Figure 4.5). ${ }^{[149,154]}$ The main drawback of this method is that it assumes these interactions to be completely independent of each other. Furthermore, when considering a tandem repeat of zinc fingers the binding of adjacent fingers is a synergistic event due to an overlap in the DNA binding subsite consisting of 4 base pairs. However, this interdependence of neighbouring domains is not taken into account during the sequence selection procedure. The method is biased towards selection of a three base pair code of the form GNN (wherein $\mathrm{N}$ is any nucleotide), hence limiting the selection of the recognition code from a very confined subset of trinucleotide sequences. ${ }^{[157]}$ The solution to overcome this limitation lies in exploiting the very synergistic binding of adjacent zinc fingers. Though, the proposed recognition code is not always most suited with respect to its binding specificity but can provide valuable information to begin with predicting the possible sequences. Further optimization can lead to better sequence choices. Several advances have been made in strategies to design a specific binder for a longer preset DNA sequence. These strategies include a combination of single preselected fingers, ${ }^{[158]}$ sequential selection of individual fingers to build the polymeric protein $^{[159]}$ or parallel selection of domains from two premade libraries followed by splicing the two selected units. ${ }^{[160]}$

\subsubsection{Zinc finger nuclease technology}

One of the most attractive applications of the zinc finger DNA binding module is to design artificial endonucleases with specificity for novel restriction sites. Restriction enzymes are often put to use in biotechnology and molecular biology field for genome editing in cell lines. Though several restriction enzymes are currently available, they are not always able to offer flexibility in choosing the desired recognition site. Engineering zinc finger proteins with novel sequence specificities has enormous potential in broadening the versatility of restriction enzyme recognition sites. ${ }^{[161-163]}$

The zinc finger nuclease technology offers a method to design chimeric custom-made domains for site specific cleavage of DNA. In this technique, a non-specific DNA cleavage domain of the naturally occurring Fokl endonuclease is combined with a tandem array of 
zinc finger modules with predetermined sequence specificity. The objective is to generate a double strand break (DSB) in the desired DNA binding site. ${ }^{[164]}$ A DSB is achieved only by the dimeric form of the Fokl endonuclease when two individual DNA cleavage domains are placed in close proximity to each other. ${ }^{[147,165,166]}$ Two conjugate zinc finger domains bind along with the Fokl domain to their corresponding closely positioned inverted binding sites (Figure 4.6). The in situ generated dimeric active nuclease leads to hydrolytic cleavage of the phosphodiester linkages in the DNA duplex. $^{[147]}$ It is important to note that the method is readily applicable to nonpalindromic sequences by choosing different zinc finger DNA binding modules on either side of the cleavage site. A dimeric zinc finger nuclease with each monomer consisting of three fingers can specifically recognize a sequence of 12-18 base pairs which is practically sufficient to site specifically cleave a single gene from the genome of an organism. Implementation of the zinc finger nucleases allow high precision site directed mutagenesis by means of primary intrinsic repair processes termed as homology directed repair (HDR) and non-homologous end joining (NHEJ). HDR works by "copy and paste" mechanism facilitating site specific recombination in the presence of a donor sister chromatid as a template, leading to insertions and corrections in a gene. ${ }^{[167]} \mathrm{NHEJ}$ is simple ligation of the broken ends of the DSB that occurs in the absence of a template DNA facilitating targeted mutations and knockout of large genes. ${ }^{[168]}$ Thus, the zinc finger nucleases technology offers tremendous potential in the direction of genetic engineering and developing clinical targets for human gene therapy.



Figure 4.6: Induction of double strand break (DSB) in DNA by the heterodimeric zinc finger nuclease (ZNF) constructed by combination of the natural nuclease domain of Fokl endonuclease with the two different zinc finger DNA recognition modules. ${ }^{[161]}$ 


\subsection{Hydrolytic cleavage of DNA phosphodiester linkage by multinuclear metal complexes}

The importance of designing DNA cleaving agents with novel specificities has become apparent due to its wide range of applications. ${ }^{[161-163,169-172]}$ Despite being very stable under physiological conditions $(\mathrm{pH} 7)$, the negatively charged DNA is an excellent target for metal cations as a result of electrostatic attraction forces between the two. Several naturally occurring nucleases consist of metal binding sites assisting in the cleavage of phosphodiester linkages. ${ }^{[173-175]}$ The binding of the metal ion to a water molecule results in significant lowering of its $\mathrm{pK}_{\mathrm{a}}$ generating a more nucleophilic hydroxide group even at physiological $\mathrm{pH}$, which plays a key role in the hydrolytic reaction (Figure 4.7). ${ }^{[176,177]}$ Moreover, the metal ion assists in pre-organization of the active site as well as in charge neutralization and stabilization of the incoming nucleophile, the DNA phosphate groups, the transition state intermediates and the leaving group. Understanding the mechanism of DNA cleavage used by natural metallonucleases can assist in the design of highly efficient artificial nucleases.



Figure 4.7: Enzymatic cleavage of the phosphodiester linkage at P-O3'. ${ }^{171]}$

Typically, the active site of metalloenzymes consists of multinuclear metal binding sites acting cooperatively in the catalytic reaction. First row transition metals complexes, particularly zinc complexes, are most commonly found in such systems due to high 
charge density and Lewis acid character. ${ }^{[171,172,176,177]}$ Metalloenzymes for the cleavage of phosphate linkages such as the alkaline phosphatase utilizes a binuclear Zn(II) complex within the catalytic core whereas phospholipase $\mathrm{C}$ and P1 nuclease rely on a tri-nuclear Zn(II) complex for their activity (Figure 4.8). ${ }^{[178,}$ 179] While phospholipase $C$ and P1 nuclease preferably cleave phosphodiester linkages, alkaline phosphatase has a different substrate selectivity and is involved in hydrolysis of monoesters.

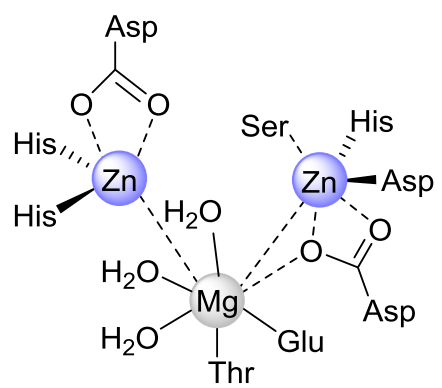

alkaline phosphatase



phospholipase C

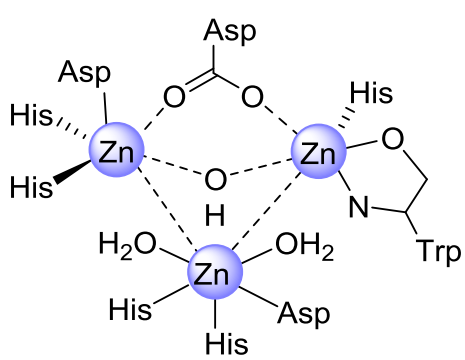

P1 nuclease

Figure 4.8: Examples of multinuclear zinc complexes involved in cleavage of phosphate linkages. ${ }^{[178,179]}$

Alkaline phosphatase is one of the most extensively studied among all binuclear zinc based enzymes facilitating phosphate transfer reaction in a series of intermediate steps (Figure 4.9). ${ }^{[173,175]}$ The presence of a binuclear metal coordination within the active site significantly enhances the rate of hydrolytic reaction. ${ }^{[180-183]}$ While one of the two $\mathrm{Zn}$ (II) ions coordinates with the ester oxygen, the other coordinates with the phosphate oxygen of the substrate creating a phosphate bridge between the metal centres. The second $\mathrm{Zn}(\mathrm{II})$ centre activates the serine residue for nucleophilic attack on the phosphorus atom leading to the formation of a phosphoserine enzyme intermediate. This leads to the cleavage of the phosphate ester and sets the first $\mathrm{Zn}$ (II) coordination site free. The newly generated vacant site becomes available for a water molecule. Activation of the water molecule upon coordination with the $\mathrm{Zn}$ (II) ion at an alkaline $\mathrm{pH}$ results in formation of a hydroxide species, which subsequently leads to hydrolysis of the phosphoserine linkage. In addition to the two central $\mathrm{Zn}(\mathrm{II})$ ions that are placed at an optimum distance of $4 \AA$ for facilitating the enzymatic reaction, a third $\mathrm{Mg}(\mathrm{II})$ ion is present within the domain of alkaline phosphatase. Despite not actively participating in 
the catalytic reaction the $\mathrm{Mg}(\mathrm{II})$ ion has been found to play an auxiliary role in enhancing the activity of the enzyme. ${ }^{[173,183,184]}$

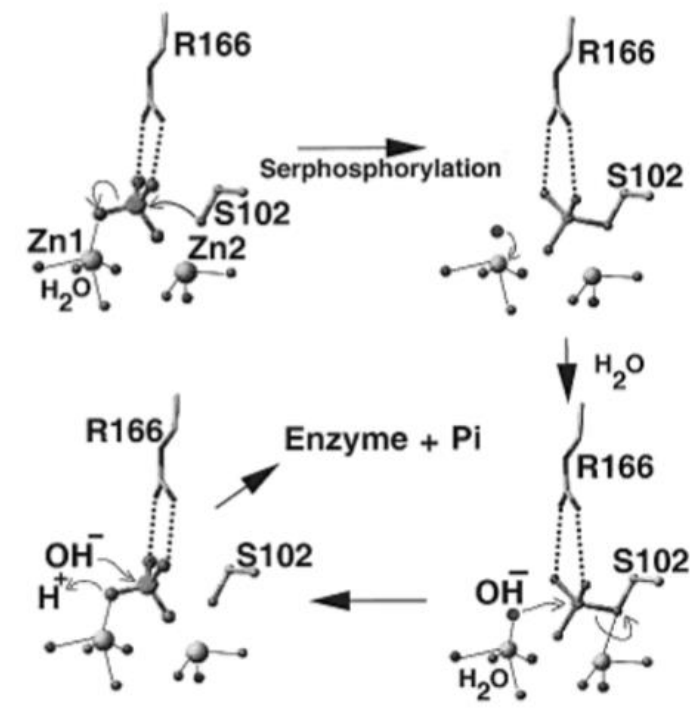

Figure 4.9: Major intermediate steps involved in the phosphate transfer mechanism by alkaline phosphatase. ${ }^{[173]}$

\subsubsection{Biomimetic systems as artificial nucleases}

Design of biomimetic systems provides a way to harness the potential of multinuclear metalloenzymes for the development of therapeutic agents as well as assists in elucidating the mechanism of the enzymatic reaction itself. ${ }^{[185]}$ The side chains of amino acid residues including imidazole of the histidine residue, sulfide of the cysteine, and carboxylate of aspartic and glutamic acid are the most common metal coordinating ligands within protein domains. In order to mimic metalloenzymes, the same metal ions as utilized in the native system should be employed. Additionally, the artificial metal ligands should be designed such that they are functionally and structurally similar to the amino acid residues coordinating to the metal ion in the natural system. Furthermore, in the multinuclear ligand systems the metal ions should be positioned in close proximity to each other to facilitate optimal conditions for the catalytic reaction. This task is fulfilled by utilizing bridging ligands such as phenolates, carboxylates, pyrozolyl rings, macrocycles or aliphatic linkers, in design of functional model complexes for holding the metal centres at appropriate positions (Figure 4.9). ${ }^{[178,186-189]}$ Employing polyaminocarboxylates and 
aromatic azacycles offers the possibility to control the hydrolytic cleavage of phosphodiester linkages by manipulating the $\mathrm{pH}$ of the system. ${ }^{[189]}$

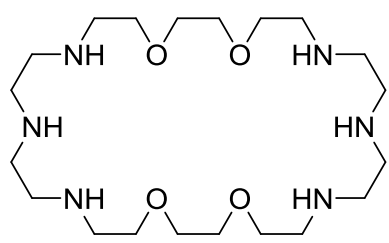<smiles>Cc1cc(CN(CCO)Cc2ccccn2)c(O)c(CN(CC(=O)O)Cc2ccccn2)c1</smiles>

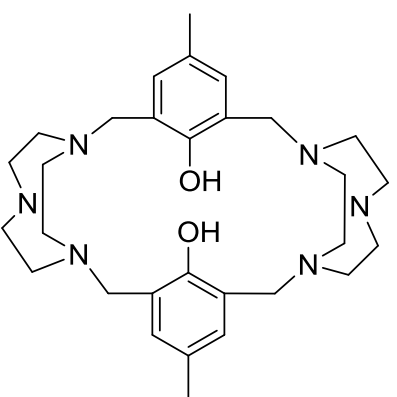

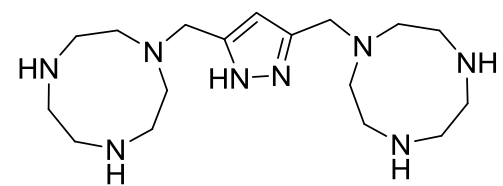

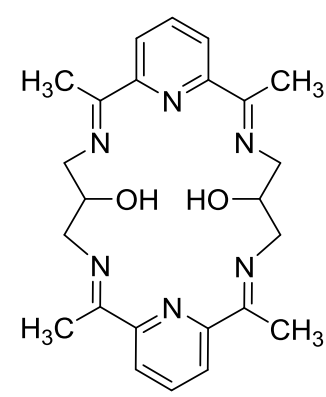

Figure 4.9: Binuclear ligand systems designed to hold two metal ions at an optimum distance for enhanced phosphatase activity. ${ }^{[178,186-189]}$

\subsubsection{Design of site specific model nucleases utilizing DNA recognition motifs}

The combination of DNA cleaving domains with DNA recognizing domains has not only shown to improve their recognition properties but also immensely enhances their nuclease activity. ${ }^{[190,191]}$ Moreover, this approach offers the possibility to design artificial restriction enzymes for site-specific cleavage of any given DNA sequence. As discussed in the previous section, binuclear metal centre play a key role in determining the activity of most of the natural nucleases. Hence, bimetallic ligands systems, mimicking the active site of the natural nuclease, with an ability to hydrolyse phosphodiester linkages can be utilized as DNA cleaving functionalities. Examples of DNA binding domains applied for the design of high affinity hybrid biomimetic systems include DNA intercalators, peptides, peptide nucleic acid sequences and antisense oligonucleotides. ${ }^{[192-195]}$ One of the most challenging aspects for applying this approach is to incorporate the binuclear metal 
complex within the DNA binding domain while retaining its DNA recognition property as well as meeting the requirements for effective DNA cleavage.

(a)

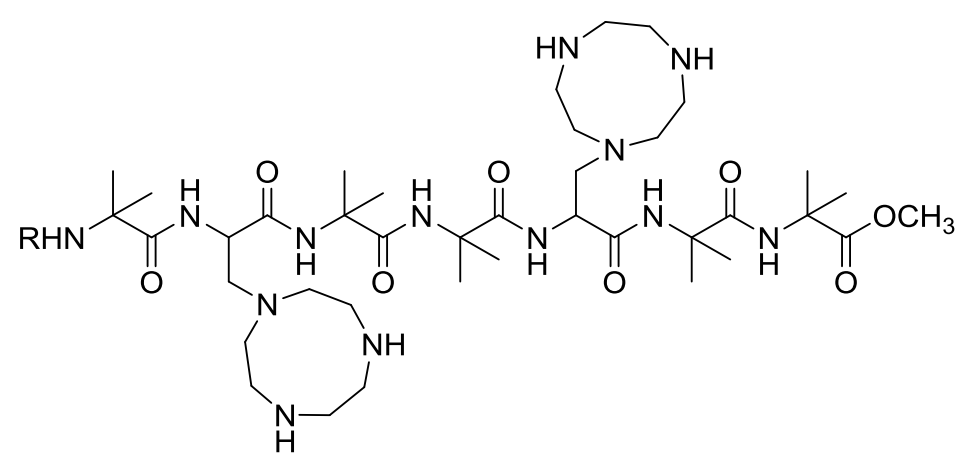

(b)

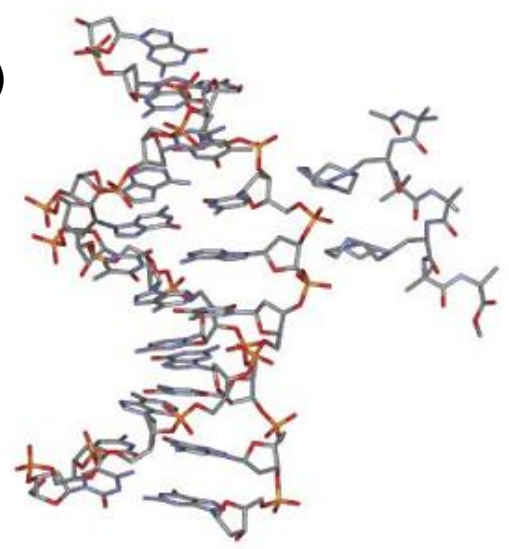

Figure 4.10: (a) The structure of binuclear $\mathrm{Zn}$ (II) chelating heptapeptide. (b) The mode of binding of the peptide to the DNA as proposed by Scrimin and co-workers for facilitating DNA cleavage. ${ }^{[171,193]}$

The peptide based binuclear $\mathrm{Zn}$ (II) complex reported by Scrimin and co-workers demonstrated an exceptional ability to cleave plasmid DNA with a first order rate constant of $1.0 \times 10^{-5} \mathrm{~s}^{-1}$ at $\mathrm{pH} 7.0$ and $3.6 \mu \mathrm{M}$ complex concentration. ${ }^{[171,193]}$ The peptide sequence consisted of seven amino acid residues forming a $3_{10}$-helical domain from which two Tacn (triazacyclononane) ligands protrude (Figure 4.10). The two Zn(II) coordinating ligands facing each other are spaced apart by a distance of $6 \AA$. Despite not satisfying the criteria of optimum intermetallic distance as found in natural nuclease, the two metal centres in the model nuclease act cooperatively to facilitates phosphodiester cleavage. 


\section{Synthesis and DNA interaction of a modified Zif268 domain containing an allosteric metal binding site}

The versatility to engineer zinc finger domains for any given DNA sequence offers the possibility to attain a high degree of specificity towards the cognate DNA. Furthermore, the role of the zinc coordination site within the zinc finger domains can be extended from merely being a structural entity into a catalytically active site for facilitating reactions such as DNA cleavage. However, introduction of the artificial metal binding pockets in protein domains is a challenging task as it can potentially disrupt the three dimensional geometry of the protein. Therefore, the design of the multinuclear ligand systems should be carefully chosen such that they resemble naturally occurring amino acids and fit appropriately into the catalytic domain of the protein. This section sheds light on the synthesis of an artificial binuclear zinc chelating amino acid mimicking histidine and its incorporation into the Zif268 domain.

The Zif268 domain utilized in this study consists of a tandem repeat of three individual zinc fingers in order to enhance sequence specificity towards the cognate DNA. The first two zinc fingers (Zf12) were prepared by expression in $E$. coli whereas the third zinc finger $(\mathrm{Zf} 3)$ was modified to contain the histidine mimicking amino acid. The two peptide fragments were combined by native chemical ligation to form the Zf13 domain containing a tandem array of three zinc fingers. The DNA interaction properties of the various Zf13 domains prepared by following the semi-synthetic strategy were studied with its consensus DNA sequence. The ultimate goal of the project is to design an artificial nuclease for site-specific cleavage of DNA by utilizing the recognition properties of the zinc finger DNA binding module. 


\subsection{Synthesis of an artificial amino acid mimicking histidine}

The Zif268 is a Cys ${ }_{2} \mathrm{His}_{2}$ type of zinc finger domain wherein two histidine and two cysteine residues of single zinc finger domains complex with a $\mathrm{Zn}(\mathrm{II})$ to form the $\beta \beta \alpha$ protein fold. Modification of the Zif268 domain was carried out by replacing a histidine residue with an artificial histdine mimicking amino acid. A substituted triazole derivative was employed to resemble the imidazole ring of the histidine and functionalized with a 1,4,7triazacyclononane (Tacn) ring. ${ }^{[1]}$ While the N2 or N3 atoms of the triazole ring readily available for coordination with various metal ions provide the first metal binding site, ${ }^{[196,}$ ${ }^{197]}$ the Tacn ring consisting of three nitrogen atoms provides the second metal binding site. The dinuclear complexes of the bis(Tacn) ligand system have shown to efficiently cleave DNA phosphate ester linkages by cooperative action of the two metal centres strategically placed in close proximity to each other. ${ }^{[186,198,199]}$ Incorporation of such $\mathrm{Zn}$ (II) chelating units within the Zif268 domain facilitate introduction of an allosteric metal coordination site in addition to the native site and hence, offer the possibility to assist in site-specific cleavage of DNA phosphodiester linkages.

Click chemistry approach offers a bio-orthogonal synthetic strategy for preparation of triazoles by coupling between an azide and an alkyne unit. ${ }^{[200]}$ The synthesis of the artificial amino acid mimicking histidine was carried out according to the procedure reported earlier by $A$. Nadler. ${ }^{[11]}$ In order to impart binuclear zinc chelation property to the artificial amino acid, a substituted Tacn ligand bearing an azide functionality was conjugated with Fmoc-propargylglycine. The synthesis of the azide substituted Tacn ligand started with tosylation of diethylenetriamine 24 (Scheme 5.1). The resulting $N, N^{\prime}, N^{\prime \prime}$-tri(tosyl)diethylenetriamine 25 was connected with ethylene ditosylate in the presence of sodium hydride to yield the tosyl protected triazacyclononane 26. Removal of the tosyl groups was followed by protection of the Tacn ring with $(\mathrm{Boc})_{2} \mathrm{O}$. The reaction led to the formation of mono-, di- and tri-boc protected Tacn ligand. The di-boc protected product 1,4-bis(tert-butoxycarbonyl)-1,4,7-triazacyclononane 27 was isolated from the mixture utilizing column chromatography. Ethylene glycol ditosylate 28 was treated with sodium azide to yield 2-azido-ethyl tosylate 29. Further substitution of $\mathbf{2 7}$ with (2-azido-ethyl)-functionality by reaction with 2-azido-ethyl tosylate $\mathbf{2 9}$ yielded $\mathbf{3 0}$. 


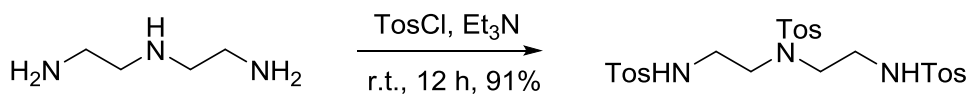

24

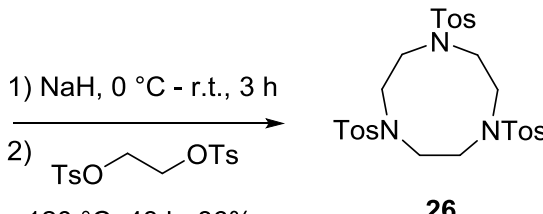

$120{ }^{\circ} \mathrm{C}, 48 \mathrm{~h}, 86 \%$

26

25

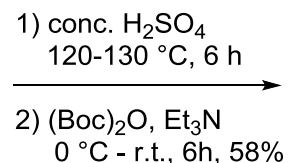

$0{ }^{\circ} \mathrm{C}$ - r.t., $6 \mathrm{~h}, 58 \%$

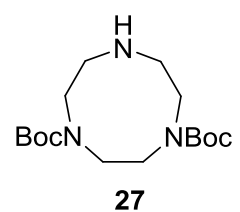

27

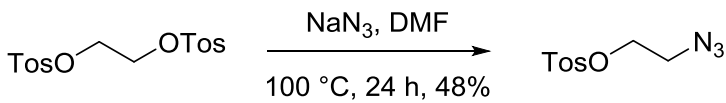

28

29

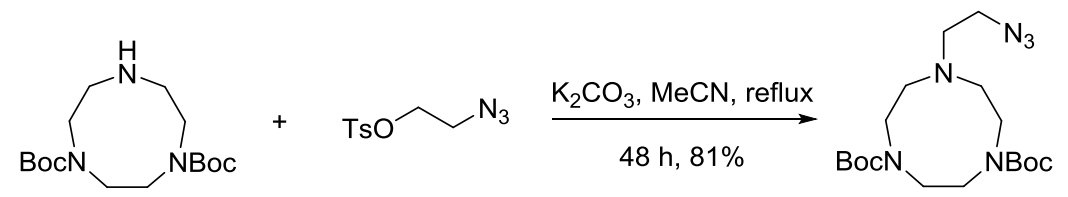

27

29

30

Scheme 5.1: Synthesis of the azide functionalized Tacn ligand 30 providing an allosteric metal binding site for Zn(II) chelation. ${ }^{[11]}$

Finally, the synthesis of the triazole based histidine mimicking amino acid $\mathbf{3 2}$ was achieved by conjugation of the azide functionalized Tacn ligand with Fmoc-propargylglycine by utilizing copper(I) catalyzed azide-alkyne cycloaddition conditions (Scheme 5.2). The building block 32 was applied in the Fmoc SPPS protocol for the preparation of the $\mathrm{Zf} 3$ domain.



30

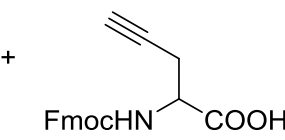

31



32

Scheme 5.2: Synthesis of the histidine mimicking artificial amino acid 32 functionalized with a Tacn ligand. 


\subsection{Preparation of the synthetic $\mathrm{Zf} 3$ domain}

The sequence of the $\mathrm{Zf3}$ domain consists of 25 amino acid residues from Cys ${ }^{65}$ to Lys ${ }^{89}$. The synthesis of the peptide fragment was achieved by Fmoc based SPPS protocol starting from Fmoc-Lys(Boc)-Wang resin. Standard coupling conditions using HBTU/HOBt as activators and DIPEA as base were applied. The deprotection of the Fmoc group was achieved in $20 \%$ piperidine. The peptide was cleaved off the resin utilizing a cleavage solution consisting of TFA/ $\mathrm{H}_{2} \mathrm{O} / \mathrm{TIS} / \mathrm{EDT}(94 / 2.5 / 1 / 2.5)$. Three variants of the $\mathrm{Zf3}$ domains were synthesized following the above mentioned procedure (Figure 5.1). The zinc finger domains consisting of adjacent cysteine residues readily undergo oxidation to form disulfide bridges with each other. The synthesized peptide fragments were isolated in the oxidized form after RP-HPLC purification.

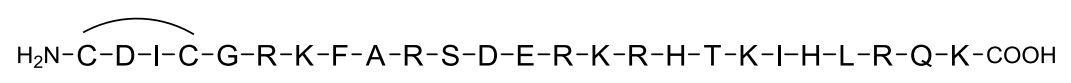

33



34

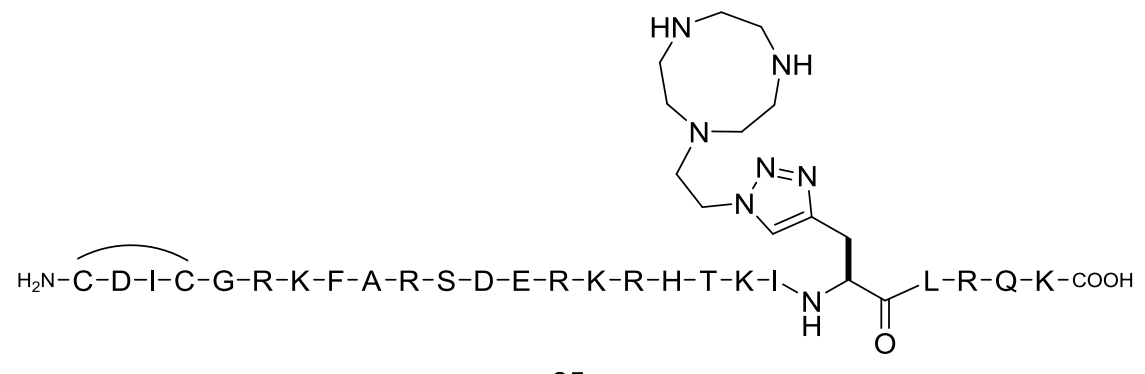

35

Figure 5.1: Various Zf3 domains utilized in this study prepared by Fmoc SPPS protocol. 
Firstly, an unmodified Zf3 domain Zf3Wildtype $\mathbf{3 3}$ was synthesized for comparative studies. Secondly, the histidine residues, $\mathrm{His}^{81}$ and $\mathrm{His}^{85}$, in the $\mathrm{Zf3}$ sequence were replaced with the histidine mimicking artificial amino acid residue one at a time leading to the formation of the modified zinc finger domains Zf3Tacn81 34 and Zf3Tacn85 35 containing an additional zinc coordination site. The reduction of the disulfide containing peptides is necessary prior to usage and is accomplished by treatment with the highly selective disulfide reducing agent tris(2-carboxyethyl)phosphine (TCEP).

\subsection{Expressed protein ligation}

Expressed protein ligation (EPL) or intein mediated protein ligation (IPL) offers a semi synthetic approach for the preparation of large peptide sequences. Inteins are protein subdomains that enable the proteins to undergo a self splicing mechanism, thereby facilitating ligation of flanking ends of neighbouring protein sequences with a peptide

linkage. ${ }^{[201]}$ Exploiting this intein mediated splicing mechanism used by nature offers a wide range of applications in the field of biotechnology and molecular biology. ${ }^{[202-204]}$ In this work, the self cleavage ability of inteins has been put to use for generation of a recombinantly expressed protein in E. coli in the form of a peptide thioester, which is one of the substrates for protein ligation. The EPL relies on chemo-selective native chemical ligation between the expressed peptide fragment consisting of a C-terminal thioester and the synthetic peptide fragment consisting of an $\mathrm{N}$-terminal cysteine residue.

\subsubsection{Protein expression in $E$. coli for the preparation of the $\mathrm{Zf12}$ domain}

The expression of the $\mathrm{Zf12}$ domain was carried out utilizing the IMPACT ${ }^{\mathrm{TM}}$ kit supplied by New England Biolabs. The method provides a highly efficient and simplified protein purification protocol utilizing a C-terminal fusion expression vector such as pTXB1 for the generation of a C-terminal thioester. The gene coding for the $\mathrm{Zf12}$ domain fused together with the gene coding for the intein tag, pTXB1-Zf12, was introduced into $E$. coli cells lines ER2566. Hence, the protein is expressed as the Zf12 domain in fusion with the intein tag. 
Furthermore, the intein tag consists of a chitin binding domain which can be exploited for purification of expressed protein by affinity chromatography on a chitin column (Figure $5.2 \mathrm{~A}$ ). A detailed protocol for protein expression and purification of the fusion protein are given in section 7.2. Introduction of thiol containing compounds such as MesNa to the chitin column saturated with the fusion protein induces a self cleavage mechanism of the intein tag, facilitating separation of the Zf12 domain from itself. The expressed zinc finger domain, Zf12 obtained as a peptide thioester $\mathbf{3 6}$ after purification by affinity chromatography was further purified by RP-HPLC (Figure 5.2 B, 5.2 C).

(A)



(B)

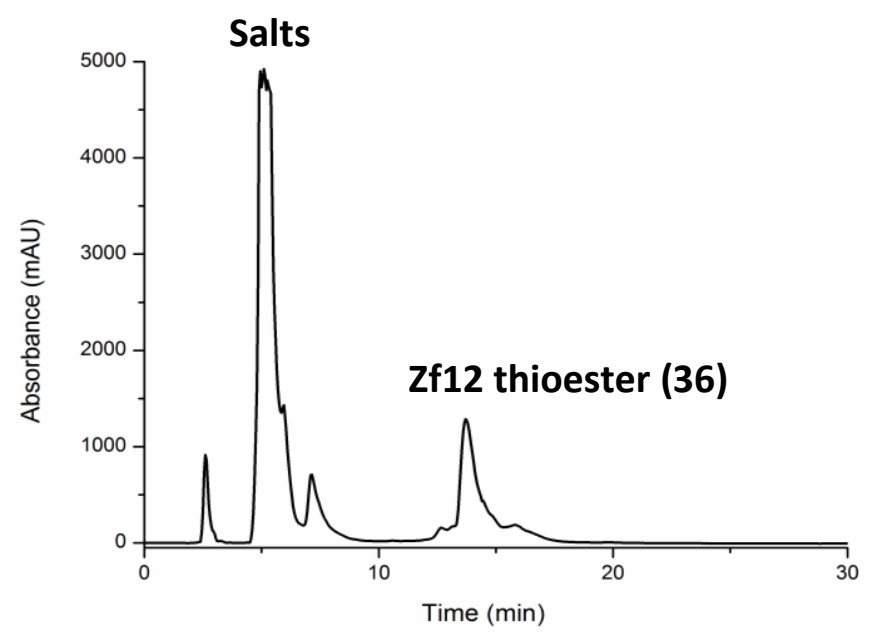

(C)

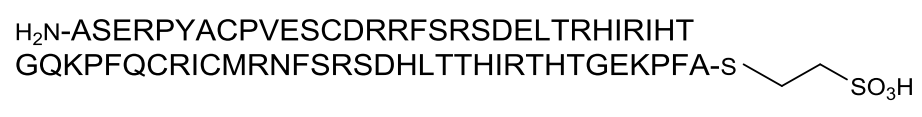

36

Figure 5.2: (A) Schematic representation of the expression protocol of the Zf12 domain. (B) RP-HPLC chromatogram of the expressed Zf12 peptide thioester 36. (C) Sequence of the ZF12 thioester 36. 


\subsubsection{Preparation of $\mathrm{Zf} 13$ domains by native chemical ligation}

Solid phase peptide synthesis developed by Merrifield, ${ }^{[205]}$ is a highly versatile method offering the possibility to synthesize non-native peptide sequences as well as incorporation of artificial amino acids at any given position within the sequence. However, one of the major shortcomings of SPPS is its inability to synthesize large peptides restricting the length of the sequence to approximately 50 amino acids. ${ }^{[206]}$ The development of native chemical ligation $(\mathrm{NCL})$ by the Kent research group, ${ }^{[207]}$ has revolutionized the field of peptide chemistry by providing an efficient method to synthesize reasonably large peptide sequences. $\mathrm{NCL}$ is a chemoselective reaction between two unprotected peptides leading to the formation of a peptide linkage at the ligation site (Figure 5.3).

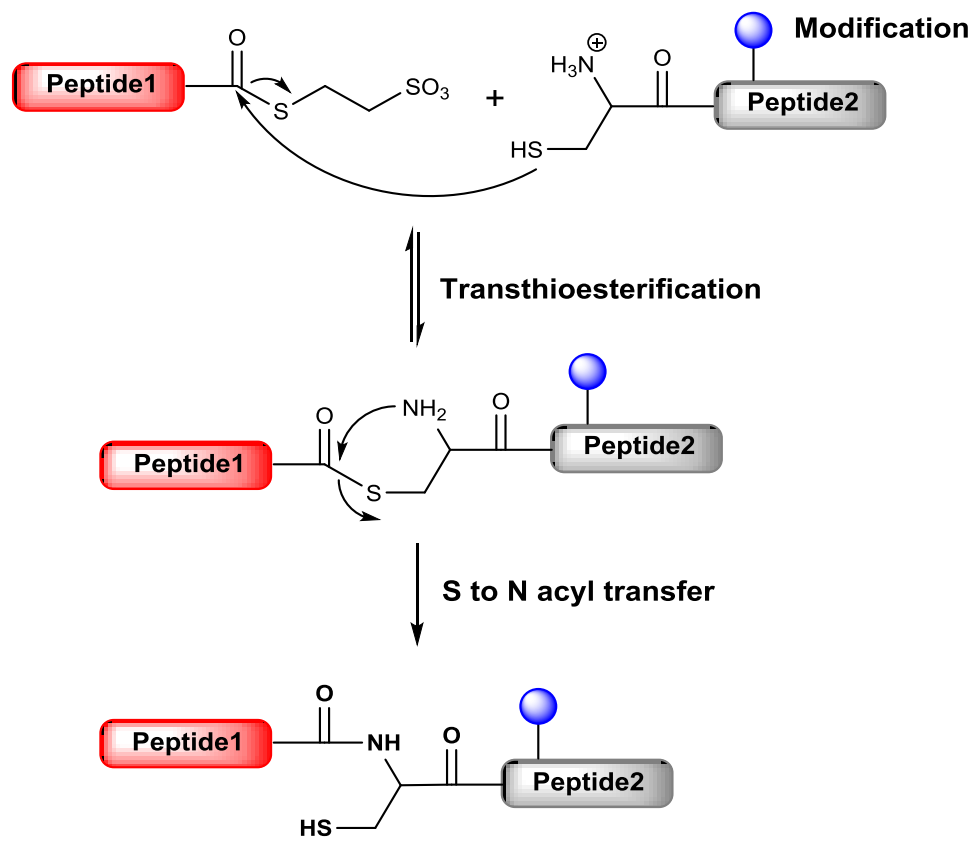

Figure 5.3: Representation of the native chemical ligation reaction scheme between a peptide fragment containing a C-terminal thioester and an $\mathrm{N}$-terminal cysteine containing peptide.

One of the two peptides consists of a C-terminal thioester while the other consists of an $\mathrm{N}$-terminal cysteine residue. The reaction follows a capture/rearrangement pathway mainly via two steps. The first step involves transthioesterification wherein the thioester 
containing peptide undergoes nucleophilic attack with the thiol of the $\mathrm{N}$-terminal cysteine. The second step involves a rapid and irreversible intermolecular $\mathrm{S}$ to $\mathrm{N}$ acyl shift in order to generate a covalent peptide linkage at the position of ligation.
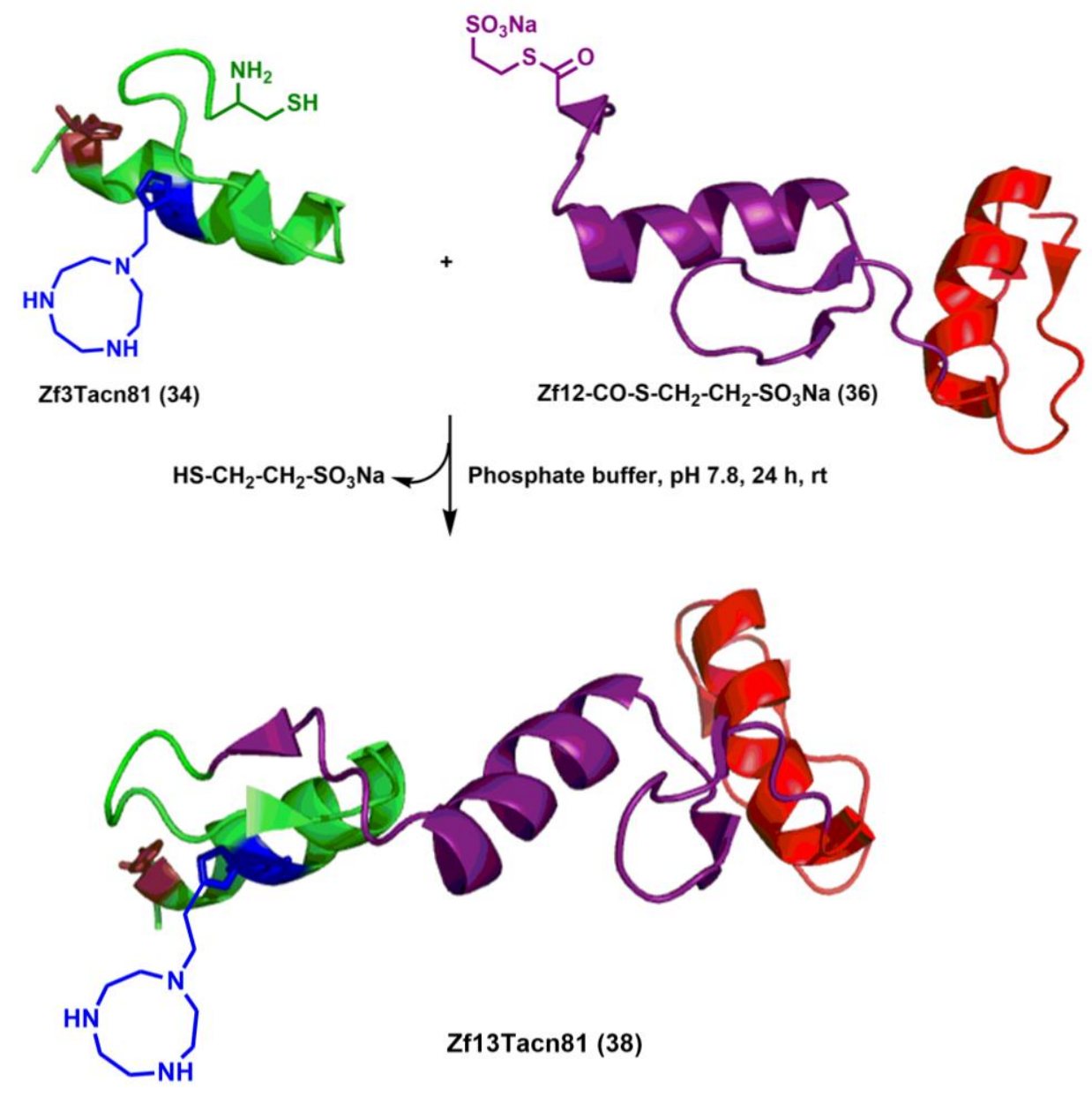

Scheme 5.3: NCL between the expressed Zf12 thioester $\mathbf{3 6}$ and the synthetic peptide Zf3Tacn81 $\mathbf{3 4}$ leading to the formation of the ligated Zf13Tacn81 38. The other two Zf13 domains Zf13Wildtype $\mathbf{3 7}$ and Zf13Tacn85 39 were prepared in an analogous manner.

The $\mathrm{Zf13}$ domains consisting of a tandem repeat of three zinc fingers were synthesized by native chemical ligation between the expressed Zf12 thioester $\mathbf{3 6}$ and the synthetic $\mathbf{Z f 3}$ domains. The Zf3 peptide sequences after SPPS and RP-HPLC purification were isolated in the oxidized form containing disulfide bridges between adjacent cysteine residues. The $\mathrm{Zf3}$ domains were reduced with TCEP to release the thiol of the $\mathrm{N}$-terminal cysteine residue which is necessary for nucleophilic attack on the C-terminal thioester of the Zf12 
domain. The reactions were carried out under denaturing conditions in the presence of $6 \mathrm{M} \mathrm{Gnd.HCl}$ to prevent aggregation while maintaining a high concentration of reactants. ${ }^{[206-208]}$ The average yield of the ligation reaction was around $20 \%$. The Zf13Tacn81 38 and Zf13Tacn85 39 consist of a histidine mimicking artificial amino acid bearing a triazacyclononane ligand in the $\mathrm{Zf3}$ domain instead of $\mathrm{His}^{81}$ and $\mathrm{His}^{85}$, respectively. The Zf13Wildtype $\mathbf{3 7}$ is the native sequence prepared for comparative studies.

$\mathrm{H}_{2} \mathrm{~N}$-ASERPYACPVESCDRRFSRSDELTRHIRIHTGQKPFQCRICMRNF SRSDHLTTHIRTHTGEKPFACDICGRKFARSDERKRHTKIHLRQK-COOH

Zf13Wildtype (37)

$\mathrm{H}_{2} \mathrm{~N}$-ASERPYACPVESCDRRFSRSDELTRHIRIHTGQKPFQCRICMRNF SRSDHLTTHIRTHTGEKPFACDICGRKFARSDERKR-X-TKIHLRQK-COOH

Zf13Tacn81 (38)

$\mathrm{H}_{2} \mathrm{~N}$-ASERPYACPVESCDRRFSRSDELTRHIRIHTGQKPFQCRICMRNF SRSDHLTTHIRTHTGEKPFACDICGRKFARSDERKRHTKI-X-LRQK-COOH

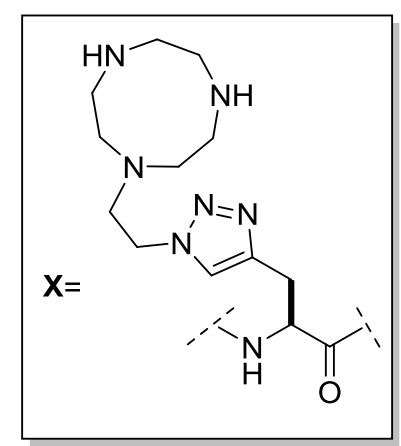

Zf13Tacn85 (39)

Figure 5.4: Sequence of the Zf13 domains prepared by native chemical ligation: Zf13Wildtype (37), Zf13Tacn81 (38), Zf13Tacn85 (39). $X$ is the histidine mimicking artificial amino acid bearing a triazacyclononane ligand.

\subsection{Determination of the structure and DNA recognition of the modified zinc finger domains}

CD spectroscopy offers an efficient method to study the secondary structure and folding patterns of biomolecules such as nucleic acid sequences and proteins. Introduction of an artificial amino acid residue within the zinc finger domain might perturb its conformational stability as well as influence its DNA recognition. In this section CD measurements have been performed in order to compare the DNA binding and folding 
pattern of the modified zinc finger domains with respect to the naturally occurring zinc finger sequence.

The $\mathrm{Zn}(\mathrm{II})$ ion plays a structural role in stabilizing the $\beta \beta \alpha$ fold around the tetrahedral metal complex in zinc finger constructs. ${ }^{[9]}$ The folding pattern of the modified zinc finger constructs Zf3Tacn81 $\mathbf{3 4}$ and Zf3Tacn85 $\mathbf{3 5}$ was measured in the absence or presence of the $\mathrm{Zn}(\mathrm{II})$ ion and compared with the unmodified construct Zf3Wildtype 33 (Figure 5.5). The zinc fingers were reduced with TCEP prior to use and the measurement was performed in $2.5 \mathrm{mM}$ Tris buffer $(\mathrm{pH}=7.8)$ containing $0.5 \mathrm{mM}$ TCEP and $50 \mu \mathrm{M}$ of $\mathrm{Zf3}$ peptides. CD spectra of the $\mathrm{Zf3}$ domains were recorded in absence and presence of $100 \mu \mathrm{M}$ of $\mathrm{Zn}^{2+}$. The binding of the metal ion should be able to induce protein folding, thereby, making the zinc finger constructs more structured.

(A)

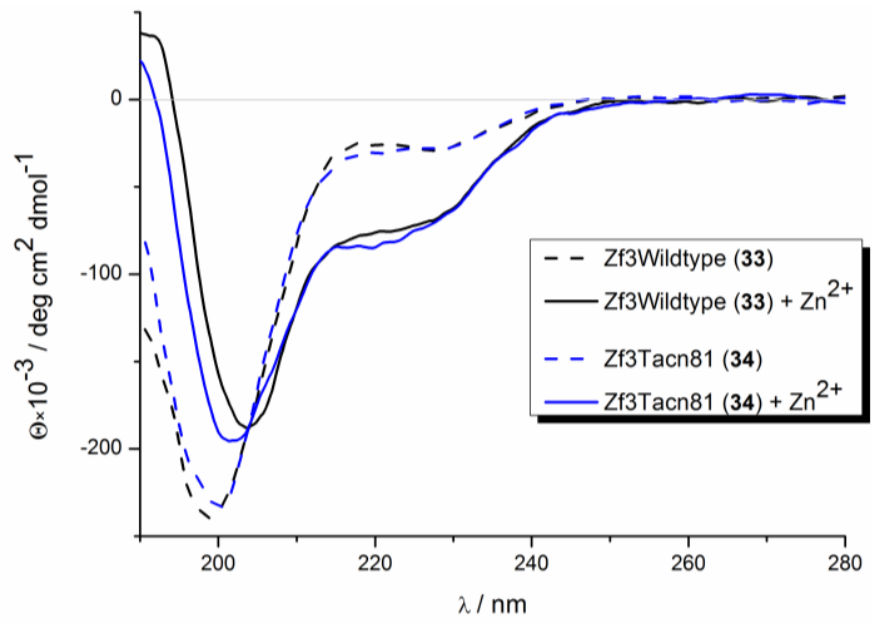

(B)

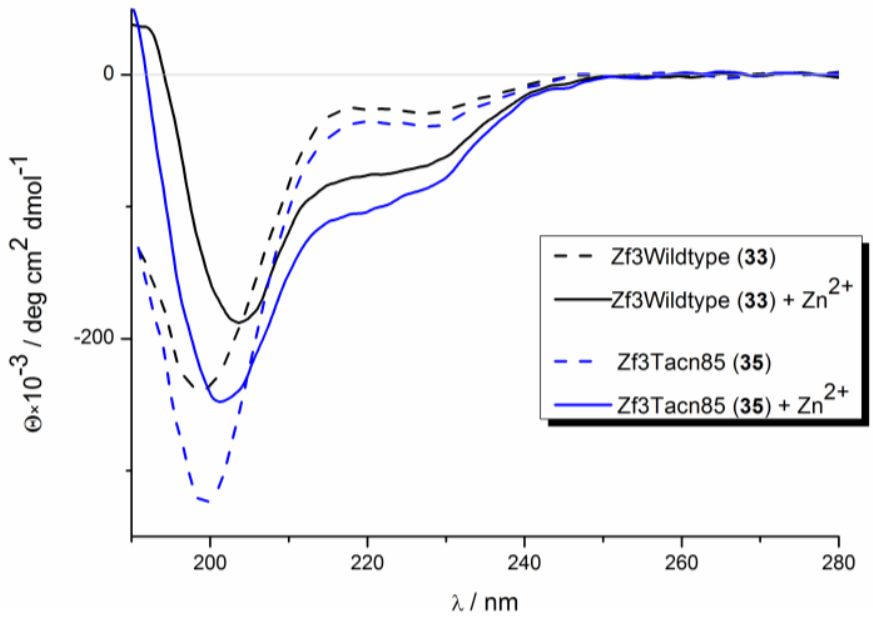

Figure 5.5: (A) Comparison of the CD spectra of the Zf3Tacn81 34 with Zf3 Wildtype 33 in the absence and presence of $\mathrm{Zn}$ (II) ion. (B) Comparison of the CD spectra of the Zf3Tacn85 35 with Zf3Wildtype $\mathbf{3 3}$ in the 
absence and presence of $\mathrm{Zn}(\mathrm{II})$ ion. The measurements were performed in $2.5 \mathrm{mM}$ Tris buffer ( $\mathrm{pH}=7.8$ ) containing $0.5 \mathrm{mM}$ TCEP and $50 \mu \mathrm{M}$ of $\mathrm{Zf3}$ peptides in absence and presence of $100 \mu \mathrm{M}$ of $\mathrm{Zn}^{2+}$.

The observed CD spectra is a net result of the combination of $\alpha$-helix, $\beta$-sheet and random coil structures. Their characteristic CD spectra are as following: 1) An $\alpha$-helix features a negative maxima at $222 \mathrm{~nm}$ and $208 \mathrm{~nm}$, and a positive molar ellipticity at $193 \mathrm{~nm} \cdot{ }^{[209]}$ 2) A $\beta$-sheet features a negative maxima at $218 \mathrm{~nm}$ and a positive molar ellipticity at $195 \mathrm{~nm} .{ }^{[210]}$ 3) A random coil features very low positive molar ellipticity at $210 \mathrm{~nm}$ and negative molar ellipticity at around $195 \mathrm{~nm} .{ }^{[211]}$ With the addition of $\mathrm{Zn}$ (II) ion all three zinc finger constructs Zf3Wildtype 33, Zf3Tacn81 34 and Zf3Tacn85 36 indicate an increase in the negative molar ellipticity at $222 \mathrm{~nm}$, a decrease in the negative molar ellipticity at $208 \mathrm{~nm}$ and a positive molar ellipticity at $190 \mathrm{~nm}$. Additionally, the negative molar ellipticity maximum at around $200 \mathrm{~nm}$ is slightly red shifted in the presence of $\mathrm{Zn}$ (II). All these spectral changes together indicate the Zf3 domains become more structured upon $\mathrm{Zn}(\mathrm{II})$ binding. The $\mathrm{CD}$ profile of the modified zinc finger domains Zf3Tacn81 34 and Zf3Tacn85 35 is quite similar to that of the unmodified domain Zf3Wildtype 33, indicating that the modification does not cause any major structural perturbation or changes in the folding pattern of the modified domains. Furthermore, the binuclear zinc chelation ability of the modified zinc finger constructs Zf3Tacn81 34 and Zf3Tacn85 35 was confirmed by mass spectrometry utilizing the ZipTip protocol (Figure5.6 A and Figure 5.6 B). However, both mono-nuclear and bi-nuclear species were observed in the mass spectrum (see details in section 7.8.1).
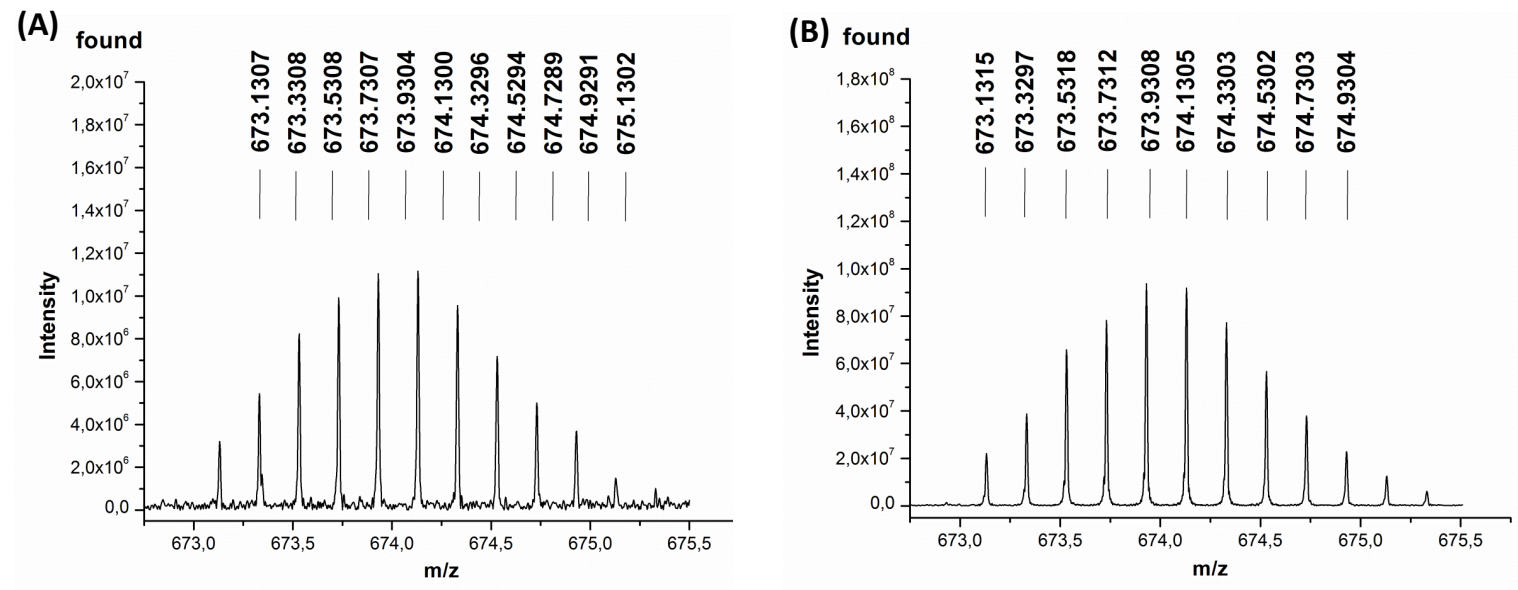
Figure 5.6: ESI-HRMS of the calculated charged state $[\mathrm{M}+\mathrm{H}+2 \mathrm{Zn}]^{5+}$ of the binuclear zinc complex of (A) Zf3Tacn81 34 and (B) Zf3Tacn85 35.

CD spectroscopy can also be utilized in order to study the DNA interaction of the zinc finger domains with their consensus DNA sequence. The CD spectrum of the $30 \mathrm{bp}$ dsDNA 5'-GTGTGTGTGTGATCTTAGCGTGGGCGTAAG-3', consisting of the Zif268 binding site, was measured in the presence of the zinc finger constructs Zf3Wildtype 33, Zf3Tacn81 34, Zf3Tacn85 35 and Zf13Tacn85 39 and compared with that of the DNA alone (see appendix Figure. A1). Changes in the CD profile of the dsDNA in the presence of the various zinc finger domains hint towards their interaction with DNA. However, the observed spectral changes do not provide substantial evidence to support the DNA binding ability of the zinc finger constructs. Therefore, further studies utilizing a gel mobility shift assay were performed in order to examine their DNA binding ability.

\subsection{Consensus DNA binding studies}

Polyacrylamide gel electrophoresis was performed under native conditions in order to study the binding interactions of the zinc finger constructs with the Zif268 consensus sequence contained within a 30-mer DNA duplex. The duplex DNA was formed by

annealing the oligomer 5'-GTGTGTGTGTGATCTTAGCGTGGGCGTAAG-3'consisting of a FAM label at the 5'-end and its complimentary sequence 5'-CTTACGCCCACGCTAAGATCACACACACAC-3'. The zinc finger $(1 \mathrm{mM})$ constructs were reduced with an aqueous solution of TCEP $(5 \mathrm{mM})$ for $30 \mathrm{~min}$ and dialyzed against a $\mathrm{Zn}^{2+}$ rich buffer system (40 mM Tris, $200 \mathrm{mM} \mathrm{NaCl}, 1 \mathrm{mM}$ TCEP, $10 \mu \mathrm{M} \mathrm{ZnCl}_{2}, \mathrm{pH}=7.8$ ) for $6 \mathrm{~h}$ in order to induce peptide folding. Subsequently, excess of $\mathrm{Zn}^{2+}$ was removed by overnight dialysis against a buffer system ( $40 \mathrm{mM}$ Tris, $200 \mathrm{mM} \mathrm{NaCl}, 1 \mathrm{mM}$ TCEP, $1 \mu \mathrm{M} \mathrm{ZnCl}$, pH = 7.8) with lower $\mathrm{ZnCl}_{2}$ concentration. Prior to electrophoresis the DNA was incubated with the peptides such that the $r_{f}\left(C_{\text {peptide }} / C_{D N A}\right)$ value was varied between 0 and 40 . The incubation was carried out for $45 \mathrm{~min}$ at $0{ }^{\circ} \mathrm{C}$ in Tris buffer $(40 \mathrm{mM}$ Tris, $200 \mathrm{mM} \mathrm{NaCl}$, $1 \mathrm{mM}$ TCEP, $1 \mu \mathrm{M} \mathrm{ZnCl} 2, \mathrm{pH}=7.8$ ). The binding of the peptide to the DNA can be visualized by monitoring the gel mobility shift (Figure 5.5). Formation of a slower 
migrating band in comparison to that of the unbound DNA corresponds to the peptide bound DNA.

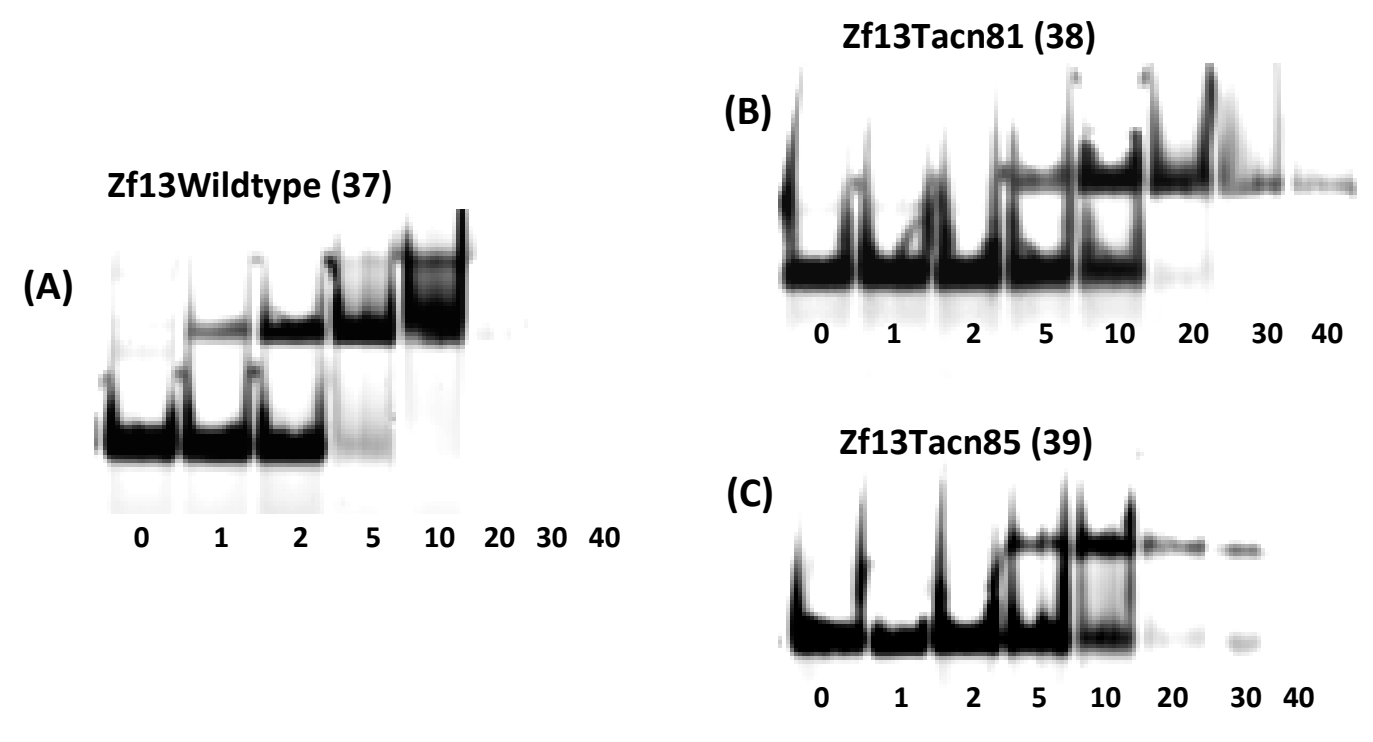

Figure 5.5: Gel electrophoresis assay to study the interaction of the Zf13 constructs with the 30mer DNA duplex consisting of the ZIF268 consensus sequence. The duplex DNA $(0.5 \mu \mathrm{M})$ was incubated with increasing concentration of peptides such that the $r_{f}\left(C_{\text {peptide }} / C_{D N A}\right)$ values were varied from 0 to 40 . The incubation was done for $45 \mathrm{~min}$ at $0{ }^{\circ} \mathrm{C}$ in $40 \mathrm{mM}$ Tris, $200 \mathrm{mM} \mathrm{NaCl}, 1 \mathrm{mM}$ TCEP, $1 \mu \mathrm{M} \mathrm{ZnCl}, \mathrm{pH}=7.8$.

The zinc finger peptides reconstituted with $\mathrm{Zn}^{2+}$ retain their intrinsic folding pattern and recognize their consensus DNA binding site whereas the apopeptides are unable to bind to the DNA (see appendix Figure A.2). The Zf13Wildtype $\mathbf{3 7}$ leads to the formation of a slower migrating band at a lower peptide concentration $\left(r_{f}=1\right)$ in comparison to the modified zinc finger constructs, Zf13Tacn81 38 and Zf13Tacn85 39, containing an allosteric metal binding site $\left(r_{\mathrm{f}}=5\right)$. Therefore, introduction of the histidine mimicking artificial amino acid bearing the TACN ligand decreases the binding affinity of the modified zinc finger constructs $\mathbf{3 8}$ and 39. Beyond a certain peptide concentration $\left(r_{f}>10\right)$ the DNA begins to precipitate in the wells. The DNA is completely bound to the Zf13Wildtype $\mathbf{3 7}$ at an $r_{\mathrm{f}}$ value 5, however, in case the modified Zf13 domains Zf13Tacn81 38 and Zf13Tacn85 39 it was not possible to clearly visualize the completely bound DNA even at higher peptide concentrations. 


\subsection{Plasmid DNA cleavage experiments}

Agarose gel electrophoresis was performed in order to examine in the DNA cleavage ability of the modified Zf13 constructs. The pJET cloning vector was engineered to contain the Zif268 consensus DNA sequence at two different positions within the plasmid DNA as binding sites for the Zf13 domain. The zinc finger constructs were reduced followed by reconstitution with $\mathrm{Zn}^{2+}$ ion according to the procedure mentioned in section 5.5. Excess of unbound $\mathrm{Zn}^{2+}$ ion was removed by overnight dialysis against a buffer system (40 mM Tris, $200 \mathrm{mM} \mathrm{NaCl}, \mathrm{pH}=7.8$ ) completely excluding $\mathrm{Zn}^{2+}$ and TCEP as they were found to interfere with the DNA cleavage assay. Prior to electrophoresis the DNA was incubated with the peptides such that the $r_{f}\left(C_{\text {peptide }} / C_{D N A}\right)$ value was varied between 0 and 600. The incubation was carried out for $72 \mathrm{~h}$ at $37{ }^{\circ} \mathrm{C}$ in Tris buffer ( $40 \mathrm{mM}$ Tris, $200 \mathrm{mM} \mathrm{NaCl}, \mathrm{pH}=7.8$ ). The supercoiled form of plasmid DNA due to its compact structure migrates faster on gel in comparison to the open circular form. The cleavage of a phosphodiester linkage in the supercoiled form results in the formation of the open circular form of the plasmid DNA. Thus, the DNA cleavage ability of the zinc finger constructs can be monitored by the formation of increasing amount of the slower migrating open circular plasmid DNA.

The Zf13Wildtype $\mathbf{3 7}$ influences the migration pattern of both the supercoiled and relaxed form of DNA (Figure 5.6 A). However, there is no evidence of DNA cleavage as the amount of open circular form of DNA remained constant even after a prolonged incubation time of $72 \mathrm{~h}$ with the peptide. The changes in the migration properties of the supercoiled and relaxed form of DNA could be associated with induction of DNA conformation changes upon binding to the Zf13Wildtype 37. On the contrary, the modified zinc finger constructs Zf13Tacn81 38 and Zf13Tacn85 $\mathbf{3 9}$ led to a mild increase in the intensity of the open circular form of plasmid DNA, starting at an $r_{\mathrm{f}}$ value 100 . However, increasing the $r_{\mathrm{f}}$ value did not seem to improve the DNA cleavage reaction and led to precipitation of the sample in the wells (Figure $5.6 \mathrm{~B}$ and Figure $5.6 \mathrm{C}$ ). Further experiments need to be performed in order to optimize the cleavage reaction as well as to determine the site of DNA cleavage. 


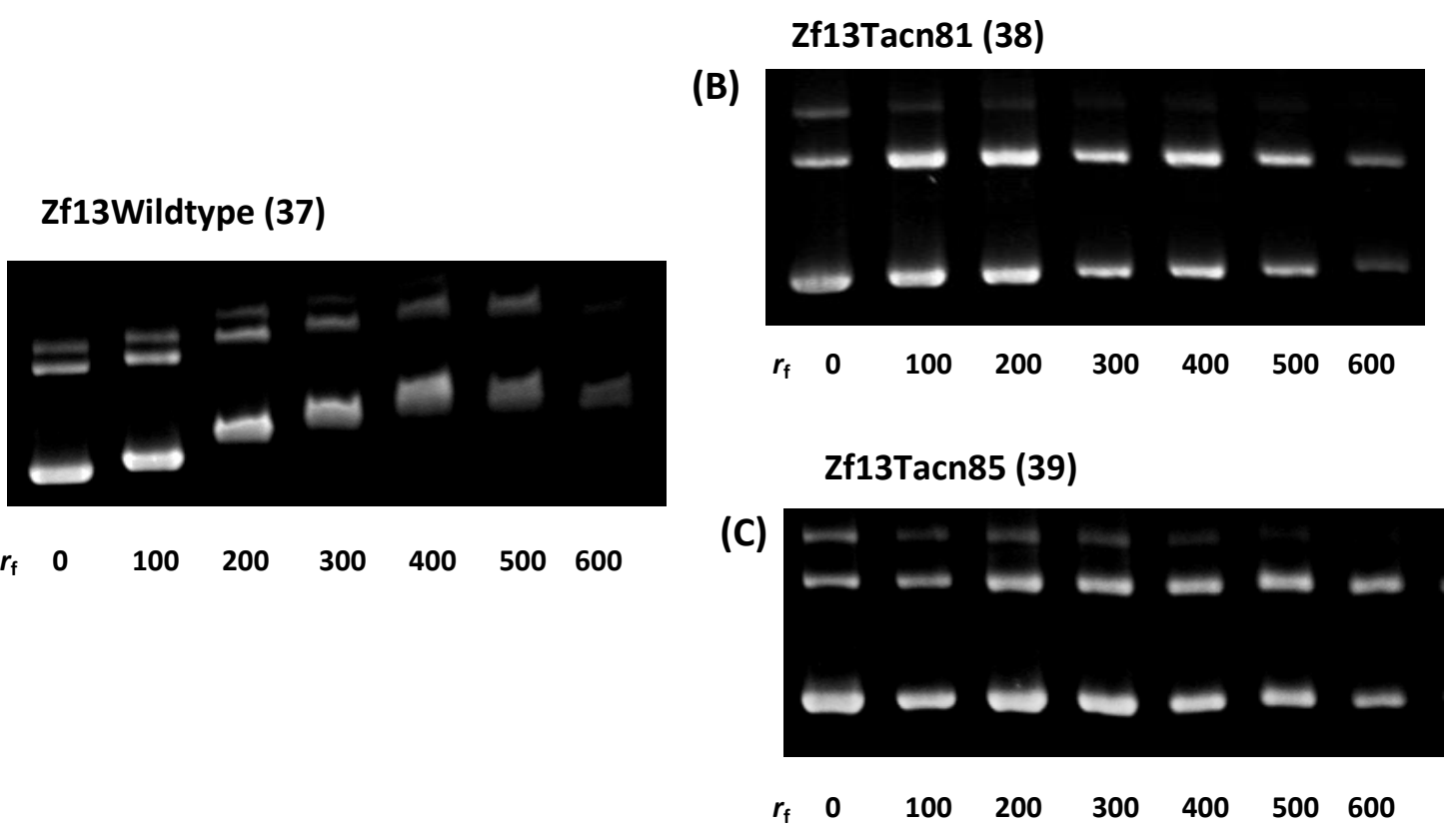

Figure 5.6: Agarose gel electrophoresis to study the DNA cleavage ability of the Zf13 constructs Zf13Wildtype 37, Zf13Tacn81 38 and Zf13Tacn85 39 with pJET cloning vector modified to containing two Zif268 binding site. The DNA was incubated with the peptides at $37^{\circ} \mathrm{C}$ for $72 \mathrm{~h}$, with $r_{f}\left(C_{\text {peptide }} / \mathrm{C}_{D N A}\right)$ varying from 0 to $600,40 \mathrm{mM}$ Tris, $200 \mathrm{mM} \mathrm{NaCl}, \mathrm{pH}=7.8$ and electrophoresis was performed on $1 \%$ agarose gel. 



\section{Summary and Conclusion}

Peptide-DNA recognition plays an important role in performing several essential biochemical functions in the cell. Development of strategies to modulate these interactions has the potential to control cellular events such as transcription, regulation of gene expression, recognition and repair of damaged genes, etc. The design of small model peptides presented in this work is based on appended domains of proteins which are found to be crucial in terms of generating a particular response or function. The model peptides include metal binding sites due to their well defined geometry and ability to stabilize the entire protein structure around the coordination sphere of the metal ion. Moreover, peptidomimetic scaffolds based on chimeric metal-peptide conjugates offer a possibility to harness the recognition properties of natural metalloenzymes and hence, assist in performing biochemical reactions in a sequence specific manner.

The first part of this thesis (chapter 2 and 3) sheds light on the potential of hybrid platinum complex-peptide conjugates and their applicability in developing novel potential chemotherapeutic agents. One of the main reasons behind the chemotherapeutic ability of cisplatin and related platinum drugs is their ability to bind to adjacent guanine residues within a DNA sequence and produce a kink in the duplex. ${ }^{[43-47]}$ However, the currently available platinum based chemotherapeutics lack specificity towards DNA and their use is often associated with undesired toxic side effects. ${ }^{[20]}$ The main idea behind the design of chimeric platinum complexes was to improve DNA targeting in chemotherapy. Furthermore, design of such chimeric drugs with enhanced recognition and improved pharmacological properties has the potential to overcome the drawbacks of the currently marketed chemotherapeutics. IHF is a DNA architectural protein binding to its consensus sequence with a high degree of specificity. ${ }^{[109]}$ The binding of IHF to the DNA minor grove is accompanied by induction of a sharp U-turn in the duplex by intercalation of a proline residue in between adjacent base pairs. ${ }^{[5]}$ The combination of a platinum complex with such DNA recognition domains is assumed to 
have a synergistic effect on the DNA bending and binding properties of the hybrid platinum complex (Figure 6.1).

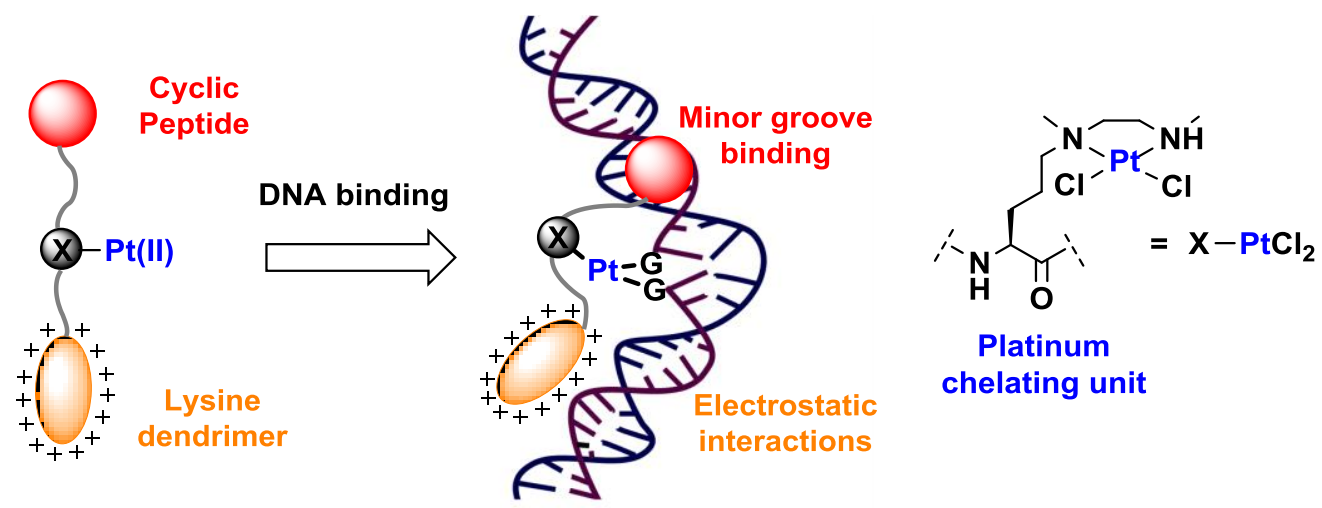

Figure 6.1: DNA targeting utilizing a chimera of a Pt complex and an IHF mimicking peptide by means of minor grove binding and electrostatic interactions with negatively charged DNA.

The design of the platinum complex/peptide chimera proposed in this study is based on a model peptide reported earlier in Diederichsen group. ${ }^{[6]}$ Various peptides were synthesized that mimicked subdomains of IHF in order to establish enhanced DNA recognition. The DNA interaction properties of the unplatinated IHF mimic IHF-1, platinated IHF mimics IHF-2/3/4, platinated lysine dendrimer P1 and the cyclic unit P2 were compared. Agarose gel electrophoresis indicates the ability of platinated IHF mimics IHF-2/3/4 to unwind the negatively supercoiled pUC18 plasmid DNA within $2 \mathrm{~h}$ reaction time already at a low peptide/nucleotide concentration. The effect is observed at a higher peptide/nucleotide concentration for the unplatinated mimic IHF-1 and the platinated lysine dendrimer P1 whereas the unplatinated cyclic P2 does not seem to have an unwinding effect at all. Polyacrylamide gel electrophoresis indicated enhanced targeting of DNA duplexes consisting of adjacent guanine residues by the platinated IHF mimics IHF-2/3/4. While denaturing gels provide evidence supporting the formation of covalent linkages between the DNA and the platinated IHF mimics even in the presence of excess cisplatin. Thus, the IHF mimicking platinum/complex peptide chimeras are able to compete for the same site as cisplatin for covalent modification of DNA. Native gels on 
the other hand indicate their ability to bind to DNA sequences already modified with cisplatin. Such interactions might have a synergistic effect on cisplatin induced DNA bending and hence, on the chemotherapeutic efficacy of the drug. These results validate the design of the IHF mimicking Pt complex/peptide chimera consisting of the cyclic minor grove recognizing unit, the positively charged lysine dendrimer and the platinum chelating unit contained within the glycine linker tethering the two peptidic units. Though it was not possible to attain sequence specific recognition with the platinated IHF mimics, these provide good lead structures to begin with. Further optimization of the design offers the possibility to generate a library of Pt complex/peptide chimera as potential chemotherapeutics.

The second part of the thesis (chapter 4 and 5) involves synthesis of a modified Zif268 domain, a $\mathrm{Cys}_{2} \mathrm{His}_{2}$ type of zinc finger. The wide occurrence and extra-ordinary properties of the $\mathrm{Cys}_{2} \mathrm{His}_{2}$ type of zinc fingers to sequence specifically bind to DNA make them a lucrative target to mimic. ${ }^{[138,139]}$ Every individual zinc finger domain has the ability to recognize a subsite of $3-4$ base pairs on the duplex. ${ }^{[148,149]}$ Following a combinatorial approach for preparing novel zinc finger motifs, with single DNA recognizing zinc finger domains connected together in tandem, offers a possibility to design a highly specific binder for any given DNA sequence. The aim of this work was to design artificial zinc finger nucleases for site specific DNA cleavage. The zinc finger domain proteins due to their modular design and high affinity towards cognate DNA can be applied for engineering artificial nucleases by incorporation of additional metal binding sites within its structure. The artificial amino acid residues can be functionalized to introduce multiple metal binding sites within the protein domains. In this study, the Zif268 sequence was modified to contain a histidine mimicking amino acid bearing a triazacyclononane (TACN) ligand. The TACN ligand provides an allosteric $\mathrm{Zn}(\mathrm{II})$ coordination site and is expected to assist in cleavage of the DNA phosphodiester backbone (Figure 6.2). The Zif268 domain consisting of a tandem repeat of three zinc fingers was prepared by following a semi-synthetic strategy that utilizes intein mediated protein ligation. 




Figure 6.2: The Zif268 domain containing a tandem repeat of three zinc fingers wherein the third zinc finger consisting of a histidine mimicking artificial amino acid providing an allosteric $\mathrm{Zn}^{2+}$ binding site and can further offer the possibility of DNA cleavage. (pdb code: $1 \mathrm{AAY}) .{ }^{\left[{ }^{[9]}\right.}$ Image genetrated by PyMOL.

The histidine mimicking amino acid was incorporated into Zf3 domain by SPPS whereas the $\mathrm{Zf12}$ domain was expressed in E. coli. The two peptide fragments were connected to form the Zf13 domains by native chemical ligation. The Zf13Tacn81 38 and Zf13Tacn85 39 consisted of the artificial amino acid in the $\mathrm{Zf3}$ domain at $\mathrm{His}^{81}$ and $\mathrm{His}^{85}$ whereas Zf13Wiltype 37 consisted of the native peptide sequence. The binuclear zinc chelation ability of the modified Zf3 constructs Zf3Tacn81 34 and Zf3Tacn85 35 was confirmed by mass spectrometry. Furthermore, CD spectroscopy confirms that introduction of the artificial amino acid into the $\mathrm{Zf3}$ domains cause only minimal structural perturbation and changes in the folding pattern of the peptides. However, native polyacrylamide gel electrophoresis performed utilizing the Zif268 consensus sequence reveals that the modification of the zinc finger constructs decreases their DNA recognition ability. Agarose gel electrophoresis was performed to study the nuclease activity of the $\mathrm{Zf13}$ constructs with the PJET cloning vector engineered to contain two binding sites for the 
Zif268 domain. The experimental results indicate poor DNA cleavage ability of the modified zinc finger constructs Zf13His81 38 and Zf13His85 39 even after prolonged incubation time of $72 \mathrm{~h}$ at $37{ }^{\circ} \mathrm{C}$ and very high peptide/DNA concentration. In order to design Zif268 model systems with better nuclease activity novel amino acid mimics providing an additional metal coordination sites should be incorporated. The goal is to keep the multinuclear metal coordination sites within the model peptide in close proximity to the DNA backbone as well as to maintain appropriate intermetallic distances between them in order to facilitate phosphodiester hydrolysis.

Model peptides mimicking high affinity DNA binding modules can be exploited for achieving enhanced recognition properties. In this work, peptide mimics have been proposed for the two naturally occurring proteins, the IHF and the Zif268 domain, that bind to DNA with a high degree of sequence selectivity. Combination of these model peptides to other effector domains is expected to provide enhanced DNA recognition properties to the novel chimeric proteins and furthermore, alter their activity. Design of such molecules can prove to be a valuable tool in biomedical applications including cancer research, gene therapy as well as development of novel diagnostic probes. 



\section{Experimental Section}

\subsection{Materials and General Methods Applied for Synthesis}

\section{Solvents}

All the technical grade solvents were distilled prior to use. Anhydrous (stored over molecular sieves), analytic and HPLC grade solvents were supplied from Acros Organics (Geel, Belgium), Fluka (Taufkirchen, Germany), Sigma-Aldrich (Taufkirchen, Germany), Fisher Scientific (Nidderau, Germany) and VWR (Darmstadt, Germany). Solvent systems for HPLC purification as well as all the buffers systems utilized in various experiments were prepared using ultrapure water obtained from a water purification system Simplicity from Merck Millipore (Billerica, USA).

\section{Reagents}

All the reagents were of analytical grade and were utilized without any further purification. All the amino acid derivatives, coupling reagents and resins utilized in solid peptide synthesis were purchased from NovaBiochem (Darmstadt, Germany), GL Biochem (Shanghai, China), ABCR (Karlsruhe, Germany), Bachem (Bubendorf, Switzerland), and IRIS Biotech (Marktredwitz, Germany). All other reagents were purchased from Merck (Darmstadt, Germany), Carl Roth GmbH (Karlsruhe, Germany), Fisher Scientific GmbH (Nidderau, Germany), Alfa Aesar (Karlsruhe, Germany), Bachem (Bubendorf, Switzerland), TCI (Eschborn, Germany), VWR (Darmstadt, Germany), NovaBiochem (Darmstadt, Germany), Sigma Aldrich (Taufkirchen, Germany) and Acros Organic (Geel, Belgium). ZipTip pipette tips for mass analysis of $\mathrm{Zn}^{2+}$ bound samples were obtained from Merck Millipore (Billerica, USA). DNA oligomers were supplied by 
PURIMEX (Grebenstein, Germany), IBA (Goettingen, Germany) and Biomers (UIm, Germany). Other Biochemical reagents were supplied by Fermentas (St. Leon-Rot, Germany), Biorad (Munich, Germany) and GERBU (Heidelberg, Germany).

\section{Reactions}

All the air and moisture sensitive reactions were carried out under inert (argon/nitrogen) atmosphere. The utilized glassware was first flame dried under vacuum followed by purging argon. Reactions done in small scales were carried out in Eppendorf caps by utilizing a purge and refill technique. The reaction buffers were degassed by applying vacuum while purging argon into the solution at the same time with the help of a cannula.

\section{Lyophilization}

The HPLC fractions were evaporated under low vacuum to get rid of most of the acetonitrile. The resulting aqueous solutions were lyophilized using a freeze drying device Christ Alpha-2-4 attached to a high vacuum pump. For lyophilization of samples with relatively smaller volume an evacuable Christ RCV-2-18 ultracentrifuge connected to the lyophilizer was utilized. All the samples were frozen over liquid nitrogen before being attached to the lyophilizer.

\section{Thin Layer Chromatography (TLC)}

The progress of the reaction was monitored by TLC using aluminium backed plates coated with silica gel $60 \mathrm{~F}_{254}$ (layer thickness: $0.20 \mathrm{~mm}$ ) from Merck. Fluorescence quenching at wavelength $254 \mathrm{~nm}$ was exploited to detect the spots corresponding to respective compounds on the TLC plate. Non-Fluorescence quenching substances were visualized by staining the plate with ninhydrin staining solution $(1.5 \mathrm{~g}$ ninhydrin, $3 \mathrm{~mL}$ acetic acid, $100 \mathrm{~mL}$ of $n$-butanol) followed by mildly heating it until the spots appear. 


\section{Flash Chromatography}

The crude reaction mixture was purified by means a fritted glass column using Merck Silica Gel 60 (particle size: 40-62 $\mu \mathrm{m}$ ). The crude product was either absorbed on silica (35 fold weight excess) or prepared as a concentrated solution in the eluent and added to the column packed with wet silica gel (50-100 fold weight excess). The elution was performed under a positive pressure of 0.1-1 bar. Solvent systems used for elution are mentioned along with each individual reaction protocol.

\section{High Performance Liquid Chromatography (HPLC)}

Reverse phase HPLC was conducted using Amersham Pharmacia Biotech systems (Äkta basic, Pump-type P-900, variable wavelength UV detector 900). UV absorption of the peptides was detected at wavelengths $215 \mathrm{~nm}, 254 \mathrm{~nm}$ and $280 \mathrm{~nm}$ while performing HPLC under a linear gradient of one the following solvent systems:

A [0.1\% TFA, $\left.\mathrm{H}_{2} \mathrm{O}\right]$ to $\mathrm{B}\left[0.1 \%\right.$ TFA, $\left.\mathrm{MeCN} / \mathrm{H}_{2} \mathrm{O}(8 / 2)\right]$;

A [0.1\% TFA, $\left.\mathrm{H}_{2} \mathrm{O}\right]$ to $\mathrm{C}\left[0.1 \%\right.$ TFA, $\left.\mathrm{MeCN} / \mathrm{H}_{2} \mathrm{O}(9 / 1)\right]$;

A [0.1\% TFA, $\left.\mathrm{H}_{2} \mathrm{O}\right]$ to $D[0.1 \%$ TFA, $\mathrm{MeCN}]$

The samples were prepared in ultrapure water containing minimum amount of $\mathrm{MeCN}$ needed to dissolve the substance completely and then were also filtered prior to injection into the system. The column used for HPLC is mentioned along with the analytical data of the corresponding compound. The flow rates for analytical, semi preparative and preparative columns were $1 \mathrm{~mL} / \mathrm{min}, 3 \mathrm{~mL} / \mathrm{min}$ and $10 \mathrm{~mL} / \mathrm{min}$ respectively. The fractions corresponding to the desired product were pooled together and lyophilized. 


\section{Nuclear Magnetic Resonance Spectroscopy (NMR)}

All the NMR spectra were recorded with Varian instruments (Mercury 300, Unity 300, INOVA 500, INOVA 600). Chemical shifts are quoted in parts per million (ppm) downfield of TMS $\left(\delta_{\mathrm{TMS}}=0 \mathrm{ppm}\right)$. As internal standards the resonances from the rest protons of deuterated solvents $\mathrm{CDCl}_{3}$ : $7.24 \mathrm{ppm}\left({ }^{1} \mathrm{H}-\mathrm{NMR}\right)$ and $77.0 \mathrm{ppm}\left({ }^{13} \mathrm{C}-\mathrm{NMR}\right)$, [D6]DMSO: $2.49 \mathrm{ppm}\left({ }^{1} \mathrm{H}-\mathrm{NMR}\right)$ and $39.5 \mathrm{ppm}\left({ }^{13} \mathrm{C}-\mathrm{NMR}\right), \mathrm{CD}_{3} \mathrm{OD} 4.87 \mathrm{ppm}\left({ }^{1} \mathrm{H}-\mathrm{NMR}\right)$ and $49.1 \mathrm{ppm}$ $\left({ }^{13} \mathrm{C}-\mathrm{NMR}\right)$ were used. Signal multiplicities were abbreviated as follows: $s=$ singlet, $d=$ doublet, $\mathrm{t}=$ triplet, $\mathrm{q}=$ quartet, $\mathrm{m}=$ multiplet, $\mathrm{br}=$ broad. Coupling constants ${ }^{n} J_{X X}$ are stated in hertz $(\mathrm{Hz})$, where $\mathrm{n}$ is the order of coupling and $\mathrm{X}$ stands for the nuclei.

\section{Mass Spectroscopy}

The electron spray ionization mass spectrums (ESI-MS) were measured using Finnigan instruments (type LCQ or TSQ 7000) or Bruker spectrometers (types Apex-Q IV 7T and micrOTOF API). High resolution mass spectrums were collected on Bruker Apex-Q IV 7T or Bruker micrOTOF, respectively.

\section{Preparation $\mathrm{Zn}^{2+}$ bound zinc fingers for mass analysis using ZipTip}

The zinc fingers $\left(0.1 \mathrm{mM}\right.$ in $\left.\mathrm{H}_{2} \mathrm{O}\right)$ were first reduced by TCEP $\left(0.5 \mathrm{mM}\right.$ in $\left.\mathrm{H}_{2} \mathrm{O}\right)$ for $2 \mathrm{~h}$ at room temperature to make the thiol of the cysteine residues available for complex formation. Thereafter, $500 \mu \mathrm{L}$ of $\mathrm{ZnCl}_{2}\left(2.5 \mathrm{mM}\right.$ Tris buffer, $100 \mu \mathrm{M}$ of $\mathrm{Zn}^{2+}, \mathrm{pH}=7.8$ ) was added and incubated at room temperature for $1 \mathrm{~h}$. Prior to mass spectrometric measurement the ZipTip pipette tip was used for desalting and concentrating the sample as following:

- The tip was placed on the pipettor followed by aspirating and dispensing several times through the media for binding the sample to the chromatography media fixed at the end of the tip. 
- Then the tip was several times aspirated and dispensed through water which used as washing solvent to remove contaminants such as excess salts from the buffer and the unbound $\mathrm{Zn}^{2+}$ ion.

- The purified sample was eluted in $\mathrm{H}_{2} \mathrm{O} / \mathrm{ACN}(1 / 1, \mathrm{v} / \mathrm{v})$.

- The process was repeated 5-6 times and all the purified samples were pooled together, lyophilized and subjected to mass analysis.

\section{UV spectroscopy}

The UV spectrums were recorded using Nanodrop ND-2000c $(d=0.1 \mathrm{~cm})$ or a JASCO $V$-550 UV/VIS spectrophotometer $(d=1 \mathrm{~cm})$. The molar extinction coefficients for DNA samples were obtained by summing up individual coefficients of each base pair at 260 $\mathrm{nm}$. The absorbance of the samples was measured at the same wavelength and their concentrations were determined by applying the LAMBERT-BEER law.

\section{Spectroscopy}

The CD spectra were recorded either using a Jasco-810 or a Jasco-1500 spectropolarimeter equipped with a Jasco-PTC432S or a Julabo-F250 temperature controller respectively. Quartz precision cell with a thickness of $1 \mathrm{~mm}$ was used for the measurements. The sample cell was flushed with nitrogen prior to as well as during the measurement. The following parameters were applied for the measurement: The spectrums were recorded at a constant temperature of $20^{\circ} \mathrm{C}$ within a wavelength range of $260-190 \mathrm{~nm}$ for peptides and $360-200 \mathrm{~nm}$ for DNA. The following parameters were applied for the measurement: $1 \mathrm{~nm}$ band width, $0.1 \mathrm{~s}$ response time, standard sensitivity, $0.1 \mathrm{~nm}$ data pitch and $50 \mathrm{~nm} / \mathrm{min}$ scanning speed. The measured spectrums obtained as an average of eight curves were background corrected and smoothed applying the means movement method. Experimental conditions are mentioned in detail along with the respective measurement. 
Ө. $10^{-3}\left[\right.$ deg. $\left.\mathrm{cm}^{2} \cdot \mathrm{dmol}^{-1}\right]=\frac{C D[\mathrm{mdeg}] \times 10^{-3}}{10 . d[\mathrm{~cm}] \cdot C[\mathrm{~mol} / \mathrm{L}]}$

Wherein $\theta$ is the degree of ellipticity, $d$ is the cell path length, $C D$ is the circular dichroism value and $\mathrm{C}$ is the concentration of the measured sample.

\section{Thermal Melting Analysis}

Thermal melting analysis of dsDNA was performed in $1 \mathrm{~cm}$ quartz cuvettes utilizing a Cary 100 UV/Vis spectrophotometer (Varian) equipped with a multiple cell holder and a peltier controlled temperature setup. Complementary DNA strands were mixed in 1:1 ratio in $10 \mathrm{mM}$ phosphate buffer $\left(\mathrm{Na}_{2} \mathrm{HPO} 4 / \mathrm{NaH}_{2} \mathrm{PO}_{4}, \mathrm{pH}=5.8\right)$ and annealed to form the duplex. The peptides were added to the duplex and pre-incubated with it for $17 \mathrm{~h}$ at $37{ }^{\circ} \mathrm{C}$ prior to the measurement such that the duplex concentration was $1 \mu \mathrm{M}$ and the peptide concentration was $5 \mu \mathrm{M}$ in $10 \mathrm{mM}$ phosphate buffer $\left(\mathrm{Na}_{2} \mathrm{HPO} / \mathrm{NaH}_{2} \mathrm{PO}_{4}\right.$, $\mathrm{pH}=5.8$ ). The absorbance versus temperature profiles were measured at $250 \mathrm{~nm}$ and the data points were taken after every $0.5^{\circ} \mathrm{C}$ for the following three cycles: heating from 20-95 ${ }^{\circ} \mathrm{C}$, cooling from $95-10{ }^{\circ} \mathrm{C}$ and then heating from $10-95{ }^{\circ} \mathrm{C}$. The heating/cooling rate during the cycle was $0.7^{\circ} \mathrm{C} / \mathrm{min}$. The $T_{m}$ values were obtained from the maximum of the first derivative of the cooling curve from $95-10{ }^{\circ} \mathrm{C}$. All experiments were performed in at least triplicates on independent occasions.

\section{Annealing DNA Oligonucleotides}

DNA oligomers obtained as lyophilised solid from the supplier were dissolved in a known quantity of ultrapure MilliQ water and the concentration of DNA in each sample was determined. Thereafter, complementary DNA strands were resuspended in the annealing buffer contained in a microfuge tube such that in the resulting mixture the two strands were present in equimolar ratio. The tube was placed on a heat block at $95{ }^{\circ} \mathrm{C}$ for $5 \mathrm{~min}$ and then slowly cooled to room temperature on a workbench. The annealing DNA oligonucleotides were kept at $-20{ }^{\circ} \mathrm{C}$ for long term storage. 


\subsection{Materials and General methods Applied in Biochemistry}

\section{Basic Handling}

All equipment that comes into contact with the bacterial cultures was sterilized prior to usage and wherever applicable disposable pre-sterilized items were used. Inoculations and cultivations of bacterial cultures were performed under a laminar flow biological safety cabinet Prettl-Telsta Bioll-A from Telstar. Autoclaved MilliQ water was used for the preparation of bacterial media and in other biochemistry procedures such as plasmid amplification, protein expression etc.

\section{Materials}

Luria-Bertani (LB)-media: ${ }^{[212]}$ Tryptone $(1 \%, \mathrm{w} / \mathrm{v})$, yeast $(0.5 \%, \mathrm{w} / \mathrm{v})$ and $\mathrm{NaCl}(1 \%, \mathrm{w} / \mathrm{v})$ were dissolved in double distilled water and autoclaved at $120{ }^{\circ} \mathrm{C}$ for $20 \mathrm{~min}$.

LB plates: Tryptone $(1 \%, w / v)$, yeast $(0.5 \%, w / v), \mathrm{NaCl}(1 \%, w / v)$ and agar $(7.5 \%, w / v)$ were dissolved in double distilled water and autoclaved at $120{ }^{\circ} \mathrm{C}$ for $20 \mathrm{~min}$. After cooling to $55^{\circ} \mathrm{C}$ a desired antibiotic was added to the media and in poured in sterile Petri dishes.

Antibiotics: Depending on the antibiotic marker present within the sequence of the plasmid DNA, in order to select the transformed E. coli cells, a suitable antibiotic is introduced into the media. The concentration of antibiotics carbinicillin and chloramphenicol used in the experiments is $100 \mu \mathrm{g} / \mathrm{mL}$.

Cell Strain: Competent E. coli strain ER2566 used for protein expression was obtained from New England Biolabs Inc. 
Vectors: Plasmid vector pTXB1 (carbinicillin resistant) was used for recombinant protein expression of the Zf12 domain and the pJET (carbinicillin and chloramphenicol resistant) vector was used for cloning the Zif268 consensus sequence.

\section{Preparation of Competent E. coli Cells}

Competent E. coli cells were prepared in order to facilitate easy uptake of foreign plasmid DNA into the cells prior to cellular transformation. A single colony from the LB plate was inoculated into $5 \mathrm{~mL}$ of LB media and cultivated overnight by shaking at $37^{\circ} \mathrm{C}$. Overnight culture of $2 \mathrm{~mL}$ was inoculated into $50 \mathrm{~mL}$ of $L B$ medium followed by shaking vigorously at $37{ }^{\circ} \mathrm{C}$ for about $2 \mathrm{~h}$ (until this time the $\mathrm{OD}_{600} \sim 0.3$ ). The cell culture was centrifuged at $3000 \mathrm{rpm}$ at $4{ }^{\circ} \mathrm{C}$ after cooling on ice for 10-15 min. The supernatant was discarded and the cell pellet was resuspended in $10 \mathrm{~mL}$ of pre-cooled solution of $0.1 \mathrm{M}$ $\mathrm{CaCl}_{2}$. The suspension was incubated on ice for additional $20 \mathrm{~min}$ and the centrifugation was repeated. Thereafter, cell pellet was again resuspended in $5 \mathrm{~mL}$ of pre-cooled solution of $0.1 \mathrm{M} \mathrm{CaCl}_{2}$ containing $15 \%$ glycerol, aliquoted in batches of $500 \mu \mathrm{L}$, quickly frozen on nitrogen and stored at $-80^{\circ} \mathrm{C}$.

\section{Cultivation of E. coli Cells}

Bacterial cells from a glycerol stock were streaked on an agar plate with a help of a sterile metal loop (sterilized by flaming) and incubated at $37{ }^{\circ} \mathrm{C}$ while placed upside down until some microbial colonies appear on it. A typical $5 \mathrm{~mL}$ liquid culture was inoculated with a single colony picked from the agar plate and an appropriate amount of a desired antibiotic was added to it. Thereafter, the cells were cultivated at $37{ }^{\circ} \mathrm{C}$ while shaking at $200 \mathrm{rpm}$ for approximately $24 \mathrm{~h}$. 


\section{Transformation of competent E. coli cells}

Competent E. coli cells were taken out of $-80{ }^{\circ} \mathrm{C}$ and thawed on ice. To $100 \mu \mathrm{L}$ of the cellular suspension 2-3 $\mu \mathrm{L}$ of plasmid DNA was added and incubated on ice for $30 \mathrm{~min}$. Thereafter, the cells were subjected to a heat shock at $42{ }^{\circ} \mathrm{C}$ for $45 \mathrm{sec}$ and immediately placed on ice for about $30 \mathrm{sec}$. After addition of $900 \mu \mathrm{L}$ of LB medium to this mixture it was incubated at $37^{\circ} \mathrm{C}$ for $1 \mathrm{~h}$. From this mixture $100 \mu \mathrm{L}$ was streaked on a LB agar plate containing a suitable antibiotic. The remaining cells were centrifuged at $6000 \mathrm{rpm}$ for 1 $\min$ and $800 \mu \mathrm{L}$ the supernatant was discarded. The pellet was resuspended and also streaked on the agar plate. The plates were incubated overnight at $37{ }^{\circ} \mathrm{C}$ while placed inverted until some transformed single colonies appeared on them.

\section{Extraction of Plasmid DNA}

E. coli cells were transformed with the PJET containing the Zif268 consensus sequence. $50 \mathrm{~mL}$ of LB medium containing appropriate antibiotic (50 $\mu \mathrm{L}$ of each, carbinicillin and chloramphenicol) was inoculated with single colonies from the agar plate and incubated overnight at $37{ }^{\circ} \mathrm{C}$ on a shaker. Thereafter, the plasmid was purified using Qiagen Plasmid Midi Kit by carefully following the manufacturer's protocol which was based on modified alkaline lysis of the cells, followed by subsequent binding of DNA under low salt and $\mathrm{pH}$ conditions compatible with the anion exchange chromatography. The DNA pellet obtained was ethanol precipitated twice using $70 \% \mathrm{EtOH}$ in water; the residue was dissolved in a known quantity of autoclaved MilliQ water and quantified using the Nanodrop ND-2000c spectrometer.

\section{Protein Expression in E. coli}

The Zf12 domain was obtained by recombinant protein expression in E. coli. The E. coli cells were transformed with the expression clones, pTXB1, containing the gene coding for intein tag fused to the gene coding for Zf12 domain. Single colonies were picked and $5 \mathrm{~mL}$ of preparatory cultures containing LB medium and an appropriate antibiotic ( $5 \mu \mathrm{L}$ of 
carbinicillin in this case) were inoculated with them. These cultures were incubated at $37{ }^{\circ} \mathrm{C}$ while shaking for $24 \mathrm{~h}$ and were further used to inoculate expression cultures containing $400 \mathrm{~mL}$ of $\mathrm{LB}$ medium and the respective antibiotic. The cultures were cultivated for additional $4-5 \mathrm{~h}$ at $37{ }^{\circ} \mathrm{C}$ on a shaker followed by addition of $40 \mu \mathrm{L}$ IPTG $(1 \mathrm{mM})$ and further incubation at $16{ }^{\circ} \mathrm{C}$ for about $24 \mathrm{~h}$. Later on the cells were centrifuged at $4000 \mathrm{rpm}$ for $20 \mathrm{~min}$ while the temperature was maintained at $4{ }^{\circ} \mathrm{C}$. The cell pellet was frozen on nitrogen and then transferred to $-80{ }^{\circ} \mathrm{C}$. This process makes the cell wall more fragile and easy to rupture.

Thereafter, the cell pellet was thawed on ice and was resuspended in BPer (cell lysis reagent, Thermoscientific) in a concentration of $1 \mathrm{~g} / \mathrm{mL}$. Complete lysis of the cell wall was achieved by pulsed sonification ( $5 \times 45 \mathrm{sec}, 50 \%$ power, $50 \%$ impulse) on ice utilizing a Sonoplus GM 7 from Bandelin. Most of the cellular debris was discarded by centrifugation at $14000 \mathrm{rpm}$ for $20 \mathrm{~min}$ while the temperature was $4{ }^{\circ} \mathrm{C}$. The supernatant contained the all proteins expressed in the cell including the Zf12 domain, obtained in fusion with the intein tag containing the chitin binding domain, which was purified by affinity chromatography.

\section{Purification of the Expressed Protein by Affinity Chromatography ${ }^{[213]}$}

IMPACT (Intein Mediated Purification with an Affinity Chitin-binding Tag) is a method for purification of proteins that utilizes the self-cleavage ability of intein, a protein splicing component, to separate the desired protein from the affinity tag. The crude cell lysate containing the CBD-Zf12 fused protein was purified using Chitin beads obtained from New England Biolabs. Entire purification step was performed at $4{ }^{\circ} \mathrm{C}$ with only cold solutions. Firstly, the chitin column was prepared by loading $100 \mathrm{~mL}$ of chitin beads on a vertical column and then equilibrated with 2 bed volumes of water and 10 bed volumes of column buffer ( $20 \mathrm{mM}$ HEPES, $500 \mathrm{mM} \mathrm{NaCl}$, 0.1\% Tween20, $20 \mathrm{mM} \mathrm{TCEP}, \mathrm{pH}=8$ ). The lysate was loaded onto the column overnight at a flow rate of $0.5-1 \mathrm{~mL} / \mathrm{min}$ until all the CBD-Zf12 fused protein was immobilized on the chitin beads. Thereafter, the column was washed with at least 20 bed volumes of the column buffer at a flow rate of $2 \mathrm{~mL} / \mathrm{min}$ 
to remove the unspecifically bound cellular proteins. On-column cleavage of the intein tag was induced with the help of the thiol MeSNa (Sodium 2-mercaptoethanesulfonate). After 3 bed volumes of cleavage buffer ( 20 mM HEPES, $500 \mathrm{mM} \mathrm{NaCl}, 0.1 \%$ Tween20, 20 mM TCEP, $250 \mathrm{mM}$ MeSNa, $\mathrm{pH}=8$ ) were quickly flushed onto the column, the flow was stopped and the column was allowed to stand at $4{ }^{\circ} \mathrm{C}$ for $16-40 \mathrm{~h}$. This led to complete cleavage of the target protein which was then eluted using the column buffer. While the intein-CBD tag remained on the column $\mathrm{Zf12}$ domain was obtained as a thioester.

\section{Gel Electrophoresis}

Gel electrophoresis, including polyacrylamide and agarose gels, is an efficient method to separate, analyse and purify DNA and protein fragments under an externally applied electric field based on size as well as charge. The gel matrix is chosen depending of the size of the molecules that need to be analyzed. Agarose gels can be used to separate DNA fragments that are in the range of $200 \mathrm{bp}-50 \mathrm{~kb}$ depending on the percentage of agarose in the gels. Shorter oligonucleotide fragments in range of $5-500 \mathrm{bp}$ can be separated on polyacrylamide gels. Our interest in this study was to analyze interaction between the synthesized peptide sequences, mimicking a naturally occurring protein domain, and their consensus DNA sequence.

\section{Agarose Gel Electrophoresis}

Agarose is a polysaccharide made up of alternating units of D-galactose and 3,6-anhydroL-galactose. Melting the agarose in a desired buffer system followed by cooling it leads to the formation of a cross-linked porous gel matrix that is often utilized to separate of large biomolecules. In this study, agarose gel electrophoresis were performed under nondenaturing conditions in order to visualize the DNA unwinding ability of IHF mimicking/Pt complex peptides chimeras and for testing the DNA cleavable ability of the modified Zf13 domains. Plasmid vectors pUC18 and pJET were used for this study respectively. Agarose gels were prepared by dissolving $1 \%(\mathrm{w} / \mathrm{v})$ of agarose in $1 \times$ TAE-buffer, keeping into account that for testing the zinc finger domains EDTA was excluded from the buffer to 
avoid zinc chelation with EDTA. To every 5 volumes of the sample, 1 volume of $6 \times$ DNA loading dye from Fermentas was added prior to loading the sample in the well. The length of the DNA fragments was estimated by loading the following mixture into one of the wells as control: 1 volume of $6 \times$ GeneRuler $1 \mathrm{~kb}$ DNA Ladder Mix and 1 volume $6 \times$ DNA loading dye from Fermentas mixed with 4 volumes of water. Depending on the length of the gel it was run at a constant voltage $(6 \mathrm{~V} / \mathrm{cm})$ for about $2 \mathrm{~h}$. Thereafter, the gel was incubated in an ethidium-bromide staining solution $(0.5 \mu \mathrm{g} / \mathrm{mL})$ for $30 \mathrm{~min}$ as it has ability to intercalate between the DNA base pairs by means $\pi-\pi$ stacking. It was then possible to visualize the DNA bands utilizing a UV-transilluminator ECX-F26-MX from Vilber Lourmat.

50xTAE Buffer (1 L):

$242 \mathrm{~g}$ Tris Base

$57.1 \mathrm{~mL}$ glacial acetic acid $100 \mathrm{~mL} 0.5 \mathrm{M}$ EDTA

$\mathrm{pH}$ adjusted to 8

6xDNA Loading Dye:

$10 \mathrm{mM}$ Tris $\mathrm{HCl}(\mathrm{pH}=7.6)$

$60 \mathrm{mM}$ EDTA

$0.03 \%$ bromophenol blue

$0.03 \%$ xylene cyanol FF

$60 \%$ Glycerol

\section{Polyacrylamide Gel Electrophoresis}

Like agarose gels, polyacrylamide gels are also cross-linked porous materials. However, the pore size in polyacrylamide gels is much smaller and is suitable for the separation of polynucleotides with 5-500 base pairs. The gel matrix is formed by co-polymerization of acrylamide with $\mathrm{N}, \mathrm{N}^{\prime}$-methylenebisacrylamide, a cross-linking monomer, in the presence 
of TEMED and APS used for radical initiation reaction. OWL ${ }^{\mathrm{TM}}$ S4S Aluminium backed sequencing system from Thermo Scientific was used for electrophoresis. In order to visualize the DNA sequences fluorescent DNA sequences labelled with 6-FAM at the 5' end were used in the experiments. After the electrophoresis was complete the gel was visualized utilizing the Typhoon 9400 Variable Mode Gel Imager from Amersham Biosciences (GE Healthcare) by scanning under the blue laser module and quantified by the ImageQuant software.

\section{Native PAGE}

Native or non-denaturing polyacrylamide gel electrophoresis allows separation of double stranded DNA fragments based on their size. In addition, it is possible to retain the DNA-protein interactions assisted by ionic, electrostatic or Vander Waal forces.

The gel plates $20 \times 45 \mathrm{~cm}$ were carefully washed with double distilled water followed by wiping with a solution of $70 \% \mathrm{EtOH}$ in water and air drying. The plates were assembled by inserting the spacers ( $0.4 \mathrm{~mm}$ thick) in between them and were secured by clamping. $50 \mathrm{~mL}$ of gel solution of desired concentration was prepared and poured in between the glass plates. After the polymerization was the complete the glass plates were secured in the electrophoresis apparatus and the gel was pre-run at a constant current of $15 \mathrm{~mA}$ and later after loading the samples at $20 \mathrm{~mA}$ in $1 \times$ TBE buffer. Prior to loading the samples $3 \mu \mathrm{L}$ of $30 \%$ glycerol was added to them. While performing electrophoresis with the zinc fingers EDTA was excluded from the buffer system as it binds to divalent metals.

10x TBE Buffer $(1 \mathrm{~L}): \quad 108 \mathrm{~g}$ Tris Base

$55 \mathrm{~g}$ Boric acid

$40 \mathrm{~mL} 0.5 \mathrm{M}$ EDTA

$\mathrm{pH}$ adjusted to 8 
Gel Solution $(50 \mathrm{~mL}): \quad 15 \mathrm{~mL} \& 25 \mathrm{~mL}$ of Rotiphorese Gel 40 for $12 \%$ \& $20 \%$ gel

$5 \mathrm{~mL}$ of $10 \times \mathrm{TBE}$

$270 \mu \mathrm{L}$ of $10 \%$ APS

$27 \mu \mathrm{L}$ of TEMED

Add MilliQ water to adjust the total volume to $50 \mathrm{~mL}$

\section{Urea-Denaturing PAGE}

Denaturing polyacrylamide gels were performed to separate single stranded DNA fragments. Unlike native gels, non-covalent interactions cannot be visualized by performing urea-denaturing PAGE. However, for this study the method is suitable to test the ability of IHF mimicking peptides to covalently modify DNA as well as to investigate the DNA cleavage ability of zinc finger domains. The procedure for preparing the gel was similar to that of native gel except that the gel solution contained an additional $8 \mathrm{M}$ urea for denaturation. 1 volume of TriTrack DNA loading dye from Fermentas was added to 5 volumes of the sample prior to electrophoresis.

6x TriTrack Loading Dye: $\quad 10 \mathrm{mM}$ Tris $\mathrm{HCl}(\mathrm{pH}=7.6)$

$60 \mathrm{mM}$ EDTA

$0.03 \%$ bromophenol blue

$0.03 \%$ xylene cyanol FF

$0.15 \%$ orange $\mathrm{G}$

$60 \%$ Glycerol 


\subsection{Solid Phase Peptide synthesis}

All peptides were synthesized by standard Fmoc solid phase peptide synthesis (Fmoc-SPPS) protocol using preloaded resins. Fmoc-Lys(Boc)-Wang $(0.34 \mathrm{mmol} / \mathrm{g})$ was used for the synthesis of the zinc finger domains. H-Ileu-2-Chlorotrityl resin $(0.57 \mathrm{mmol} / \mathrm{g})$ was used for the synthesis of the cyclic peptide of IHF whereas Fmoc-Gly Novasyn TGT resin $(0.21 \mathrm{mmol} / \mathrm{g})$ was used for the synthesis of the dendrimeric peptide of IHF.

\section{Automated Solid Phase Peptide Synthesis}

Automated solid phase peptide synthesis was carried out on a microwave assisted peptide synthesizer Liberty TM (CEM, Kamp-Lintford, Germany) equipped with a Discover microwave reaction cavity (CEM). The resin was swollen in DCM for at least $30 \mathrm{~min}$ and in $\mathrm{NMP}$ for at least $1 \mathrm{~h}$. All the Fmoc-amino acids were prepared as $0.2 \mathrm{M}$ solutions in NMP. Standard reagents were used for deprotection of the Fmoc group (20\% piperidine in NMP), activation of the free amino acid (0.5 M HBTU/HOBt, $0.2 \mathrm{M}$ DIPEA in DMF) and for washing (NMP, DCM) in between the steps. The standard cycle involved two subsequent deprotection steps of $30 \mathrm{~s}$ and $180 \mathrm{~s}$ each. All amino acids were double coupled at $50{ }^{\circ} \mathrm{C}$ for $10 \mathrm{~min}$ except cysteine, histidine and arginine. Coupling of arginine was performed at room temperature for $25 \mathrm{~min}$ followed by microwave assisted coupling for $10 \mathrm{~min}$ at 50 ${ }^{\circ} \mathrm{C}$. Amino acids histidine and cysteine were coupled without microwave assistance at room temperature for an hour.

\section{Manual Solid Phase Peptide Synthesis}

Manual SPPS was carried out at a 0.05-0.1 mM scale using preloaded resins in a $B D$ syringe (acid/base resistant) equipped with a polyethylene frit. Prior to the synthesis, the resin was swollen in DCM for at least $30 \mathrm{~min}$ and in NMP for at least an hour. At first the 
Fmoc group from the amino acid attached to the resin was deprotected using $20 \%$ piperdine in NMP ( $2 \mathrm{~mL}$ in $100 \mathrm{mg}$ resin), thereafter the reaction was carried out for 10 min at room temperature and the procedure was repeated twice. All amino acids were double coupled in minimum amount of NMP at room temperature for $45 \mathrm{~min}$. For coupling the synthetically modified amino acid building blocks ( 3 eq) activators HATU/HOAt (2.9/3 eq) were used whereas natural amino acids (5 eq) were coupled using HBTU/HOBt (4.9/5 eq). The activators were used in combination with an equimolar ratio of activator base 35\% DIPEA (3/5 eq) in NMP. Washing in between the steps was done with NMP $(5 \times 5 \mathrm{~mL}), \mathrm{DCM}(5 \times 5 \mathrm{~mL})$ and again with NMP $(5 \times 5 \mathrm{~mL})$.

\section{Manual SPPS of lysine dendrimer}

The synthesis of the lysine dendrimer was performed using Fmoc-Gly-Novasyn TGT resin $(0.21 \mathrm{mmol} / \mathrm{g})$ at a scale of $0.1 \mathrm{mmol}$. All amino acids were sequentially double coupled manually onto the resin. After coupling the amino acids contained within the glycine linker (6 glycine residues and the platinum chelating building block) Fmoc-Lys(Fmoc)-OH was coupled according to the above mentioned procedure to give the first generation dendrimer. For the synthesis of the second generation and the third generation lysine dendrimer 10 eq and 20 eq of Fmoc-Lys(Fmoc)-OH were coupled again, respectively. The proportion of the activators (HATU/HOAt) and the activator base (DIPEA) utilized in the coupling reaction were increased accordingly.

\section{Resin Loading Density measurement ${ }^{[214]}$}

Loading density of the resin after coupling amino acids on it was determined by measuring UV absorption of dibenzofulvene $\left(\varepsilon_{304}=7624 \mathrm{~L} \mathrm{~mol}^{-1} \mathrm{~cm}^{-1}\right)$, the product of Fmoc cleavage. A known quantity $(\leq 5 \mathrm{mg}$ ) of dried resin was weighed in a $10 \mathrm{~mL}$ graduated flask and to it was added $2 \mathrm{~mL}$ of $2 \%$ DBU (1,8-diazabicyclo[5.4.0]undec-7-ene) in DMF. The mixture was diluted to $10 \mathrm{~mL}$ by adding MeCN after gently stirring it for 1.5 h. A second dilution was prepared by taking $2 \mathrm{~mL}$ of the resulting solution and further 
diluting it to $25 \mathrm{~mL}$ by adding $\mathrm{MeCN}$. A reference was prepared in a similar way without the addition of the resin. The UV absorbance was recorded at $304 \mathrm{~nm}$ and the resin loading was determined by applying the following formula:

resin loading $(\mathrm{mmol} / \mathrm{g})=\frac{\left(A b s_{\text {sample }}-A b s_{\text {ref }}\right) \times 16.4}{m_{\text {resin }}}$

where $A b s_{\text {sample }}$ and $A b s_{\text {ref }}$ are the absorbances of the sample and the reference, respectively at wavelength $304 \mathrm{~nm}$ and $m_{\text {resin }}$ is the mass of the analyzed resin in milligrams.

\section{Kaiser test}

Qualitative analysis was performed for detecting free primary amino groups after a coupling step by using Kaiser test. The following three reagents were used:

Reagent $A=$ Prepared by dissolving $1 \mathrm{~g}$ of ninhydrin in $20 \mathrm{~mL}$ of ethanol.

Reagent $\mathrm{B}=$ Prepared by dissolving $80 \mathrm{~g}$ of liquefied phenol in $20 \mathrm{~mL}$ of ethanol.

Reagent $\mathrm{C}=$ Prepared by mixing $1 \mathrm{~mL}$ of $0.001 \mathrm{M}$ aqueous solution of $\mathrm{KCN}$ in $49 \mathrm{~mL}$ pyridine.

A few beads of the resin were taken in a glass vial and washed thoroughly with ethanol. 2-3 drops of reagent $A, B$ and $C$ were added to the vial and the suspension was heated at $110{ }^{\circ} \mathrm{C}$ for $5 \mathrm{~min}$. The presence of free amines upon reaction with ninhydrin leads the formation of a deep blue colored resin beads. Kaiser test is not reliable for peptides containing secondary amines, asparagine or serine. 


\section{Cleavage}

The resin contained in syringe equipped with a PE-frit was washed thoroughly with $5 \times 5$ $\mathrm{mL} \mathrm{DCM}, 5 \times 5 \mathrm{~mL} \mathrm{MeOH}, 5 \times 5 \mathrm{~mL} \mathrm{DCM}$ and again with $5 \times 5 \mathrm{~mL} \mathrm{MeOH}$. After drying the resin overnight under reduced pressure the following cleavage conditions were applied:-

(a) Cleavage from Wang resin:

Cleavage of the peptide from resin as well as global deprotection of all the amino acid side chain protecting groups from the resin was performed in a solution containing TFA/ $\mathrm{H}_{2} \mathrm{O} / \mathrm{TIS} / \mathrm{EDT}(94 / 2.5 / 1 / 2.5)$. The reaction was done for $2 \mathrm{~h}$ at room temperature and the cleavage solution was subsequently filtered.

(b) Cleavage from NovaSyn TGT and 2-Chlorotrityl resin:

Cleavage of the peptide from the resin while keeping all the amino side chain protecting groups intact was done in a solution containing $30 \%$ hexafluoroisopropanol (HFIP) in DCM. The reaction was performed at room temperature for $45 \mathrm{~min}$ and the cleavage solution was subsequently filtered.

\section{Post Cleavage workup}

The cleavage solution was concentrated by blow drying with nitrogen. Addition of ice cold diethylether or t-butylmethylether (MTBE) led to the precipitation of the crude product, which was further isolated by centrifugation (9000 rpm, $10 \mathrm{~min},-5^{\circ} \mathrm{C}$ ). After decanting the supernatant the precipitation was repeated once again. The pellet was lyophilized from $\mathrm{H}_{2} \mathrm{O}$ and the product was purified by reverse phase HPLC. 


\subsection{Native Chemical Ligation (NCL)}

After the protein expression, intein mediated cleavage of the Zf12 domain using a thiol containing reagent MESNA rendered the $\mathrm{Zf12}$ as a C-terminal peptide thioester. Therefore, the product obtained was directly applicable as a substrate for native chemical ligation with any peptide containing an $\mathrm{N}$-terminal cystine residue. However, the synthetic domain, Zf3 after SPPS was obtained in the oxidized form containing disulfide brides between the cysteine residues of the peptide. In order to release the thiol of the $\mathrm{N}$-terminal cysteine residue and make it available for $\mathrm{NCL}$, the disulfide bridges were first reduced with TCEP. The Zf3 peptides $(3 \mathrm{mM})$ were dissolved in a thoroughly degassed solution of $10 \mathrm{mM} \mathrm{Na} 2 \mathrm{HPO}_{4} / \mathrm{NaH}_{2} \mathrm{PO}_{4}, 6 \mathrm{M} \mathrm{Gnd} . \mathrm{HCl}$ and $20 \mathrm{mM}$ TCEP and the $\mathrm{pH}$ was adjusted to 4 for optimal reduction. After performing the reaction for $2 \mathrm{~h}$ at room temperature, an equal volume of a solution containing Zf12 peptide thioester $(1 \mathrm{mM})$ in $500 \mathrm{mM} \mathrm{Na}{ }_{2} \mathrm{HPO}_{4} / \mathrm{NaH}_{2} \mathrm{PO}_{4}$ and $6 \mathrm{M} \mathrm{Gnd} . \mathrm{HCl}$ was added it and the $\mathrm{pH}$ was maintained in the range 7.8 to 8 . The ligation reaction was performed for $24 \mathrm{~h}$ at room temperature. Thereafter, the reaction mixture was subjected to RP-HPLC, the peaks from different substrates were analyzed utilizing mass spectroscopic measurements and the product corresponding to the ligated Zf13 peptides were isolated. 


\subsection{Synthesis of the artificial amino acid building blocks contained in IHF mimicking peptides}

\subsubsection{Synthesis of the platinum chelating unit}

\section{$N$-Allyloxycarbonyl- $N, N^{\prime}$-dimethylethylenediamine}

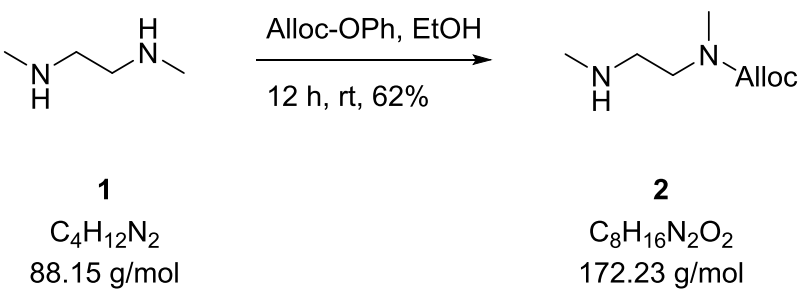

To a solution of $N, N^{\prime}$-dimethylethylenediamine $1(3.27 \mathrm{~mL}, 30 \mathrm{mmol}, 1 \mathrm{eq})$ in EtOH p.a. $(100 \mathrm{~mL})$ allyl phenyl carbonate $(4.82 \mathrm{~mL}, 30 \mathrm{mmol}, 1 \mathrm{eq})$ was added dropwise. The reaction mixture was continued to stir overnight at room temperature followed by removing the solvent under reduced pressure. The residue was dissolved in water (100 $\mathrm{mL}$ ) and the $\mathrm{pH}$ was adjusted to around 3 by adding $1 \mathrm{M} \mathrm{HCl}$. After extracting the aqueous phase by $\mathrm{DCM}(4 \times 100 \mathrm{~mL})$ it was made strongly alkaline by adjusting the $\mathrm{pH}$ to around 13 with the addition of $\mathrm{NaOH}$. The organic phase was discarded and the basic aqueous layer was again extracted with DCM $(4 \times 100 \mathrm{~mL})$. The combined organic phase was washed with $2 \mathrm{M} \mathrm{NaOH}(3 \times 100 \mathrm{~mL})$ and dried over sodium sulphate. Removal of solvent under reduced pressure yielded the product $N$-allyloxycarbonyl- $N, N^{\prime}$ dimethylethylenediamine 2 ( $3.2 \mathrm{~g}, 18.6 \mathrm{mmol}, 62 \%)$ as a colourless oil.

${ }^{1} \mathrm{H}-\mathrm{NMR}\left(300 \mathrm{MHz}, \mathrm{CDCl}_{3}\right): \delta(\mathrm{ppm})=5.94-5.81\left(\mathrm{~m}, 1-\mathrm{H}, \mathrm{CH}=\mathrm{CH}_{2}\right)$, 5.28-5.12 (m, 2-H, $\left.\mathrm{CH}=\mathrm{CH}_{2}\right), 4.55-4.50\left(\mathrm{~m}, 2-\mathrm{H},-\mathrm{OCH}_{2}\right), 3.35\left(\mathrm{t},{ }^{3} \mathrm{~J}_{\mathrm{H}-\mathrm{H}}=6.6 \mathrm{~Hz}, 2-\mathrm{H}, \mathrm{N}-\mathrm{CH}_{2}\right), 2.90(\mathrm{~s}, 3-\mathrm{H}, \mathrm{N}-$ $\left.\mathrm{CH}_{3}\right), 2.70\left(\mathrm{t}^{3}{ }^{3} \mathrm{H}_{-\mathrm{H}}=6.6 \mathrm{~Hz}, 2-\mathrm{H}, \mathrm{NH}-\mathrm{CH}_{2}\right), 2.39\left(\mathrm{~s}, 3-\mathrm{H}, \mathrm{NH}-\mathrm{CH}_{3}\right), 1.36\left(\mathrm{~s}_{\mathrm{br}}, 1-\mathrm{H}, \mathrm{NH}\right)$.

${ }^{13} \mathrm{C}-\mathrm{NMR}\left(500 \mathrm{MHz}, \mathrm{CDCl}_{3}\right): \delta(\mathrm{ppm})=156.1(\mathrm{C}=\mathrm{O}), 133.0\left(-\mathrm{CH}=\mathrm{CH}_{2}\right), 117.1\left(-\mathrm{CH}=\mathrm{CH}_{2}\right)$, $66.0\left(\mathrm{O}-\mathrm{CH}_{2}\right), 49.7\left(\mathrm{NHCH}_{2}\right), 48.6\left(\mathrm{NCH}_{2}\right), 36.4\left(\mathrm{NHCH}_{3}\right), 35.2\left(\mathrm{NCH}_{3}\right)$. 
ESI-MS $m / z: 173.1[\mathrm{M}+\mathrm{H}]^{+}, 195.1[\mathrm{M}+\mathrm{Na}]^{+}, 345.2[2 \mathrm{M}+\mathrm{H}]^{+}, 367.2[2 \mathrm{M}+\mathrm{Na}]^{+}$.

ESI-HRMS: calculated for $\left[\mathrm{C}_{8} \mathrm{H}_{17} \mathrm{~N}_{2} \mathrm{O}_{2}\right]^{+}\left([\mathrm{M}+\mathrm{H}]^{+}\right)=173.1285$, found = 173.1286; calculated for $\left[\mathrm{C}_{8} \mathrm{H}_{16} \mathrm{~N}_{2} \mathrm{O}_{2} \mathrm{Na}\right]^{+}\left([\mathrm{M}+\mathrm{Na}]^{+}\right)=195.1104$, found $=195.1108$.

(S)-N-tert-butoxycarbonyl- $\delta$-hydroxy-norvaline benzyl ester ${ }^{[124]}$<smiles>CC(C)(C)OC(=O)NC(CCC(=O)O)C(=O)OCc1ccccc1</smiles>

3

$\mathrm{C}_{17} \mathrm{H}_{23} \mathrm{NO}_{6}$ $337.37 \mathrm{~g} / \mathrm{mol}$
1) $N$-Ethylmorpholine, i-BuOCOCl $\mathrm{THF},-10^{\circ} \mathrm{C}, 10 \mathrm{~min}$

2) $\mathrm{NaBH}_{4}, \mathrm{MeOH}$, $-10^{\circ} \mathrm{C}$-r.t., $45 \min , 89.7 \%$

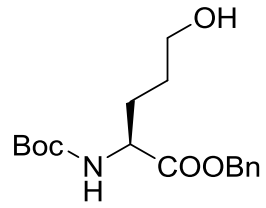

4

$\mathrm{C}_{17} \mathrm{H}_{25} \mathrm{NO}_{5}$ $323.39 \mathrm{~g} / \mathrm{mol}$

To a solution of $N$-Boc-Glutamic acid benzyl ester 3 (5 g, $14.82 \mathrm{mmol}, 1 \mathrm{eq})$ in anhydrous THF (70 mL) N-Ethylmorpholine $(2.05 \mathrm{~mL}, 16.3 \mathrm{mmol}, 1.1 \mathrm{eq})$ and isobutyl chloroformate (2.13 mL, $16.3 \mathrm{mmol}, 1.1 \mathrm{eq})$ were added at $-10{ }^{\circ} \mathrm{C}$ under argon. The mixture was continued to stir for an additional $10 \mathrm{~min}$ at $-10{ }^{\circ} \mathrm{C}$ followed by addition of a solution of sodium borohydride (1.68 $\mathrm{g}, 44.4 \mathrm{mmol}, 3 \mathrm{eq})$ in $\mathrm{MeOH}(280 \mathrm{~mL})$. Thereafter, the reaction was stirred for $30 \mathrm{~min}$ at $-10{ }^{\circ} \mathrm{C}$ and another $30 \mathrm{~min}$ at room temperature. The reaction mixture was neutralized by addition of $1 \mathrm{~N} \mathrm{HCl}$ (30 mL approx) such that the final $\mathrm{pH}$ was in the range of 3-4. The solvents were removed under reduced pressure and the residue was dissolved in EtOAc $(120 \mathrm{~mL})$. The organic layer was successively washed with $1 \mathrm{~N} \mathrm{HCl}, 6 \%$ aq $\mathrm{KHCO}_{3}$ and brine, dried over sodium sulphate and removed under vacuum. Purification by column chromatography [eluent: Pentane/EtOAc, 3/2 (v/v)] yielded (S)-N-tert-butoxycarbonyl- $\delta$-hydroxy-norvaline benzyl ester 4 (4.3 g, $13.3 \mathrm{mmol}$, $89.7 \%)$ as a viscous colourless oil. 
$\boldsymbol{R}_{\mathrm{f}}=0.21($ Pentane $/$ EtOAc $=2 / 1, \mathrm{v} / \mathrm{v})$.

${ }^{1} \mathbf{H}-\mathbf{N M R}\left(300 \mathrm{MHz}, \mathrm{CDCl}_{3}\right): \delta(\mathrm{ppm})=7.42-7.29(\mathrm{~m}, 5-\mathrm{H}, \mathrm{Ar}-\mathrm{H})$, 5.29-5.11 (m, 3-H, NHBoc, $\left.\mathrm{CH}_{2} \mathrm{Ph}\right), 4.42-4.31(\mathrm{~m}, 1-\mathrm{H}, \mathrm{H}-\alpha), 3.61\left(\mathrm{t},{ }^{3} \mathrm{~J}_{\mathrm{H}-\mathrm{H}}=6.2 \mathrm{~Hz}, 2-\mathrm{H}, \mathrm{H}-\delta\right), 2.00-1.56(\mathrm{~m}, 4-\mathrm{H}, \mathrm{H}-\beta$, $\mathrm{H}-\gamma), 1.42\left(\mathrm{~s}, 9-\mathrm{H},{ }^{t} \mathrm{Boc}^{-\mathrm{CH}_{3}}\right)$.

${ }^{13} \mathrm{C}-\mathrm{NMR}\left(500 \mathrm{MHz}, \mathrm{CDCl}_{3}\right): \delta(\mathrm{ppm})=172.7$ (COBn), $155.4(\mathrm{CONH}), 135.4(\mathrm{Ar}-\mathrm{C}), 128.6$ (Ar-C), $127.7(\mathrm{Ar}-\mathrm{C}), 127.1(\mathrm{Ar}-\mathrm{C}), 80.3\left[\mathrm{C}\left(\mathrm{CH}_{3}\right)_{3}\right], 67.5\left(\mathrm{CH}_{2}-\mathrm{Ph}\right), 62.1(\mathrm{C}-\delta), 53.3(\mathrm{C}-\alpha)$, 29.4, 28.4, $28.3\left[\mathrm{C}\left(\mathrm{CH}_{3}\right)_{3}\right]$.

ESI-MS $m / z: 346.2[\mathrm{M}+\mathrm{Na}]^{+}, 669.4[2 \mathrm{M}+\mathrm{Na}]^{+}$.

ESI-HRMS: calculated for $\left[\mathrm{C}_{17} \mathrm{H}_{25} \mathrm{NO}_{5} \mathrm{Na}\right]^{+}\left([\mathrm{M}+\mathrm{Na}]^{+}\right)=346.1625$, found $=346.1622$; calculated for $\left[\mathrm{C}_{17} \mathrm{H}_{24} \mathrm{NO}_{5}\right]^{-}\left([\mathrm{M}-\mathrm{H}]^{-}\right)=322.1660$, found $=322.1665$.

(S)-N-tert-butoxycarbonyl- $\delta$-bromo-norvaline benzyl ester ${ }^{[124]}$<smiles>CC(C)(C)OC(=O)NC(CCCO)C(=O)OCc1ccccc1</smiles>

4

$\mathrm{C}_{17} \mathrm{H}_{25} \mathrm{NO}_{5}$ $323.39 \mathrm{~g} / \mathrm{mol}$<smiles>CC(C)(C)OC(=O)NC(CCCBr)C(=O)OCc1ccccc1</smiles>

5

$\mathrm{C}_{17} \mathrm{H}_{24} \mathrm{BrNO}_{4}$ $386.29 \mathrm{~g} / \mathrm{mol}$

$N$-Boc- $\delta$-hydroxy-norvaline benzyl ester 4 ( $4 \mathrm{~g}, 12.37 \mathrm{mmol}, 1 \mathrm{eq}$ ) was dissolved under argon in dry DCM $(80 \mathrm{~mL})$ and cooled to $-5{ }^{\circ} \mathrm{C}$. The mixture was protected from light 
followed by addition of $\mathrm{CBr}_{4}(6.14 \mathrm{~g}, 18.5 \mathrm{mmol}, 1.5 \mathrm{eq})$ and $\mathrm{PPh}_{3}(4.65 \mathrm{~g}, 18.5 \mathrm{mmol}, 1.5$ eq) to it. The reaction was continued to stir at $-5{ }^{\circ} \mathrm{C}$ for $30 \mathrm{~min}$ and $2 \mathrm{~h}$ at room temperature. Purification by column chromatography [eluent: Pentane/EtOAc, 9/1 (v/v)] yielded $(S)$ - $N$-tert-butoxycarbonyl- $\delta$-bromo-norvaline benzyl ester 5 (3.28 g, 8.5 mmol, $69 \%)$ as a pale yellow oil.

$\boldsymbol{R}_{\mathrm{f}}=0.4($ Pentane $/$ EtOAc $=9 / 1, \mathrm{v} / \mathrm{v})$.

${ }^{1} \mathrm{H}-\mathrm{NMR}\left(300 \mathrm{MHz}, \mathrm{CDCl}_{3}\right): \delta(\mathrm{ppm})=7.41-7.30(\mathrm{~m}, 5-\mathrm{H}, \mathrm{Ar}-\mathrm{H})$, 5.23-5.06 (m, 3-H, NHBoc,


$1.44\left(\mathrm{~s}, 9-\mathrm{H},{ }^{t} \mathrm{Boc}-\mathrm{CH}_{3}\right)$.

${ }^{13} \mathrm{C}-\mathrm{NMR}\left(500 \mathrm{MHz}, \mathrm{CDCl}_{3}\right): \delta(\mathrm{ppm})=172.2(\mathrm{COBn}), 155.3(\mathrm{CONH}), 135.3(\mathrm{Ar}-\mathrm{C}), 128.7$ (Ar-C), $128.5(\mathrm{Ar}-\mathrm{C}), 128.4(\mathrm{Ar}-\mathrm{C}), 80.2\left[\mathrm{C}\left(\mathrm{CH}_{3}\right)_{3}\right], 67.3\left(\mathrm{CH}_{2}-\mathrm{Ph}\right), 53.0(\mathrm{C}-\alpha), 32.9,31.6$, 28.7, $28.5\left[\mathrm{C}\left(\mathrm{CH}_{3}\right)_{3}\right]$.

ESI-MS m/z: $386.1[\mathrm{M}+\mathrm{H}]^{+}, 408.1[\mathrm{M}+\mathrm{Na}]^{+}, 773.2[2 \mathrm{M}+\mathrm{H}]^{+}, 795.2[2 \mathrm{M}+\mathrm{Na}]^{+}$.

ESI-HRMS: calculated for $\left[\mathrm{C}_{17} \mathrm{H}_{25} \mathrm{NO}_{4} \mathrm{Br}\right]^{+}\left([\mathrm{M}+\mathrm{H}]^{+}\right)=386.0961$, found = 386.0959; calculated for $\left[\mathrm{C}_{17} \mathrm{H}_{24} \mathrm{NO}_{4} \mathrm{BrNa}\right]^{+}\left([\mathrm{M}+\mathrm{Na}]^{+}\right)=408.0781$, found $=408.0782$. 


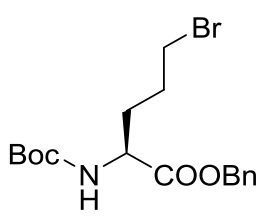

5

$\mathrm{C}_{17} \mathrm{H}_{24} \mathrm{BrNO}_{4}$

$386.29 \mathrm{~g} / \mathrm{mol}$



$81 \%$

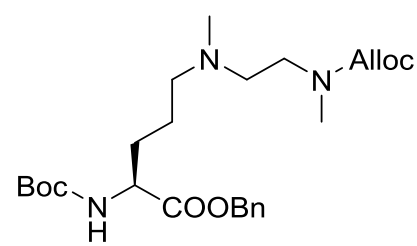

6

$\mathrm{C}_{25} \mathrm{H}_{39} \mathrm{~N}_{3} \mathrm{O}_{6}$ $477.6 \mathrm{~g} / \mathrm{mol}$

$N$-allyloxycarbonyl- $N, N^{\prime}$-dimethylethylenediamine $2(4.01 \mathrm{~g}, 23.31 \mathrm{mmol}, 3 \mathrm{eq})$ was dissolved in dry DMF $(40 \mathrm{~mL})$ under argon atmosphere at room temperature. To this solution DIPEA ( $4 \mathrm{~mL}, 23.31 \mathrm{mmol}, 3 \mathrm{eq}$ ) was added followed by dropwise addition of a solution of (S)-N-tert-butoxycarbonyl- $\delta$-bromo-norvaline benzyl ester 5 (3 g, $7.77 \mathrm{mmol}$, 1 eq) in dry DMF (35 mL). After letting the reaction mixture to stir for $48 \mathrm{~h}$ at room temperature the solvent was removed under vacuum. The residue was dissolved in EtOAc and the organic phase was washed with water, dried over sodium sulphate and concentrated under vacuum. Purification by column chromatography [eluent: Pentane/EtOAc, $1 / 1$ (v/v) $\rightarrow$ EtOAc (100\%)] yielded (S)- $N$-(tert-butoxycarbonylamino)- $\delta$ ( $N$-(allyloxycarbonyl)- $N, N^{\prime}$-dimethylethylenediamino)norvaline benzyl ester $\mathbf{6}$ as a colourless oil ( $3 \mathrm{~g}, 6.29 \mathrm{mmol}, 81 \%)$.

$\boldsymbol{R}_{\mathrm{f}}=0.53$ (Ethylacetate/Methanol = 9/1, v/v).

${ }^{1} \mathrm{H}-\mathrm{NMR}\left(300 \mathrm{MHz}, \mathrm{DMSO}-\mathrm{d}_{6}\right): \delta(\mathrm{ppm})=7.40-7.30(\mathrm{~m}, 5-\mathrm{H}, \mathrm{Ar}-\mathrm{H}), 7.28\left(\mathrm{~d},{ }^{3} \mathrm{~J}_{\mathrm{H}-\mathrm{H}}=7.5 \mathrm{~Hz}\right.$, 1-H, $\mathrm{NH})$, 5.97-5.84 (m, 1- $\left.\mathrm{H}, \mathrm{CH}=\mathrm{CH}_{2}\right)$, 5.30-5.05 (m, 4- $\left.\mathrm{H}, \mathrm{CH}=\mathrm{CH}_{2}, \mathrm{CH}_{2}-\mathrm{Ph}\right), 4.49$ (dt, 2-H, ${ }^{4} J_{\mathrm{H}-\mathrm{H}}=1.5 \mathrm{~Hz},{ }^{3} J_{\mathrm{H}-\mathrm{H}}=5.4 \mathrm{~Hz}, \mathrm{CH}_{2}$-Alloc), 4.10-3.97 (m, 1-H, $\left.\alpha-\mathrm{CH}\right), 3.27\left(\mathrm{t},{ }^{3} J_{\mathrm{H}-\mathrm{H}}=6.9 \mathrm{~Hz}, 2-\right.$ $\left.\mathrm{H}, \mathrm{CO}-\mathrm{NCH}_{2}\right), 2.83\left(\mathrm{~s}, 3-\mathrm{H}, \mathrm{CO}-\mathrm{NCH}_{3}\right), 2.39\left(\mathrm{t},{ }^{3} \mathrm{~J}_{\mathrm{H}-\mathrm{H}}=6.75 \mathrm{~Hz}, 2-\mathrm{H}, \mathrm{N}-\mathrm{CH}_{2}\right), 2.27\left(\mathrm{t},{ }^{3} \mathrm{~J}_{\mathrm{H}-\mathrm{H}}=\right.$ 
$\left.6.9 \mathrm{~Hz}, 2-\mathrm{H}, \delta-\mathrm{CH}_{2}\right), 2.12\left(\mathrm{~s}, 3-\mathrm{H}, \mathrm{NCH}_{3}\right), 1.72-1.55\left(\mathrm{~m}, 2-\mathrm{H}, \beta-\mathrm{CH}_{2}\right), 1.46-1.40(\mathrm{~m}, 2-\mathrm{H}, \mathrm{\gamma}-$ $\left.\mathrm{CH}_{2}\right), 1.38\left(\mathrm{~s}, 8-\mathrm{H},{ }^{t}\right.$ Boc- $\left.\mathrm{CH}_{3}\right), 1.29\left(\mathrm{~s}, 1-\mathrm{H},{ }^{t} \mathrm{Boc}-\mathrm{CH}_{3}\right.$, rotamer).

${ }^{13}$ C-NMR (125 MHz, DMSO-d 6 ): $\delta(p p m)=172.4$ (CO-OBn), 155.5 (CO-Boc), 155.1 (COAlloc), $136.0\left(\mathrm{Ph}_{\text {ipso }}\right), 133.5\left(-\mathrm{CH}_{2}-\mathrm{CH}=\mathrm{CH}_{2}\right), 128.3,127.9,127.7(\mathrm{Ph}), 116.6\left(-\mathrm{CH}_{2}-\mathrm{CH}=\mathrm{CH}_{2}\right)$, $78.1\left[\mathrm{C}\left(\mathrm{CH}_{3}\right)_{3}\right], 65.6\left(\mathrm{CH}_{2}-\mathrm{Ph}\right), 64.9\left(-\mathrm{CH}_{2}-\mathrm{CH}=\mathrm{CH}_{2}\right), 56.5\left(\delta-\mathrm{CH}_{2}\right), 54.4\left(\mathrm{NCH}_{2}\right), 53.5(\alpha-\mathrm{CH})$, $46.1\left(\mathrm{CO}-\mathrm{NH}_{2}\right), 41.6\left(\mathrm{NCH}_{3}\right), 33.9\left(\mathrm{CO}-\mathrm{NCH}_{3}\right), 28.4\left(\beta-\mathrm{CH}_{2}\right), 28.1\left[\mathrm{C}\left(\mathrm{CH}_{3}\right)_{3}\right], 23.0\left(\gamma-\mathrm{CH}_{2}\right)$.

ESI-MS m/z: $478.3[\mathrm{M}+\mathrm{H}]^{+}, 476.3[\mathrm{M}-\mathrm{H}]^{-}$.

ESI-HRMS: calculated for $\left[\mathrm{C}_{25} \mathrm{H}_{40} \mathrm{~N}_{3} \mathrm{O}_{6}\right]^{+}\left([\mathrm{M}+\mathrm{H}]^{+}\right)=478.2912$, found $=478.2917$; calculated for $\left[\mathrm{C}_{25} \mathrm{H}_{39} \mathrm{~N}_{3} \mathrm{O}_{6} \mathrm{Na}\right]^{+}\left([\mathrm{M}+\mathrm{Na}]^{+}\right)=500.2731$, found $=500.2725$.

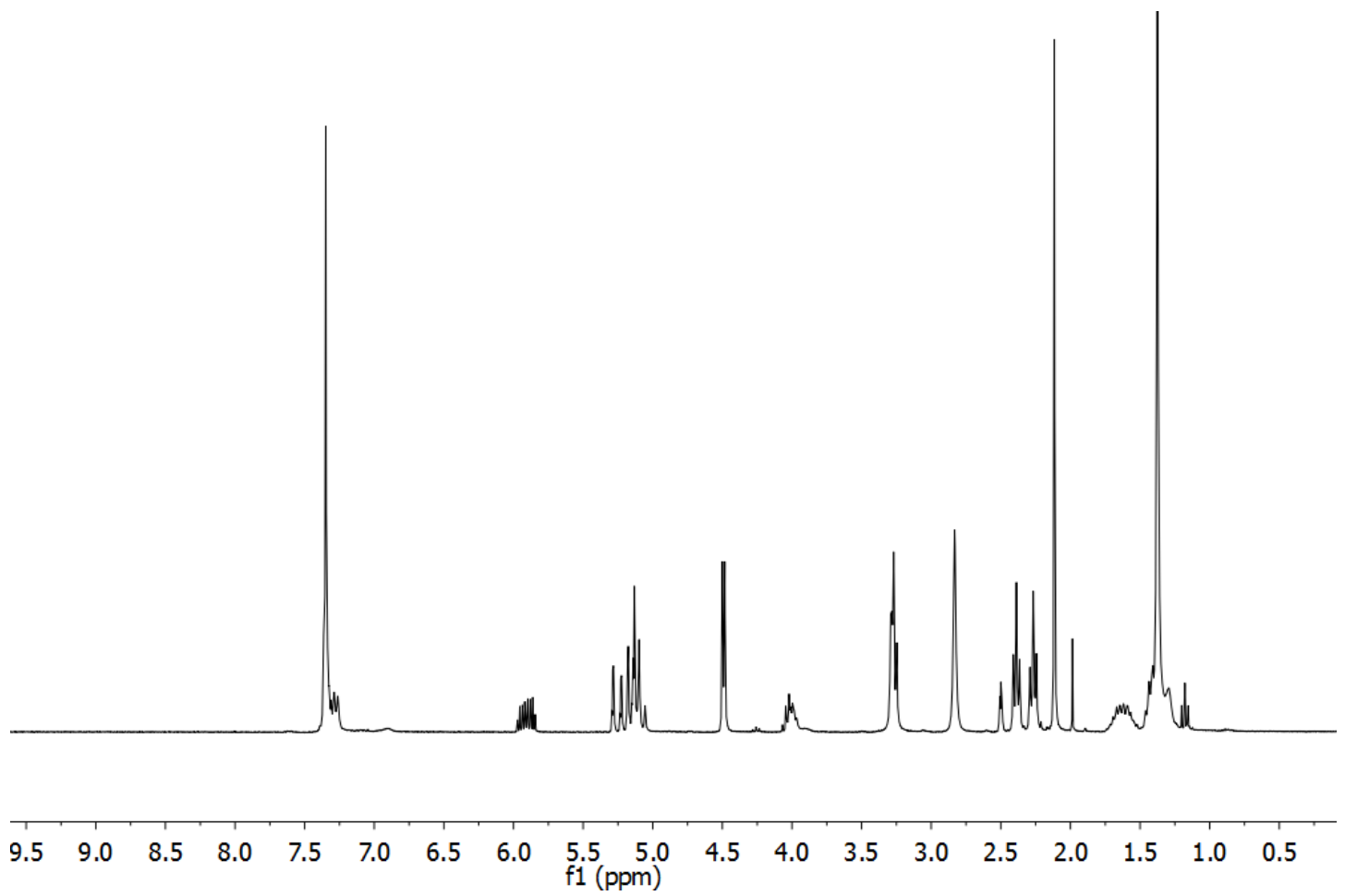

Figure 7.1: ${ }^{1} \mathrm{H}$-NMR spectra of $(S)-N$-(tert-butoxycarbonylamino)- $\delta$-( $N$-(allyloxycarbonyl)- $N, N^{\prime}$ dimethylethylene diamino)pentanoic acid benzyl ester 6 . 




Figure 7.2: ${ }^{13} \mathrm{C}$-NMR spectra of $(S)-N$-(tert-butoxycarbonylamino)- $\delta$-( $N$-(allyloxycarbonyl)- $N, N^{\prime}-$ dimethylethylenediamino)norvaline benzyl ester $\boldsymbol{6}$. 


\section{(S)-N-(((9H-fluoren-9-yl)methoxy)carbonyl)- $\delta$-(N-(allyloxycarbonyl)- $N, N^{\prime}-$}

\section{dimethylethylenediamino)norvaline benzyl ester}

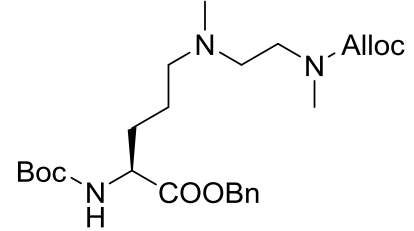

$\mathrm{C}_{25} \mathrm{H}_{39} \mathrm{~N}_{3} \mathrm{O}_{6}$

$477.6 \mathrm{~g} / \mathrm{mol}$
1) $1 \mathrm{~N} \mathrm{NaOH}, 6 \mathrm{~h}$

2) $95 \%$ TFA, $6 \mathrm{~h}$

3) Fmoc-OSu, $10 \% \mathrm{Na}_{2} \mathrm{CO}_{3}$, dioxane, $4 \mathrm{~h}, 65 \%$

7

$\mathrm{C}_{28} \mathrm{H}_{35} \mathrm{~N}_{3} \mathrm{O}_{6}$ $509.6 \mathrm{~g} / \mathrm{mol}$

(S)- $N$-(tert-butoxycarbonylamino)- $\delta$-(N-(allyloxycarbonyl)- $N, N^{\prime}$-dimethylethylenediamino) norvaline benzyl ester 6 (1.8 g, $3.77 \mathrm{mmol}, 1 \mathrm{eq})$ was dissolved in dioxane (16.5 mL). To it was added water $(11 \mathrm{~mL})$ and $1 \mathrm{M}$ aq. $\mathrm{NaOH}(5.5 \mathrm{~mL})$ and the resulting solution was stirred for $6 \mathrm{~h}$ at room temperature. Thereafter, the reaction mixture was neutralized by addition of $1 \mathrm{M} \mathrm{HCl}(5.5 \mathrm{~mL})$ and concentrated under reduced pressure followed by Iyophilization. The residue was dissolved in TFA/ $\mathrm{H}_{2} \mathrm{O}(95 / 5, \mathrm{v} / \mathrm{v}, 30 \mathrm{~mL})$ while cooling at 0 ${ }^{\circ} \mathrm{C}$ and the mixture was allowed to stir for $15 \mathrm{~min}$ at $0{ }^{\circ} \mathrm{C}$ followed by stirring at room temperature for $6 \mathrm{~h}$. After removing the TFA under reduced pressure the water phase was co-evaporated with $1 \mathrm{~N} \mathrm{HCl}(3 \times 15 \mathrm{~mL})$ followed by lyophilization. The residue obtained was then dissolved in $10 \% \mathrm{Na}_{2} \mathrm{CO}_{3}(25 \mathrm{~mL})$ and to it Fmoc-OSu $(1.53 \mathrm{~g}, 4.53$ $\mathrm{mmol}, 1.2 \mathrm{eq})$ solubilised in dioxane $(16 \mathrm{~mL})$ was added dropwise at $0{ }^{\circ} \mathrm{C}$. The reaction mixture was stirred at $0{ }^{\circ} \mathrm{C}$ for $15 \mathrm{~min}$ and then at room temperature for another $4 \mathrm{~h}$. The organic phase was removed under reduced pressure and the aqueous phase was diluted by addition of water $(35 \mathrm{~mL})$ followed by washing with $\mathrm{Et}_{2} \mathrm{O}(3 \times 70 \mathrm{~mL})$. Thereafter, the aqueous phase was acidified to $\mathrm{pH} 3$ with the addition of $1 \mathrm{~N} \mathrm{HCl}$ and extracted with EtOAc $(4 \times 70 \mathrm{~mL})$. The combined organic phase was dried over sodium sulphate and evaporated under vacuum. After purification by column chromatography [eluent: $\mathrm{DCM} / \mathrm{MeOH}, 9 / 1(\mathrm{v} / \mathrm{v}) \rightarrow \mathrm{DCM} / \mathrm{MeOH}, 4 / 1(\mathrm{v} / \mathrm{v})]$ the product $(\mathrm{S})-\mathrm{N}-(((9 \mathrm{H}-$ fluoren-9yl)methoxy)carbonyl)- $\delta$-( $N$-(allyloxycarbonyl)- $N, N^{\prime}$-dimethylethylenediamino)norvaline benzyl ester 7 (1.25 g, $2.45 \mathrm{mmol}, 65 \%)$ was obtained as a white solid. 
$\boldsymbol{R}_{\mathrm{f}}=0.15(\mathrm{DCM} / \mathrm{MeOH}=5 / 1, \mathrm{v} / \mathrm{v})$.

${ }^{1} \mathrm{H}-\mathrm{NMR}\left(300 \mathrm{MHz}\right.$, DMSO- $\left.\mathrm{d}_{6}\right): \delta(\mathrm{ppm})=7.88\left(\mathrm{~d},{ }^{3} \mathrm{~J}_{\mathrm{H}-\mathrm{H}}=6.72 \mathrm{~Hz}, 2-\mathrm{H}, \mathrm{C} 4-\mathrm{Fmoc}\right), 7.70(\mathrm{~m}$, 2-H, C1-Fmoc), 7.40 (t, $\left.{ }^{3} \mathrm{~J}_{\mathrm{H}-\mathrm{H}}=7.5 \mathrm{~Hz}, 2-\mathrm{H}, \mathrm{C} 3-\mathrm{Fmoc}\right), 7.33-7.30$ (m, 2-H, C2-Fmoc), 5.95$5.87\left(\mathrm{~m}, 1-\mathrm{H}, \mathrm{CH}-\right.$ Alloc), $5.25\left(\mathrm{~d},{ }^{3} \mathrm{~J}_{\mathrm{H}-\mathrm{H}}=18.6 \mathrm{~Hz}, 1-\mathrm{H},=\mathrm{CH}_{2}\right), 5.17-5.13\left(\mathrm{~m}, 1-\mathrm{H},=\mathrm{CH}_{2}\right)$, 4.50-4.48 (m, 2-H, CH $\mathrm{CH}_{2}$-Alloc), 4.31-4.24 (m, 2-H, $\mathrm{CH}_{2}-\mathrm{Fmoc}$ ), 4.23-4.19 (m, 1-H, CH-Fmoc), 3.92-3.88 (m, 1-H, $\alpha-\mathrm{CH}), 3.29\left(\mathrm{t},{ }^{3} \mathrm{~J}_{\mathrm{H}-\mathrm{H}}=6.6 \mathrm{~Hz}, 2-\mathrm{H}, \mathrm{CONCH}_{2}\right), 2.83\left(\mathrm{~s}_{\mathrm{br}}, 3-\mathrm{H}, \mathrm{CONCH}_{3}\right)$, $2.44\left(\mathrm{t},{ }^{3} \mathrm{~J}_{\mathrm{H}-\mathrm{H}}=6.6 \mathrm{~Hz}, 2-\mathrm{H}, \mathrm{NCH}_{2}\right), 2.33\left(\mathrm{~s}_{\mathrm{br}}, 2-\mathrm{H}, \delta-\mathrm{CH}_{2}\right), 2.16\left(\mathrm{~s}, 3-\mathrm{H}, \mathrm{NCH}_{3}\right), 1.74-1.68(\mathrm{~m}$, 1- $\left.\mathrm{H}, \beta-\mathrm{CH}_{2}\right), 1.62-1.56\left(\mathrm{~m}, 1-\mathrm{H}, \beta-\mathrm{CH}_{2}\right), 1.49-1.41\left(\mathrm{~m}, 2-\mathrm{H}, \gamma-\mathrm{CH}_{2}\right)$.

${ }^{13} \mathrm{C}-\mathrm{NMR}\left(125 \mathrm{MHz}, \mathrm{DMSO}-\mathrm{d}_{6}\right): \delta(\mathrm{ppm})=174.2(\mathrm{COOH}), 155.8$ (CO-Fmoc), 155.1 (COAlloc), 143.7 (C6-Fmoc), 140.7 (C5-Fmoc), 133.52 (CH=Alloc), 127.5 (C3-Fmoc), 127.0 (C2-Fmoc), 125.2 (C1-Fmoc), 120.0 (C4-Fmoc), 116.7 (= $\mathrm{CH}_{2} \mathrm{Alloc}$ ), 65.5 ( $\mathrm{CH}_{2} \mathrm{Alloc}$ ), 65.0 $\left(\mathrm{CH}_{2} \mathrm{Fmoc}\right), 56.7\left(\delta-\mathrm{CH}_{2}\right), 54.7\left(\mathrm{NCH}_{2}\right), 54.1(\alpha-\mathrm{CH}), 46.7(\mathrm{CH}-\mathrm{Fmoc}), 45.8\left(\mathrm{CONCH}_{2}\right), 41.5$ $\left(\mathrm{NCH}_{3}\right), 33.9\left(\mathrm{CONCH}_{3}\right), 29.1\left(\beta-\mathrm{CH}_{2}\right), 23.0\left(\gamma-\mathrm{CH}_{2}\right)$.

ESI-MS m/z: $510.3[\mathrm{M}+\mathrm{H}]^{+}, 532.3[\mathrm{M}+\mathrm{Na}]^{+}, 548.2[\mathrm{M}+\mathrm{K}]^{+}, 1019.5[2 \mathrm{M}+\mathrm{H}]^{+}$.

ESI-HRMS: calculated for $\left[\mathrm{C}_{28} \mathrm{H}_{36} \mathrm{~N}_{3} \mathrm{O}_{6}\right]^{+}\left([\mathrm{M}+\mathrm{H}]^{+}\right)=510.2599$, found $=510.2601$. 


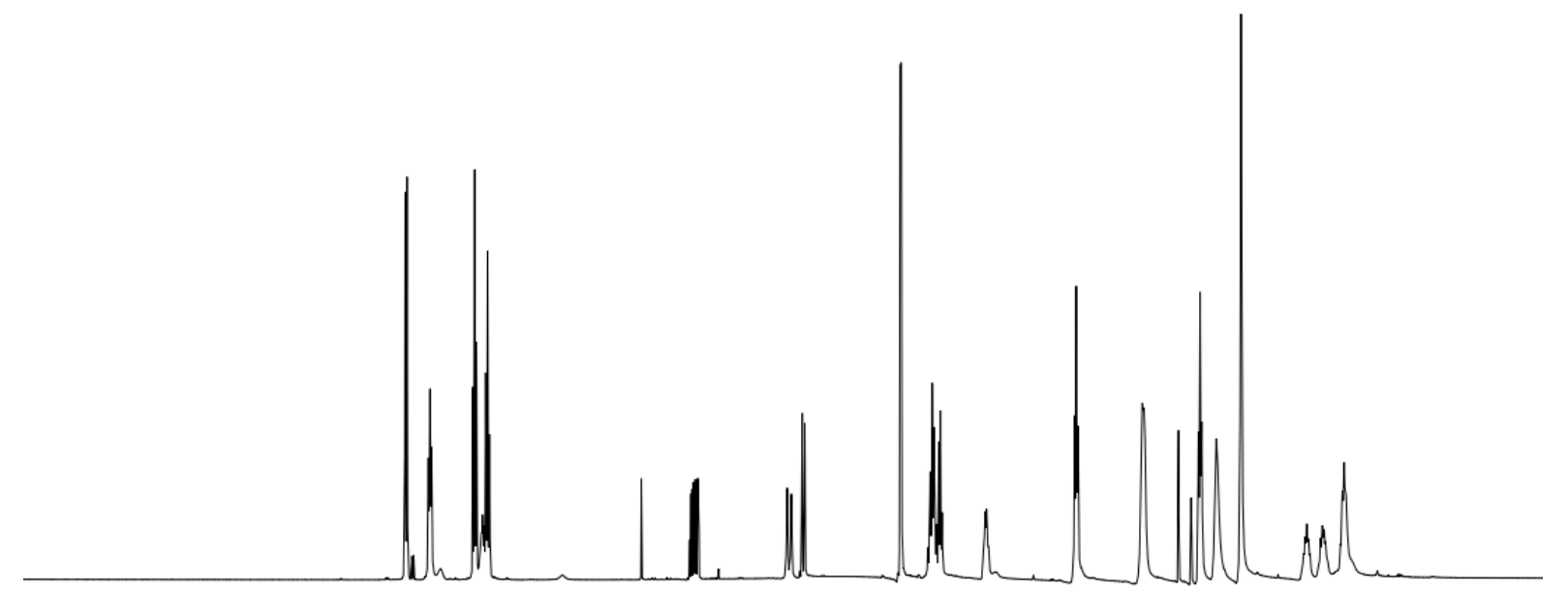

$\begin{array}{llllllllllllllllllll}10.0 & 9.5 & 9.0 & 8.5 & 8.0 & 7.5 & 7.0 & 6.5 & 6.0 & \begin{array}{c}5.5 \\ \mathrm{f} 1(\mathrm{ppm})\end{array} & 4.0 & 4.0 & 3.5 & 3.0 & 2.5 & 2.0 & 1.5 & 1.0 & 0.5\end{array}$

Figure 7.3: ${ }^{1} \mathrm{H}-\mathrm{NMR}$ spectra of $(S)-\mathrm{N}-(((9 \mathrm{H}-$ fluoren-9-yl)methoxy)carbonyl)- $\delta$-(2-(allyloxycarbonyl)$N, N^{\prime}$-dimethylethylene diamino)norvaline benzyl ester 7 .



Figure 7.4: ${ }^{13} \mathrm{C}-\mathrm{NMR}$ spectra of $(S)-N-(((9 \mathrm{H}$-fluoren-9-yl)methoxy)carbonyl)- $\delta$-( $N$-(allyloxycarbonyl)$N, N^{\prime}$-dimethylethylene diamino)pentanoic acid benzyl ester $\mathbf{7}$. 


\subsubsection{Synthesis of the dendrimeric building block}

$\boldsymbol{N}^{\alpha}$-Boc- $\boldsymbol{N}^{\varepsilon}$-dimethyl-L-Lysine ${ }^{[125]}$

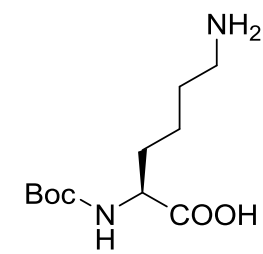

8

$\mathrm{C}_{11} \mathrm{H}_{22} \mathrm{~N}_{2} \mathrm{O}_{4}$

$246.31 \mathrm{~g} / \mathrm{mol}$

$$
\underset{\text { r.t., } 24 \mathrm{~h}, 82 \%}{\stackrel{37 \% \mathrm{CH}_{2} \mathrm{O}, \mathrm{H}_{2} / \mathrm{Pd} / \mathrm{C}}{\longrightarrow}}
$$

$\mathrm{C}_{13} \mathrm{H}_{26} \mathrm{~N}_{2} \mathrm{O}_{4}$

$274.36 \mathrm{~g} / \mathrm{mol}$

Boc-Lysine 8 (5 g, $20.3 \mathrm{mmol}, 1 \mathrm{eq})$ was dissolved in $\mathrm{MeOH}(200 \mathrm{~mL})$ and it this solution $37 \%$ of formaldehyde $(9.3 \mathrm{~mL}, 295 \mathrm{mmol}, 14.53 \mathrm{eq}$ ) was added dropwise over a period of 5 min while stirring continuously. The solution was degassed thoroughly by purging with argon followed by addition of $18 \mathrm{~g}$ of $\mathrm{Pd} / \mathrm{C}(5 \mathrm{wt} \%)$. Thereafter, the flask was flushed with $\mathrm{H}_{2}$ gas and then a balloon filled with $\mathrm{H}_{2}$ was attached to it. After stirring the reaction mixture at room temperature for $24 \mathrm{~h}$ the solid components were filtered by passing through a celite bed. Purification by column chromatography [eluent: Acetone/water, $3 / 1(\mathrm{v} / \mathrm{v})$ ] yielded $\mathrm{N}^{\alpha}$-boc- $\mathrm{N}^{\varepsilon}$-dimethyl-L-Lysine 9 (4.56 g, $\left.16.62 \mathrm{mmol}, 82 \%\right)$ as a white solid.

$\boldsymbol{R}_{\mathrm{f}}=0.6$ (Acetone/Water $\left.=3 / 1, \mathrm{v} / \mathrm{v}\right)$.

${ }^{1} \mathrm{H}-\mathrm{NMR}\left(300 \mathrm{MHz}, \mathrm{CD}_{3} \mathrm{OD}-\mathrm{d}_{4}\right): \delta(\mathrm{ppm})=3.95-3.91(\mathrm{~m}, 1-\mathrm{H}, \alpha-\mathrm{H}), 3.04\left(\mathrm{t},{ }^{3} \mathrm{~J}_{\mathrm{H}-\mathrm{H}}=8.1 \mathrm{~Hz}, 2-\right.$ $\left.\mathrm{H}, \varepsilon-\mathrm{CH}_{2}\right), 2.81\left(\mathrm{~s}, 6-\mathrm{H}, \mathrm{N}\left(\mathrm{CH}_{3}\right)_{2}\right), 1.84-1.62\left(\mathrm{~m}, 4-\mathrm{H}, \beta-\mathrm{CH}_{2}, \delta-\mathrm{CH}_{2}\right)$ 1.50-1.32 (m, 11- $\mathrm{H}$, ${ }^{t} \mathrm{Boc}^{-} \mathrm{CH}_{3}, \mathrm{Y}-\mathrm{CH}_{2}$ ). 
${ }^{13} \mathrm{C}-\mathrm{NMR}\left(125 \mathrm{MHz}, \mathrm{CD}_{3} \mathrm{OD}-\mathrm{d}_{4}\right): \delta(\mathrm{ppm})=179.5(\mathrm{COOH}), 157.6\left[\mathrm{CO}-\mathrm{C}\left(\mathrm{CH}_{3}\right)_{3}\right], 80.0$ $\left[\mathrm{CO}-\mathrm{C}\left(\mathrm{CH}_{3}\right)_{3}\right], 58.6(\varepsilon-\mathrm{C}), 56.6(\alpha-\mathrm{C}), 43.3\left[\mathrm{~N}\left(\mathrm{CH}_{3}\right)_{2}\right], 33.6(\beta-\mathrm{C}), 28.8\left[\mathrm{CO}-\mathrm{C}\left(\mathrm{CH}_{3}\right)_{3}\right], 25.2(\delta-$ C), $23.6(\gamma-C)$.

ESI-MS m/z: $275.2[\mathrm{M}+\mathrm{H}]^{+}, 297.2[\mathrm{M}+\mathrm{Na}]^{+}, 549.4[2 \mathrm{M}+\mathrm{H}]^{+}, 571.4[2 \mathrm{M}+\mathrm{Na}]^{+}, 273.2[\mathrm{M}-\mathrm{H}]^{-}$, $547.4[2 \mathrm{M}-\mathrm{H}]^{-}$.

ESI-HRMS: calculated for $\left[\mathrm{C}_{13} \mathrm{H}_{27} \mathrm{~N}_{2} \mathrm{O}_{4}\right]^{+}\left([\mathrm{M}+\mathrm{H}]^{+}\right)=275.1965$, found = 275.1969; calculated for $\left[\mathrm{C}_{13} \mathrm{H}_{25} \mathrm{~N}_{2} \mathrm{O}_{4}\right]^{-}\left([\mathrm{M}-\mathrm{H}]^{-}\right)=273.1820$, found $=273.1824$.

7.5.3. Synthesis of the linking unit between the dendrimeric and the cyclic peptide

$\boldsymbol{N}_{\boldsymbol{\alpha}}$-Fmoc-L-Diaminopropionic acid ${ }^{[126]}$<smiles>NC(=O)CC(NC(=O)OCC1c2ccccc2-c2ccccc21)C(=O)O</smiles>

10

$\mathrm{C}_{19} \mathrm{H}_{18} \mathrm{~N}_{2} \mathrm{O}_{5}$ $354.36 \mathrm{~g} / \mathrm{mol}$
PIDA,

EtOAc, n-propanol, $\mathrm{H}_{2} \mathrm{O}$

$1 \mathrm{~h}, 25^{\circ} \mathrm{C}$

$5 \mathrm{~h}, 32{ }^{\circ} \mathrm{C}, 60 \%$

11

$\mathrm{C}_{18} \mathrm{H}_{18} \mathrm{~N}_{2} \mathrm{O}_{4}$ $326.35 \mathrm{~g} / \mathrm{mol}$

To a suspension of $\mathrm{N \alpha}$-(Fmoc)-L-Asparginine 10 (2.0 g, $5.64 \mathrm{mmol}, 1 \mathrm{eq})$ in ethylacetate $(20 \mathrm{~mL}), \mathrm{n}$-propanol $(20 \mathrm{~mL})$ and water $(20 \mathrm{~mL})$ was added PIDA (2.36 g, $7.33 \mathrm{mmol}, 1.3$ eq). After stirring the solution at room temperature for $1 \mathrm{~h}$ at $25^{\circ} \mathrm{C}$ and $5 \mathrm{~h}$ at $32{ }^{\circ} \mathrm{C}$ the 
reaction mixture was filtered and the filter cake was washed with propanol $(2 \times 10 \mathrm{~mL})$, methanol $(2 \times 10 \mathrm{~mL})$ and ethyl acetate $(2 \times 10 \mathrm{~mL})$. After drying the residue under vacuum the product $N_{\alpha}$-Fmoc-L-Diaminopropionic acid 11 (1.1 g, $\left.3.37 \mathrm{mmol}, 60 \%\right)$ was obtained as a white solid.

${ }^{1} \mathrm{H}-\mathrm{NMR}\left(300 \mathrm{MHz}, \mathrm{DMSO}-\mathrm{d}_{6}\right): \delta(\mathrm{ppm})=12.48\left(\mathrm{~s}_{\mathrm{br}}, 1-\mathrm{H}, \mathrm{COOH}\right), 7.88\left(\mathrm{~d},{ }^{3} \mathrm{~J}_{\mathrm{H}-\mathrm{H}}=7.4 \mathrm{~Hz}, 2-\right.$ $\mathrm{H}, \mathrm{C} 4-\mathrm{Fmoc}$ ), 7.70 (d, $\left.{ }^{3} \mathrm{~J}_{\mathrm{H}-\mathrm{H}}=7.4 \mathrm{~Hz}, 2-\mathrm{H}, \mathrm{C} 1-\mathrm{Fmoc}\right), 7.40$ (t, ${ }^{3} \mathrm{~J}_{\mathrm{H}-\mathrm{H}}=7.4 \mathrm{~Hz}, 2-\mathrm{H}, \mathrm{C} 3-\mathrm{Fmoc}$ ), $7.31\left(\mathrm{t}, 2-\mathrm{H},{ }^{3} \mathrm{~J}_{\mathrm{H}-\mathrm{H}}=7.4 \mathrm{~Hz}, \mathrm{C} 2-\mathrm{Fmoc}\right), 6.76\left(\mathrm{~s}_{\mathrm{br}}, 1-\mathrm{H}, \mathrm{NH}-\mathrm{Boc}\right), 6.30\left(\mathrm{~s}_{\mathrm{br}}, 2-\mathrm{H}, \mathrm{NH}_{2}\right), 4.31$ (d, $\left.{ }^{3} J_{\mathrm{H}-\mathrm{H}}=6.9 \mathrm{~Hz}, 2-\mathrm{H}, \mathrm{Fmoc}-\mathrm{CH}_{2}\right), 4.20\left(\mathrm{t},{ }^{3} \mathrm{~J}_{\mathrm{H}-\mathrm{H}}=5.9 \mathrm{~Hz}, 1-\mathrm{H}, \mathrm{Fmoc}-\mathrm{CH}, 4.09\left(\mathrm{dd},{ }^{3} \mathrm{~J}_{\mathrm{H}-\mathrm{H}}=7.1\right.\right.$ $\mathrm{Hz}, 1-\mathrm{H}$, Dap- $\left.\mathrm{H}_{\alpha}\right)$, 3.31-3.24 (m, 2-H, Dap- $\left.\mathrm{H}_{\beta}\right)$.

ESI-MS m/z: $327.1[\mathrm{M}+\mathrm{H}]^{+}, 349.1[\mathrm{M}+\mathrm{Na}]^{+}, 675.2[2 \mathrm{M}+\mathrm{Na}]^{+}, 325.1[\mathrm{M}-\mathrm{H}]^{-}, 651.3[2 \mathrm{M}-\mathrm{H}]^{-}$.

ESI-HRMS: calculated for $\left[\mathrm{C}_{18} \mathrm{H}_{19} \mathrm{~N}_{2} \mathrm{O}_{4}\right]^{+}\left([\mathrm{M}+\mathrm{H}]^{+}\right)=327.1339$, found = 327.1335; calculated for $\left[\mathrm{C}_{18} \mathrm{H}_{18} \mathrm{~N}_{2} \mathrm{O}_{4} \mathrm{Na}\right]^{+}\left([\mathrm{M}+\mathrm{Na}]^{+}\right)=349.1159$, found $=349.1147$; calculated for $\left[\mathrm{C}_{18} \mathrm{H}_{17} \mathrm{~N}_{2} \mathrm{O}_{4}\right]^{-}\left([\mathrm{M}-\mathrm{H}]^{-}\right)=325.1194$, found $=325.1191$.

\section{$\boldsymbol{N}_{\alpha}$-Fmoc- $\boldsymbol{N}_{\boldsymbol{B}}$-Alloc-L-2,3-Diaminopropionic acid ${ }^{[215]}$}

11

$\mathrm{C}_{18} \mathrm{H}_{18} \mathrm{~N}_{2} \mathrm{O}_{4}$ $326.35 \mathrm{~g} / \mathrm{mol}$
Allyl chloroformate $\underset{6 \text { h, r.t., } 78 \%}{\stackrel{\mathrm{Na}_{2} \mathrm{CO}_{3} \text {, dioxane, } \mathrm{H}_{2} \mathrm{O}}{\longrightarrow}}$ 12 $\mathrm{C}_{22} \mathrm{H}_{22} \mathrm{~N}_{2} \mathrm{O}_{6}$ $410.43 \mathrm{~g} / \mathrm{mol}$ 
Allyl chloroformate $(0.54 \mathrm{~mL}, 5.06 \mathrm{mmol} 1.5 \mathrm{eq})$ was added dropwise at $0{ }^{\circ} \mathrm{C}$ to a solution of $\mathrm{N}_{\alpha}$-Fmoc-L-Diaminopropionic acid 11 (1.1 g, $\left.3.37 \mathrm{mmol}, 1 \mathrm{eq}\right)$ and $\mathrm{Na}_{2} \mathrm{CO}_{3}(1.79 \mathrm{~g}$, $16.85 \mathrm{mmol}, 5 \mathrm{eq})$ in Dioxane/water $(1 / 1,30 \mathrm{~mL})$. After the reaction mixture was allowed to stir at $0{ }^{\circ} \mathrm{C}$ for $40 \mathrm{~min}$ it was acidified to $\mathrm{pH}^{\sim 1-2}$ by addition of $10 \% \mathrm{HCl}$ and extracted with DCM $(3 \times 30 \mathrm{~mL})$. Purification by column chromatography [eluent: $\mathrm{MeOH} / \mathrm{DCM}, 1 / 9$ (v/v)] yielded $N_{\alpha}$-Fmoc- $N_{B}$-Alloc-L-2,3-Diaminopropionic acid 12 (1.08 g, 2.63 mmol, 78\%) as white solid.

$\boldsymbol{R}_{\mathrm{f}}=0.38(\mathrm{MeOH} / \mathrm{DCM}=1 / 4, \mathrm{v} / \mathrm{v})$.

${ }^{1} \mathrm{H}-\mathrm{NMR}\left(300 \mathrm{MHz}, \mathrm{CD}_{3} \mathrm{OD}-\mathrm{d}_{4}\right): \delta(\mathrm{ppm})=7.74\left(\mathrm{~d},{ }^{3} \mathrm{~J}_{\mathrm{H}-\mathrm{H}}=4.5 \mathrm{~Hz}, 2-\mathrm{H}, \mathrm{C} 4-\mathrm{Fmoc}\right), 7.62$ (dd, $\left.{ }^{4} J_{\mathrm{H}-\mathrm{H}}=1.5 \mathrm{~Hz},{ }^{3} \mathrm{~J}_{\mathrm{H}-\mathrm{H}}=4.35,2-\mathrm{H}, \mathrm{C} 1-\mathrm{Fmoc}\right), 7.34\left(\mathrm{t},{ }^{3} J_{\mathrm{H}-\mathrm{H}}=4.5 \mathrm{~Hz}, \mathrm{C} 3-\mathrm{Fmoc}\right), 7.28-7.24(\mathrm{~m}, 2-$ $\mathrm{H}, \mathrm{C} 2-\mathrm{Fmoc}$ ), 5.91-5.83 (m, 1- $\left.\mathrm{H}, \mathrm{CH}_{2}=\mathrm{CH}\right), 5.26-5.10\left(\mathrm{~m}, 2-\mathrm{H}, \mathrm{CH}_{2}=\mathrm{CH}\right), 4.49\left(\mathrm{~d},{ }^{3} \mathrm{~J}_{\mathrm{H}-\mathrm{H}}=3.3\right.$ $\left.\mathrm{Hz}, 2-\mathrm{H}, \mathrm{Fmoc}-\mathrm{CH}_{2}\right)$, 4.34-4.27 (m, 3-H, Dap- $\left.\mathrm{H}_{\alpha}, 2-\mathrm{H}, \mathrm{CH}_{2}=\mathrm{CH}-\mathrm{CH}_{2}-\right), 4.17\left(\mathrm{t},{ }^{3} \mathrm{~J}_{\mathrm{H}-\mathrm{H}}=4.2 \mathrm{~Hz}\right.$, 1-H, Fmoc-CH), 3.61-3.41 (m, 2-H, Dap- $\left.\mathrm{H}_{\beta}\right)$.

${ }^{13} \mathrm{C}-\mathrm{NMR}\left(125 \mathrm{MHz}, \mathrm{CD}_{3} \mathrm{OD}-\mathrm{d}_{4}\right): \delta(\mathrm{ppm})=173.6(\mathrm{COOH}), 158.9$ (CO-Fmoc), 158.5 (COAlloc), 145.2 (C6-Fmoc), 142.5 (C5-Fmoc), 134.3 (CH=Alloc), 128.7 (C3-Fmoc), 128.1 (C2-Fmoc), 126.3 (C1-Fmoc), 120.9 (C4-Fmoc), 117.5 (= $\mathrm{CH}_{2} \mathrm{Alloc}$ ), 68.2 ( $\mathrm{CH}_{2} \mathrm{Alloc}$ ), 66.6 ( $\left.\mathrm{CH}_{2} \mathrm{Fmoc}\right), 55.7$ ( $\left.\alpha-\mathrm{CH}\right), 48.3$ (CH-Fmoc), $43.0\left(\beta-\mathrm{CH}_{2}\right)$.

ESI-MS m/z: $433.2[\mathrm{M}+\mathrm{Na}]^{+}, 843.3[2 \mathrm{M}+\mathrm{Na}]^{+}, 409.1[\mathrm{M}-\mathrm{H}]^{-}, 819.3[2 \mathrm{M}-\mathrm{H}]^{-}$.

ESI-HRMS: calculated for $\left[\mathrm{C}_{22} \mathrm{H}_{22} \mathrm{~N}_{2} \mathrm{O}_{6} \mathrm{Na}\right]^{+}\left([\mathrm{M}+\mathrm{Na}]^{+}\right)=433.1370$, found $=433.1372$. 


\subsection{Synthesis of IHF Mimicking Peptides}

\subsubsection{Synthesis of the cyclic peptide}

H-DapD(Alloc)ProGlyArg(Pbf)Asn(Trt)ProLys(Boc)Thr(tBoc)GlyGlu(tBu)Asp(tBu)

Ile-OH

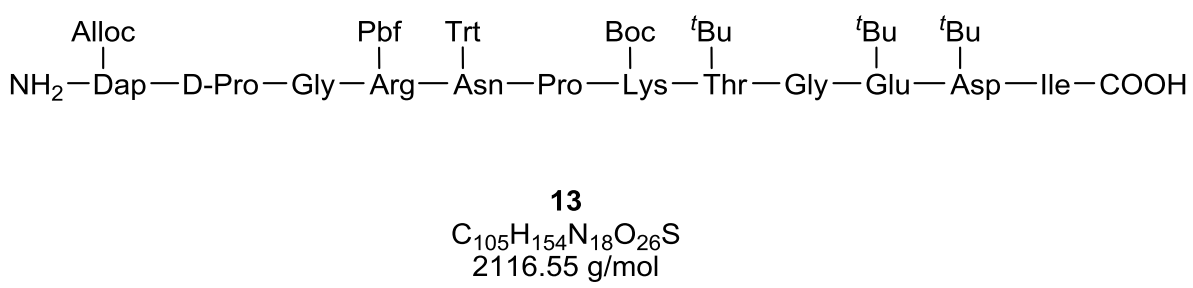

The linear peptide 13 was synthesized using 2-chlorotrityl resin preloaded with isoleucine. The synthesis was carried out at a scale of $0.1 \mathrm{mmol}$ in accordance with the Fmoc automated SPPS protocol (mentioned in section 7.3). Cleavage of the peptide from the resin using 30\% HFIP in DCM followed by HPLC purification yielded the peptide 13 (165.1 mg, $0.078 \mathrm{mmol}, 78 \%$ ) as a white solid.

HPLC Purification: Column Pep 1 (MN_Nucleodur100_5_C18, RP-C18, preparative, $250 \times 21.0 \mathrm{~mm}, 5 \mu \mathrm{m}), \quad 10-60 \%$ gradient of $B$ in $30 \mathrm{~min}$, flow rate $10 \mathrm{~mL} / \mathrm{min}, t_{R}=$ $36.8 \mathrm{~min}$.

ESI-MS m/z: $1070.1[\mathrm{M}+\mathrm{H}+\mathrm{Na}]^{2+}, 2117.1[\mathrm{M}+\mathrm{H}]^{1+}$.

ESI-HRMS: calculated for $\left[\mathrm{C}_{105} \mathrm{H}_{156} \mathrm{~N}_{18} \mathrm{O}_{26} \mathrm{~S}\right]^{2+}\left([\mathrm{M}+2 \mathrm{H}]^{2+}\right)=1059.0589$, found = 1059.0597; calculated for $\left[\mathrm{C}_{105} \mathrm{H}_{155} \mathrm{~N}_{18} \mathrm{O}_{26} \mathrm{~S}\right]^{+}\left([\mathrm{M}+\mathrm{H}]^{+}\right)=2117.1106$, found $=2117.1113$; calculated for $\left[\mathrm{C}_{105} \mathrm{H}_{154} \mathrm{~N}_{18} \mathrm{O}_{26} \mathrm{SNa}\right]^{+}\left([\mathrm{M}+\mathrm{Na}]^{+}\right)=2139.0925$, found $=2139.0909$. 


\section{Asp(tBu)lle-]}

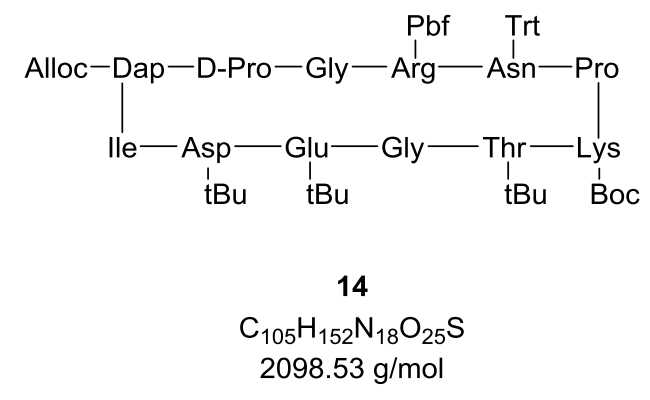

The linear peptide 13 (165.1 $\mathrm{mg}, 0.078 \mathrm{mmol}, 1 \mathrm{eq})$ was dissolved in a mixture of anhydrous DCM/DMF ( $80 \mathrm{~mL}, 9: 1)$ under argon atmosphere. To it DIC (10 eq), NMM (3 eq) and HOAt (1 eq) were added while stirring vigorously and solution was continued to stir for $48 \mathrm{~h}$ at room temperature. After the solvent was removed under reduced pressure purification of the crude product using RP-HPLC yielded the alloc protected cyclo peptide 14 (134.22 $\mathrm{mg}, 0.064 \mathrm{mmol}, 82 \%)$ as a white solid.

HPLC Purification: Column Pep 2 (MN_Nucleodur100_5_C18, RP-C18, semi-preparative, $250 \times 10 \mathrm{~mm}, 5 \mu \mathrm{m}), 80-100 \%$ gradient of $B$ in $30 \mathrm{~min}$, flow rate $3 \mathrm{~mL} / \mathrm{min}, t_{R}=15.04 \mathrm{~min}$.

ESI-MS m/z: $2121.0[\mathrm{M}+\mathrm{Na}]^{+}, 2099.1[\mathrm{M}+\mathrm{H}]^{+}, 1050.0[\mathrm{M}+2 \mathrm{H}]^{2+}$.

ESI-HRMS: calculated for $\left[\mathrm{C}_{105} \mathrm{H}_{153} \mathrm{~N}_{18} \mathrm{O}_{25} \mathrm{~S}\right]\left([\mathrm{M}+\mathrm{H}]^{+}\right)=2099.1000$, found = 2099.1007; calculated for $\left[\mathrm{C}_{105} \mathrm{H}_{152} \mathrm{~N}_{18} \mathrm{O}_{25} \mathrm{SNa}\right]^{+}\left([\mathrm{M}+\mathrm{Na}]^{+}\right)=2120.0819$, found = 2120.0819; calculated for $\left[\mathrm{C}_{105} \mathrm{H}_{154} \mathrm{~N}_{18} \mathrm{O}_{25} \mathrm{~S}\right]^{2+}\left([\mathrm{M}+2 \mathrm{H}]^{2+}\right)=1050.0536$, found $=1050.0550$. 
cyclo[-DapDProGlyArg(Pbf)Asn(Trt)ProLys(Boc)Thr(tBoc)GlyGlu(tBu)Asp(tBu)Ile-]

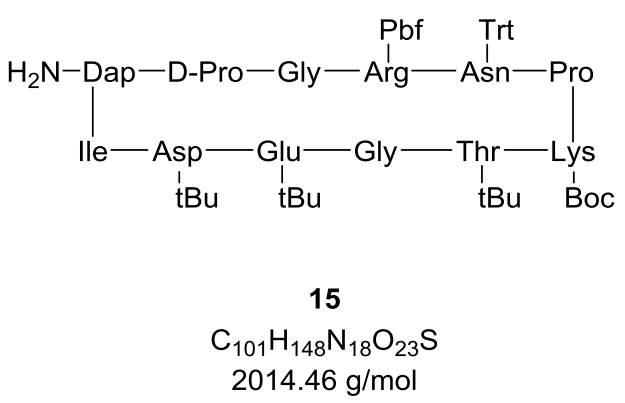

The alloc protected cyclic peptide 14 (75 mg, $36 \mu \mathrm{mol}, 1$ eq) was dissolved in $7 \mathrm{~mL}$ of dry DMF under argon atmosphere. To it was added dimethylborane complex $\mathrm{Me}_{2} \mathrm{NH} . \mathrm{BH}_{3}$ (85 mg, $1.44 \mathrm{mmol}, 40 \mathrm{eq}$ ) and tetrakis(triphenylphosphine)palladium(0) $\mathrm{Pd}\left(\mathrm{PPh}_{3}\right)_{4}$ (4.2 $\mathrm{mg}, 3.6 \mu \mathrm{mol}, 0.1 \mathrm{eq}$ ) and the mixture was allowed to stir at room temperature for $6 \mathrm{~h}$. Thereafter, the solvent was removed under reduced pressure and the residue was purified by RPLC. The alloc deprotected cyclo peptide 15 (53 mg, $26.3 \mu \mathrm{mol}, 73 \%$ ) was obtained as a white solid.

HPLC Purification: Column Pep 1 (MN_Nucleodur100_5_C18, RP-C18, preparative, $250 \times 21.0 \mathrm{~mm}, 5 \mu \mathrm{m}), \quad 70-100 \%$ gradient of $B$ in $30 \mathrm{~min}$, flow rate $10 \mathrm{~mL} / \mathrm{min}, t_{R}=$ $20.4 \mathrm{~min}$.

ESI-MS m/z: $1008.1[\mathrm{M}+2 \mathrm{H}]^{2+}, 2015.1[\mathrm{M}+\mathrm{H}]^{+}, 1019.1[\mathrm{M}+\mathrm{H}+\mathrm{Na}]^{2+}$.

ESI-HRMS: calculated for $\left[\mathrm{C}_{101} \mathrm{H}_{149} \mathrm{~N}_{18} \mathrm{O}_{23} \mathrm{~S}\right]^{+}\left([\mathrm{M}+\mathrm{H}]^{+}\right)=2015.0788$, found $=2015.0757$; calculated for $\left[\mathrm{C}_{101} \mathrm{H}_{150} \mathrm{~N}_{18} \mathrm{O}_{23} \mathrm{~S}\right]^{2+}\left([\mathrm{M}+2 \mathrm{H}]^{2+}\right)=1008.0431$, found = 1008.0414; calculated for $\left[\mathrm{C}_{101} \mathrm{H}_{149} \mathrm{~N}_{18} \mathrm{O}_{23} \mathrm{SNa}\right]^{2+}\left([\mathrm{M}+\mathrm{H}+\mathrm{Na}]^{2+}\right)=1019.5357$, found $=1019.5354$. 


\section{cyclo[-DapD-ProGlyArgAsnProLysThrGlyGluAsplle-]}

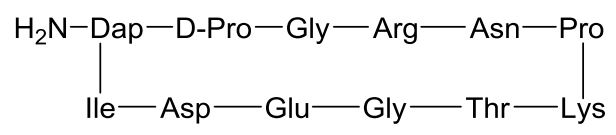

P2

$\mathrm{C}_{52} \mathrm{H}_{86} \mathrm{~N}_{18} \mathrm{O}_{18}$

$1250.37 \mathrm{~g} / \mathrm{mol}$

The cyclic peptide 15 ( $5 \mathrm{mg}, 2.48 \mu \mathrm{mol}, 1 \mathrm{eq}$ ) was dissolved in 95\% of TFA in $\mathrm{H}_{2} \mathrm{O}(1.5 \mathrm{~mL})$ and the mixture was stirred at room temperature for $45 \mathrm{~min}$. Thereafter, the solvent was evaporated by blow drying with air. The crude product was precipitated out by pouring pre-cooled diethylether. Cold centrifugation followed by decanting the supernatant, lyophilization from water and purification by RP-HLPC yielded the peptide P2 $(2.12 \mathrm{mg}$, $1.69 \mu \mathrm{mol}, 68 \%)$ as a white solid.

HPLC Purification: Column Pep 1 (MN_Nucleodur100_5_C18, RP-C18, preparative, $250 \times 21.0 \mathrm{~mm}, 5 \mu \mathrm{m}), 60-100 \%$ gradient of $B$ in $30 \mathrm{~min}$, flow rate $10 \mathrm{~mL} / \mathrm{min}$, $t_{R}=13.2 \mathrm{~min}$.

ESI-MS $m / z: 1251.7[\mathrm{M}+\mathrm{H}]^{+}, 626.3[\mathrm{M}+2 \mathrm{H}]^{2+}$.

ESI-HRMS: calculated for $\left[\mathrm{C}_{52} \mathrm{H}_{87} \mathrm{~N}_{18} \mathrm{O}_{18}\right]^{+}\left([\mathrm{M}+\mathrm{H}]^{+}\right)=1251.6440$, found $=1251.6442$; calculated for $\left[\mathrm{C}_{52} \mathrm{H}_{88} \mathrm{~N}_{18} \mathrm{O}_{18}\right]^{2+}\left([\mathrm{M}+2 \mathrm{H}]^{2+}\right)=626.3257$, found $=626.3260$. 


\subsubsection{Synthesis of IHF-1}

\section{$\left[\text { Boc-Lys }(\mathrm{Me})_{2}\right]_{4} \mathrm{Lys}_{2} \mathrm{LysGly}_{7}-\mathrm{OH}$}

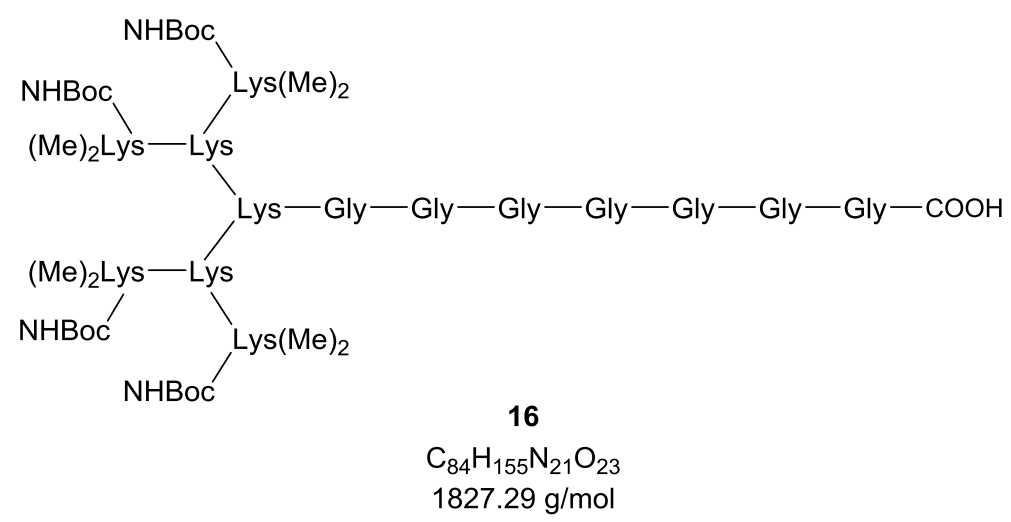

The synthesis of the lysine dendrimer was performed manually according the procedure (mentioned in section 7.3). Cleavage of the peptide from the resin using $30 \%$ (HFIP) in DCM followed by purification with RP-HPLC yielded the peptide 16 (113 mg, $62 \mu \mathrm{mol}$, $62 \%)$ as a white solid.

HPLC Purification: Column Pep 1 (MN_Nucleodur100_5_C18, RP-C18, preparative, $250 \times 21.0 \mathrm{~mm}, 5 \mu \mathrm{m}), \quad 20-40 \%$ gradient of $B$ in $30 \mathrm{~min}$, flow rate $10 \mathrm{~mL} / \mathrm{min}, t_{R}=$ $8.9 \mathrm{~min}$.

ESI-MS m/z: $1828.2[\mathrm{M}+\mathrm{H}]^{+}, 914.6[\mathrm{M}+2 \mathrm{H}]^{2+}, 610.1[\mathrm{M}+3 \mathrm{H}]^{3+}, 457.0[\mathrm{M}+4 \mathrm{H}]^{4+}$.

ESI-HRMS: calculated for $\left[\mathrm{C}_{84} \mathrm{H}_{156} \mathrm{~N}_{21} \mathrm{O}_{23}\right]^{+}\left([\mathrm{M}+\mathrm{H}]^{+}\right)=1828.1710$, found $=1828.1671$; calculated for $\left[\mathrm{C}_{84} \mathrm{H}_{155} \mathrm{~N}_{21} \mathrm{O}_{23} \mathrm{Na}\right]^{+}\left([\mathrm{M}+\mathrm{Na}]^{+}\right)=1850.1529$, found $=1850.1501$; calculated for $\left[\mathrm{C}_{84} \mathrm{H}_{157} \mathrm{~N}_{21} \mathrm{O}_{23}\right]^{2+}\left([\mathrm{M}+2 \mathrm{H}]^{2+}\right)=914.5891$, found $=914.5898$; calculated for $\left[\mathrm{C}_{84} \mathrm{H}_{158} \mathrm{~N}_{21} \mathrm{O}_{23}\right]^{3+}\left([\mathrm{M}+3 \mathrm{H}]^{3+}\right)=610.0618$, found $=610.0627$; calculated for $\left[\mathrm{C}_{84} \mathrm{H}_{159} \mathrm{~N}_{21} \mathrm{O}_{23}\right]^{4+}\left([\mathrm{M}+4 \mathrm{H}]^{4+}\right)=457.5474$, found $=457.5485$. 


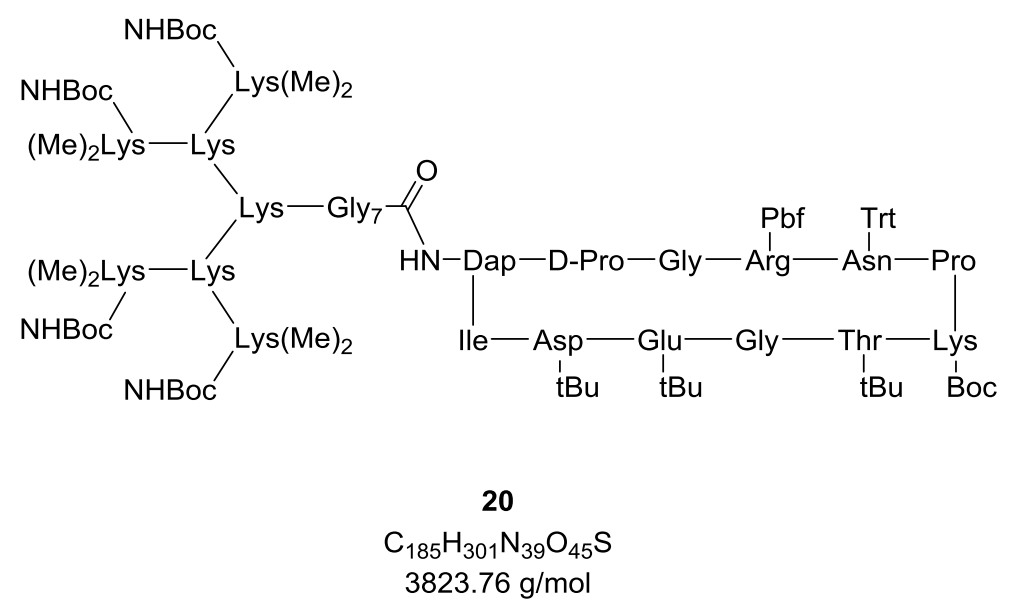

The dendrimer 16 (60 mg, $32.83 \mu \mathrm{mol}, 2$ eq) was dissolved in dry DMF (3.5 mL) under argon atmosphere and to it were added DIC (13.8 $\mu \mathrm{L}, 0.131 \mathrm{mmol}, 8 \mathrm{eq}), \mathrm{NMM}(18.1 \mu \mathrm{L}$, $0.164 \mathrm{mmol}, 10 \mathrm{eq}$ ) and HOAt (17.69 mg, $0.13 \mathrm{mmol}, 7.9 \mathrm{eq})$. After stirring the mixture at room temperature for $10 \mathrm{~min}$ the cyclic peptide $15(33.1 \mathrm{mg}, 16.42 \mu \mathrm{mol}, 1 \mathrm{eq})$ was added to it and allowed to stir for additional $48 \mathrm{~h}$. Thereafter, removal of the solvent under vacuum followed by purification of the residue by RP-HPLC yielded the product $\mathbf{2 0}$ (25.73 mg, $6.73 \mu \mathrm{mol}, 41 \%$ ) as a white solid.

HPLC Purification: Column Pep 2 (MN_Nucleodur100_5_C18, RP-C18, semi-preparative, $250 \times 10 \mathrm{~mm}, 5 \mu \mathrm{m}), 30-100 \%$ gradient of $C$ in $30 \mathrm{~min}$, flow rate $3 \mathrm{~mL} / \mathrm{min}, t_{R}=21.4 \mathrm{~min}$.

ESI-MS m/z: $1912.6[\mathrm{M}+2 \mathrm{H}]^{2+}, 1275.4[\mathrm{M}+3 \mathrm{H}]^{3+}, 956.8[\mathrm{M}+4 \mathrm{H}]^{4+}$.

ESI-HRMS: calculated for $\left[\mathrm{C}_{185} \mathrm{H}_{303} \mathrm{~N}_{39} \mathrm{O}_{45} \mathrm{~S}\right]^{2+}\left([\mathrm{M}+2 \mathrm{H}]^{2+}\right)=1912.6197$, found = 1912.6200; calculated for $\left[\mathrm{C}_{185} \mathrm{H}_{304} \mathrm{~N}_{39} \mathrm{O}_{45} \mathrm{~S}\right]^{3+}\left([\mathrm{M}+3 \mathrm{H}]^{3+}\right)=1275.4156$, found = 1275.4166; calculated for $\left[\mathrm{C}_{185} \mathrm{H}_{305} \mathrm{~N}_{39} \mathrm{O}_{45} \mathrm{~S}\right]^{4+}\left([\mathrm{M}+4 \mathrm{H}]^{4+}\right)=956.8135$, found $=956.8151$; calculated for $\left[\mathrm{C}_{185} \mathrm{H}_{306} \mathrm{~N}_{39} \mathrm{O}_{45} \mathrm{~S}\right]^{5+}\left([\mathrm{M}+5 \mathrm{H}]^{5+}\right)=765.7623$, found $=765.6530$. 


\section{[Lys(Me) $\left.)_{2}\right]_{4}$ Lys $_{2}$ LysGly $_{7}$-cyclo [-DapD-ProGlyArgAsnProLysThrGlyGluAsplle-]}

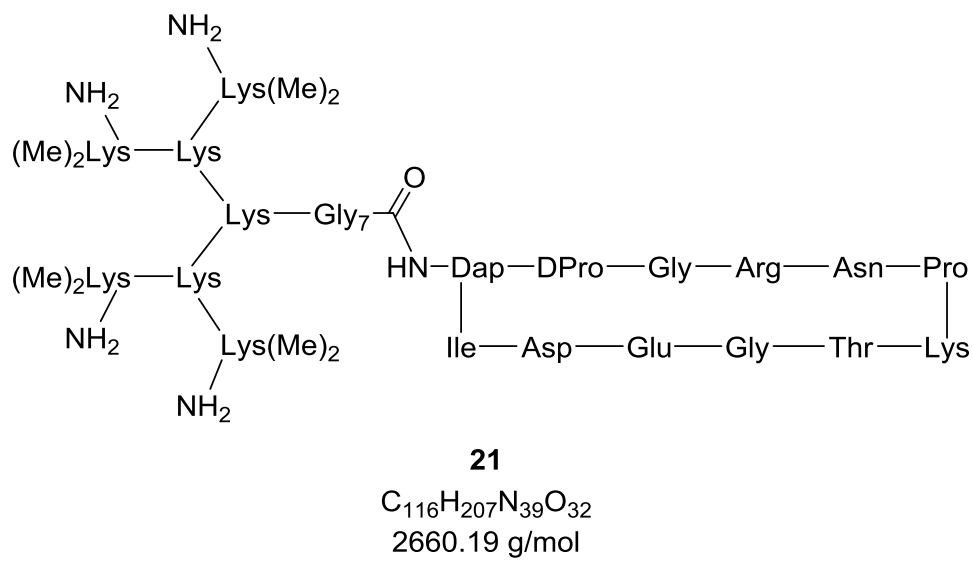

The peptide 20 (25.73 mg, $6.73 \mu \mathrm{mol})$ was dissolved in 95\% TFA in $\mathrm{H}_{2} \mathrm{O}(2 \mathrm{~mL})$ and stirred for $45 \mathrm{~min}$ at room temperature. Thereafter, the solvent was blow dried with argon and the residue was purified by RP-HPLC yielding the product $\mathbf{2 1}(7.34 \mathrm{mg}, 2.76 \mu \mathrm{mol}, 41 \%)$ as a pale yellow crystalline solid.

HPLC Purification: Column Pep 2 (MN_Nucleodur100_5_C18, RP-C18, semi-preparative, $250 \times 10 \mathrm{~mm}, 5 \mu \mathrm{m}), 3-40 \%$ gradient of $C$ in $30 \mathrm{~min}$, flow rate $3 \mathrm{~mL} / \mathrm{min}, t_{R}=17.1 \mathrm{~min}$.

ESI-MS $m / z: 1330.8[\mathrm{M}+2 \mathrm{H}]^{2+}, 887.5[\mathrm{M}+3 \mathrm{H}]^{3+}, 665.9[\mathrm{M}+4 \mathrm{H}]^{4+}, 532.9[\mathrm{M}+5 \mathrm{H}]^{5+}$, $444.3[\mathrm{M}+6 \mathrm{H}]^{6+}$.

ESI-HRMS: calculated for $\left[\mathrm{C}_{116} \mathrm{H}_{209} \mathrm{~N}_{39} \mathrm{O}_{32}\right]^{2+}\left([\mathrm{M}+2 \mathrm{H}]^{2+}\right)=1330.7971$, found $=1330.7987$. 


\subsubsection{Synthesis of IHF-2}

\section{[Boc-Lys(Me) $\left.)_{2}\right]_{4}$ Lys $_{2}$ LysGly-5-(2-(allyloxycarbonyl)-N, $N^{\prime}$-dimethylethylene}

diamino) pentanoic acid-Gly $y_{5}-\mathrm{OH}$

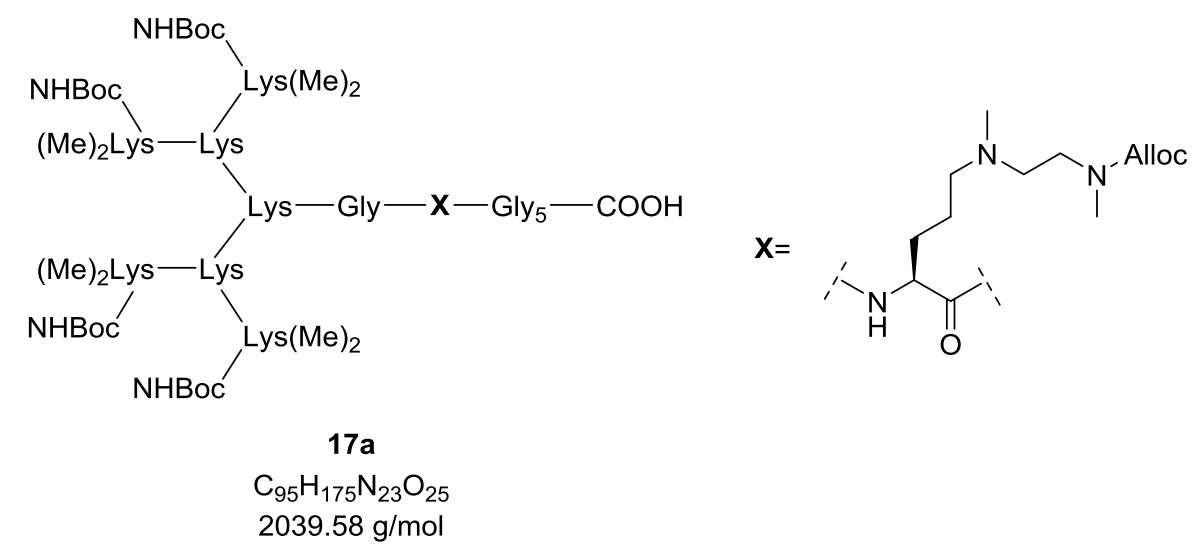

The synthesis of the lysine dendrimer was performed manually according the procedure (mentioned in section 7.3). Cleavage of the peptide from the resin using $30 \%$ (HFIP) in DCM followed by purification with RP-HPLC yielded the peptide 17a (98 mg, $48 \mu \mathrm{mol}$, $48 \%)$ as a white solid.

HPLC Purification: Column Pep 1 (MN_Nucleodur100_5_C18, RP-C18, preparative, $250 \times 21.0 \mathrm{~mm}, 5 \mu \mathrm{m}), \quad 10-60 \%$ gradient of $B$ in $30 \mathrm{~min}$, flow rate $10 \mathrm{~mL} / \mathrm{min}$, $t_{R}=24.48 \mathrm{~min}$.

ESI-MS m/z: 2040.3, $[\mathrm{M}+\mathrm{H}]^{+}, 1020.7[\mathrm{M}+2 \mathrm{H}]^{2+}, 680.8[\mathrm{M}+3 \mathrm{H}]^{3+}, 510.8[\mathrm{M}+4 \mathrm{H}]^{4+}$.

ESI-HRMS: calculated for $\left[\mathrm{C}_{95} \mathrm{H}_{176} \mathrm{~N}_{23} \mathrm{O}_{25}\right]^{+}\left([\mathrm{M}+\mathrm{H}]^{+}\right)=2040.3232$, found $=2040.3204$ calculated for $\left[\mathrm{C}_{95} \mathrm{H}_{175} \mathrm{~N}_{23} \mathrm{O}_{25} \mathrm{Na}\right]^{+}\left([\mathrm{M}+\mathrm{Na}]^{+}\right)=2061.3022$, found $=2061.3015$; calculated for $\left[\mathrm{C}_{95} \mathrm{H}_{177} \mathrm{~N}_{23} \mathrm{O}_{25}\right]^{2+}\left([\mathrm{M}+2 \mathrm{H}]^{2+}\right)=1020.6652$, found = 1020.6649; calculated for $\left[\mathrm{C}_{95} \mathrm{H}_{178} \mathrm{~N}_{23} \mathrm{O}_{25}\right]^{3+}\left([\mathrm{M}+3 \mathrm{H}]^{3+}\right)=680.7792$, found $=680.7809$. 
[Boc-Lys(Me) $\left.{ }_{2}\right]_{4}$ Lys $_{2}$ LysGly-5-(2-(allyloxycarbonyl)-N,N'-dimethylethylene diamino)pentanoic acid-Gly ${ }_{5}$-cyclo[-DapD-ProGlyArg(Pbf)Asn(Trt)ProLys(Boc) Thr(tBoc)Gly Glu(tBu)Asp(tBu)Ile-]



The dendrimer 17a ( $80 \mathrm{mg}, 39.22 \mu \mathrm{mol}, 2$ eq) was dissolved in dry DMF (4 mL) under argon atmosphere and to it were added DIC (16.5 $\mu \mathrm{L}, 0.157 \mathrm{mmol}, 8 \mathrm{eq}), \mathrm{NMM}(21.6 \mu \mathrm{L}$, $0.196 \mathrm{mmol}, 10 \mathrm{eq})$ and HOAt $(21.78 \mathrm{mg}, 0.16 \mathrm{mmol}, 7.9 \mathrm{eq})$. After stirring the mixture at room temperature for $10 \mathrm{~min}$ the cyclic peptide $15(39.5 \mathrm{mg}, 19.61 \mu \mathrm{mol}, 1 \mathrm{eq})$ was added to it and allowed to stir for additional $48 \mathrm{~h}$. Thereafter, removal of the solvent under vacuum followed by purification of the residue by RP-HPLC yielded the product 21a (37.2 mg, $9.22 \mu \mathrm{mol}, 47 \%$ ) as a white solid.

HPLC Purification: Column Pep 2 (MN_Nucleodur100_5_C18, RP-C18, semi-preparative, $250 \times 10 \mathrm{~mm}, 5 \mu \mathrm{m}), 55-75 \%$ gradient of $C$ in $30 \mathrm{~min}$, flow rate $3 \mathrm{~mL} / \mathrm{min}, t_{R}=20.31 \mathrm{~min}$.

ESI-MS $m / z: 1345.8[\mathrm{M}+3 \mathrm{H}]^{3+}, 1009.6[\mathrm{M}+4 \mathrm{H}]^{4+}, 807.9[\mathrm{M}+5 \mathrm{H}]^{5+}$.

ESI-HRMS: calculated for $\left[\mathrm{C}_{196} \mathrm{H}_{325} \mathrm{~N}_{41} \mathrm{O}_{47} \mathrm{~S}\right]^{4+}\left([\mathrm{M}+4 \mathrm{H}]^{4+}\right)=1009.6008$, found = 1009.6005; calculated for $\left[\mathrm{C}_{196} \mathrm{H}_{326} \mathrm{~N}_{41} \mathrm{O}_{47} \mathrm{~S}\right]^{4+}\left([\mathrm{M}+5 \mathrm{H}]^{5+}\right)=807.807 .8821$, found $=807.8820$. 
[Boc-Lys(Me) $\left.{ }_{2}\right]_{4}$ Lys $_{2}$ LysGly-5-( $N, N^{\prime}$-dimethylethylenediamino)pentanoic acidGly $_{5}$-cyclo[-DapDProGlyArg(Pbf)Asn(Trt)ProLys(Boc)Thr(tBoc)GlyGlu(tBu) $\operatorname{Asp}(t \mathrm{Bu})$ Ile-]



To a solution of peptide 21a (30 mg, $7.43 \mu \mathrm{mol}, 1 \mathrm{eq}$ ) in dry DMF (3 mL) were added $\mathrm{Me}_{2} \mathrm{NH}_{\mathrm{BH}}(17.68 \mathrm{mg}, 0.3 \mathrm{mmol}, 40 \mathrm{eq})$ and $\mathrm{Pd}\left(\mathrm{PPh}_{3}\right)_{4}(0.86 \mathrm{mg}, 0.743 \mu \mathrm{mol}, 0.1 \mathrm{eq})$ under argon atmosphere. The reaction mixture was allowed to stir for $6 \mathrm{~h}$ at room temperature. The solvent was removed under vacuum and the residue was purified by RP-HPLC yielding the peptide $22 \mathrm{a}(19.38 \mathrm{mg}, 4.90 \mu \mathrm{mol}, 66 \%)$ as a white solid.

HPLC Purification: Column Pep 1 (MN_Nucleodur100_5_C18, RP-C18, preparative, $250 \times 21.0 \mathrm{~mm}, 5 \mu \mathrm{m}), 60-100 \%$ gradient of $B$ in $30 \mathrm{~min}$, flow rate $10 \mathrm{~mL} / \mathrm{min}$, $t_{R}=14.4 \mathrm{~min}$.

ESI-MS m/z: $1976.7[\mathrm{M}+2 \mathrm{H}]^{2+}, 1318.1[\mathrm{M}+3 \mathrm{H}]^{3+}, 988.8[\mathrm{M}+4 \mathrm{H}]^{4+}, 791.3[\mathrm{M}+5 \mathrm{H}]^{5+}$.

ESI-HRMS: calculated for $\left[\mathrm{C}_{192} \mathrm{H}_{319} \mathrm{~N}_{41} \mathrm{O}_{45} \mathrm{~S}\right]^{2+}\left([\mathrm{M}+2 \mathrm{H}]^{2+}\right)=1976.6850$, found = 1976.6772; calculated for $\left[\mathrm{C}_{192} \mathrm{H}_{320} \mathrm{~N}_{41} \mathrm{O}_{45} \mathrm{~S}\right]^{3+}\left([\mathrm{M}+3 \mathrm{H}]^{3+}\right)=1318.1258$, found = 1318.1269; calculated for $\left[\mathrm{C}_{192} \mathrm{H}_{321} \mathrm{~N}_{41} \mathrm{O}_{45} \mathrm{~S}\right]^{4+}\left([\mathrm{M}+4 \mathrm{H}]^{4+}\right)=988.8462$, found = 988.8457; calculated for $\left[\mathrm{C}_{192} \mathrm{H}_{322} \mathrm{~N}_{41} \mathrm{O}_{45} \mathrm{~S}\right]^{5+}\left([\mathrm{M}+5 \mathrm{H}]^{5+}\right)=791.2784$, found $=791.2785$. 
[Boc-Lys(Me) $\left.{ }_{2}\right]_{4}$ Lys $_{2}$ LysGly-5-( $N, N^{\prime}$-dimethylethylenediamino)pentanoic acidGly $_{5}$-cyclo[-DapD-ProGlyArg(Pbf)Asn(Trt)ProLys(Boc)Thr(tBoc)GlyGlu(tBu) Asp(tBu) Ile-]dichloroplatinum(II)



A solution of $\mathrm{K}_{2} \mathrm{PtCl}_{4}(61 \mathrm{mg}, 0.147 \mathrm{mmol}, 30 \mathrm{eq})$ and peptide $22 \mathrm{a}(19.38 \mathrm{mg}, 4.90 \mu \mathrm{mol}$, 1 eq) in $\mathrm{DMF} / \mathrm{H}_{2} \mathrm{O}(3.5 \mathrm{~mL}, 9 / 1)$ was stirred at room temperature for $48 \mathrm{~h}$ in dark. Thereafter, the solvent was removed under reduced pressure and the residue was purified by RP-HPLC yielding the product 23a (14.26 mg, $3.38 \mu \mathrm{mol}, 69 \%)$ as a white solid.

HPLC Purification: Column All 2 (MN_Nucleodur100_5_C18, RP-C18, semi-preparative, $250 \times 10 \mathrm{~mm}, 5 \mu \mathrm{m}), 15-70 \%$ gradient of $B$ in $30 \mathrm{~min}$, flow rate $3 \mathrm{~mL} / \mathrm{min}, t_{R}=35.1 \mathrm{~min}$.

ESI-MS $m / z: 2109.6[\mathrm{M}+2 \mathrm{H}]^{2+}, 1406.8[\mathrm{M}+3 \mathrm{H}]^{3+}, 1055.6[\mathrm{M}+4 \mathrm{H}]^{4+}$.

ESI-HRMS: calculated for $\left[\mathrm{C}_{192} \mathrm{H}_{319} \mathrm{Cl}_{2} \mathrm{~N}_{41} \mathrm{O}_{45} \mathrm{PtS}\right]^{2+}\left([\mathrm{M}+2 \mathrm{H}]^{2+}\right)=2109.6356$, found $=$ 2109.6349; calculated for $\left[\mathrm{C}_{192} \mathrm{H}_{320} \mathrm{Cl}_{2} \mathrm{~N}_{41} \mathrm{O}_{45} \mathrm{PtS}\right]^{3+}\left([\mathrm{M}+3 \mathrm{H}]^{3+}\right)=1406.7595$, found $=$ 1406.7646; calculated for $\left[\mathrm{C}_{192} \mathrm{H}_{321} \mathrm{Cl}_{2} \mathrm{~N}_{41} \mathrm{O}_{45} \mathrm{SPt}\right]^{4+}\left([\mathrm{M}+4 \mathrm{H}]^{4+}\right)=1055.5717$, found $=$ 1055.5759 . 
[Lys $\left.(\mathrm{Me})_{2}\right]_{4}$ Lys $_{2}$ LysGly-5-(N, $N^{\prime}$-dimethylethylenediamino) pentanoic acid-Gly $5^{-}$ cyclo [-DapD-ProGlyArgAsnProLysThrGlyGluAsplle-]dichloroplatinum(II)



The peptide 23a $(14.26 \mathrm{mg}, 3.38 \mu \mathrm{mol})$ was dissolved in 95\% TFA in $\mathrm{H}_{2} \mathrm{O}(2 \mathrm{~mL})$ and stirred for $45 \mathrm{~min}$ at room temperature. Thereafter, the solvent was blow dried with argon and the residue was purified by RP-HPLC yielding the product IHF-2 (4.43 mg, 1.45 $\mu \mathrm{mol}, 43 \%)$ as a pale yellow crystalline solid.

HPLC Purification: Column Pep 2 (MN_Nucleodur100_5_C18, RP-C18, semi-preparative, $250 \times 10 \mathrm{~mm}, 5 \mu \mathrm{m}), 10-40 \%$ gradient of $B$ in $30 \mathrm{~min}$, flow rate $3 \mathrm{~mL} / \mathrm{min}, t_{R}=14.4 \mathrm{~min}$.

ESI-MS $m / z: 1527.3[\mathrm{M}+2 \mathrm{H}]^{2+}, 1018.5[\mathrm{M}+3 \mathrm{H}]^{3+}, 764.2[\mathrm{M}+4 \mathrm{H}]^{4+}, 611.5[\mathrm{M}+5 \mathrm{H}]^{5+}$, $509.8[\mathrm{M}+6 \mathrm{H}]^{6+}$.

ESI-HRMS: calculated for $\left[\mathrm{C}_{123} \mathrm{H}_{226} \mathrm{Cl}_{2} \mathrm{~N}_{41} \mathrm{O}_{32} \mathrm{Pt}\right]^{3+}\left([\mathrm{M}+3 \mathrm{H}]^{3+}\right)=1018.5446$, found $=$ 1018.5440; calculated for $\left[\mathrm{C}_{123} \mathrm{H}_{227} \mathrm{Cl}_{2} \mathrm{~N}_{41} \mathrm{O}_{32} \mathrm{Pt}\right]^{3+}\left([\mathrm{M}+4 \mathrm{H}]^{4+}\right)=764.1603$, found $=$ 764.1603 . 


\subsubsection{Synthesis of IHF-3}

\section{[Boc-Lys(Me) $\left.{ }_{2}\right]_{4}$ Lys $_{2}$ LysGly 3 -5-(2-(allyloxycarbonyl)-N, $N^{\prime}$-dimethylethylene diamino) pentanoic acid-Gly ${ }_{3}-\mathrm{OH}$}
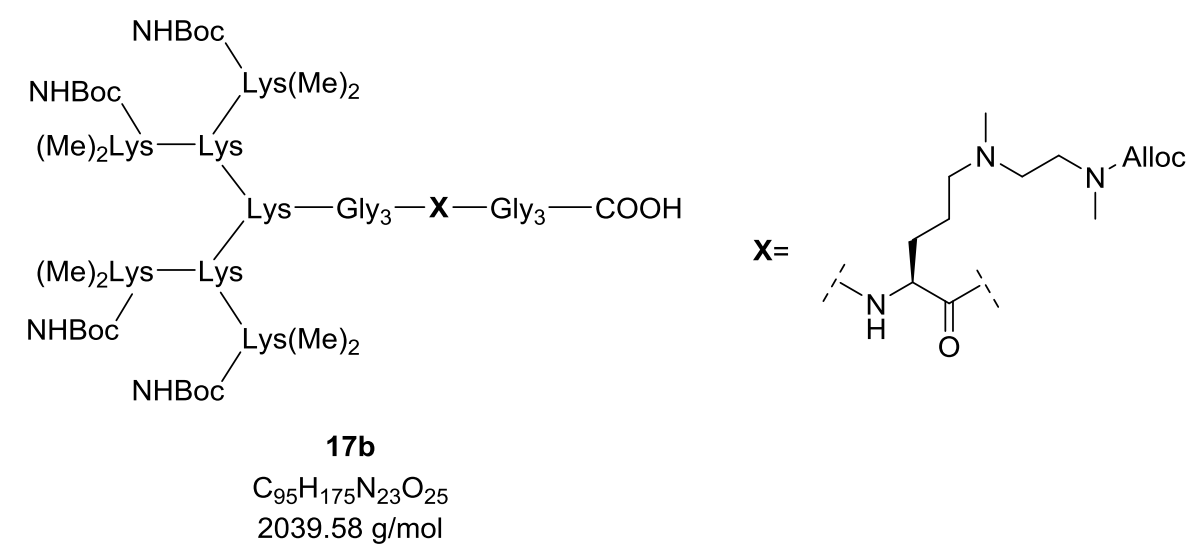

The synthesis of the lysine dendrimer was performed manually according the procedure (mentioned in section 7.3). Cleavage of the peptide from the resin using $30 \%$ (HFIP) in DCM followed by purification with RP-HPLC yielded the peptide 17b $(108 \mathrm{mg}, 53 \mu \mathrm{mol}$, $53 \%)$ as a white solid.

HPLC Purification: Column Pep 1 (MN_Nucleodur100_5_C18, RP-C18, preparative, $250 \times 21.0 \mathrm{~mm}, 5 \mu \mathrm{m}), \quad 10-60 \%$ gradient of $B$ in $30 \mathrm{~min}$, flow rate $10 \mathrm{~mL} / \mathrm{min}, t_{R}=$ $23.6 \mathrm{~min}$.

ESI-MS m/z: $2040.4[\mathrm{M}+\mathrm{H}]^{+}, 1020.7[\mathrm{M}+2 \mathrm{H}]^{2+}, 680.8[\mathrm{M}+3 \mathrm{H}]^{3+}, 510.9[\mathrm{M}+4 \mathrm{H}]^{4+}$.

ESI-HRMS: calculated for $\left[\mathrm{C}_{95} \mathrm{H}_{176} \mathrm{~N}_{23} \mathrm{O}_{25}\right]^{+}\left([\mathrm{M}+\mathrm{H}]^{+}\right)=2040.3232$, found $=2040.3206$; calculated for $\left[\mathrm{C}_{95} \mathrm{H}_{177} \mathrm{~N}_{23} \mathrm{O}_{25}\right]^{2+}\left([\mathrm{M}+2 \mathrm{H}]^{2+}\right)=1020.6652$, found = 1020.6668; calculated for $\left[\mathrm{C}_{95} \mathrm{H}_{178} \mathrm{~N}_{23} \mathrm{O}_{25}\right]^{3+}\left([\mathrm{M}+3 \mathrm{H}]^{3+}\right)=680.7792$, found $=680.7779$. 
[Boc-Lys(Me) $\left.{ }_{2}\right]_{4}$ Lys $_{2}$ LysGly $_{3}-5$-(2-(allyloxycarbonyl)-N, $N^{\prime}$-dimethylethylene diamino) pentanoic acid-Gly ${ }_{3}$-cyclo[-DapD-ProGlyArg(Pbf)Asn(Trt)ProLys(Boc) Thr(tBoc)Gly Glu(tBu)Asp(tBu)Ile-]

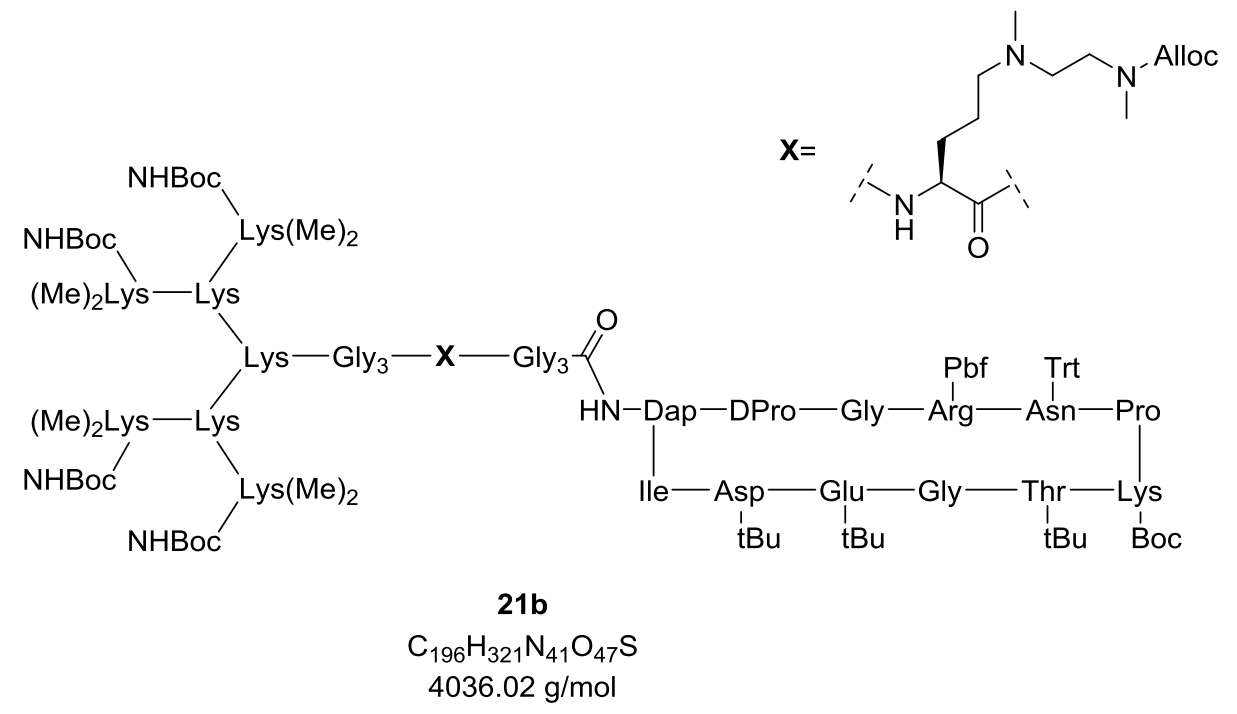

To a solution of dendrimer $17 \mathrm{~b}$ ( $83 \mathrm{mg}, 40.7 \mu \mathrm{mol}, 2 \mathrm{eq}$ ) in dry DMF ( $4 \mathrm{~mL}$ ) under argon DIC (17.1 $\mu \mathrm{L}, 0.163 \mathrm{mmol}, 8 \mathrm{eq}), \mathrm{NMM}(22.4 \mu \mathrm{L}, 0.204 \mathrm{mmol}, 10 \mathrm{eq})$ and HOAt $(21.88 \mathrm{mg}$, $0.161 \mathrm{mmol}, 7.9 \mathrm{eq})$ were added. After stirring the mixture at room temperature for 10 min the cyclic peptide 15 (41 mg, $20.35 \mu \mathrm{mol}, 1$ eq) was added and reaction allowed to stir for additional $48 \mathrm{~h}$. Thereafter, removal of the solvent under vacuum and purification of the residue by RP-HPLC yielded the product $21 \mathbf{b}(43.55 \mathrm{mg}, 10.79 \mu \mathrm{mol}$, $53 \%)$ as a white solid.

HPLC Purification: Column Pep 1 (MN_Nucleodur100_5_C18, RP-C18, preparative, $250 \times 21.0 \mathrm{~mm}, 5 \mu \mathrm{m}), \quad 30-100 \%$ gradient of $\mathrm{C}$ in $30 \mathrm{~min}$, flow rate $10 \mathrm{~mL} / \mathrm{min}$, $t_{R}=22.4 \mathrm{~min}$.

ESI-MS m/z: $2018.8[\mathrm{M}+2 \mathrm{H}]^{2+}, 1346.2[\mathrm{M}+3 \mathrm{H}]^{3+}, 1009.9[\mathrm{M}+4 \mathrm{H}]^{4+}, 808.1[\mathrm{M}+5 \mathrm{H}]^{5+}$. 
ESI-HRMS: $\left[\mathrm{C}_{196} \mathrm{H}_{323} \mathrm{~N}_{41} \mathrm{O}_{47} \mathrm{~S}\right]^{2+}\left([\mathrm{M}+2 \mathrm{H}]^{2+}\right)=2018.6956$, found $=2018.6982$, calculated for $\left[\mathrm{C}_{196} \mathrm{H}_{324} \mathrm{~N}_{41} \mathrm{O}_{47} \mathrm{~S}\right]^{3+}\left([\mathrm{M}+3 \mathrm{H}]^{3+}\right)=1346.1328$, found $=1346.1352$; calculated for $\left[\mathrm{C}_{196} \mathrm{H}_{325} \mathrm{~N}_{41} \mathrm{O}_{47} \mathrm{~S}\right]^{4+}\left([\mathrm{M}+4 \mathrm{H}]^{4+}\right)=1009.8514$, found $=1009.8536$; calculated for $\left[\mathrm{C}_{196} \mathrm{H}_{326} \mathrm{~N}_{41} \mathrm{O}_{47} \mathrm{~S}\right]^{5+}\left([\mathrm{M}+5 \mathrm{H}]^{5+}\right)=808.0826$, found $=808.0829$.

[Boc-Lys(Me) $\left.{ }_{2}\right]_{4}$ Lys $_{2} \mathrm{LysGly}_{3}-5$-( $N, N^{\prime}$-dimethylethylenediamino)pentanoic acidGly ${ }_{3}$-cyclo[-DapD-ProGlyArg(Pbf)Asn(Trt)ProLys(Boc)Thr(tBoc)GlyGlu(tBu) Asp(tBu)Ile-]

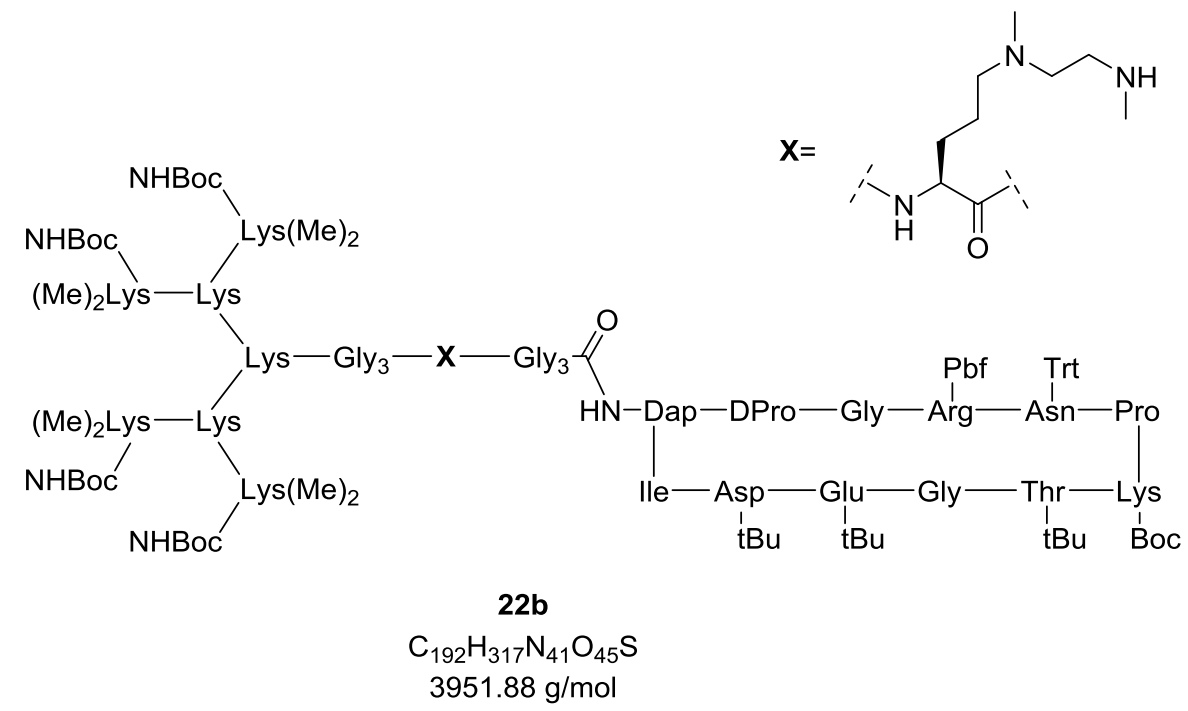

To a solution of peptide 21b (40 mg, $9.91 \mu \mathrm{mol}, 1 \mathrm{eq}$ ) in $4 \mathrm{~mL}$ of dry DMF under argon atmosphere were added $\mathrm{Me}_{2} \mathrm{NH} \cdot \mathrm{BH}_{3}\left(23.33 \mathrm{mg}, 0.396 \mathrm{mmol}, 40\right.$ eq) and $\mathrm{Pd}\left(\mathrm{PPh}_{3}\right)_{4}$ $(1.15 \mathrm{mg}, 0.991 \mu \mathrm{mol}, 0.1 \mathrm{eq})$. The reaction mixture was allowed to stir for $6 \mathrm{~h}$ at room temperature. The solvent was removed under vacuum and the residue was purified by RP-HPLC yielding the peptide $22 \mathbf{b}$ (30.15 mg, $7.63 \mu \mathrm{mol}, 77 \%)$ as a white solid.

HPLC Purification: Column Pep 1 (MN_Nucleodur100_5_C18, RP-C18, preparative, $250 \times 21.0 \mathrm{~mm}, 5 \mu \mathrm{m}), \quad 65-80 \%$ gradient of $B$ in $30 \mathrm{~min}$, flow rate $10 \mathrm{~mL} / \mathrm{min}, t_{R}=$ $19.1 \mathrm{~min}$. 
ESI-MS m/z: $1976.7[\mathrm{M}+2 \mathrm{H}]^{2+}, 1318.1[\mathrm{M}+3 \mathrm{H}]^{3+}, 988.8[\mathrm{M}+4 \mathrm{H}]^{4+}, 791.3[\mathrm{M}+5 \mathrm{H}]^{5+}$.

ESI-HRMS: calculated for $\left[\mathrm{C}_{192} \mathrm{H}_{319} \mathrm{~N}_{41} \mathrm{O}_{45} \mathrm{~S}\right]^{2+}\left([\mathrm{M}+2 \mathrm{H}]^{2+}\right)=1976.6850$, found = 1976.6837; calculated for $\left[\mathrm{C}_{192} \mathrm{H}_{320} \mathrm{~N}_{41} \mathrm{O}_{45} \mathrm{~S}\right]^{3+}\left([\mathrm{M}+3 \mathrm{H}]^{3+}\right)=1318.1258$, found = 1318.1268; calculated for $\left[\mathrm{C}_{192} \mathrm{H}_{321} \mathrm{~N}_{41} \mathrm{O}_{45} \mathrm{~S}\right]^{4+}\left([\mathrm{M}+4 \mathrm{H}]^{4+}\right)=988.8462$, found $=988.8483$.

[Boc-Lys(Me) $\left.{ }_{2}\right]_{4}$ Lys $_{2}$ LysGly $_{3}-5$-( $N, N^{\prime}$-dimethylethylenediamino) pentanoic acidGly ${ }_{3}$-cyclo[-DapD-ProGlyArg(Pbf)Asn(Trt)ProLys(Boc)Thr(tBoc)GlyGlu(tBu) Asp(tBu)Ile-]dichloroplatinum(II)

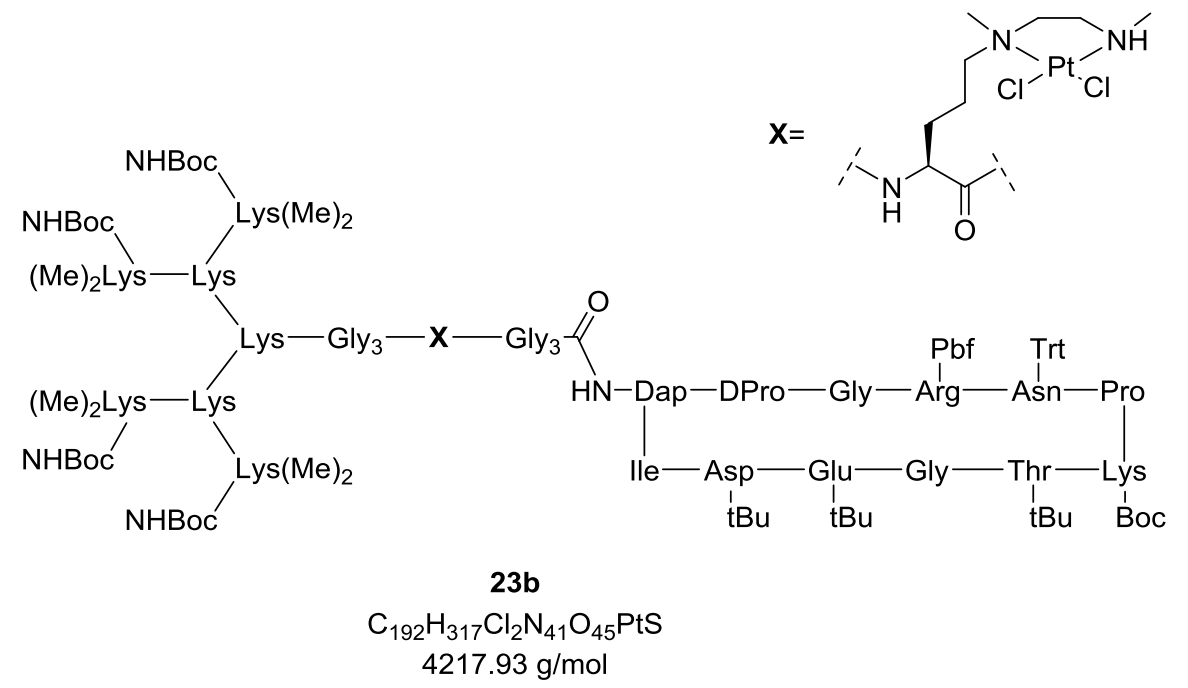

A solution of $\mathrm{K}_{2} \mathrm{PtCl}_{4}(95.1 \mathrm{mg}, 0.229 \mathrm{mmol}, 30 \mathrm{eq})$ and peptide $22 \mathbf{b}$ (30.15 mg, 7.63 $\mu \mathrm{mol}, 1 \mathrm{eq})$ in $\mathrm{DMF} / \mathrm{H}_{2} \mathrm{O}(5 \mathrm{~mL}, 9 / 1)$ was stirred at room temperature for $48 \mathrm{~h}$ in dark. Thereafter, the solvent was removed under reduced pressure and the residue was purified by RP-HPLC yielding the product $23 \mathrm{~b}$ (19.95 mg, $4.73 \mu \mathrm{mol}, 62 \%)$ as a white solid.

HPLC Purification: Column All2 (MN_Nucleodur100_5_C18, RP-C18, semi-preparative, $250 \times 10 \mathrm{~mm}, 5 \mu \mathrm{m}), 15-75 \%$ gradient of $B$ in $30 \mathrm{~min}$, flow rate $3 \mathrm{~mL} / \mathrm{min}, t_{R}=35.2 \mathrm{~min}$. 
ESI-MS m/z: $2109.6[\mathrm{M}+2 \mathrm{H}]^{2+}, 1406.8[\mathrm{M}+3 \mathrm{H}]^{3+}, 1055.3[\mathrm{M}+4 \mathrm{H}]^{4+}, 845.5[\mathrm{M}+5 \mathrm{H}]^{5+}$.

ESI-HRMS: calculated for $\left[\mathrm{C}_{192} \mathrm{H}_{319} \mathrm{Cl}_{2} \mathrm{~N}_{41} \mathrm{O}_{45} \mathrm{PtS}\right]^{2+}\left([\mathrm{M}+2 \mathrm{H}]^{2+}\right)=2109.6397$, found $=$ 2109.6356; calculated for $\left[\mathrm{C}_{192} \mathrm{H}_{320} \mathrm{Cl}_{2} \mathrm{~N}_{41} \mathrm{O}_{45} \mathrm{PtS}\right]^{3+}\left([\mathrm{M}+3 \mathrm{H}]^{3+}\right)=1406.7595$, found $=$ 1406.7627; calculated for $\left[\mathrm{C}_{192} \mathrm{H}_{321} \mathrm{Cl}_{2} \mathrm{~N}_{41} \mathrm{O}_{45} \mathrm{PtS}\right]^{4+}\left([\mathrm{M}+4 \mathrm{H}]^{4+}\right)=1055.3215$, found $=$ 1055.3273.

\section{[Lys(Me $\left.)_{2}\right]_{4}$ Lys $_{2}$ LysGly $_{3}-5$-( $N, N^{\prime}$-dimethylethylenediamino)pentanoic acid-Gly ${ }_{3}-$ cyclo [-DapD-ProGlyArgAsnProLysThrGlyGluAsplle-]dichloroplatinum(II)}



The peptide 23b (19.95 $\mathrm{mg}, 4.73 \mu \mathrm{mol})$ was dissolved in 95\% TFA in $\mathrm{H}_{2} \mathrm{O}(2 \mathrm{~mL})$ and stirred for $45 \mathrm{~min}$ at room temperature. Thereafter, the solvent was blow dried with argon and the residue was purified by RP-HPLC yielding the product IHF-3 (8.09 mg, 2.65 $\mu \mathrm{mol}, 56 \%)$ as a pale yellow crystalline solid.

HPLC Purification: Column Pep 2 (MN_Nucleodur100_5_C18, RP-C18, semi-preparative, $250 \times 10 \mathrm{~mm}, 5 \mu \mathrm{m}), 10-40 \%$ gradient of $B$ in $30 \mathrm{~min}$, flow rate $3 \mathrm{~mL} / \mathrm{min}, t_{R}=14.85$, $15.46,15.9 \mathrm{~min}$. 
ESI-MS m/z: $1528.3[\mathrm{M}+2 \mathrm{H}]^{2+}, 1018.9[\mathrm{M}+3 \mathrm{H}]^{3+}, 764.4[\mathrm{M}+4 \mathrm{H}]^{4+}, 611.7[\mathrm{M}+5 \mathrm{H}]^{5+}$.

ESI-HRMS: calculated for $\left[\mathrm{C}_{123} \mathrm{H}_{225} \mathrm{Cl}_{2} \mathrm{~N}_{41} \mathrm{O}_{32} \mathrm{Pt}\right]^{2+}\left([\mathrm{M}+2 \mathrm{H}]^{2+}\right)=1528.3140$, found $=$ 1528.3128; calculated for $\left[\mathrm{C}_{123} \mathrm{H}_{226} \mathrm{Cl}_{2} \mathrm{~N}_{41} \mathrm{O}_{32} \mathrm{Pt}\right]^{3+}\left([\mathrm{M}+3 \mathrm{H}]^{3+}\right)=1018.8782$, found $=$ 1018.8782; calculated for $\left[\mathrm{C}_{123} \mathrm{H}_{227} \mathrm{Cl}_{2} \mathrm{~N}_{41} \mathrm{O}_{32} \mathrm{Pt}\right]^{4+}\left([\mathrm{M}+4 \mathrm{H}]^{4+}\right)=764.4105$, found $=$ 764.4100; calculated for $\left[\mathrm{C}_{123} \mathrm{H}_{228} \mathrm{Cl}_{2} \mathrm{~N}_{41} \mathrm{O}_{32} \mathrm{Pt}\right]^{5+}\left([\mathrm{M}+5 \mathrm{H}]^{5+}\right)=611.7299$, found $=$ 611.7290; calculated for $\left[\mathrm{C}_{123} \mathrm{H}_{229} \mathrm{Cl}_{2} \mathrm{~N}_{41} \mathrm{O}_{32} \mathrm{Pt}\right]^{6+}\left([\mathrm{M}+6 \mathrm{H}]^{6+}\right)=509.9428$, found $=$ 509.9423.

\subsubsection{Synthesis of IHF-4}

[Boc-Lys(Me) $\left.{ }_{2}\right]_{4}$ Lys $_{2} \mathrm{LysGly}_{5}-5-(2-($ allyloxycarbonyl)-N,N'-dimethylethylene diamino)pentanoic acid-Gly-OH

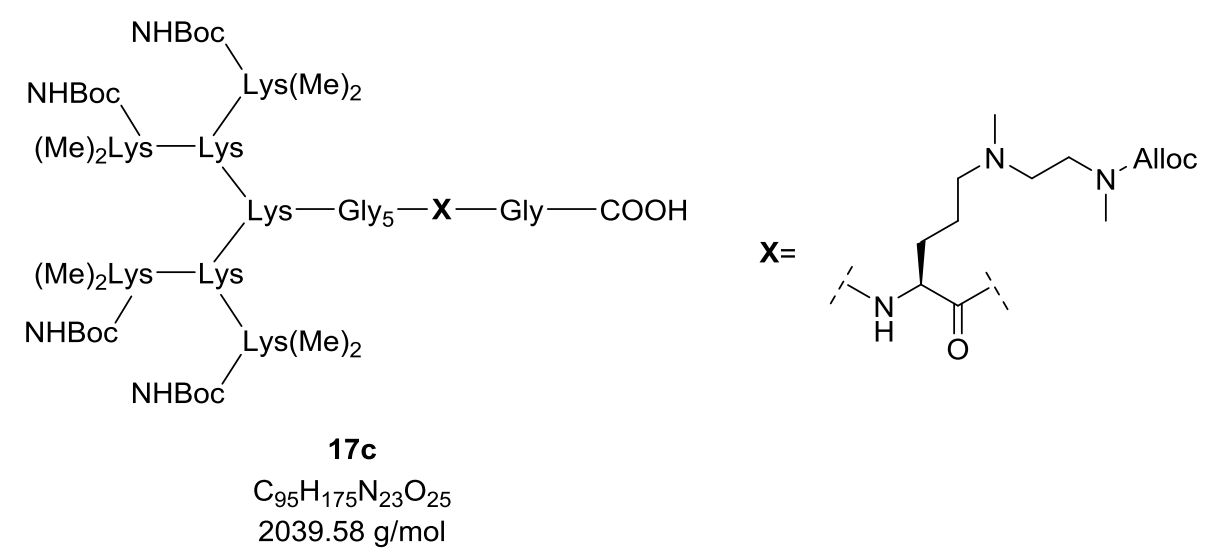

The synthesis of the lysine dendrimer was performed manually according the procedure (mentioned in section 7.3). Cleavage of the peptide from the resin using $30 \%$ (HFIP) in DCM followed by purification with RP-HPLC yielded the peptide 17c $(118 \mathrm{mg}, 58 \mu \mathrm{mol}$, $58 \%)$ as a white solid. 
HPLC Purification: Column Pep 1 (MN_Nucleodur100_5_C18, RP-C18, preparative, $250 \times 21.0 \mathrm{~mm}, 5 \mu \mathrm{m}), 10-60 \%$ gradient of $B$ in $30 \mathrm{~min}$, flow rate $10 \mathrm{~mL} / \mathrm{min}$, $t_{R}=24.65 \mathrm{~min}$.

ESI-MS m/z: $2040.4[\mathrm{M}+\mathrm{H}]^{+}, 1020.7[\mathrm{M}+2 \mathrm{H}]^{2+}, 680.8[\mathrm{M}+3 \mathrm{H}]^{3+}, 510.8[\mathrm{M}+4 \mathrm{H}]^{4+}$.

ESI-HRMS: calculated for $\left[\mathrm{C}_{95} \mathrm{H}_{176} \mathrm{~N}_{23} \mathrm{O}_{25}\right]^{+}\left([\mathrm{M}+\mathrm{H}]^{+}\right)=2040.3232$, found $=2040.3183$; calculated for $\left[\mathrm{C}_{95} \mathrm{H}_{177} \mathrm{~N}_{23} \mathrm{O}_{25}\right]^{2+}\left([\mathrm{M}+2 \mathrm{H}]^{2+}\right)=1020.6652$, found $=1020.6639$; calculated for $\left[\mathrm{C}_{95} \mathrm{H}_{178} \mathrm{~N}_{23} \mathrm{O}_{25}\right]^{3+}\left([\mathrm{M}+3 \mathrm{H}]^{3+}\right)=680.7792$, found $=680.7800$.

[Boc-Lys(Me) $\left.{ }_{2}\right]_{4}$ Lys $_{2}$ LysGly $_{5}-5$-(2-(allyloxycarbonyl)-N, $N^{\prime}$-dimethylethylene diamino)pentanoic acid-Gly-cyclo[-DapD-ProGlyArg(Pbf)Asn(Trt)ProLys(Boc) $\operatorname{Thr}(t B o c)$ Gly Glu(tBu)Asp(tBu)Ile-]

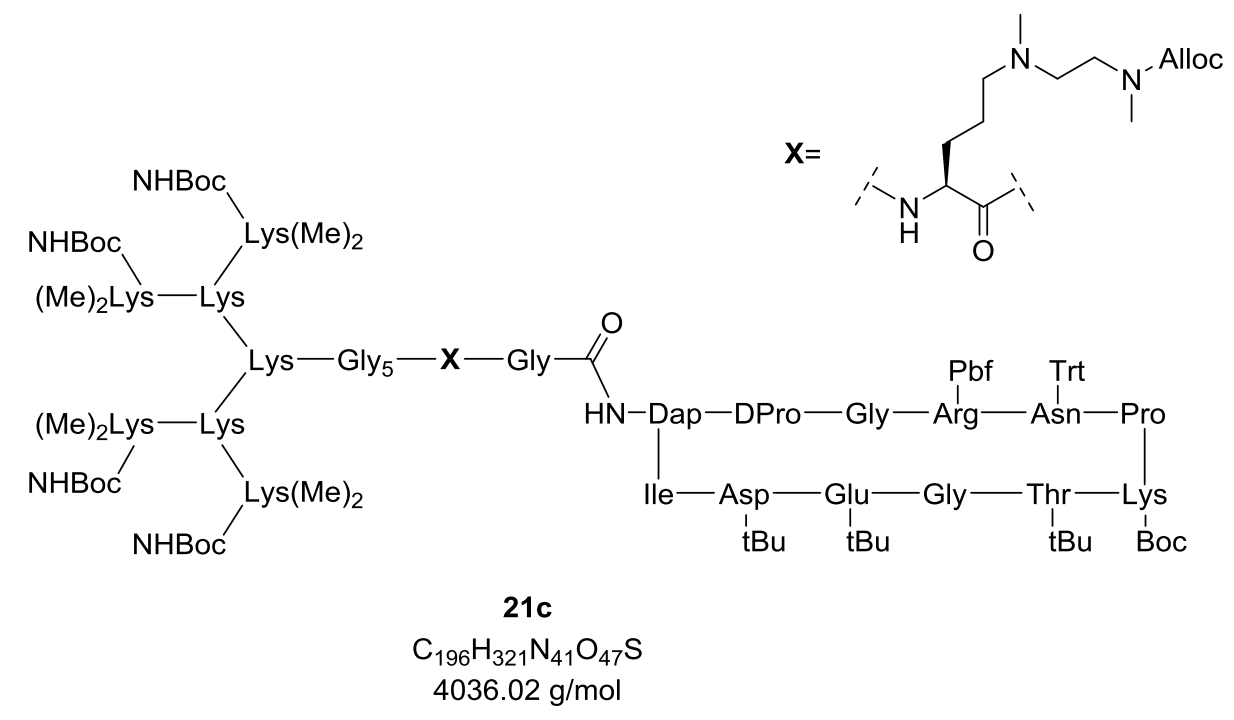

The dendrimer 17c ( $85 \mathrm{mg}, 41.6 \mu \mathrm{mol}, 2 \mathrm{eq}$ ) was dissolved in dry DMF (4 mL) under argon atmosphere and to it were added DIC (17.5 $\mu \mathrm{L}, 166.4 \mu \mathrm{mol}, 8 \mathrm{eq}), \mathrm{NMM}(22.9 \mu \mathrm{L}$, $208 \mu \mathrm{mol}, 10 \mathrm{eq})$ and HOAt (22.36 mg, $164.32 \mu \mathrm{mol}, 7.9 \mathrm{eq})$. After stirring the mixture at 
room temperature for $10 \mathrm{~min}$ the cyclic peptide 15 (41.9 mg, $20.8 \mu \mathrm{mol}, 1 \mathrm{eq})$ was added to it and allowed to stir for additional $48 \mathrm{~h}$. Thereafter, removal of the solvent under vacuum followed by purification of the residue by RP-HPLC yielded the product 21c (36.93 mg, $9.15 \mu \mathrm{mol}, 44 \%$ ) as a white solid.

HPLC Purification: Pep 1 (MN_Nucleodur100_5_C18, RP-C18, preparative, $250 \times 21.0$ $\mathrm{mm}, 5 \mu \mathrm{m}), 30-100 \%$ gradient of $\mathrm{B}$ in $30 \mathrm{~min}$, flow rate $3 \mathrm{~mL} / \mathrm{min}, t_{R}=25.1 \mathrm{~min}$.

ESI-MS m/z: $2018.7[\mathrm{M}+2 \mathrm{H}]^{2+}, 1346.1[\mathrm{M}+3 \mathrm{H}]^{3+}, 1009.9[\mathrm{M}+4 \mathrm{H}]^{4+}, 808.1[\mathrm{M}+5 \mathrm{H}]^{5+}$.

ESI-HRMS: calculated for $\left[\mathrm{C}_{196} \mathrm{H}_{324} \mathrm{~N}_{41} \mathrm{O}_{47} \mathrm{~S}\right]^{3+}\left([\mathrm{M}+3 \mathrm{H}]^{3+}\right)=1346.1328$, found = 1346.1347; calculated for $\left[\mathrm{C}_{196} \mathrm{H}_{325} \mathrm{~N}_{41} \mathrm{O}_{47} \mathrm{~S}\right]^{4+}\left([\mathrm{M}+4 \mathrm{H}]^{4+}\right)=1009.8514$, found $=1009.8531$; calculated for $\left[\mathrm{C}_{196} \mathrm{H}_{326} \mathrm{~N}_{41} \mathrm{O}_{47} \mathrm{~S}\right]^{5+}\left([\mathrm{M}+5 \mathrm{H}]^{5+}\right)=808.0826$, found $=808.0837$. 
[Boc-Lys(Me $\left.)_{2}\right]_{4}$ Lys $_{2}$ LysGly $_{5}-5-\left(N, N^{\prime}\right.$-dimethylethylenediamino)pentanoic acidGly-cyclo[-DapD-ProGlyArg(Pbf)Asn(Trt)ProLys(Boc)Thr(tBoc)GlyGlu(tBu) $\operatorname{Asp}(t \mathrm{Bu})$ Ile-]

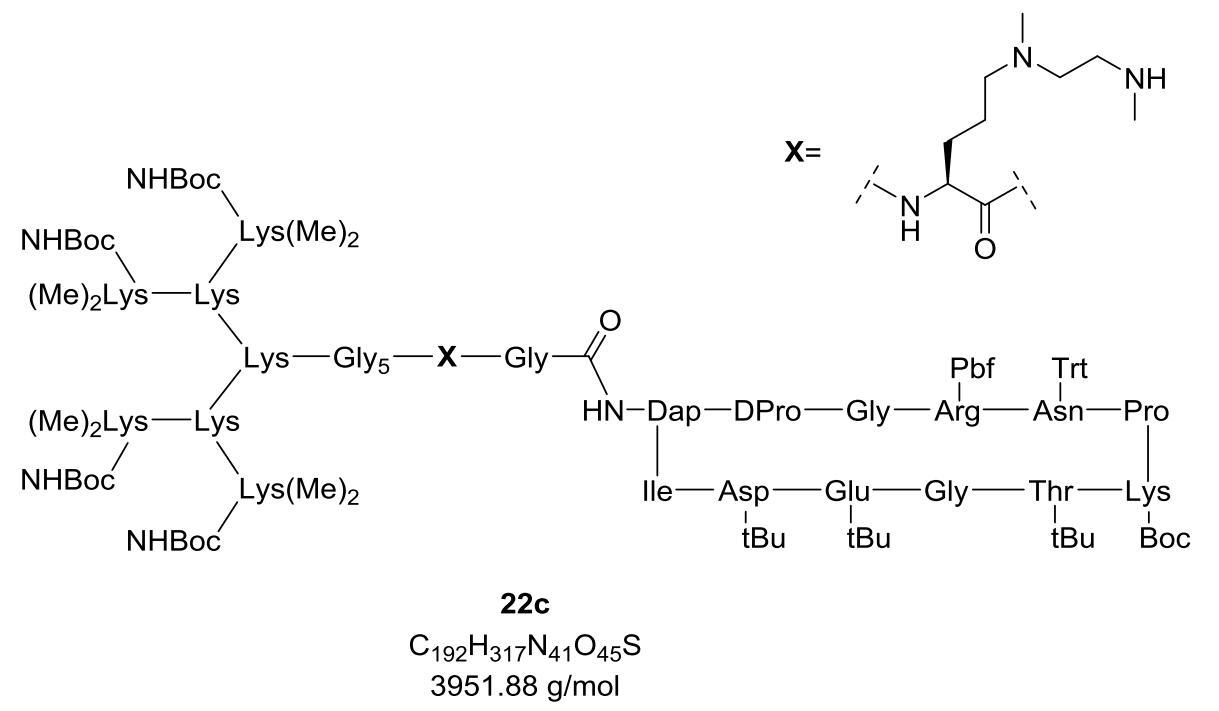

To a solution of peptide 21c (35 mg, $8.67 \mu \mathrm{mol}, 1 \mathrm{eq}$ ) in $3.5 \mathrm{~mL}$ of dry DMF under argon atmosphere were added $\mathrm{Me}_{2} \mathrm{NH}_{3} \mathrm{BH}_{3}(20.2 \mathrm{mg}, 0.347 \mathrm{mmol}, 40 \mathrm{eq})$ and $\mathrm{Pd}\left(\mathrm{PPh}_{3}\right)_{4}$ (1.0 mg, $0.0867 \mu \mathrm{mol}, 0.1 \mathrm{eq}$ ). The reaction mixture was allowed to stir for $6 \mathrm{~h}$ at room temperature. The solvent was removed under vacuum and the residue was purified by RP-HPLC yielding the peptide $22 \mathrm{c}(24.65 \mathrm{mg}, 6.24 \mu \mathrm{mol}, 72 \%)$ as a white solid.

HPLC Purification: Column Pep 1 (MN_Nucleodur100_5_C18, RP-C18, spreparative, $250 \times 21.0 \mathrm{~mm}, 5 \mu \mathrm{m}), \quad 60-80 \%$ gradient of $B$ in $30 \mathrm{~min}$, flow rate $10 \mathrm{~mL} / \mathrm{min}, t_{R}=$ $16.2 \mathrm{~min}$.

ESI-MS $m / z: 1318.1[\mathrm{M}+3 \mathrm{H}]^{3+}, 988.8[\mathrm{M}+4 \mathrm{H}]^{4+}, 791.3[\mathrm{M}+5 \mathrm{H}]^{5+}, 659.6[\mathrm{M}+6 \mathrm{H}]^{6+}$.

ESI-HRMS: calculated for $\left[\mathrm{C}_{192} \mathrm{H}_{320} \mathrm{~N}_{41} \mathrm{O}_{45} \mathrm{~S}\right]^{3+}\left([\mathrm{M}+3 \mathrm{H}]^{3+}\right)=1318.1258$, found = 1318.1275; calculated for $\left[\mathrm{C}_{192} \mathrm{H}_{321} \mathrm{~N}_{41} \mathrm{O}_{45} \mathrm{~S}\right]^{4+}\left([\mathrm{M}+4 \mathrm{H}]^{4+}\right)=988.8462$, found = 988.8482; calculated for $\left[\mathrm{C}_{192} \mathrm{H}_{322} \mathrm{~N}_{41} \mathrm{O}_{45} \mathrm{~S}\right]^{5+}\left([\mathrm{M}+5 \mathrm{H}]^{5+}\right)=791.2784$, found $=791.2795$; calculated for $\left[\mathrm{C}_{192} \mathrm{H}_{323} \mathrm{~N}_{41} \mathrm{O}_{45} \mathrm{~S}\right]^{6+}\left([\mathrm{M}+6 \mathrm{H}]^{6+}\right)=659.5665$, found $=659.5673$. 
[Boc-Lys(Me $\left.)_{2}\right]_{4}$ Lys $_{2}$ LysGly $_{5}-5$-(N,N'-dimethylethylenediamino)pentanoic acidGly-cyclo[-DapD-ProGlyArg(Pbf)Asn(Trt)ProLys(Boc)Thr(tBoc)GlyGlu(tBu) Asp(tBu)Ile-]dichloroplatinum(II)

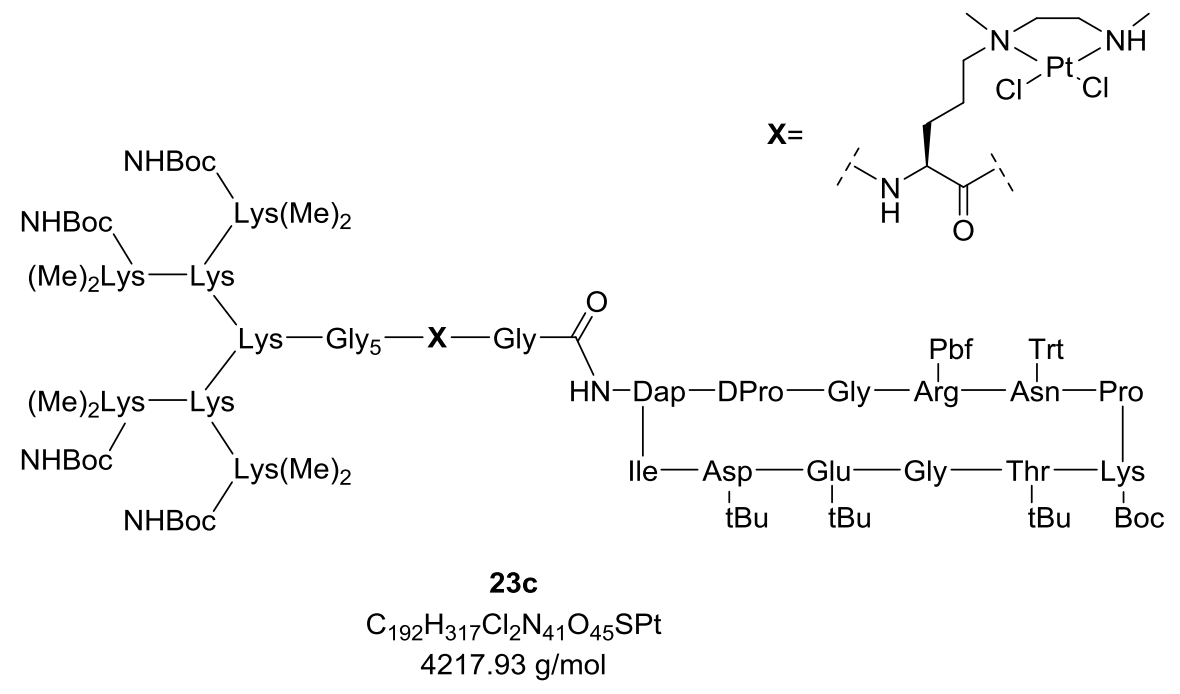

A solution of $\mathrm{K}_{2} \mathrm{PtCl}_{4}(77.63 \mathrm{mg}, 0.187 \mathrm{mmol}, 30 \mathrm{eq})$ and peptide $22 \mathrm{c}(24.65 \mathrm{mg}, 6.24$ $\mu \mathrm{mol}, 1$ eq) in $\mathrm{DMF} / \mathrm{H}_{2} \mathrm{O}(4 \mathrm{~mL}, 9 / 1)$ was stirred at room temperature for $48 \mathrm{~h}$ in dark. Thereafter, the solvent was removed under reduced pressure and the residue was purified by RP-HPLC yielding the product 23c (18.7 mg, $4.43 \mu \mathrm{mol}, 71 \%)$ as a white solid.

HPLC Purification: Column Pep 2 (MN_Nucleodur100_5_C18, RP-C18, semi-preparative, $250 \times 10 \mathrm{~mm}, 5 \mu \mathrm{m}), 15-70 \%$ gradient of $B$ in $30 \mathrm{~min}$, flow rate $3 \mathrm{~mL} / \mathrm{min}, t_{R}=35.2 \mathrm{~min}$.

ESI-MS m/z: $1406.8[\mathrm{M}+3 \mathrm{H}]^{3+}, 1055.3[\mathrm{M}+4 \mathrm{H}]^{4+}$.

ESI-HRMS: calculated for $\left[\mathrm{C}_{192} \mathrm{H}_{320} \mathrm{Cl}_{2} \mathrm{~N}_{41} \mathrm{O}_{45} \mathrm{SPt}\right]^{3+}\left([\mathrm{M}+3 \mathrm{H}]^{3+}\right)=1406.7595$, found $=$ 1406.7617; calculated for $\left[\mathrm{C}_{192} \mathrm{H}_{321} \mathrm{Cl}_{2} \mathrm{~N}_{41} \mathrm{O}_{45} \mathrm{SPt}\right]^{4+}\left([\mathrm{M}+4 \mathrm{H}]^{4+}\right)=1055.3215$, found $=$ 1055.3226; calculated for $\left[\mathrm{C}_{192} \mathrm{H}_{322} \mathrm{Cl}_{2} \mathrm{~N}_{41} \mathrm{O}_{45} \mathrm{SPt}\right]^{5+}\left([\mathrm{M}+5 \mathrm{H}]^{5+}\right)=844.4586$, found $=$ 844.4584. 
[Lys(Me $\left.)_{2}\right]_{4}$ Lys $_{2}$ LysGly ${ }_{5}-5-\left(N, N^{\prime}\right.$-dimethylethylenediamino)pentanoic acid-Glycyclo [-DapD-ProGlyArgAsnProLysThrGlyGluAsplle-]dichloroplatinum(II)

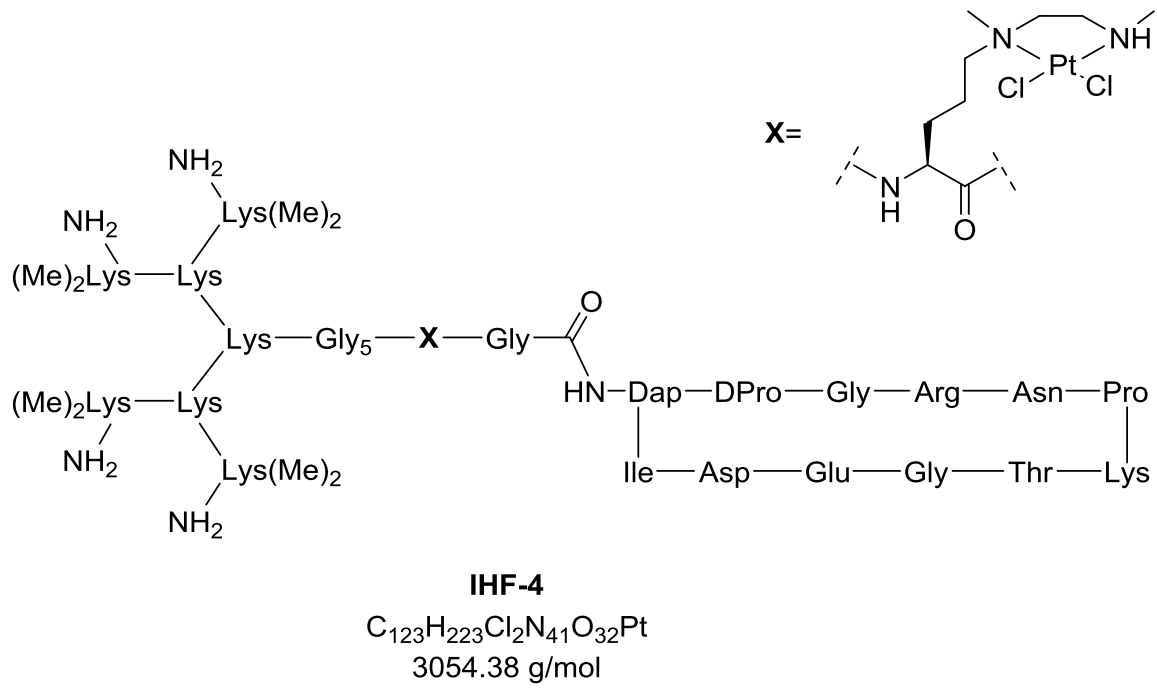

The peptide 23c (18.7 mg, $4.43 \mu \mathrm{mol})$ was dissolved in 95\% TFA in $\mathrm{H}_{2} \mathrm{O}(2 \mathrm{~mL})$ and stirred for $45 \mathrm{~min}$ at room temperature. Thereafter, was solvent blow dried with argon and the residue was purified by RP-HPLC yielding the product IHF-4 (6.9 mg, $2.26 \mu \mathrm{mol}, 51 \%)$ as a pale yellow crystalline solid.

HPLC Purification: Column Pep 2 (MN_Nucleodur100_5_C18, RP-C18, semi-preparative, $250 \times 10 \mathrm{~mm}, 5 \mu \mathrm{m}), 10-40 \%$ gradient of $B$ in $30 \mathrm{~min}$, flow rate $3 \mathrm{~mL} / \mathrm{min}, t_{R}=15.0,15.7$, $16.16 \mathrm{~min}$.

ESI-MS $m / z: 1019.2[\mathrm{M}+3 \mathrm{H}]^{3+}, 764.4[\mathrm{M}+4 \mathrm{H}]^{4+}, 611.7[\mathrm{M}+5 \mathrm{H}]^{5+}, 509.9[\mathrm{M}+6 \mathrm{H}]^{6+}$, $437.2[\mathrm{M}+7 \mathrm{H}]^{7+}$.

ESI-HRMS: calculated for $\left[\mathrm{C}_{123} \mathrm{H}_{226} \mathrm{Cl}_{2} \mathrm{~N}_{41} \mathrm{O}_{32} \mathrm{Pt}\right]^{3+}\left([\mathrm{M}+3 \mathrm{H}]^{3+}\right)=1019.2118$, found $=$ 1019.2139; calculated for $\left[\mathrm{C}_{123} \mathrm{H}_{227} \mathrm{Cl}_{2} \mathrm{~N}_{41} \mathrm{O}_{32} \mathrm{Pt}\right]^{4+}\left([\mathrm{M}+4 \mathrm{H}]^{4+}\right)=764.4105$, found $=$ 764.4124; calculated for $\left[\mathrm{C}_{123} \mathrm{H}_{228} \mathrm{Cl}_{2} \mathrm{~N}_{41} \mathrm{O}_{32} \mathrm{Pt}\right]^{5+}\left([\mathrm{M}+5 \mathrm{H}]^{5+}\right)=611.7299$, found = 611.7313. 


\subsubsection{Synthesis of the platinated lysine dendrimer}

[Boc-Lys $\left.(M e)_{2}\right]_{4}$ Lys $_{2}$ Lys-Gly $3-5-\left(N, N^{\prime}\right.$-dimethylethylenediamino)pentanoic acid $-\mathrm{Gly}_{3}-\mathrm{OH}$

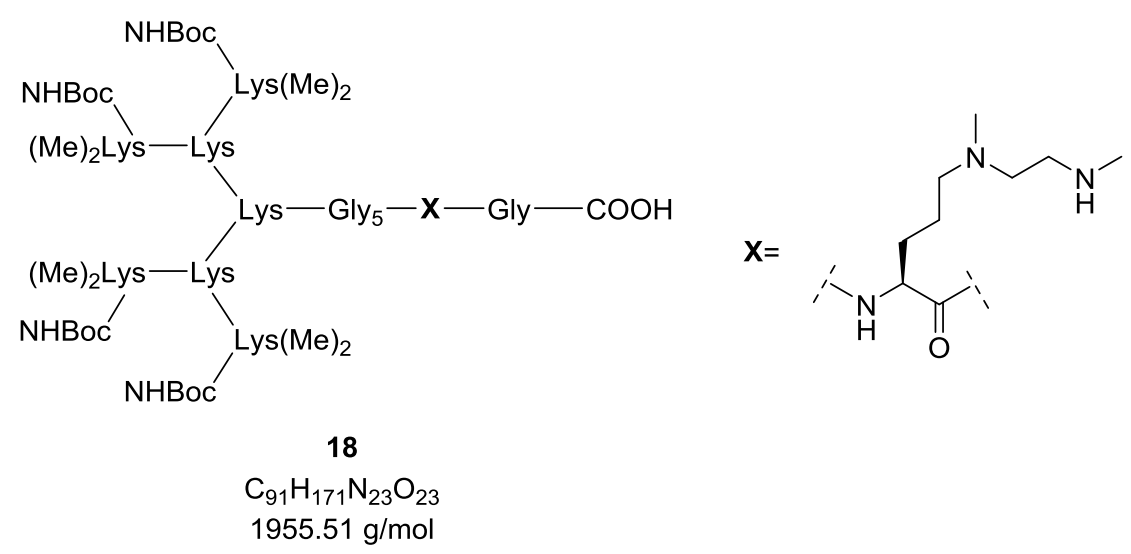

To a solution of peptide 17c ( $45 \mathrm{mg}, 22 \mu \mathrm{mol}, 1 \mathrm{eq}$ ) in $4.5 \mathrm{~mL}$ of dry DMF under argon atmosphere were added $\mathrm{Me}_{2} \mathrm{NH}_{\mathrm{BH}}(52 \mathrm{mg}, 0.88 \mathrm{mmol}, 40 \mathrm{eq})$ and $\mathrm{Pd}\left(\mathrm{PPh}_{3}\right)_{4}(2.55 \mathrm{mg}$, $2.2 \mu \mathrm{mol}, 0.1 \mathrm{eq})$. The reaction mixture was allowed to stir for $6 \mathrm{~h}$ at room temperature. The solvent was removed under vacuum and the residue was purified by RP-HPLC yielding the peptide 18 (17 mg, $8.7 \mu \mathrm{mol}, 40 \%$ ) as a white solid.

HPLC Purification: Column Pep 1 (MN_Nucleodur100_5_C18, RP-C18, preparative, $250 \times 21.0 \mathrm{~mm}, 5 \mu \mathrm{m}), 10-60 \%$ gradient of $B$ in $30 \mathrm{~min}$, flow rate $10 \mathrm{~mL} / \mathrm{min}$, $t_{R}=21.81 \mathrm{~min}$.

ESI-MS $m / z: 978.7[\mathrm{M}+2 \mathrm{H}]^{2+}, 652.8[\mathrm{M}+3 \mathrm{H}]^{3+}, 489.8[\mathrm{M}+4 \mathrm{H}]^{4+}, 392.1[\mathrm{M}+5 \mathrm{H}]^{5+}$.

ESI-HRMS: calculated for $\left[\mathrm{C}_{91} \mathrm{H}_{173} \mathrm{~N}_{23} \mathrm{O}_{23}\right]^{2+}\left([\mathrm{M}+2 \mathrm{H}]^{2+}\right)=978.6548$, found $=978.6550$; calculated for $\left[\mathrm{C}_{91} \mathrm{H}_{174} \mathrm{~N}_{23} \mathrm{O}_{23}\right]^{3+}\left([\mathrm{M}+3 \mathrm{H}]^{3+}\right)=652.7723$, found $=652.7728$; calculated for $\left[\mathrm{C}_{95} \mathrm{H}_{175} \mathrm{~N}_{23} \mathrm{O}_{23}\right]^{4+}\left([\mathrm{M}+4 \mathrm{H}]^{4+}\right)=489.8310$, found $=489.8316$; calculated for $\left.\left[\mathrm{C}_{95} \mathrm{H}_{176} \mathrm{~N}_{23} \mathrm{O}_{23}\right]^{5+}[\mathrm{M}+5 \mathrm{H}]^{5+}\right)=392.0663$, found $=392.0660$. 
[Boc-Lys(Me $\left.)_{2}\right]_{4}$ Lys 2 Lys-Gly $-5-\left(N, N^{\prime}\right.$-dimethylethylenediamino)pentanoic acid

-Gly ${ }_{3}$-dichloroplatinum(II)

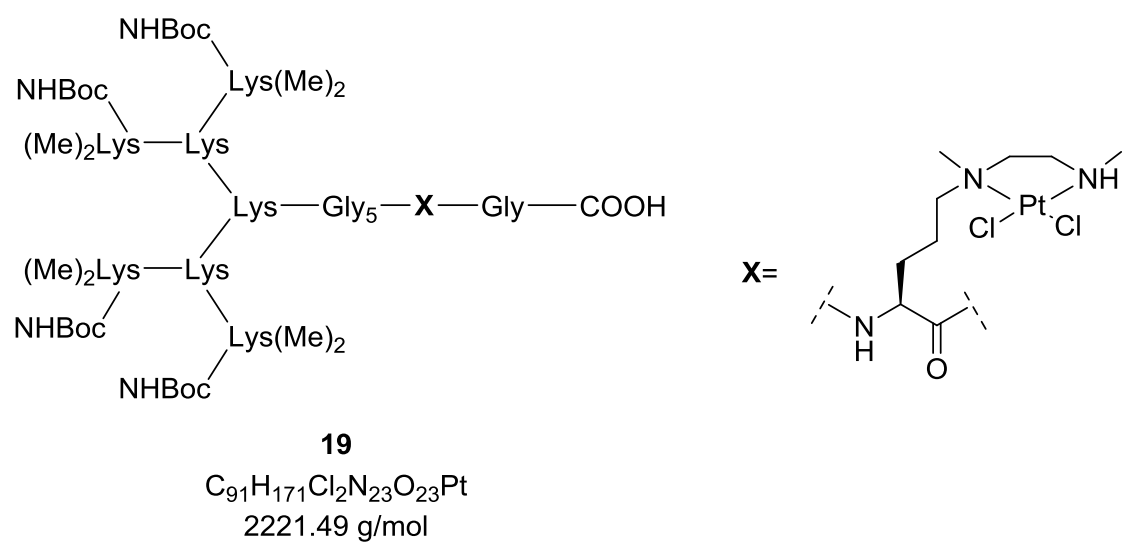

A solution of $\mathrm{K}_{2} \mathrm{PtCl}_{4}(108.34 \mathrm{mg}, 0.261 \mathrm{mmol}, 30 \mathrm{eq})$ and peptide 18 (17 mg, $8.7 \mu \mathrm{mol}$, 1 eq) in $\mathrm{DMF} / \mathrm{H}_{2} \mathrm{O}(4 \mathrm{~mL}, 9 / 1)$ was stirred at room temperature for $48 \mathrm{~h}$ in dark. Thereafter, the solvent was removed under reduced pressure and the residue was purified by RP-HPLC yielding the product 19 (12.18 mg, $5.48 \mu \mathrm{mol}, 63 \%)$ as a white solid.

HPLC Purification: Column Pep 1 (MN_Nucleodur100_5_C18, RP-C18, preparative, $250 \times 21.0 \mathrm{~mm}, 5 \mu \mathrm{m}), \quad 5-60 \%$ gradient of $B$ in $30 \mathrm{~min}$, flow rate $10 \mathrm{~mL} / \mathrm{min}, t_{R}=$ $25.33 \mathrm{~min}$.

ESI-MS $m / z: 1111.6[\mathrm{M}+2 \mathrm{H}]^{2+}, 741.1[\mathrm{M}+3 \mathrm{H}]^{3+}, 556.1[\mathrm{M}+4 \mathrm{H}]^{4+}, 446.1[\mathrm{M}+5 \mathrm{H}]^{5+}$.

ESI-HRMS: calculated for $\left[\mathrm{C}_{91} \mathrm{H}_{173} \mathrm{Cl}_{2} \mathrm{~N}_{23} \mathrm{O}_{23} \mathrm{Pt}\right]^{2+}\left([\mathrm{M}+2 \mathrm{H}]^{2+}\right)=1111.6052$, found $=$ 1111.6068; calculated for $\left[\mathrm{C}_{91} \mathrm{H}_{174} \mathrm{Cl}_{2} \mathrm{~N}_{23} \mathrm{O}_{23} \mathrm{Pt}\right]^{3+}\left([\mathrm{M}+3 \mathrm{H}]^{3+}\right)=741.0723$, found $=$ 741.0737; calculated for $\left[\mathrm{C}_{91} \mathrm{H}_{175} \mathrm{Cl}_{2} \mathrm{~N}_{23} \mathrm{O}_{23} \mathrm{Pt}\right]^{4+}\left([\mathrm{M}+4 \mathrm{H}]^{4+}\right)=556.0560$, found $=556.0570$. 


\section{[Lys(Me $\left.)_{2}\right]_{4}$ Lys $_{2}$ Lys-Gly ${ }_{3}-5-\left(N, N^{\prime}\right.$-dimethylethylenediamino $)$ pentanoic acid}

\section{-Gly $\mathbf{y}_{3}$-dichloroplatinum(II)}
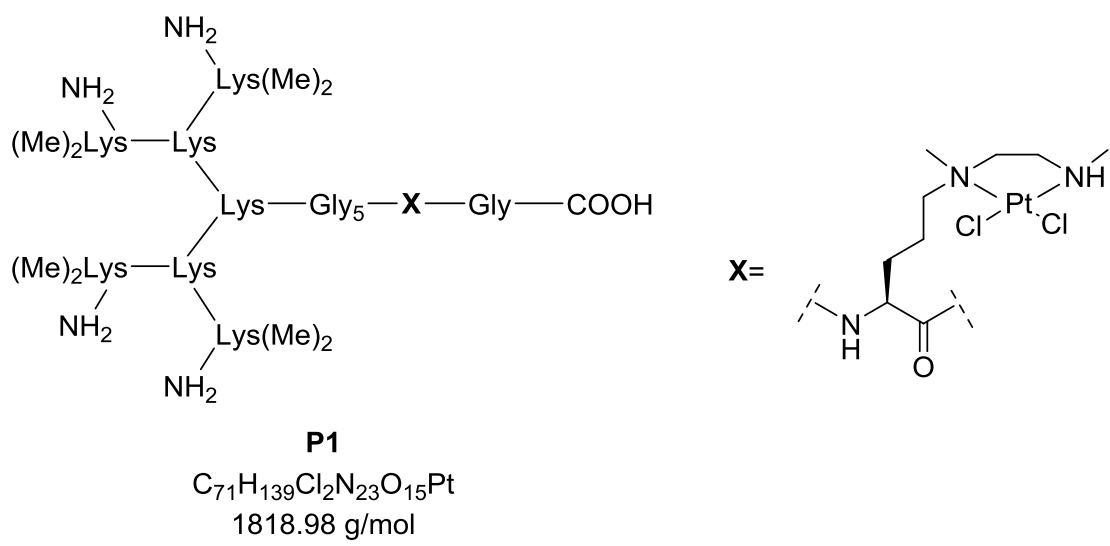

The peptide 19 (12.18 mg, $5.48 \mu \mathrm{mol})$ was dissolved in 95\% TFA in $\mathrm{H}_{2} \mathrm{O}(1.5 \mathrm{~mL})$ and stirred for $45 \mathrm{~min}$ at room temperature. Thereafter, the solvent was blow dried with argon and the residue was purified by RP-HPLC yielding the product P1 $(4.78 \mathrm{mg}$, $2.63 \mu \mathrm{mol}, 48 \%)$ as a pale yellow crystalline solid.

HPLC Purification: Column Pep 2 (MN_Nucleodur100_5_C18, RP-C18, semi-preparative, $250 \times 10 \mathrm{~mm}, 5 \mu \mathrm{m}), 5-30 \%$ gradient of $B$ in $30 \mathrm{~min}$, flow rate $3 \mathrm{~mL} / \mathrm{min}, t_{R}=17.91$, 19.38, $20.74 \mathrm{~min}$.

ESI-MS m/z: $911.0[\mathrm{M}+2 \mathrm{H}]^{2+}, 607.7[\mathrm{M}+3 \mathrm{H}]^{3+}, 456.0[\mathrm{M}+4 \mathrm{H}]^{4+}, 366.0[\mathrm{M}+5 \mathrm{H}]^{5+}$.

ESI-HRMS: calculated for $\left[\mathrm{C}_{71} \mathrm{H}_{141} \mathrm{Cl}_{2} \mathrm{~N}_{23} \mathrm{O}_{15} \mathrm{Pt}\right]^{2+}\left([\mathrm{M}+2 \mathrm{H}]^{2+}\right)=910.9997$, found = 910.9999; calculated for $\left[\mathrm{C}_{71} \mathrm{H}_{142} \mathrm{Cl}_{2} \mathrm{~N}_{23} \mathrm{O}_{15} \mathrm{Pt}\right]^{3+}\left([\mathrm{M}+3 \mathrm{H}]^{3+}\right)=607.6689$, found $=607.6694$; calculated for $\left[\mathrm{C}_{71} \mathrm{H}_{143} \mathrm{Cl}_{2} \mathrm{~N}_{23} \mathrm{O}_{15} \mathrm{Pt}\right]^{4+}\left([\mathrm{M}+4 \mathrm{H}]^{4+}\right)=456.0035$, found $=456.0041$. 


\subsection{Synthesis of Binuclear Histidine Mimicking Amino Acid}

\section{$N, N^{\prime}, N^{\prime \prime}$-tri(tosyl)diethylenetriamine ${ }^{[216]}$}

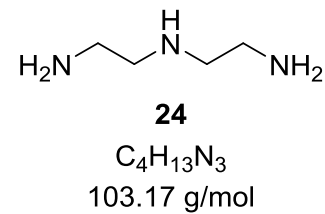

$103.17 \mathrm{~g} / \mathrm{mol}$

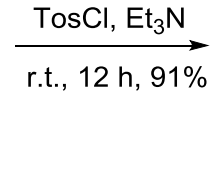

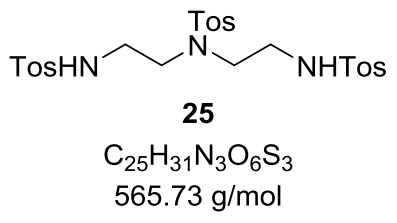

To a solution of diethylenetriamine $24(9.4 \mathrm{~mL}, 0.087 \mathrm{~mol}, 1 \mathrm{eq})$ and triethylamine $(40 \mathrm{~mL}, 0.287 \mathrm{~mol}, 3.3 \mathrm{eq})$ in dichloromethane $(400 \mathrm{~mL})$ was added tosylchloride $(51.48 \mathrm{~g}, 0.27 \mathrm{~mol}, 3.1 \mathrm{eq})$ at $0{ }^{\circ} \mathrm{C}$. After stirring the reaction for $12 \mathrm{~h}$ at room temperature the solvent was removed under reduced pressure. Recrystallization in methanol yielded $N, N^{\prime}, N^{\prime \prime}$-tri(tosyl)diethylenetriamine 25 (44.8 g, $\left.0.079 \mathrm{~mol}, 91 \%\right)$.

$\boldsymbol{R}_{\mathbf{f}}=0.8($ Methanol/Dichloromethane $=1 / 9, \mathrm{v} / \mathrm{v})$.

${ }^{1} \mathrm{H}-\mathrm{NMR}\left(300 \mathrm{MHz}, \mathrm{DMSO}-\mathrm{d}_{6}\right): \delta(\mathrm{ppm})=7.67-7.62(\mathrm{~m}, 6-\mathrm{H}, \mathrm{Ar}-\mathrm{H}), 7.56-7.53(\mathrm{~m}, 2-\mathrm{H}, \mathrm{N}-$ $\mathrm{H}), 7.40-7.35(\mathrm{~m}, 6-\mathrm{H}, \mathrm{Ar}-\mathrm{H}), 3.04\left(\mathrm{t},{ }^{3} \mathrm{~J}_{\mathrm{H}-\mathrm{H}}=7.5 \mathrm{~Hz}, 4-\mathrm{H}, \mathrm{CH}_{2}\right), 2.83\left(\mathrm{t},{ }^{3} \mathrm{~J}_{\mathrm{H}-\mathrm{H}}=7.5 \mathrm{~Hz}, 4-\mathrm{H}\right.$, $\left.\mathrm{CH}_{2}\right), 2.39\left(\mathrm{~s}, 9-\mathrm{H}, \mathrm{CH}_{3}\right)$.

ESI-MS m/z: $566.0[\mathrm{M}+\mathrm{H}]^{+}, 587.9[\mathrm{M}+\mathrm{Na}]^{+}, 564.1[\mathrm{M}-\mathrm{H}]^{-}, 1129.3[2 \mathrm{M}-\mathrm{H}]^{-}$.

ESI-HRMS: calculated for $\left[\mathrm{C}_{25} \mathrm{H}_{32} \mathrm{~N}_{3} \mathrm{O}_{6} \mathrm{~S}_{3}\right]^{+}\left([\mathrm{M}+\mathrm{H}]^{+}\right)=566.1453$, found = 566.1447; calculated for $\left[\mathrm{C}_{25} \mathrm{H}_{30} \mathrm{~N}_{3} \mathrm{O}_{6} \mathrm{~S}_{3}\right]^{-}\left([\mathrm{M}-\mathrm{H}]^{-}\right)=564.1296$, found $=564.1303$. 


\section{1,4,7-Tritosyl-1,4,7-triazacyclononane ${ }^{[217]}$}



25

$\mathrm{C}_{25} \mathrm{H}_{31} \mathrm{~N}_{3} \mathrm{O}_{6} \mathrm{~S}_{3}$

$565.73 \mathrm{~g} / \mathrm{mol}$

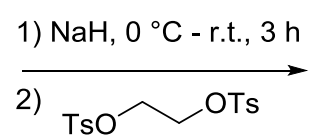

$120{ }^{\circ} \mathrm{C}, 48 \mathrm{~h}, 86 \%$

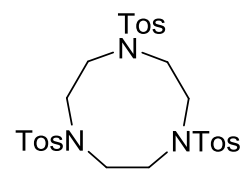

26

$\mathrm{C}_{27} \mathrm{H}_{33} \mathrm{~N}_{3} \mathrm{O}_{6} \mathrm{~S}_{3}$ $591.76 \mathrm{~g} / \mathrm{mol}$

To a solution of sodium hydride $(5.7 \mathrm{~g}, 0.237 \mathrm{~mol}, 3 \mathrm{eq})$ in dry DMF (100 mL) $N, N^{\prime}, N^{\prime \prime}$-tri(tosyl)diethylenetriamine 25 (44.8 g, $\left.0.079 \mathrm{~mol}, 1 \mathrm{eq}\right)$ dissolved in dry DMF $\left(300 \mathrm{~mL}\right.$ ) was added under argon at $0{ }^{\circ} \mathrm{C}$. The reaction mixture was stirred for $1 \mathrm{~h}$ at $0{ }^{\circ} \mathrm{C}$ and $2 \mathrm{~h}$ at room temperature. Thereafter, a solution of ethylene ditosylate $(29.23 \mathrm{~g}$, $0.079 \mathrm{~mol}, 1 \mathrm{eq})$ in DMF $(200 \mathrm{~mL})$ was added to it dropwise $120^{\circ} \mathrm{C}$ over a period of $45 \mathrm{~min}$ and subsequently stirred at $120^{\circ} \mathrm{C}$ for $48 \mathrm{~h}$. After destroying the excess sodium hydride by dropwise addition of $\mathrm{MeOH}(25 \mathrm{~mL})$, the solvents were removed under reduced pressure and ice cold water $(500 \mathrm{~mL})$ was added to the mixture. Filtration followed by recrystallization in ethanol yielded 1,4,7-Tritosyl-1,4,7-triazacyclononane (40.24 g, $0.068 \mathrm{~mol}, 86 \%)$.

$\boldsymbol{R}_{\mathbf{f}}=0.56$ (Methanol/Dichloromethane $\left.=1 / 9, \mathrm{v} / \mathrm{v}\right)$.

${ }^{1} \mathrm{H}-\mathrm{NMR}\left(300 \mathrm{MHz}, \mathrm{CDCl}_{3}\right): \delta(\mathrm{ppm})=7.69\left(\mathrm{~d},{ }^{3} J_{\mathrm{H}-\mathrm{H}}=9 \mathrm{~Hz}, 6-\mathrm{H}, \mathrm{Ar}-\mathrm{H}\right), 7.32\left(\mathrm{~d},{ }^{4} J_{\mathrm{H}-\mathrm{H}}=6 \mathrm{~Hz}\right.$, 6-H, Ar-H), $3.42\left(\mathrm{~s}, 12-\mathrm{H}, \mathrm{CH}_{2}\right), 2.41\left(\mathrm{~s}, 9-\mathrm{H}, \mathrm{CH}_{3}\right)$.

ESI-MS m/z: $592.2[\mathrm{M}+\mathrm{H}]^{+}, 614.2[\mathrm{M}+\mathrm{Na}]^{+}, 590.1[\mathrm{M}-\mathrm{H}]^{-}$.

ESI-HRMS: calculated for $\left[\mathrm{C}_{27} \mathrm{H}_{32} \mathrm{~N}_{3} \mathrm{O}_{6} \mathrm{~S}_{3}\right]^{-}\left([\mathrm{M}-\mathrm{H}]^{-}\right)=590.1459$, found = 590.1454; calculated for $\left[\mathrm{C}_{27} \mathrm{H}_{33} \mathrm{~N}_{3} \mathrm{O}_{6} \mathrm{~S}_{3} \mathrm{Na}\right]^{+}\left([\mathrm{M}+\mathrm{Na}]^{+}\right)=614.1424$, found $=614.1415$. 


\section{1,4-Bis(tert-butoxycarbonyl)-1,4,7-triazacyclononane ${ }^{[218]}$}

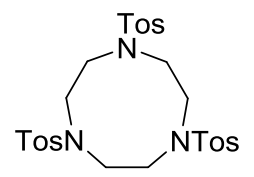

26

$\mathrm{C}_{27} \mathrm{H}_{33} \mathrm{~N}_{3} \mathrm{O}_{6} \mathrm{~S}_{3}$ $591.76 \mathrm{~g} / \mathrm{mol}$

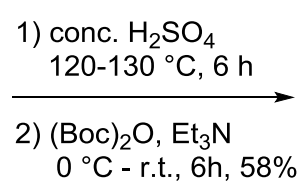

$0{ }^{\circ} \mathrm{C}-$ r.t., 6 h, $58 \%$

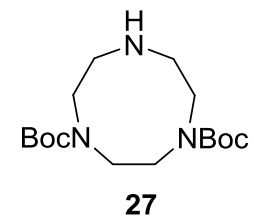

$\mathrm{C}_{16} \mathrm{H}_{31} \mathrm{~N}_{3} \mathrm{O}_{4}$ $329.44 \mathrm{~g} / \mathrm{mol}$

Tritosyl-1,4,7-triazacyclononane $26(10 \mathrm{~g}, 16.9 \mathrm{mmol})$ was refluxed at $120-130{ }^{\circ} \mathrm{C}$ for $6 \mathrm{~h}$ in concentrated $\mathrm{H}_{2} \mathrm{SO}_{4}$. After cooling the reaction mixture to $0{ }^{\circ} \mathrm{C}$ it was poured into ice cold ethanol $(600 \mathrm{~mL})$. Addition of ice cold diethyl ether $(600 \mathrm{~mL})$ led to precipitation of a pale yellow solid. The solid was filtered and dissolved in conc. $\mathrm{NaOH}$ (aq). The water phase was extracted with $\mathrm{CHCl}_{3}(3 \times 300 \mathrm{~mL})$, dried over $\mathrm{Na}_{2} \mathrm{SO}_{4}$ and concentrated under reduced pressure (>300 mbar, product is volatile). Triazacyclononane obtained as a pale yellow oil was dissolved in dry DCM $(40 \mathrm{~mL})$ and $\mathrm{Et}_{3} \mathrm{~N}(4.2 \mathrm{~mL}, 30.42 \mathrm{mmol}, 1.8 \mathrm{eq})$ was added to it under argon atmosphere. Thereafter, a solution of $(\mathrm{Boc})_{2} \mathrm{O}(6.64 \mathrm{~g}, 30.42$ mmol, $1.8 \mathrm{eq})$ in dry DCM $(20 \mathrm{~mL})$ was slowly added at $0{ }^{\circ} \mathrm{C}$ over a period of $30 \mathrm{~min}$ and the reaction was continued to stir for another $6 \mathrm{~h}$ at room temperature. The solvent was removed under reduced pressure. Purification by column chromatography [eluent: EtoAc/MeOH, 95/5 (v/v)] yielded 1,4-Bis(tert-butoxycarbonyl)-1,4,7-triazacyclononane 27 (3.2 $\mathrm{g}, 9.71 \mathrm{mmol}, 58 \%)$ as a viscous colourless oil .

$\boldsymbol{R}_{\mathrm{f}}=0.37$ (Methanol/Dichloromethane $\left.=1 / 4, \mathrm{v} / \mathrm{v}\right)$.

${ }^{1} \mathrm{H}-\mathrm{NMR}\left(300 \mathrm{MHz}, \mathrm{CDCl}_{3}\right): \delta(\mathrm{ppm})=3.48-3.41\left(\mathrm{~m}, 4-\mathrm{H}, 5-\mathrm{CH}_{2}, 6-\mathrm{CH}_{2}\right), 3.28-3.21(\mathrm{~m}, 4-\mathrm{H}$, 3- $\left.\mathrm{CH}_{2}, 8-\mathrm{CH}_{2}\right), 2.94-2.90\left(\mathrm{~m}, 4-\mathrm{H}, 2-\mathrm{CH}_{2}, 9-\mathrm{CH}_{2}\right), 1.47\left(\mathrm{~s}, 18-\mathrm{H},{ }^{t} \mathrm{Boc}-\mathrm{CH}_{3}\right)$.

ESI-MS m/z: $330.2[\mathrm{M}+\mathrm{H}]^{+}, 352.2[\mathrm{M}+\mathrm{Na}]^{+}, 659.5[2 \mathrm{M}+\mathrm{H}]^{+}, 681.5[2 \mathrm{M}+\mathrm{Na}]^{+}$. 
ESI-HRMS: calculated for $\left[\mathrm{C}_{16} \mathrm{H}_{32} \mathrm{~N}_{3} \mathrm{O}_{4}\right]^{+}\left([\mathrm{M}+\mathrm{H}]^{+}\right)=330.2387$, found $=330.2387$; calculated for $\left[\mathrm{C}_{16} \mathrm{H}_{31} \mathrm{~N}_{3} \mathrm{O}_{4} \mathrm{Na}\right]^{+}\left([\mathrm{M}+\mathrm{Na}]^{+}\right)=352.2206$, found $=352.2207$.

\section{(2-Azidoethyl) Tosylate}

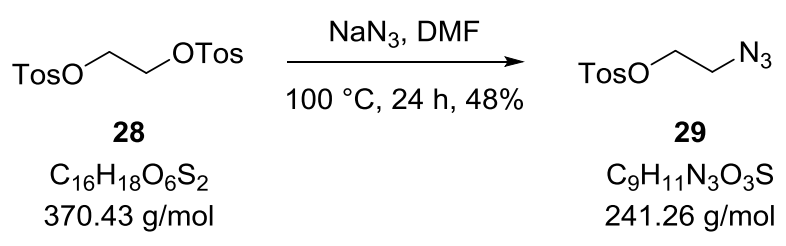

Sodium azide (4.2 g, $64.8 \mathrm{mmol}, 1.2 \mathrm{eq})$ was added to a solution of 1,2bis(tosyloxy)ethane 28 (20 g, $54 \mathrm{mmol}, 1 \mathrm{eq})$ in dry DMF (140 mL) and stirred at $100{ }^{\circ} \mathrm{C}$ for $24 \mathrm{~h}$. The solvent was removed under reduced pressure. The residue was suspended in water $(100 \mathrm{~mL})$, extracted with ether $(3 \times 300 \mathrm{~mL})$, dried over $\mathrm{Na}_{2} \mathrm{SO}_{4}$ and concentrated in vacuum. Purification by column chromatography (eluent: dichloromethane) yielded (2-azidoethyl)tosylate 29 as a colourless oil $(6.25 \mathrm{~g}$, $25.6 \mathrm{mmol}, 48 \%)$.

$\boldsymbol{R}_{\mathrm{f}}=0.77$ (dichloromethane).

${ }^{1} \mathrm{H}-\mathrm{NMR}\left(300 \mathrm{MHz}, \mathrm{CDCl}_{3}\right): \delta(\mathrm{ppm})=7.81\left(\mathrm{dd},{ }^{3} \mathrm{~J}_{\mathrm{H}-\mathrm{H}}=8.4 \mathrm{~Hz}, 2-\mathrm{H}, \mathrm{Ar}-\mathrm{H}\right), 7.36\left(\mathrm{dd},{ }^{3} J_{\mathrm{H}-\mathrm{H}}=\right.$ $8.1 \mathrm{~Hz}, 2-\mathrm{H}, \mathrm{Ar}-\mathrm{H}), 4.16\left(\mathrm{t},{ }^{3} J_{\mathrm{H}-\mathrm{H}}=5.1 \mathrm{~Hz}, 2-\mathrm{H}, \mathrm{CH}_{2}\right), 3.5-3.45\left(\mathrm{~m}, 2-\mathrm{H}, \mathrm{CH}_{2}\right), 2.45(\mathrm{~s}, 3-\mathrm{H}$, $\left.\mathrm{CH}_{3}\right)$.

ESI-MS $m / z: 264.1[\mathrm{M}+\mathrm{Na}]^{+}, 505.1[2 \mathrm{M}+\mathrm{Na}]^{+}$.

ESI-HRMS: calculated for $\left[\mathrm{C}_{9} \mathrm{H}_{11} \mathrm{~N}_{3} \mathrm{O}_{3} \mathrm{SNa}\right]^{+}\left([\mathrm{M}+\mathrm{Na}]^{+}\right)=264.0413$, found $=264.0417$. 


\section{7-(2-Azidoethyl)-1,4-bis(tert-butoxycarbonyl)-1,4,7-triazacyclononane ${ }^{[11]}$}

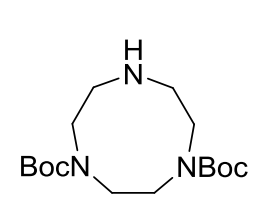

27

$\mathrm{C}_{16} \mathrm{H}_{13} \mathrm{~N}_{3} \mathrm{O}_{4}$ $329.44 \mathrm{~g} / \mathrm{mol}$<smiles>NCCOCCOCCO</smiles>

29

$\mathrm{C}_{9} \mathrm{H}_{11} \mathrm{~N}_{3} \mathrm{O}_{3} \mathrm{~S}$ $241.26 \mathrm{~g} / \mathrm{mol}$



30

$\mathrm{C}_{18} \mathrm{H}_{34} \mathrm{~N}_{6} \mathrm{O}_{4}$ $398.508 \mathrm{~g} / \mathrm{mol}$

1,4-bis(tert-butoxycarbonyl)-1,4,7-triazacylonane 27 (1.12 g, $3.4 \mathrm{mmol}, 1 \mathrm{eq}), \mathrm{K}_{2} \mathrm{CO}_{3}(0.56$ g, $4.08 \mathrm{mmol}, 1.2 \mathrm{eq})$ and (2-azidoethyl)tosylate $(0.9 \mathrm{~g}, 3.74 \mathrm{mmol}, 1.1 \mathrm{eq})$ were suspended in dry MeCN $(25 \mathrm{~mL})$ under inert atmosphere. The reaction mixture was refluxed for $48 \mathrm{~h}$ followed by cooling to room temperature and filtration. After removing the solvent under reduced pressure and the residue was purified by column chromatography [eluent: DCM (100\%) $\rightarrow$ DCM/MeOH, 95/5 (v/v)]. The product 7-(2Azidoethyl)-1,4-bis(tert-butoxycarbonyl)-1,4,7-triazacyclononane 30 (1.1 g, 2.76 mmol, $81 \%)$ was obtained as a colourless oil.

$\boldsymbol{R}_{\mathrm{f}}=0.79($ Methanol/Dichloromethane $=5 / 95, \mathrm{v} / \mathrm{v})$.

${ }^{1} \mathrm{H}-\mathrm{NMR}\left(300 \mathrm{MHz}, \mathrm{CDCl}_{3}\right): \delta(\mathrm{ppm})=3.47-3.43\left(\mathrm{~m}, 4-\mathrm{H}, \mathrm{CH}_{2}\right)$, 3.33-3.23 (m, 6- $\left.\mathrm{H}, \mathrm{CH}_{2}\right)$, 2.78-2.69 (m, 6- $\left.\mathrm{H}, \mathrm{CH}_{2}\right), 1.47\left(\mathrm{~s}, 18-\mathrm{H},{ }^{t}\right.$ Boc- $\left.\mathrm{CH}_{3}\right)$.

ESI-MS m/z: $399.3[\mathrm{M}+\mathrm{H}]^{+}, 421.2[\mathrm{M}+\mathrm{Na}]^{+}, 819.5[2 \mathrm{M}+\mathrm{Na}]^{+}$.

ESI-HRMS: calculated for $\left[\mathrm{C}_{18} \mathrm{H}_{35} \mathrm{~N}_{6} \mathrm{O}_{4}\right]^{+}\left([\mathrm{M}+\mathrm{H}]^{+}\right)=399.2714$, found = 399.2714; calculated for $\left[\mathrm{C}_{18} \mathrm{H}_{34} \mathrm{~N}_{6} \mathrm{O}_{4} \mathrm{Na}\right]^{+}\left([\mathrm{M}+\mathrm{Na}]^{+}\right)=421.2534$, found $=421.2534$. 




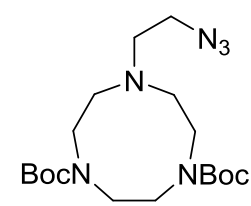

30

$\mathrm{C}_{18} \mathrm{H}_{34} \mathrm{~N}_{6} \mathrm{O}_{4}$ $398.508 \mathrm{~g} / \mathrm{mol}$



31

$\mathrm{C}_{18} \mathrm{H}_{34} \mathrm{~N}_{6} \mathrm{O}_{4}$

$335.36 \mathrm{~g} / \mathrm{mol}$

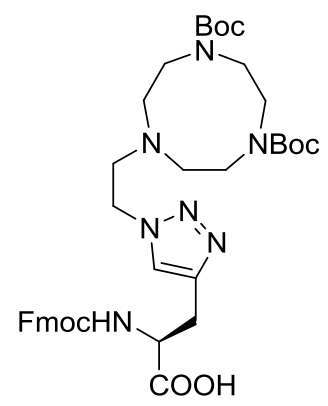

32

$\mathrm{C}_{38} \mathrm{H}_{51} \mathrm{~N}_{7} \mathrm{O}_{8}$ $733.88 \mathrm{~g} / \mathrm{mol}$

After thoroughly degassing a solution of 7-(2-Azidoethyl)-1,4-bis(tert-butoxycarbonyl)1,4,7-triazacyclononane 30 (1 g, 2.52 mmol, 1 eq) and Fmoc-L-propargyl-glycine 31 (0.7 g, $2.52 \mathrm{mmol}$, 1eq) in dry DMF (13.5 mL), Cul (96 mg, $0.5 \mathrm{mmol}, 0.2 \mathrm{eq})$ and sodium ascorbate $(0.5 \mathrm{~g}, 2.52 \mathrm{mmol}, 1 \mathrm{eq})$ were added to it under argon. The reaction mixture was stirred at room temperature for $12 \mathrm{~h}$ followed by removing the solvent under reduced pressure. Purification of the residue by column chromatography [eluent: $\mathrm{MeOH} / \mathrm{DCM} 10 / 90, \mathrm{v} / \mathrm{v}$ ] afforded the product $N^{\alpha}$-Fmoc- $\beta$-[1-(2-bbt-ethyl)-1,2,3-triazol-4yl]-L-alanine 32 as a bright yellow solid (1.54 g, $2.1 \mathrm{mmol}, 83 \%)$.

$\boldsymbol{R}_{\mathrm{f}}=0.75$ (Methanol/Dichloromethane $\left.=20 / 80, \mathrm{v} / \mathrm{v}\right)$.

${ }^{1} \mathrm{H}-\mathrm{NMR}\left(300 \mathrm{MHz}, \mathrm{DMSO}-\mathrm{d}_{6}\right): \delta(\mathrm{ppm})=7.88-7.86(\mathrm{~m}, 2-\mathrm{H}, \mathrm{Ar}-\mathrm{CH}), 7.75(\mathrm{~s}, 1-\mathrm{H}$, triazolH), 7.67-7.64 (m, 2-H, Ar-CH), 7.42-7.28 (m, 4-H, Ar-CH), 7.02 (sbr, 1-H, NH), 4.36-4.27 (m, 2-H, $\left.\mathrm{N}_{\mathrm{Ar}} \mathrm{CH}_{2}\right), 4.21-4.13\left(\mathrm{~m}, 3-\mathrm{H}, \mathrm{Fmoc}-\mathrm{CH}, \mathrm{Fmoc}-\mathrm{CH}_{2}\right), 4.10-4.05(\mathrm{~m}, 1-\mathrm{H}, \mathrm{H \alpha}), 3.27-3.16$ ( $m, 4-\mathrm{H}$, tacn- $\left.\mathrm{CH}_{2}\right), 3.12-3.01\left(\mathrm{~m}, 5-\mathrm{H}\right.$, tacn- $\left.\mathrm{CH}_{2}, \beta-\mathrm{CH}_{2}\right), 2.94-2.81\left(\mathrm{~m}, 3-\mathrm{H}, \mathrm{NCH}_{2}, \beta-\mathrm{CH}_{2}\right)$, 2.57-2.52 (m, 4-H, tacn- $\left.\mathrm{CH}_{2}\right), 1.37,1.35\left(2 \times \mathrm{s}, 18-\mathrm{H},{ }^{t}\right.$ Boc- $\left.\mathrm{CH}_{3}\right)$. 
${ }^{13} \mathrm{C}-\mathrm{NMR}\left(100 \mathrm{MHz}, \mathrm{CDCl}_{3}\right): \delta(\mathrm{ppm})=155.51(\mathrm{COOH}), 154.60(\mathrm{C}=0), 154.56(\mathrm{C}=\mathrm{O})$, 143.93 (Ar-C), 143.78 (Ar-C), 143.75 (Ar-C), 140.58 (Ar-C), 127.49 (Ar-C), 126.96 (Ar-C), $125.14(\mathrm{Ar}-\mathrm{C}), 122.64(\mathrm{Ar}-\mathrm{C}), 119.96(\mathrm{Ar}-\mathrm{C}), 78.49\left[\mathrm{O}-\mathrm{C}\left(\mathrm{CH}_{3}\right)_{3}\right], 78.40\left[\mathrm{O}-\mathrm{C}\left(\mathrm{CH}_{3}\right)_{3}\right], 78.36$ $\left[\mathrm{O}-\mathrm{C}\left(\mathrm{CH}_{3}\right)_{3}\right], 65.52\left(\mathrm{Fmoc}-\mathrm{CH}_{2}\right), 55.68,55.01,53.80,53.49,53.37,52.99,50.44,49.75$, 49.30, 49.04, 48.51, 48.28, 48.00, 47.86, 46.59 (Fmoc-CH), $28.04\left[\mathrm{C}\left(\mathrm{CH}_{3}\right)_{3}\right]$.

ESI-MS m/z: $734.4[\mathrm{M}+\mathrm{H}]^{+}, 756.4[\mathrm{M}+\mathrm{Na}]^{+}$.

ESI-HRMS: calculated for $\left[\mathrm{C}_{38} \mathrm{H}_{52} \mathrm{~N}_{7} \mathrm{O}_{8}\right]^{+}\left([\mathrm{M}+\mathrm{H}]^{+}\right)=734.3872$, found = 734.3861; calculated for $\left[\mathrm{C}_{38} \mathrm{H}_{51} \mathrm{~N}_{7} \mathrm{O}_{8} \mathrm{Na}\right]^{+}\left([\mathrm{M}+\mathrm{Na}]^{+}\right)=756.3680$, found $=756.3691$.

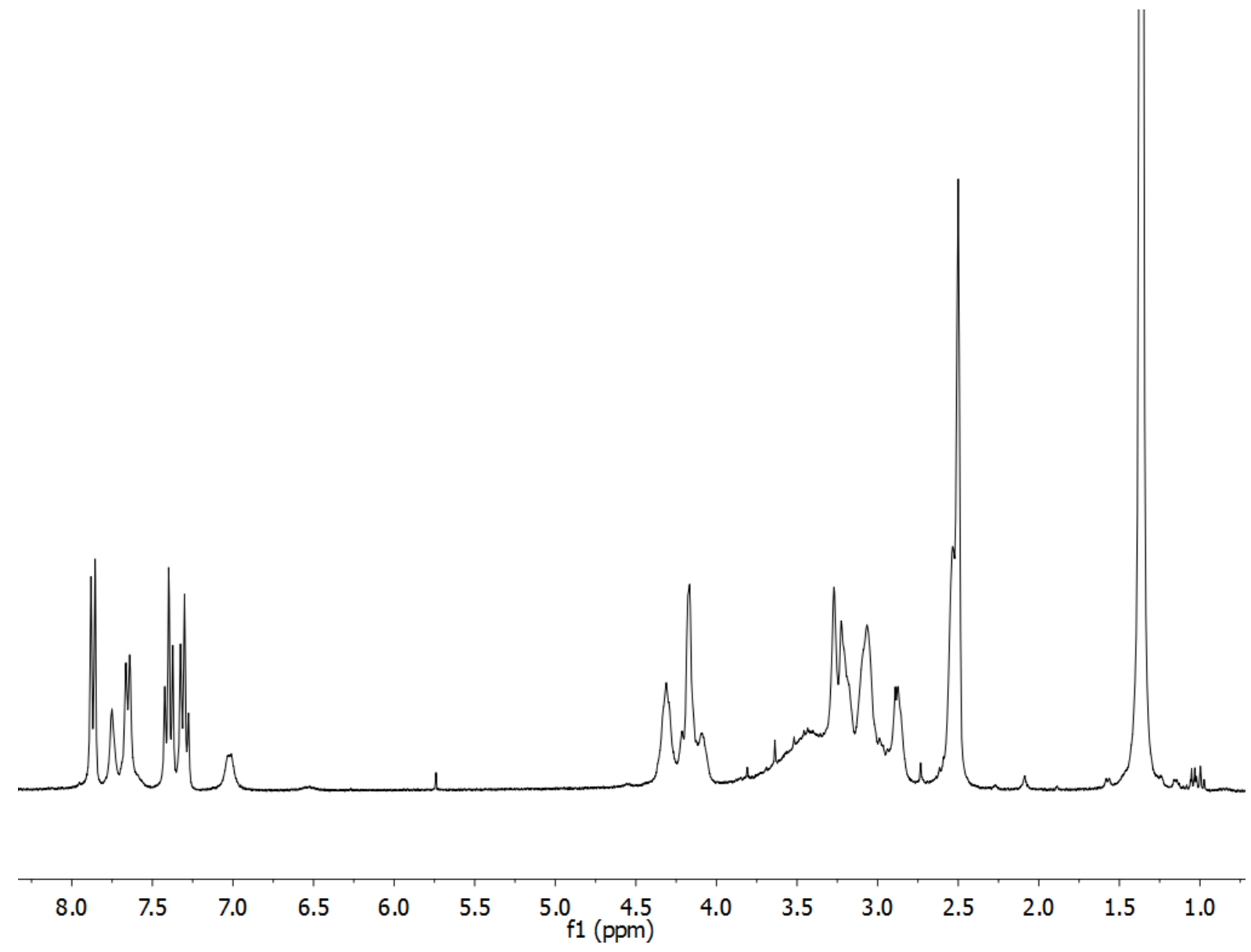

Figure 7.5: ${ }^{1} \mathrm{H}-\mathrm{NMR}$ spectra of $N^{\alpha}$-Fmoc- $\beta$-[1-(2-bbt-ethyl)-1,2,3-triazol-4-yl]-L-alanine 32. 




Figure 7.6: ${ }^{13} \mathrm{C}-\mathrm{NMR}$ spectra of $N^{\alpha}$-Fmoc- $\beta$-[1-(2-bbt-ethyl)-1,2,3-triazol-4-yl]-L-alanine 32. 


\subsection{Preparation of the Zinc Finger Domains}

\subsubsection{Solid phase synthesis of $\mathrm{Zf3}$ domains}

\section{Zf3Wildtype}



Zf3Wildtype was synthesised using Fmoc-Lys(Boc)-Wang $(0.34 \mathrm{mmol} / \mathrm{g})$. The synthesis was carried out at a scale of $0.1 \mathrm{mmol}$ in accordance with Fmoc automated SPPS protocol (section 7.3). Cleavage of the peptide from the resin using TFA/ $\mathrm{H}_{2} \mathrm{O} / \mathrm{TIS} / \mathrm{EDT}$ (94/2.5/1/2.5) followed by HPLC purification yielded the Zf3wildtype (99 mg, $32.1 \mathrm{mmol}$, $32.1 \%)$ as a white solid in the oxidised disulfide form of the peptide 33 (Zf3Wildtype).

HPLC Purification: Column Pep 2 (MN_Nucleodur100_5_C18, RP-C18, semi-preparative, $250 \times 10 \mathrm{~mm}, 5 \mu \mathrm{m}), \quad 10-60 \%$ gradient of $\mathrm{B}$ in $30 \mathrm{~min}$, flow rate $3 \mathrm{~mL} / \mathrm{min}, t_{R}=$ $16.81 \mathrm{~min}$.

ESI-MS $m / z: 514.1[\mathrm{M}+6 \mathrm{H}]^{+6}, 616.7[\mathrm{M}+5 \mathrm{H}]^{+5}, 770.9[\mathrm{M}+4 \mathrm{H}]^{+4}$

ESI-HRMS: calculated for $\left[\mathrm{C}_{129} \mathrm{H}_{225} \mathrm{~N}_{49} \mathrm{O}_{35} \mathrm{~S}_{2}\right]^{6+}\left([\mathrm{M}+6 \mathrm{H}]^{6+}\right)=514.1124$, found $=514.1126$; calculated for $\left[\mathrm{C}_{129} \mathrm{H}_{224} \mathrm{~N}_{49} \mathrm{O}_{35} \mathrm{~S}_{2}\right]^{5+}\left([\mathrm{M}+5 \mathrm{H}]^{5+}\right)=616.7334$, found $=616.7337$. 


\section{Reduction of $\mathrm{Zf} 3 \mathrm{Wildtype}$ and $\mathrm{Zn}^{2+}$ Complexation:}

A general procedure for reduction of the zinc finger domain followed by $\mathrm{Zn}^{2+}$ complexation and visualization of the $\mathrm{Zn}^{2+}$ bound form of the peptide in the mass spectra are explained in section 7.1.

ESI-MS $m / z$ : corresponding to the mononuclear zinc complex $=524.8[\mathrm{M}+4 \mathrm{H}+\mathrm{Zn}]^{6+}$, $629.5[\mathrm{M}+3 \mathrm{H}+\mathrm{Zn}]^{5+}, 786.6[\mathrm{M}+2 \mathrm{H}+\mathrm{Zn}]^{4+}, 1048.5[\mathrm{M}+\mathrm{H}+\mathrm{Zn}]^{3+}$.

ESI-HRMS: calculated for the mononuclear complex $\left[\mathrm{C}_{129} \mathrm{H}_{224} \mathrm{~N}_{49} \mathrm{O}_{35} \mathrm{~S}_{2} \mathrm{Zn}\right]^{5+}\left([\mathrm{M}+3 \mathrm{H}+\mathrm{Zn}]^{5+}\right)$ $=629.5192$, found $=629.5196$; calculated for $\left[\mathrm{C}_{129} \mathrm{H}_{223} \mathrm{~N}_{49} \mathrm{O}_{35} \mathrm{~S}_{2} \mathrm{Zn}\right]^{4+}\left([\mathrm{M}+2 \mathrm{H}+\mathrm{Zn}]^{4+}\right)=$ 786.6472 , found $=786.6475$; calculated for $\left[\mathrm{C}_{129} \mathrm{H}_{222} \mathrm{~N}_{49} \mathrm{O}_{35} \mathrm{~S}_{2} \mathrm{Zn}\right]^{3+}\left([\mathrm{M}+\mathrm{H}+\mathrm{Zn}]^{3+}=\right.$ 1048.5272 , found $=1048.5275$.

\section{Zf3Tacn81}

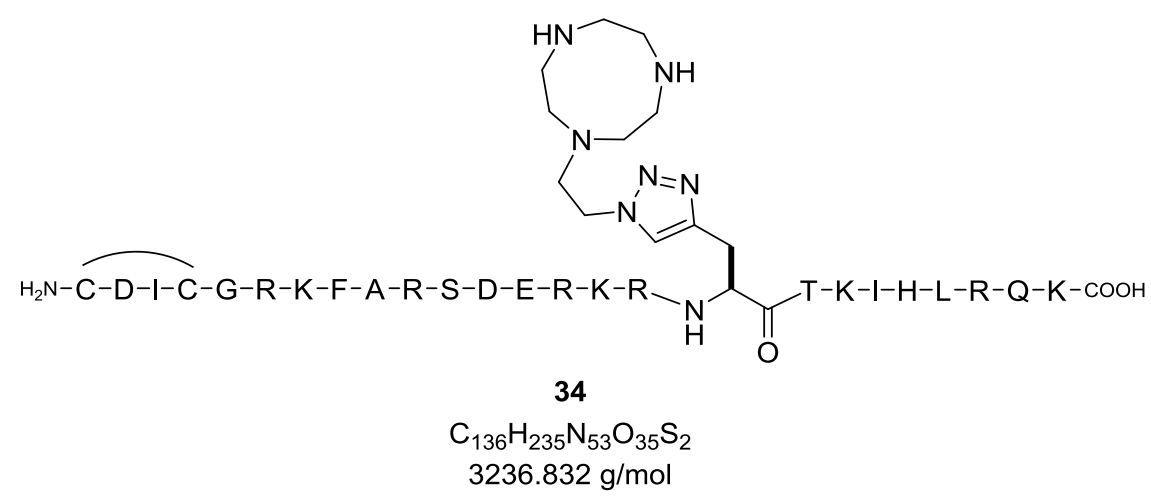

Zf3Tacn81 was synthesised using Fmoc-Lys(Boc)-Wang $(0.34 \mathrm{mmol} / \mathrm{g})$ resin at a scale of $0.1 \mathrm{mmol}$. The first eight amino acids in the sequence were coupled according to the manual SPPS protocol and the rest of the sixteen amino acids were coupled according to the Fmoc automated SPPS (section 7.3). Cleavage of the peptide from the resin using TFA/ $\mathrm{H}_{2} \mathrm{O} / \mathrm{TIS} / \mathrm{EDT}(94 / 2.5 / 1 / 2.5)$ followed by HPLC purification yielded the Zf3Tacn81 
(56 $\mathrm{mg}, 17.3 \mathrm{mmol}, 17.3 \%$ ) as a white solid in the oxidised disulfide form of the peptide 34 (Zf3Tacn81).

HPLC Purification: Column Pep 2 (MN_Nucleodur100_5_C18, RP-C18, semi-preparative, $250 \times 10 \mathrm{~mm}, 5 \mu \mathrm{m}), 10-60 \%$ gradient of $B$ in $30 \mathrm{~min}$, flow rate $3 \mathrm{~mL} / \mathrm{min}, t_{R}=16.77 \mathrm{~min}$.

ESI-MS m/z: $540.5[\mathrm{M}+6 \mathrm{H}]^{6+}, 648.2[\mathrm{M}+5 \mathrm{H}]^{5+}, 809.9[\mathrm{M}+4 \mathrm{H}]^{4+}, 1079.9[\mathrm{M}+3 \mathrm{H}]^{3+}$

ESI-HRMS: calculated for $\left[\mathrm{C}_{136} \mathrm{H}_{241} \mathrm{~N}_{53} \mathrm{O}_{35} \mathrm{~S}_{2}\right]^{6+}\left([\mathrm{M}+6 \mathrm{H}]^{6+}\right)=540.4694$, found $=540.4700$; calculated $\left[\mathrm{C}_{136} \mathrm{H}_{240} \mathrm{~N}_{53} \mathrm{O}_{35} \mathrm{~S}_{2}\right]^{5+}\left([\mathrm{M}+5 \mathrm{H}]^{5+}\right)=648.1614$, found $=648.1622$, $\left[\mathrm{C}_{136} \mathrm{H}_{239} \mathrm{~N}_{53} \mathrm{O}_{35} \mathrm{~S}_{2}\right]^{4+}\left([\mathrm{M}+4 \mathrm{H}]^{4+}\right)=809.9499$, found $=809.9506$.

\section{Reduction of Zf3Tacn81 and $\mathrm{Zn}^{+2}$ Complexation:}

A general procedure for reduction of the zinc finger domain followed by $\mathrm{Zn}^{2+}$ complexation and visualization of the $\mathrm{Zn}^{2+}$ bound form of the peptide in the mass spectra are explained in section 7.1.

ESI-MS $m / z$ : corresponding to mononuclear zinc complex $=660.9[\mathrm{M}+3 \mathrm{H}+\mathrm{Zn}]^{5+}$; corresponding to the binuclear zinc complex $=673.5[\mathrm{M}+\mathrm{H}+2 \mathrm{Zn}]^{5+}$.

ESI-HRMS: calculated for the oxidized mononuclear complex $\left[\mathrm{C}_{136} \mathrm{H}_{240} \mathrm{~N}_{53} \mathrm{O}_{35} \mathrm{~S}_{2} \mathrm{Zn}\right]^{5+}$ $\left([\mathrm{M}+3 \mathrm{H}+\mathrm{Zn}]^{5+}\right)=660.9472$, found $=660.9478$, calculated for the binuclear complex $\left[\mathrm{C}_{136} \mathrm{H}_{238} \mathrm{~N}_{53} \mathrm{O}_{35} \mathrm{~S}_{2} \mathrm{Zn}_{2}\right]^{5+}\left([\mathrm{M}+\mathrm{H}+2 \mathrm{Zn}]^{5+}\right)=673.5297$, found $=673.5308$. 

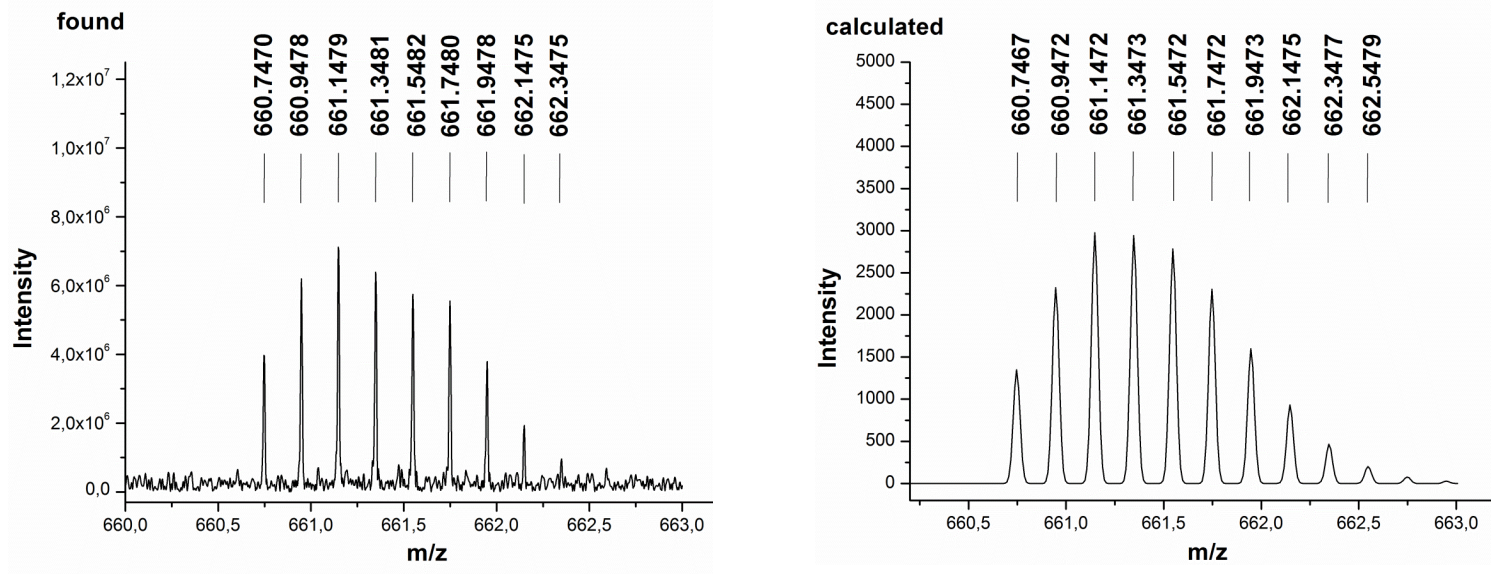

Figure 7.7: ESI-HRMS of measured and calculated charged state $[\mathrm{M}+3 \mathrm{H}+\mathrm{Zn}]^{5+}$ of the mononuclear zinc complex of Zf3Tacn81 34.
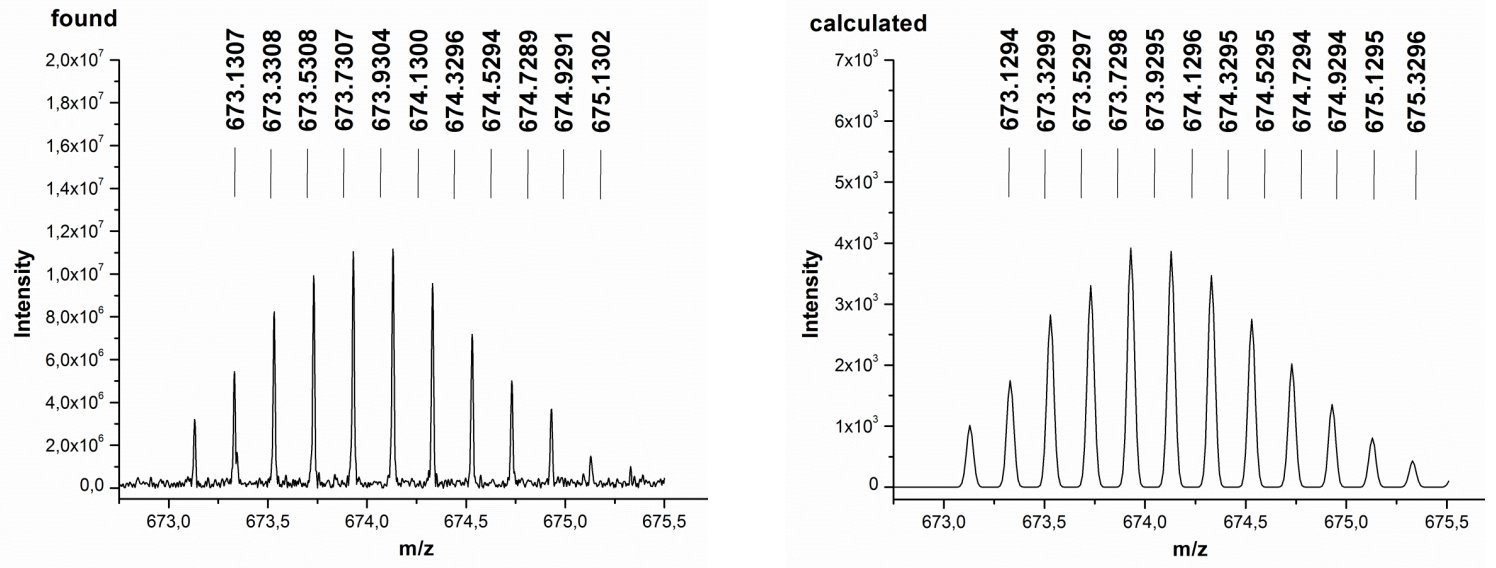

Figure 7.8: ESI-HRMS of measured and calculated charged state $[\mathrm{M}+\mathrm{H}+2 \mathrm{Zn}]^{5+}$ of the binuclear zinc complex of Zf3Tacn81 34. 


\section{Zf3Tacn85}

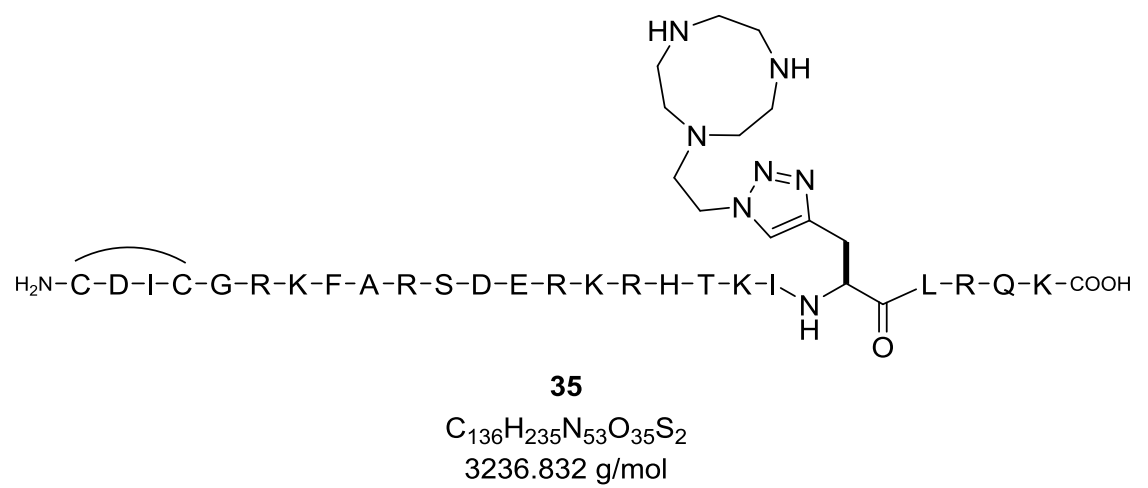

Zf3Tacn85 was synthesised using Fmoc-Lys(Boc)-Wang $(0.34 \mathrm{mmol} / \mathrm{g})$ at a scale of $0.1 \mathrm{~mol}$. The first four amino acids in the sequence were coupled according to the manual SPPS protocol and the rest of the twenty amino acids were coupled according to the Fmoc automated SPPS (section 7.3). Cleavage of the peptide from the resin using TFA/ $\mathrm{H}_{2} \mathrm{O} / \mathrm{TIS} / \mathrm{EDT}(94 / 2.5 / 1 / 2.5)$ followed by HPLC purification yielded the Zf3Tacn85 (68 $\mathrm{mg}, 21 \mathrm{mmol}, 21 \%$ ) as a white solid in the oxidised disulfide form of the peptide 35 (Zf3Tacn85).

HPLC Purification: Column Pep 2 (MN_Nucleodur100_5_18, RP-C18, semi-preparative, $250 \times 10 \mathrm{~mm}, 5 \mu \mathrm{m}), \quad 10-60 \%$ gradient of $\mathrm{B}$ in $30 \mathrm{~min}$, flow rate $3 \mathrm{~mL} / \mathrm{min}, t_{R}=$ $16.61 \mathrm{~min}$.

ESI-MS m/z: $540.5[\mathrm{M}+6 \mathrm{H}]^{6+}, 648.4[\mathrm{M}+5 \mathrm{H}]^{5+}, 810.2[\mathrm{M}+4 \mathrm{H}]^{4+}, 1079.9[\mathrm{M}+3 \mathrm{H}]^{3+}$.

ESI-HRMS: calculated for $\left[\mathrm{C}_{136} \mathrm{H}_{241} \mathrm{~N}_{53} \mathrm{O}_{35} \mathrm{~S}_{2}\right]^{6+}\left([\mathrm{M}+6 \mathrm{H}]^{6+}\right)=540.4694$, found $=540.4699$; calculated for $\left[\mathrm{C}_{136} \mathrm{H}_{240} \mathrm{~N}_{53} \mathrm{O}_{35} \mathrm{~S}_{2}\right]^{5+}\left([\mathrm{M}+5 \mathrm{H}]^{5+}\right)=648.3618$, found $=648.3624$, $\left[\mathrm{C}_{136} \mathrm{H}_{239} \mathrm{~N}_{53} \mathrm{O}_{35} \mathrm{~S}_{2}\right]^{4+}\left([\mathrm{M}+4 \mathrm{H}]^{4+}\right)=810.2004$, found $=810.2011$. 


\section{Reduction of Zf3Tacn85 and $\mathrm{Zn}^{2+}$ Complexation:}

A general procedure for reduction of the zinc finger domain followed by $\mathrm{Zn}^{2+}$ complexation and visualization of the $\mathrm{Zn}^{2+}$ bound form of the peptide in the mass spectra are explained in section 7.1.

ESI-MS $m / z$ : corresponding to the mononuclear complex $=550.96[\mathrm{M}+4 \mathrm{H}+\mathrm{Zn}]^{5+}, 660.75$ $[\mathrm{M}+3 \mathrm{H}+\mathrm{Zn}]^{5+}, 825.93[\mathrm{M}+2 \mathrm{H}+\mathrm{Zn}]^{4+}$; corresponding to the binuclear complex $=561.28$ $[\mathrm{M}+2 \mathrm{H}+2 \mathrm{Zn}]^{6+}, 673.33[\mathrm{M}+\mathrm{H}+2 \mathrm{Zn}]^{5+}, 841.66[\mathrm{M}+2 \mathrm{Zn}]^{4+}$.

ESI-HRMS: calculated for the oxidized mononuclear complex $\left[\mathrm{C}_{136} \mathrm{H}_{240} \mathrm{~N}_{53} \mathrm{O}_{35} \mathrm{~S}_{2} \mathrm{Zn}\right]^{5+}$ $\left([\mathrm{M}+3 \mathrm{H}+\mathrm{Zn}]^{5+}\right)=660.7467$, found $=660.7486$, calculated for the binuclear complex $\left[\mathrm{C}_{136} \mathrm{H}_{239} \mathrm{~N}_{53} \mathrm{O}_{35} \mathrm{~S}_{2} \mathrm{Zn}_{2}\right]^{6+}\left([\mathrm{M}+2 \mathrm{H}+2 \mathrm{Zn}]^{6+}\right)=561.2762$, found $=561.2765$; calculated for the binuclear complex $\left[\mathrm{C}_{136} \mathrm{H}_{238} \mathrm{~N}_{53} \mathrm{O}_{35} \mathrm{~S}_{2} \mathrm{Zn}_{2}\right]^{5+}\left([\mathrm{M}+\mathrm{H}+2 \mathrm{Zn}]^{5+}\right)=673.3299$, found $=673.3297$.
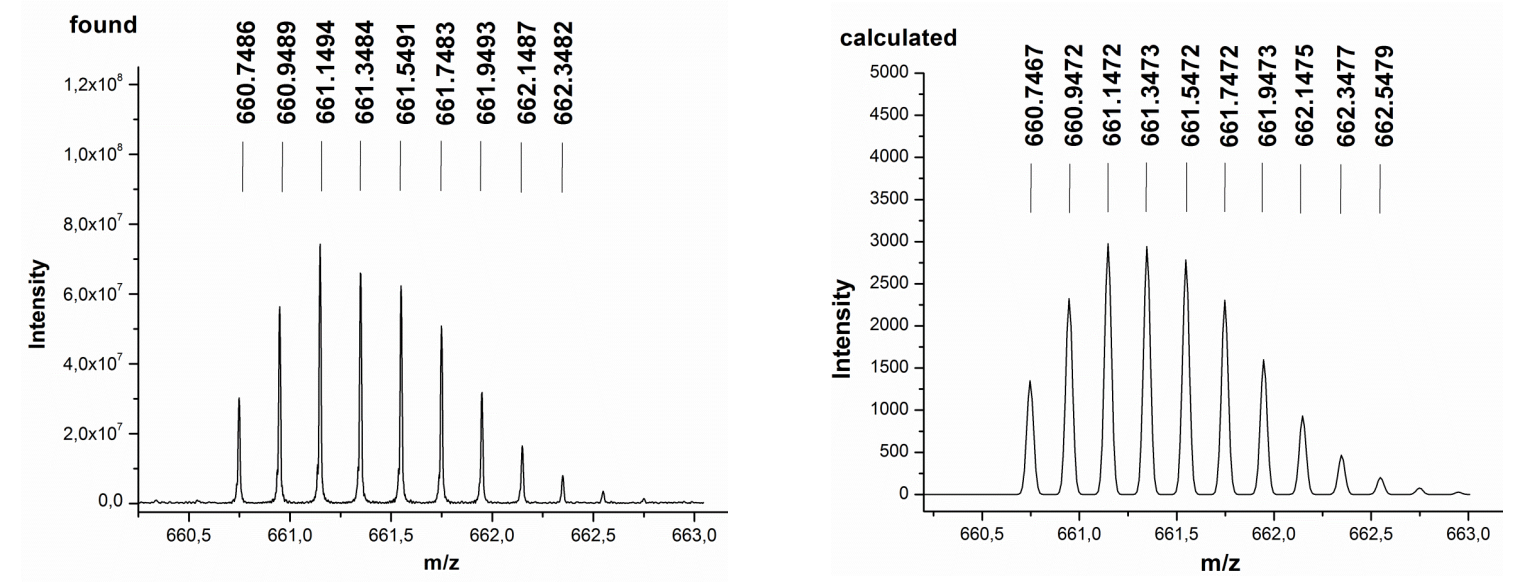

Figure 7.9: ESI-HRMS of measured and calculated charged state $[\mathrm{M}+3 \mathrm{H}+\mathrm{Zn}]^{5+}$ of the mononuclear zinc complex of Zf3Tacn85 35. 

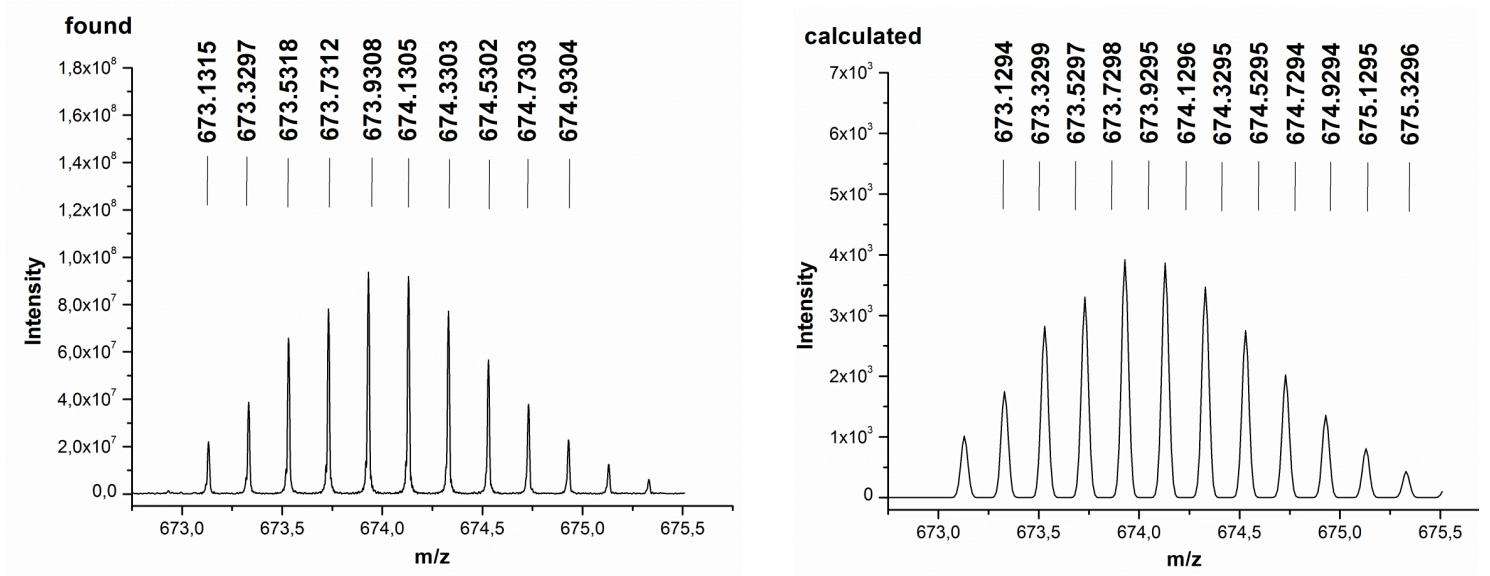

Figure 7.10: ESI-HRMS of measured and calculated charged state $[\mathrm{M}+\mathrm{H}+2 \mathrm{Zn}]^{5+}$ of the binuclear zinc complex of Zf3Tacn85 35. 


\subsubsection{Expression of $Z f 12$ domain}

\section{Zf12 Expressed Domain}

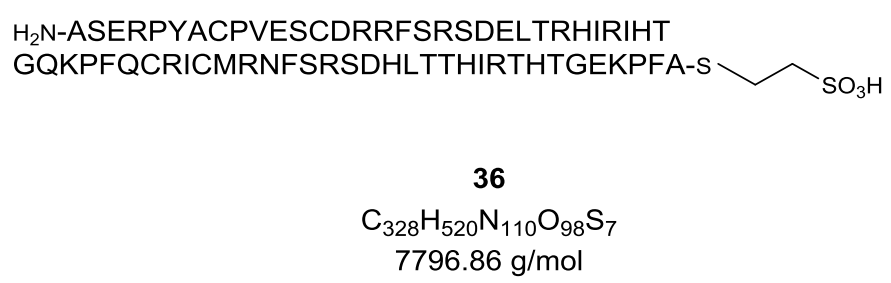

The expressed Zf12 domain $\mathbf{3 6}$ was prepared by protein expression in accordance with the protocol mentioned in section 7.2.

HPLC Purification: Column 18 (Phenomenex_Jupiter_5u_C18_300A, RP-C18, semipreparative, $250 \times 10 \mathrm{~mm}, 5 \mu \mathrm{m}), 20-50 \%$ gradient of $B$ in $30 \mathrm{~min}$, flow rate $3 \mathrm{~mL} / \mathrm{min}$, $t_{R}=23.26 \mathrm{~min}$.

ESI-MS $m / z: 600.4[\mathrm{M}+13 \mathrm{H}]^{13+}, 650.2[\mathrm{M}+12 \mathrm{H}]^{12+}, 709.2[\mathrm{M}+11 \mathrm{H}]^{11+}, 780.1[\mathrm{M}+10 \mathrm{H}]^{10+}$, $866.5[\mathrm{M}+9 \mathrm{H}]^{9+}, 974.8[\mathrm{M}+8 \mathrm{H}]^{8+}, 1114.1[\mathrm{M}+7 \mathrm{H}]^{7+}, 1299.8[\mathrm{M}+6 \mathrm{H}]^{6+}$.

ESI-HRMS: calculated for the oxidized form of $36\left[\mathrm{C}_{328} \mathrm{H}_{528} \mathrm{~N}_{110} \mathrm{O}_{98} \mathrm{~S}_{7}\right]^{12+}\left([\mathrm{M}+12 \mathrm{H}]^{12+}\right)=$ 650.2314 , found $=650.2326$; calculated for $\left[\mathrm{C}_{328} \mathrm{H}_{527} \mathrm{~N}_{110} \mathrm{O}_{98} \mathrm{~S}_{7}\right]^{11+}\left([\mathrm{M}+11 \mathrm{H}]^{11+}\right)=$ 709.1606, found $=709.1619$, calculated for $\left[\mathrm{C}_{328} \mathrm{H}_{526} \mathrm{~N}_{110} \mathrm{O}_{98} \mathrm{~S}_{7}\right]^{10+}\left([\mathrm{M}+10 \mathrm{H}]^{10+}\right)=$ 780.0762 , found $=780.0769$, calculated for $\left[\mathrm{C}_{328} \mathrm{H}_{525} \mathrm{~N}_{110} \mathrm{O}_{98} \mathrm{~S}_{7}\right]^{9+}\left([\mathrm{M}+9 \mathrm{H}]^{9+}\right)=866.5281$, found $=866.5286$, calculated for $\left[\mathrm{C}_{328} \mathrm{H}_{524} \mathrm{~N}_{110} \mathrm{O}_{98} \mathrm{~S}_{7}\right]^{8+}\left([\mathrm{M}+8 \mathrm{H}]^{8+}\right)=974.8434$, found $=$ 974.8431. 


\title{
7.8.3. Preparation of $\mathrm{Zf13}$ domain by native chemical ligation between $\mathrm{Zf3}$ and Zf12 peptide sequences
}

\section{Zf13Wildtype}

\author{
$\mathrm{NH}_{2}$-ASERPYACPVESCDRRFSRSDELTRHIRIHTGQKPFQCRICMRNFSRSDHL \\ TTHIRTHTGEKPFACDICGRKFARSDERKRHTKIHLRQK-COOH \\ 37 \\ $\mathrm{C}_{455} \mathrm{H}_{735} \mathrm{~N}_{159} \mathrm{O}_{130} \mathrm{~S}_{7}$ \\ $10737.28 \mathrm{~g} / \mathrm{mol}$
}

The peptide Zf13Wildtype $\mathbf{3 7}$ was prepared by native chemical ligation between the peptide Zf3Wildtype $\mathbf{3 3}$ and the expressed peptide $\mathbf{Z f 1 2} \mathbf{3 6}$ according to the procedure mentioned in section 7.4.

HPLC Purification: Column All 3 (MN_Nucleodur100_5_C18, RP-C18, analytical, $250 \times 4.6 \mathrm{~mm}, 5 \mu \mathrm{m}), 20-50 \%$ gradient of $B$ in $30 \mathrm{~min}$, flow rate $1 \mathrm{~mL} / \mathrm{min}, t_{R}=21.1 \mathrm{~min}$.

Yield: $1.2 \mathrm{mg}[0.11 \mu \mathrm{mol}, 22 \%]$.

ESI-MS $m / z: \quad 716.13[\mathrm{M}+15 \mathrm{H}]^{15+}, 767.25[\mathrm{M}+14 \mathrm{H}]^{14+}, 826.19[\mathrm{M}+13 \mathrm{H}]^{13+}, 894.95$ $[\mathrm{M}+12 \mathrm{H}]^{12+}, 976.31[\mathrm{M}+11 \mathrm{H}]^{11+}, 1073.74[\mathrm{M}+10 \mathrm{H}]^{10+}, 1192.93[\mathrm{M}+9 \mathrm{H}]^{9+}$.

ESI-HRMS: calculated for the oxidized form of $37\left[\mathrm{C}_{455} \mathrm{H}_{747} \mathrm{~N}_{159} \mathrm{O}_{130} \mathrm{~S}_{7}\right]^{16+}\left([\mathrm{M}+16 \mathrm{H}]^{16+}\right)=$ 671.4043, found = 671.4041; calculated $\left[\mathrm{C}_{455} \mathrm{H}_{746} \mathrm{~N}_{159} \mathrm{O}_{130} \mathrm{~S}_{7}\right]^{15+}\left([\mathrm{M}+15 \mathrm{H}]^{15+}\right)=716.1643$, found $=716.1639,\left[\mathrm{C}_{455} \mathrm{H}_{745} \mathrm{~N}_{159} \mathrm{O}_{130} \mathrm{~S}_{7}\right]^{14+}\left([\mathrm{M}+14 \mathrm{H}]^{14+}\right)=767.2469$, found $=767.2476$. 


\section{Zf13Tacn81}

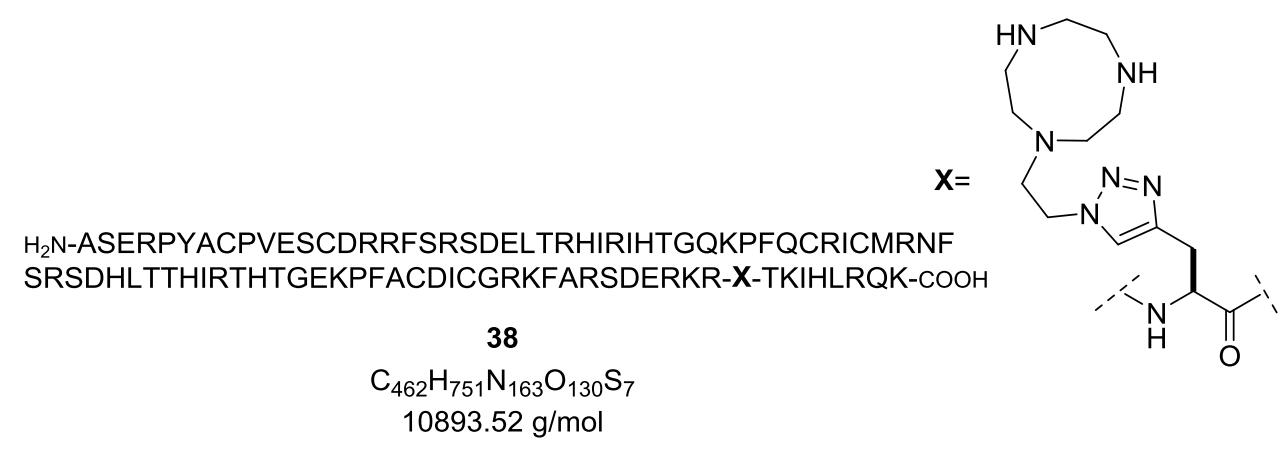

The peptide Zf13Tacn81 $\mathbf{3 8}$ was prepared by native chemical ligation between the peptide Zf3Tacn81 34 and the expressed peptide Zf12 36 according to the procedure mentioned in section 7.4.

HPLC Purification: Column All 3 (MN_Nucleodur100_5_C18, RP-C18, analytical, $250 \times 4.6 \mathrm{~mm}, 5 \mu \mathrm{m}), \quad 10-50 \%$ gradient of $\mathrm{B}$ in $30 \mathrm{~min}$, flow rate $1 \mathrm{~mL} / \mathrm{min}, t_{R}=$ $25.62 \mathrm{~min}$.

Yield: $0.95 \mathrm{mg}$ [0.087 $\mu \mathrm{mol}, 17.46 \%]$.

ESI-MS $m / z: 681.3[\mathrm{M}+16 \mathrm{H}]^{16+}, 726.6[\mathrm{M}+15 \mathrm{H}]^{15+}, 778.4[\mathrm{M}+14 \mathrm{H}]^{14+}, 838.3[\mathrm{M}+13 \mathrm{H}]^{13+}$, $908.0[\mathrm{M}+12 \mathrm{H}]^{12+}, 990.6[\mathrm{M}+11 \mathrm{H}]^{11+}$.

ESI-HRMS: calculated for the oxidized form of $38\left[\mathrm{C}_{462} \mathrm{H}_{762} \mathrm{~N}_{163} \mathrm{O}_{130} \mathrm{~S}_{7}\right]^{17+}\left([\mathrm{M}+17 \mathrm{H}]^{17+}\right)=$ 641.1531, found = 641.1530; calculated $\left[\mathrm{C}_{462} \mathrm{H}_{761} \mathrm{~N}_{163} \mathrm{O}_{130} \mathrm{~S}_{7}\right]^{16+}\left([\mathrm{M}+16 \mathrm{H}]^{16+}\right)=681.3502$, found $=681.3513,\left[\mathrm{C}_{462} \mathrm{H}_{760} \mathrm{~N}_{163} \mathrm{O}_{130} \mathrm{~S}_{7}\right]^{15+}\left([\mathrm{M}+15 \mathrm{H}]^{15+}\right)=726.6395$, found $=726.6395$, $\left[\mathrm{C}_{462} \mathrm{H}_{759} \mathrm{~N}_{163} \mathrm{O}_{130} \mathrm{~S}_{7}\right]^{14+}\left([\mathrm{M}+14 \mathrm{H}]^{14+}\right)=778.3988$, found $=778.3999,\left[\mathrm{C}_{462} \mathrm{H}_{758} \mathrm{~N}_{163} \mathrm{O}_{30} \mathrm{~S}_{7}\right]^{13+}$ $\left([\mathrm{M}+13 \mathrm{H}]^{13+}\right)=838.2753$, found $=838.2756,\left[\mathrm{C}_{462} \mathrm{H}_{757} \mathrm{~N}_{163} \mathrm{O} 1_{30} \mathrm{~S}_{7}\right]^{12+}\left([\mathrm{M}+12 \mathrm{H}]^{12+}\right)=$ 908.0476 , found $=908.0486$. 


\section{Zf13Tacn85}

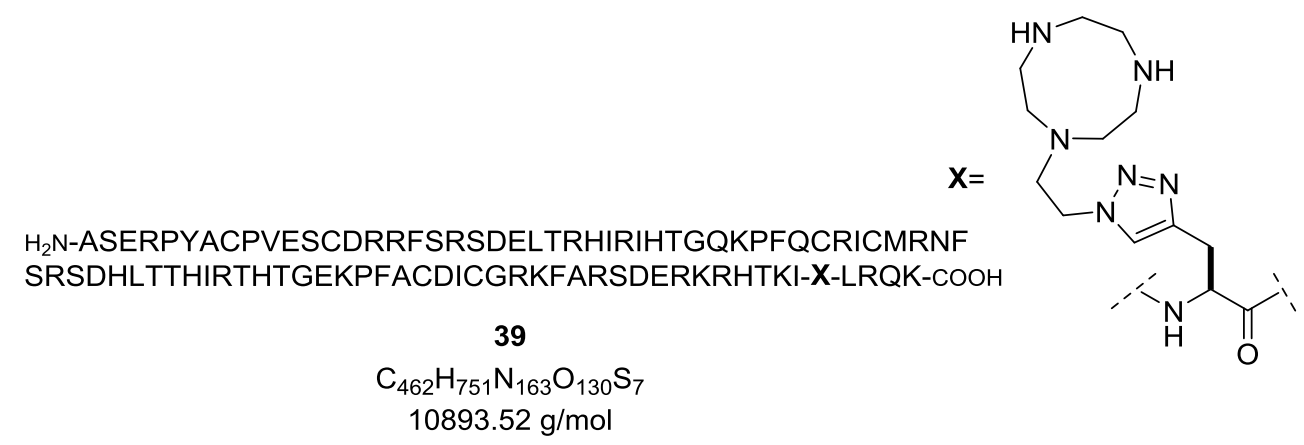

The peptide Zf13Tacn85 was prepared by native chemical ligation between the peptide Zf3Tacn81 35 and the expressed peptide Zf12 36 according to the procedure mentioned in section 7.4 .

HPLC Purification: Column All 3 (MN_Nucleodur100_5_C18, RP-C18, analytical, $250 \times 4.6 \mathrm{~mm}, 5 \mu \mathrm{m}), \quad 10-50 \%$ gradient of $\mathrm{B}$ in $30 \mathrm{~min}$, flow rate $1 \mathrm{~mL} / \mathrm{min}, t_{R}=$ $25.58 \mathrm{~min}$.

Yield: $1.32 \mathrm{mg}$ [1.21 $\mu \mathrm{mol}, 24.25 \%]$.

ESI-MS $m / z: 606.1[\mathrm{M}+18 \mathrm{H}]^{18+}, 641.7[\mathrm{M}+17 \mathrm{H}]^{17+}, 681.7[\mathrm{M}+16 \mathrm{H}]^{16+}, 727.1[\mathrm{M}+15 \mathrm{H}]^{15+}$, $778.9[\mathrm{M}+14 \mathrm{H}]^{14+}, 838.8[\mathrm{M}+13 \mathrm{H}]^{13+}, 908.5[\mathrm{M}+12 \mathrm{H}]^{12+}, 991.0[\mathrm{M}+11 \mathrm{H}]^{11+}$.

ESI-HRMS: calculated for the oxidized form of $39\left[\mathrm{C}_{462} \mathrm{H}_{758} \mathrm{~N}_{163} \mathrm{O}_{30} \mathrm{~S}_{7}\right]^{13+}\left([\mathrm{M}+13 \mathrm{H}]^{13+}\right)=$ 838.7377, found $=838.7364,\left[\mathrm{C}_{462} \mathrm{H}_{757} \mathrm{~N}_{163} \mathrm{O}_{30} \mathrm{~S}_{7}\right]^{12+}\left([\mathrm{M}+12 \mathrm{H}]^{12+}\right)=908.5496$, found $=$ 908.5499. 


\section{Appendix}

CD spectra of various zinc finger constructs with their consensus DNA binding site
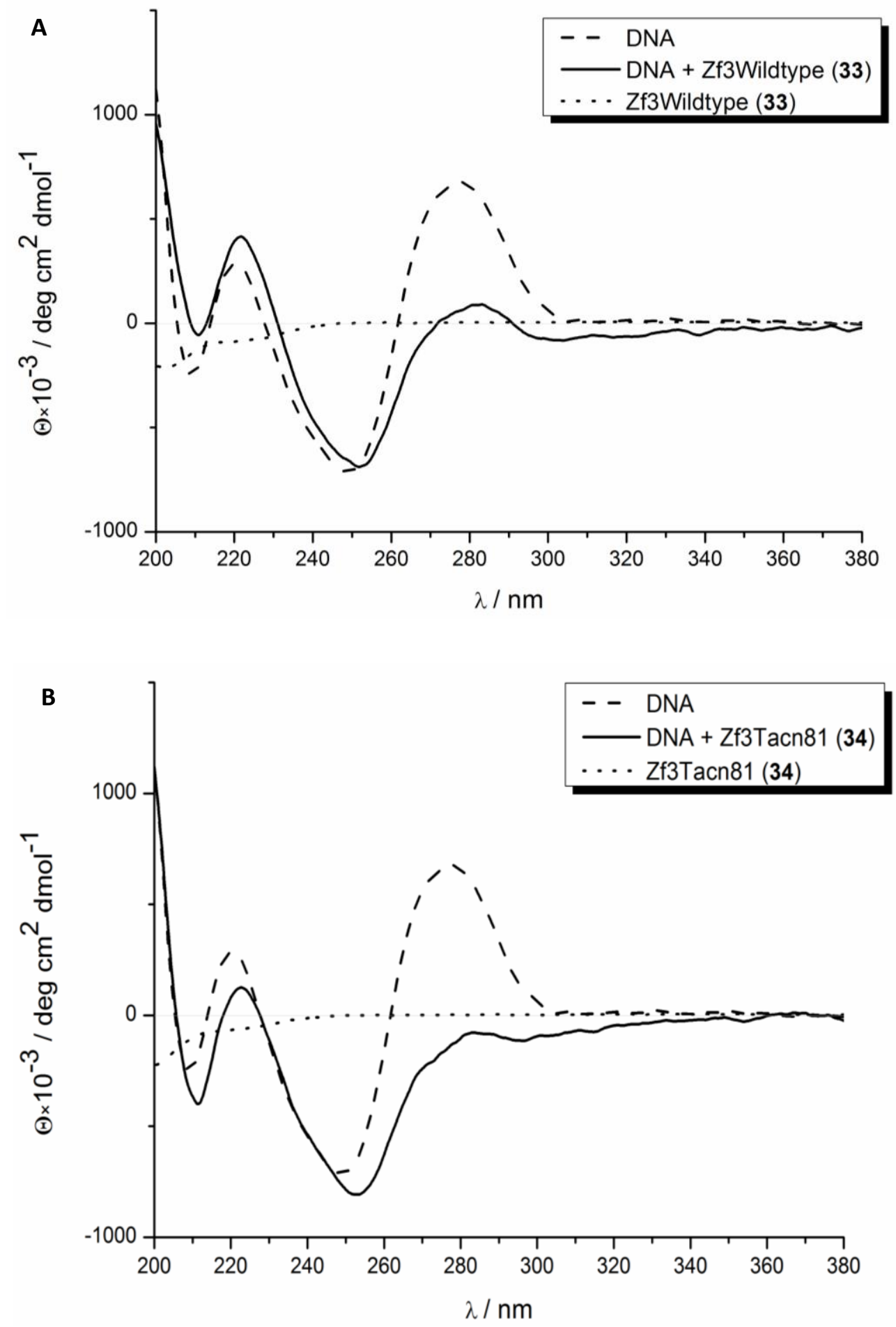

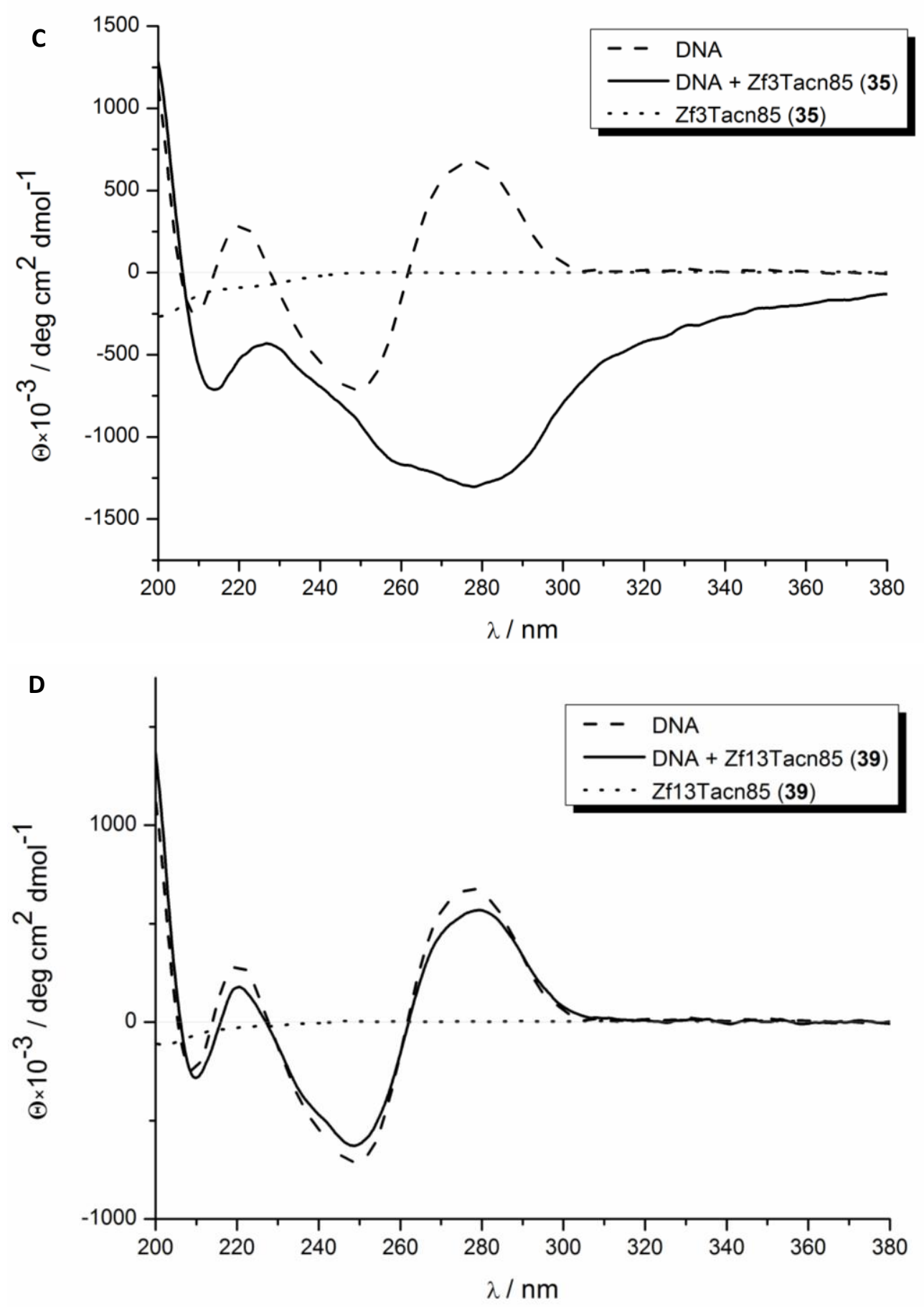

Figure A.1: Comparison of the CD spectra of the 30mer dsDNA consisting of the Zif268 DNA binding site in the absence and presence of (A) Zf3Wildtype 33; (B) Zf3Tacn81 34; (C) Zf3Tacn85 35 and (D) Zf13Tacn85 39. The measurements were performed in $2.5 \mathrm{mM}$ Tris buffer ( $\mathrm{pH}=7.8$ ) containing $5 \mu \mathrm{M}$ of DNA, $25 \mu \mathrm{M}$ of peptides, $100 \mu \mathrm{M}$ of $\mathrm{ZnCl}_{2}$ and $0.5 \mathrm{mM}$ TCEP. 
DNA binding of the modified zinc finger domain Zf13Tacn81 38 in the absence and presence of $\mathrm{Zn}^{2+}$

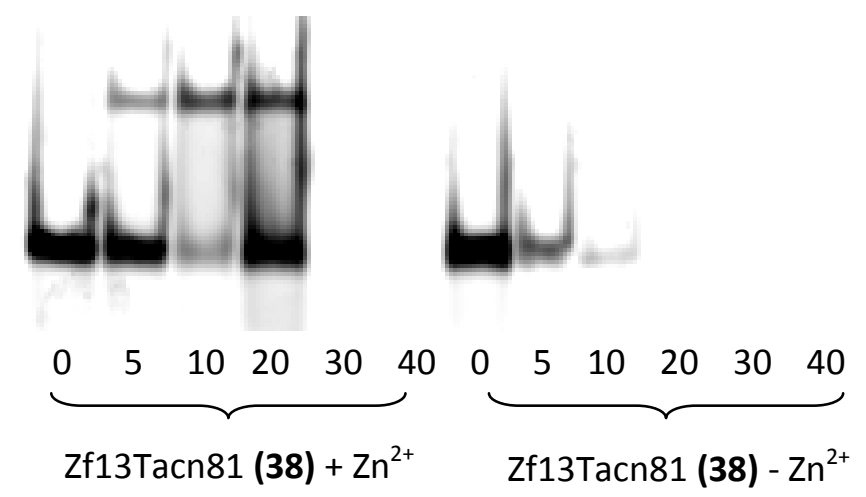

Figure A.3: (A) The Zf13Tacn81 38 reconstituted with $\mathrm{Zn}^{2+}$ ion was incubated with dsDNA in a buffer system containing $\mathrm{Zn}^{2+}$ (40 mM Tris, $200 \mathrm{mM} \mathrm{NaCl}, 1 \mathrm{mM}$ TCEP, $1 \mu \mathrm{M} \mathrm{ZnCl}, \mathrm{pH}=7.8$ ) and (B) The apopeptide Zf13Tacn81 38 was incubated with dsDNA in a buffer system excluding $\mathrm{Zn}^{2+}$ (40 mM Tris, $200 \mathrm{mM} \mathrm{NaCl,}$ $1 \mathrm{mM}$ TCEP, $\mathrm{pH}=7.8)$. $\mathrm{R}_{\mathrm{f}}$ values were varied from 0 to 40 ; wherein $r_{\mathrm{f}}=\mathrm{C}_{\text {peptide }} / \mathrm{C}_{\mathrm{DNA}}$.

\section{Plasmid DNA map}

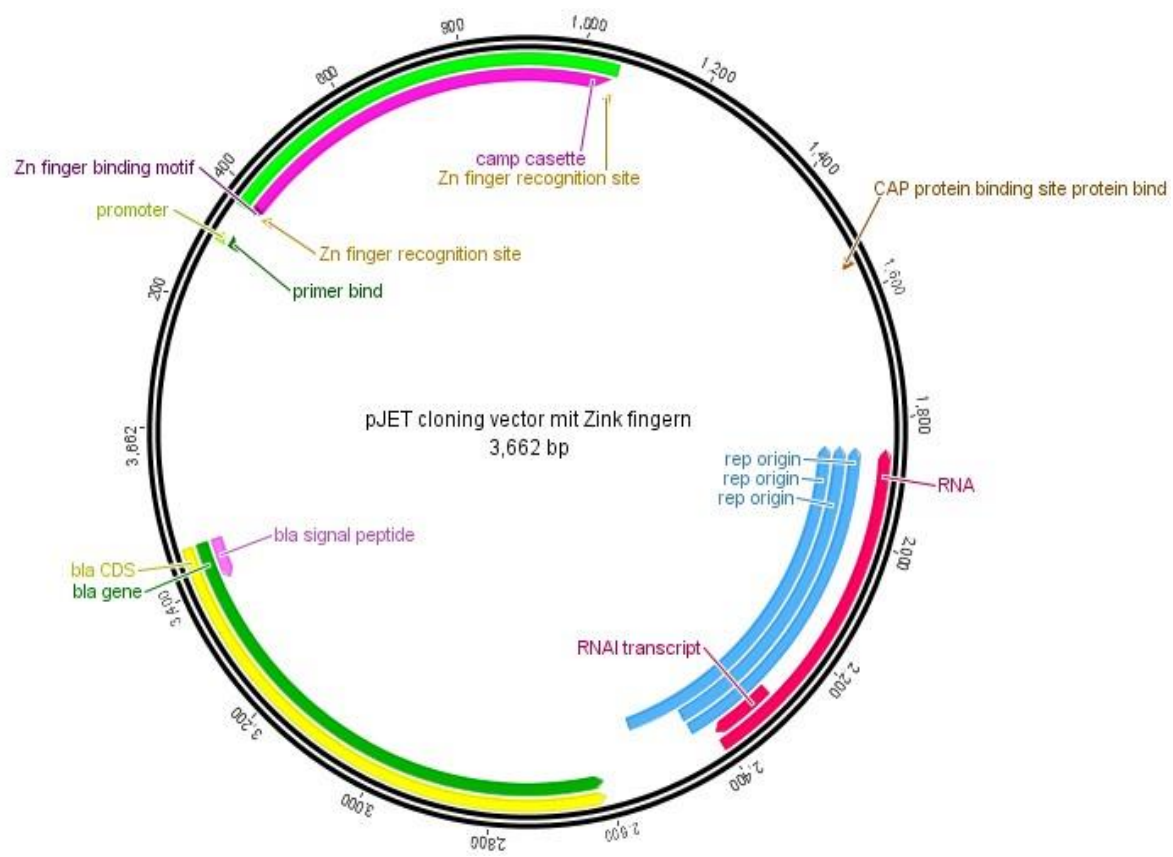

Figure A.2: pJET cloning vector modified to contain two Zif268 DNA binding sites used for analyzing the DNA cleavage ability of the modified Zif268 constructs. 


\section{References}

[1] L. E. Orgel, Trends in Biochemical Sciences 1998, 23, 491.

[2] M. W. Nirenberg, J. H. Matthaei, O. W. Jones, R. G. Martin, S. H. Barondes, Fed. Proc. 1963, 22, 55.

[3] M. N. Hughes, "Coordination compounds in biology," in Comprehensive Coordination Chemistry, G. Wilkinson, R. D. Gillard, and J. A. McCleverty, Eds.; Pergamon Press: Oxford, UK, 1987, vol. 6, p.541.

[4] L. Kelland, Nat. Rev. Cancer 2007, 7, 573-584.

[5] P. A. Rice, S.-W. Yang, K. Mizuuchi, H. A. Nash, Cell 1996, 87, 1295-1306.

[6] E. K. Liebler, U. Diederichsen, Organic Letters 2004, 6, 2893-2896.

[7] J. C. Venter, Science 2001, 291, 1304-1351.

[8] D. Jantz, B. T. Amann, G. J. Gatto, J. M. Berg, Chem. Rev. 2004, 104, 789-799.

[9] N. P. Pavletich, C. O. Pabo, Science 1991, 252, 809-817.

[10] F. Fehr, A. Nadler, F. Brodhun, I. Feussner, U. Diederichsen, ChemistryOpen 2012, 1, 26-32.

[11] A. Nadler, C. Hain, U. Diederichsen, Eur. J. Org. Chem. 2009, 4593-4599.

[12] H. E. Howard-Lock, C. J. L. Lock, "Uses in therapy," in Comprehensive Coordination Chemistry, G. Wilkinson, R. D. Gillard, and J. A. McCleverty, Eds.; Pergamon Press: Oxford, UK, 1987, vol. 6, p.755.

[13] P. J. Sadler, Adv. Inorg. Chem. 1991, 36, 1-48.

[14] C. Orvig, M. J. Abrams, Chemical Reviews 1999, 99, 2201-2203.

[15] Z. Guo, P. J. Sadler, Angew. Chem. Int. Ed. 1999, 38, 1512-1531.

[16] P. J. Loehrer, L. H. Einhorn, Ann. Intern. Med. 1984, 100, 704-713. 
[17] D. F. Bajorin, M. F. Sarosdy, D. G. Pfister, M. Mazumdar, R. J. Motzer, H. I. Scher, N. L. Geller, W. R. Fair, H. Herr, P. Sogani, J. Sheinfeld, P. Russo, V. Vlamis, R. Carey, N. J. Vogelzang, E. D. Crawford, G. J. Bosl, J. Clin. Oncol. 1993, 11, 598-606.

[18] M. Morris, P. J. Eifel, J. Lu, P. W. Grigsby, C. Levenback, R. E. Stevens, M. Rotman, D. M. Gershenson, D. G. Mutch, N. Engl. J. Med. 1999, 340, 1137-1143.

[19] B. Desoize, C. Madoulet, Crit. Rev. Oncol. Hematol. 2002, 42, 317-325.

[20] P. Pil, S. J. Lippard, In Encyclopedia of Cancer; J. R. Bertino, Ed.; Academic Press: San Diego, CA, 1997, Vol. 1.

[21] B. Rosenberg, L. Van Camp, T. Krigas, Nature 1965 205, 698-699.

[22] B. Rosenberg, L. Van Camp, J. E. Trosko, V. H. Mansour, Nature 1969 222, 385386.

[23] R. B. Weiss, M. C. Christian, Drugs 1993, 360-377.

[24] D. Lebwohl, R. Canetta, Eur. J. Cancer 1998, 34, 1522.

[25] F. M. Muggia, T. Fojo, J. Chemotherapy 2004, 16, 77-82.

[26] T. Boulikas, M. Vougiouka, Oncol. Rep. 2004, 11, 559-595.

[27] A. S. Abu-Surrah, M. Kettunen, Curr. Med. Chem. 2006, 13, 1337-1357.

[28] M. A. Fuertes, C. Alonso, J. M. Perez, Chem. Rev. 2003, 103, 645-662.

[29] Y. Jung, S. J. Lippard, Chem. Rev. 2007, 107, 1387-1407.

[30] N. J. Wheate, S. Walker, G. E. Craig, R. Oun, Dalton Trans. 2010, 39, 8113-8127.

[31] D. Wang, S. J. Lippard, Nat. Rev. Drug Discov.2005, 4, 307-320.

[32] C. A. Puckett, R. J. Ernst, J. K. Barton, Dalton Trans. 2010, 39, 1159-1170.

[33] D. P. Gately, S. B. Howell, Br. J. Cancer 1993, 67, 1171-1176.

[34] S. Ishida, J. Lee, D. J. Thiele, I. Herskowitz Proc. Natl. Acad. Sci. USA 2002, 99, 14298-14302. 
[35] M. T. Kuo, H. H. W Chen, I. S. Song, N. Savaraj, T. Ishikawa, Cancer Metast. Rev. 2007, 26, 71-83.

[36] M. E. Howe-Grant, S. J. Lippard, In Metals Ions in Biological Systems; H. Siegel, Ed.; Marcel Dekker: New York, 1980; Vol.11, 63-125.

[37] E. B. Douple, Phramc.Ther. 1984, 25, 297-326.

[38] P. Jordan, M. Carmo-Fonseca, Cell. Mol. Life. Sci. 2000, 57, 1229.

[39] S. L. Bruhn, J. H. Toney, S. J. Lippard, Prog. Inorg. Chem. 1990, 38, 477-516.

[40] K. W. Lee, D. S. Martin, Inorg. Chim. Acta 1976, 17, 105.

[41] M. C. Lim, R. B. Martin, Inorg. Nucl. Chem. 1976, 38, 1911.

[42] J. L. Roberts, A. J. Thomson, Prog Nucleic Acid Res. Mol. Biol. 1979, 71-133.

[43] S. E. Sherman, D. Gibson, A. H. -J. Wang, S. J. Lippard, Science 1985, 230, 412-417.

[44] A. L. Pinto, S. J. Lippard, Biochim. Biophys. Acta 1985, 780, 167-180.

[45] A. Eastman, Biochemistry 1986, 13, 3912-3915.

[46] J. Reedjik, Pure Appl. Chem. 1987, 59, 181-192.

[47] P. M. Takahara, A. C. Rosenzweig, C. A. Frederick, S. J. Lippard, Nature 1995, 377, 649-652.

[48] A. M. J. Fichtinger-Schepman, J. L. van der Veer, J. H. J. den Hartog, P. H. M. Lohman, J. Reedjik, Biochemistry 1985, 24, 707-713.

[49] A. Gelasco, S. J. Lippard, Biochemistry 1998, 37, 9230.

[50] C. J. Van Garderen, L. P. Van Houte, Eur. J. Biochem. 1994, 225, 1169.

[51] F. Coste, J. M. Malinge, L. Serre, W. Shepard, M. Roth, M. Leng, C. Zelwar, Nucleic Acids Res. 1999, 27, 1837.

[52] R. C. Todd, S. J. Lippard, Metallomics 2009, 1, 280-291. 
[53] S. F. Bellon, J. H. Coleman, S. J. Lippard, Biochemistry 1991, 30, 8026-8035.

[54] C. A. Lepre, K. G. Strothcamp, S. J. Lippard, Biochemistry 1987, 26, 5651-5657.

[55] A. Eastman, M. M. Jennerwein, D. L. Nagel, Chem. -Biol. Interact. 1988, 67, 71-80.

[56] G. Chen, K. J. Hutter, W. J. Zeller, Cell Biol. Toxicol. 1995, 11, 273-281.

[57] W. Dempke, W. Voigt, A. Grothey, B. T. Hill, H. J. Schmoll, Anticancer Drugs 2000, 11, 225-236.

[58] H. Niedner, R. Christen, X. Lin, A. Kondo, S. B. Howell, Mol. Pharmacol. 2001, 60, 1153-1160.

[59] D. B. Zamble, D. Mu, J. T. Reardon, A. Sancar, S. J. Lippard, Biochemistry 1996, 35, 10004-10013.

[60] M. Yamada, E. O’Regan, R. Brown, P. Karran, Nucleic Acid Res. 1997, 25, 491-495.

[61] M. Kartalou, J. M. Essigmann, Mutat. Res. 2001, 478, 1-21.

[62] E. R. Jamieson, S. J. Lippard, Chem. Rev. 1999, 99, 2467.

[63] K. Wozniak, J. Blasiak, Acta Biochim. Pol. 2002, 49, 583-596.

[64] D. Fink, S. Nebel, S. Aebi, H. Zheng, B. Cenni, A. Nehme, R. D. Christen, S. B. Howell, Cancer Res. 1996, 56, 4881-4886.

[65] D. R. Duckett, J. T. Drummond, A. I. H. Murchie, J. T. Reardon, A. Sancar, D. M. Lilley, P. Modrich, Proc. Natl. Acad. Sci. USA. 1996, 93, 6443-6447.

[66] P. Modrich J. Biol. Chem. 1997, 272, 24727-24730.

[67] R. Reeves, M. Bustin, Prog. Nucleic Acid Res. Mol. Biol. 1996, 54, 35-100.

[68] J. Zlatanova, J. Yaneva, S. H. Leuba, FASEB J. 1998, 12, 791-799.

[69] K. Saito, T. Kikuchi, H. Shirakawa, M. Yoshida, J. Biochem. 1999, 125, 399-405.

[70] S. U. Dunham, S. J. Lippard, Biochemistry 1997, 36, 11428-11432.

[71] J. J. Love, X. Li, D. A. Case, K. Giese, R. Grosschedl, P. E. Wright, Nature, 1995, 376, 791-795.

[72] M. H. Werner, J. R. Huth, A. M. Gronenborn, G. M. Clore, Cell, 1995, 81, 705-714.

[73] C. S. Chow, C. M. Barnes, S. J. Lippard, Biochemistry 1995, 34, 2956-2964. 
[74] U. M. Ohndorf, M. A. Rould, Q. He, C. O. Pabo, S. J. Lippard, Nature 1999, 399, 708-712.

[75] P. J. Sadler, ChemBioChem 2009, 10, 74-75.

[76] T. W. Hambley, Coord. Chem. Rev. 1997, 166, 181-223.

[77] D. E. Fisher, Cell 1994, 78, 539-542.

[78] J. C. Huang, D. B. Zamble, J. T. Reardon, S. J. Lippard, A. Sancar, Proc. Natl, Acad. Sci. USA 1994, 91, 10394.

[79] E. E. Trimmer, D. B. Zamble, S. J. Lippard, J. M. Essigmann, Biochemistry 1998, 37, 352-362.

[80] L. Li, X. Liu, A, B. Glassmann, M. J. Keating, M. Stros, W. Plumkett, L. Y. Yang, Cancer Res. 1997, 57, 1487-1494.

[81] Q. He, C. H. Liang, S. J. Lippard, Proc. Natl. Acad. Sci. USA 2000, 97, 5768-5772.

[82] D. K. Treiber, X. Zhai, H. -M. Jantzen, J. M. Essigmann, Proc. Natl. Acad. Sci. USA 1994, 91, 5672-5676.

[83] P. Jordon, M. Carmo-Fonseca, Nucl. Acids Res. 1998, 26, 2831-2836.

[84] D. E. Sterner, S. L. Berger, Microbiol. Mol. Biol. Rev. 2000, 64, 435.

[85] J. Zlatanova, K. E. Van Holde, Prog. Nucleic Acid Res. Mol. Biol. 1996, 52, 217-259.

[86] M. E. Bianchi, Molecular Microbiology 1994, 14, 1-5.

[87] W. I. Sundquist, S. J. Lippard, Coord. Chem. Rev. 1990, 100, 293-322.

[88] S. Van Zutphen, J. Reedjik, Coord. Chem. Rev. 2005, 249, 2845-2853.

[89] H. Maeda, Adv. Enzyme Regul. 2001, 41, 189.

[90] R. Duncun, Anti-Cancer Drugs, 1992, 3, 175.

[91] D. Peer, J. M. Karp, S. Hong, O. C. Farokhzad, R. Margalit, R. Langer, Nat. Nanotechnol. 2007, 2, 751-760.

[92] J. A. Hubbell, A. Chilkoti, Science 2012, 337, 303-305.

[93] R. K. Tekade, P. V. Kumar, N. K. Jain, Chem. Rev. 2009, 109, 49-87.

[94] C. C. Lee, J. A. MacKay, J. M. J. Frechet, F. C. Szoka, Nat. Biotechnol. 2005, 23, 1517-1526. 
[95] K. R. Barnes, A. Kutikov, S. J. Lippard, Chem. Biol. 2004, 11, 557.

[96] C. P. Leamon, J. A. Reddy, Adv. Drug. Deliv. Rev. 2004, 56, 1127.

[97] D. Görlich, I. W. Mattaj, Science 1996, 271, 1513-1518.

[98] K. H. Bremner, L. W. Seymour, A. Logan, M. L. Read, Bioconjugate Chem. 2004, 15, 152-161.

[99] O. Aronov, A. T. Horowitz, A. Gabizon, M. A. Fuertes, J. M. Perez, D. Gibson, Bioconjug. Chem 2004, 15, 814.

[100] M. S. Damian, H. K. Heman, S. K. C. Elmroth, U. Diederichsen, Eur. J. Org. Chem. 2010, 6161-6170.

[101] C. Borghouts, C. Kunz, B. Groner, J. Pept. Sci. 2005, 11, 713-726.

[102] D. J. Craik, D. P. Fairlie, S. Liras, D. Price, Chem. Biol. Drug Des. 2013, 81, 136-147.

[103] P. Vlieghe, V. Lisowski, J. Martinez, M. Khrestchatisky, Drug Discovery Today 2010, 15, 40-56.

[104] H. Cai, M.-S. Chen, Z.-Y. Sun, Y.-F. Zhao, H. Kunz, Y.-M. Li, Angew. Chem. Int. Ed. 2013, 52, 6106-6110.

[105] F. Boubrik, E. Bonnefoy, J. Rouvière-Yaniv, Res Microbiol. 1991, 142, 239-247.

[106] J. Oberto, K. Drlica, J. Rouvière-Yaniv, Biochimie 1994, 76, 901-908.

[107] K. K. Swinger, P. A. Rice, Curr. Opin. Struct. Biol. 2004, 14, 28-35.

[108] C. A. Bewley, A. M. Gronenborn, G. M. Clore, Annu. Rev. Biophys. Biomol. Struct. $1998,27,105-131$

[109] N. Goosen, P. Van de Putte Mol. Microbiol. 1996, 6, 2557-2563.

[110] D. Sun, L. H. Hurley, R. M. Harshey, Biochemistry 1996, 35, 10815-10827.

[111] G. Mengeritsky, D. Goldenberg, I. Mendelson, H. Giladi, A. B. Oppenheim, J. Mol. Biol. 1993, 231, 646-657.

[112] S.-W. Yang, H. A. Nash, EMBO J. 1995, 14, 6292-6300.

[113] L. M. Hales, R. I. Gumport, J. F. Gardner, Nucleic Acids Res. 1996, 24, 1780-1786.

[114] J. A. Goodrich, M. L. Schwartz, W. R. McClure, Nucleic Acids Res. 1990, 18, 4993-5000. 
[115] N. L. Craig, H. A. Nash, Cell 1984, 39, 7070-716.

[116] E. Liebler, Dissertation, Georg-August-Universität Göttingen, 2005.

[117] T. Ellenberger, A. Landy, Structure 1997, 5, 153-157.

[118] A. Travers, Curr. Biol. 1997, 7, R252-R254.

[119] M. S. Damian, Dissertation, Georg-August-Universität Göttingen, 2010.

[120] M. Driffield, D. M. Goodall, D. K. Smith, Org. Biomol. Chem. 2003, 1, 2612-2620.

[121] Katharina Fejfar, Dissertation, Georg-August-Universität Göttingen, 2009.

[122] S. Scholz, E. Liebler, B. Eickmann, H.-J. Fritz, U. Diederichsen, Amino Acids 2012 43, 289-298.

[123] Cornelia Panse, Dissertation, Georg-August-Universität Göttingen, 2014.

[124] U. Diederichsen, D. Weicherding, N. Diezemann, Org. Biomol. Chem. 2005, 3, 1058-66.

[125] R. M. Hughes, M. L. Benshoff, M. L. Waters, Chem. Eur. J. 2007, 13, 5753-64.

[126] L. H. Zhang, G. S. Kauffman, J. A. Pesti, J. Yin, 1997, 62, 6918-6920.

[127] R. Bollhagen, M. Schmiedberger, K. Barlos, E. Grell, J. Chem. Soc., Chem. Commun. 1994, 2559-2560.

[128] P. Gomez-Martinez, M. Dessolin, F. Guibé, F. Albericio, J. Chem. Soc., Perkin Trans. 1 1999, 2871-2874.

[129] D. Fernández-Forner, G. Casala, E. Navarro, H. Ryder, F. Albericio, Tetrahedron Lett. 2001, 42, 4471-4474.

[130] S. F. Bellon, J. H. Coleman, S. J . Lippard, Biochemistry 1991, 30, 8026-8035.

[131] G. L. Cohen, W. R. Bauer, J. K. Barton, S. J. Lippard, Science 1979, 203, 1014-1016.

[132] L. S. Lerman, H. L. Frisch, Biopolymers 1982, 21, 995-997.

[133] M. Leng, Biophys. Chem. 1990, 35, 155-163.

[134] S. F. Bellon, S. J. Lippard, Biophys. Chem. 1990, 35, 179-188.

[135] N. Poklar, D. S. Pitch, S. J. Lippard, E. A. Redding, S. U. Dunham, K. J. Breslauer, Proc. Natl. Acad. Sci. USA 1996, 93, 7606-7611. 
[136] M. C. Olmsted, J. P. Bond, C. F. Anderson, M. T. Record, Biophys.J. 1995, 68, 634-647.

[137] R. S. Brown, C. Sander, P. Agros, FEBS. Lett. 1985, 186, 271-274.

[138] J. Miller, A. D. Mclachlan, A. Klug, EMBO J. 1985, 4, 1609-1614.

[139] Y. Choo, A. Klug, Curr. Opin. Struct. Biol. 1997, 91, 11163-11167.

[140] G. Jacobs, G. Miichaels, New Biol. 1990, 2, 583.

[141] A. D. Frankel, J. M. Berg, C. O. Pabo, Proc. Natl. Acad. Sci. USA 1987, 84, 4841-4845.

[142] W. J. Cook, S. P. Mosley, D. C. Audino, D. L. Mullaney, A. Rovelli, J. Biol. Chem. 1994, 269, 9374-9379.

[143] S. K. Thukral, M. L. Morrison, E. T. Young, Proc. Natl. Acad. Sci. USA 1991, 88, 9188-9192.

[144] J. M. Berg, Proc. Natl. Acad. Sci. USA 1988, 85, 99-102.

[145] L. Nekludova, C. O. Pabo, Proc. Natl. Acad. Sci. USA 1994, 91, 6948-6952.

[146] A. Klug, Annu. Rev. Biochem. 2010, 79, 213-231.

[147] S. Durai, M. Mani, K. Kandavelou, J. Wu, M. H. Porteus, S. Chandrasegaran, Nucl. Acids Res. 2005, 33, 5978-5990.

[148] S. Negi, M. Imanishi, M. Sasaki, K. Tatsutani, Biochemistry 2011, 50, 6266-6272.

[149] S. A. Wolfe, L. Nekludova, C. O. Pabo, Annu. Rev. Biochem.Struct. 1999, 3, 183-212.

[150] L. Fairall, J. W. R. Schwabe, L. Chapman, J. T. Finch, D. Rhodes, Nature 1993, 366, 483-487.

[151] N. P. Paveltich, C. O. Pabo, Science 1993, 261, 1701-1707.

[152] E. J. Rebar, C. O. Pabo, Science 1994, 263, 671-673.

[153] A. C. Jamieson, S.-H. Kim, J. A. Wells Biochemistry 1994, 33, 5689-5695.

[154] Y. Choo, A. Kulg, Proc. Natl. Acad. Sci USA 1994, 91, 11163-11167.

[155] H. Wu, W.-P. Yang, C. F. Barbas Proc. Natl. Acad. Sci. USA 1995, 92, 344-348. 
[156] Y. Choo, M. Isalan, Curr. Opin. Struct. Biol. 2000, 10, 411-416.

[157] D. J. Segal, B. Dreier, R. R. Beerli, C. F. Barbas, Proc. Natl. Acad. Sci. USA 1999, 96, 2758-2763.

[158] Y. Choo, I. Sanchez-Garcia, A. Klug, Nature 1994, 372, 642-645.

[159] H. A. Greisman, C. O. Pabo, Science 1997, 275, 657-661.

[160] M. D. Isalan, A. Klug, Y. Choo: International patent application number W098/53057.

[161] F. D. Urnov, E. J. Rebar, M. C. Holmes, H. S. Zhang, P. D. Gregory, Nat. Rev. Genet. 2010, 11, 636-646.

[162] S. Rémy, L, Tesson, S. Ménoret, C. Usal, A. M. Scharenberg, I. Anegon, Transgenic. Res. 2010, 19, 363-371.

[163] Y.-G. Kim, J. Cha, S. Chandrasegaran, Proc. Natl. Acad. Sci. USA 1996, 93, 1156-1160.

[164] J. Smith, M. Bibikova, F. G. Whitby, A. R. Reddy, S. Chandrasegaran, D. Carroll, Nucl. Acids Res. 2000, 28, 3361-3369.

[165] J. Bitinaite, D. A. Wah, A. K. Aggarwal, I. Schildkraut, Proc. Natl. Acad. Sci. USA 1998, 95, 10570-10575.

[166] H. Katada, M. Komiyama, ChemBioChem 2009, 10, 1279-1288.

[167] S. C. West, Nat. Rev. Mol. Cell. Biol. 2003, 4, 435-445.

[168] E. E. Perez, J. Wang, J. C. Miller, Y. Jouvenot, K. A. Kim, O. Liu, N. Wang, G. Lee, V. V. Bartsevich, Y. L. Lee, D. Y. Guschin, I. Rupniewski, A. J. Waite, C. Carpenito, R. G. Carroll, J. S. Orange, F. D. Urnov, E. J. Rebar, D. Ando, P. D. Gregory, J. L. Riley, M. C. Holmes, C. H. June, Nat. Biotechnol. 2008, 26, 808-816.

[169] E. L. Hegg, J. N. Burstyn, Coord. Chem. Rev. 1998, 2, 751-757.

[170] M. Komiyama, N. Takeda, H. Shigekawa, Chem. Commun. 1999, 1443-1451.

[171] F. Mancin, P. Scrimin, P. Tecilla, U. Tonellato, Chem. Commun. 2004, 2540-2548.

[172] C. Liu, L. Wang, Dalton Trans. 2009, 2, 227-239.

[173] M. J. Jedrzejas, P. Setlow, Chem. Rev. 2001, 101, 608-618.

[174] J. A. Cowan, , Chem. Rev. 1998, 98, 1067-1087. 
[175] D. E. Wilcox, Chem. Rev. 1996, 96, 2435-2458.

[176] E. L. Hegg, J. N. Burstyn, Coord. Chem. Rev. 1998, 173, 133-165.

[177] D. W. Christianson, J. D. Cox, Annu. Rev. Biochem. 1999, 68, 33-57.

[178] L. J. Daumann, G. Schenk, D. L. Ollis, L. R. Gahan, Dalton Trans. 2014, 43, 910-928.

[179] J. Weston, Chem. Rev. 2004, 104, 699-767.

[180] R. Wolfenden, C. Ridgway, G. Young, J. Am. Chem. Soc. 1998, 120, 833-834.

[181] A. Radzicka, R. Wolfenden, Science 1995, 267, 90-93.

[182] P. J. O’ Brien, D. Herschlag, Biochemistry 2002, 41, 3207-3225.

[183] J. E. Coleman, Annu. Rev. Biophys. Biomol. Struct. 1992, 21, 441-483.

[184] R. Breslow, Acc. Chem. Res. 1995, 28, 146-153.

[185] W. H. J. Chapman, R. Breslow, J. Am. Chem. Soc. 1995, 117, 5462-5469.

[186] C. A. Vichard, T. A. Kaden, Inorg. Chim. Acta 2002, 337, 173-180.

[187] B. Bauer-Siebenlist, F. Meyer, E. Farkas, D. Vidovic, S. Dechert, Chem. -Eur. J. 2005, 11, 4349-4360.

[188] J. Qian, W. Gu, H. Liu, F. Gao, L. Feng, S. Yan, D. Liao, P. Cheng, Dalton Trans. 2007, 1060-1066.

[189] S. J. Franklin, Curr. Opin. Chem. Biol. 2001, 5, 201-208.

[190] K. E. Erkkila, D. Todom, J. K. Barton, Chem. Rev. 1999, 99, 2777-2795.

[191] C.-B. Chen, L. Milne, R. Landgraf, D. M. Perrin, D. S. Sigman, Chembiochem 2001, $2,735-740$.

[192] L. A. Basile, A. L. Raphael, J. K. Barton, J. Am. Chem. Soc. 1987, 109, 7550-7557.

[193] C. Sissi, P. Rossi, F. Felluga, F. Formaggio, M. Palumbo, P. Tecilla, C. Toniolo, P. Scrimin, J. Am. Chem. Soc. 2001, 123, 3169-3170.

[194] W. Chen, Y. Kitamura, J. M. Zhou, J. Sumaoka, M. Komiyama, J. Am. Chem. Soc. 2004, 126, 10285-10291.

[195] M. Komiyama, J. Biochem. 1995, 118, 665-670.

[196] Q. Dai, W. Gao, D. Liu, L. M. Kapes, X. Zhang, J. Org. Chem. 2006, 71, 3928-3934. 
[197] T. R. Chan, R. Hilgraf, K. B. Sharpless, V. V. Folkin, Org. Lett. 2004, 6, 2853-2855.

[198] O. Iranzo, T. Elmer, J. P. Richard, J. R. Morrow, Inorg. Chem. 2003, 42, 7737-7746.

[199] W. H. Chapman, Jr., R. Breslow, J. Am. Chem. Soc. 1995, 117, 5462-5469.

[200] F. Himo, T. Lovell, R. Hilgraf, V. V. Rostovtsev, L. Noodleman, K. B. Sharpless, V. V. Fokin, J. Am. Chem. Soc., 2005, 127, 210-216.

[201] F. B. Perler, E. O. Davis, G. E. Dean, F. S. Gimble, W. E. Jack, N. Neff, C. J. Noren, J. Thorner, M. Belofort, Nucl. Acids Res. 1994, 22, 1125-1127.

[202] T. C. Evans, M. Q. Xu, Jr., Biopolymers 1999, 51, 333-342.

[203] T. W. Muir, D. Sondhi, P. A. Cole, Proc. Natl. Acad. Sci. USA 1998, 95, 6705-6710.

[204] K. Severinov, T. W. Muir, J. Biol. Chem. 1998, 273, 16205-16209.

[205] R. B. Merrifield, J. Am. Chem. Soc. 1963, 85, 2149-2154.

[206] P. E. Dawson, S. B. Kent, Ann. Rev. Biochem. 2000, 69, 923-960.

[207] P. E. Dawson, T. W. Muir, I. Clark-Lewis, S. B. Kent, Science 1994, 266, 776-779.

[208] S. Chandrudu, P. Simerska, I. Toth, Molecules 2013, 18, 4373-4388.

[209] G. Holzwarth, P. Doty, J. Am. Chem. Soc. 1965, 87, 218-228.

[210] N. Greenfield, G. D. Fasman, Biochemistry 1969, 8, 4108-4116.

[211] S. Venyaminov, I. A. Baikalov, Z. M. Shen, C. S. Wu, J. T. Yang, Anal. Biochem. 1993, 214, 17-24.

[212] G. Bertani, J. Bacteriol. 1951, 62, 293-300.

[213] PROTEIN EXPRESSION \& ANALYSIS, Instruction Manual, IMPACT ${ }^{\mathrm{TM}}$ Kit. $^{\text {Kit }}$

[214] Novabiochem Catalog, Peptide Synthesis, 2010.

[215] S. Ahmed, R. Beleid, T. Sprules, K. Kaur, Org. Lett. 2007, 9, 25-28.

[216] J. Kang, J. H. Jo, Bull. Korean Chem. Soc. 2003, 24, 1403-1406.

[217] K. Weighardt, W. Schmidt, J. Weiss, Chem. Ber. 1979, 112, 2220-2230.

[218] S. Kimura, E. Bill, E. Bothe, T. Weyhermüller, K. Weighardt, J. Am. Chem. Soc. 2001, 123, 6025-6039. 


\section{List of abbreviations}

\begin{tabular}{|c|c|}
\hline$A$ & Adenine \\
\hline$\AA$ & Angstrom $\left(10^{-8} \mathrm{~cm}\right)$ \\
\hline$A A$ & amino acid \\
\hline Alloc & allyloxycarbonylchloride \\
\hline Approx & Approximately \\
\hline APS & Ammonium persulfate \\
\hline $\mathrm{aq}$ & aqueous \\
\hline BBT & BisBocTacn \\
\hline $\mathrm{Bn}$ & Benzyl \\
\hline Boc & Butyloxycarbonyl \\
\hline $\mathrm{bp}$ & base pairs \\
\hline $\mathrm{br}$ & broad \\
\hline $\mathrm{Bu}$ & butyl \\
\hline CBD & Chitin Binding Domain \\
\hline C & Cytosine \\
\hline${ }^{\circ} \mathrm{C}$ & degree Celsius \\
\hline$C D$ & Circular Dichroism \\
\hline $\mathrm{cm}$ & centimeter \\
\hline$\delta$ & chemical shift \\
\hline
\end{tabular}




\begin{tabular}{|c|c|}
\hline$d$ & doublet \\
\hline dd & doublet of doublet \\
\hline DCM & Dichloromethane \\
\hline DIC & diisopropylcarbodiimide \\
\hline DIPEA & diisopropylethylamine \\
\hline DMF & dimethylformamide \\
\hline DNA & deoxyribonucleic acid \\
\hline ds & double strand \\
\hline$\varepsilon$ & extinction co-efficient \\
\hline EDT & 1,2-ethanedithiol \\
\hline EPL & Expressed Protein Ligation \\
\hline ESI-MS & Electron Spray Ionization Mass Spectroscopy \\
\hline et al. & et alii \\
\hline $\mathrm{Et}_{3} \mathrm{~N}$ & Triethylamine \\
\hline EtOAc & Ethylacetate \\
\hline $\mathrm{EtOH}$ & Ethanol \\
\hline $\mathrm{Et}_{2} \mathrm{O}$ & Diethylether \\
\hline eq & equivalents \\
\hline FAM & carboxyfluorescein \\
\hline Fig. & Figure number \\
\hline Fmoc & 9-Fluorenylmethoxycarbonyl \\
\hline
\end{tabular}




\begin{tabular}{|c|c|}
\hline Fmoc-OSu & $\mathrm{N}$-(9-Fluorenylmethoxycarbonyl)succinimide \\
\hline g & gram \\
\hline G & Guanine \\
\hline Gnd. $\mathrm{HCl}$ & Guanidine hydrochloride \\
\hline h & hours \\
\hline HATU & 1-[Bis(dimethylamino)methylene]-1H-1,2,3-triazolo[4,5-b]pyridinium \\
\hline & 3-oxid hexafluorophosphate \\
\hline HBTU & $\begin{array}{l}N, N, N^{\prime}, N^{\prime} \text {-Tetramethyl-O-(1H-benzotriazol-1-yl)uranium } \\
\text { hexafluorophosphate }\end{array}$ \\
\hline HFIP & hexafluoroisopropanol \\
\hline HOAt & 1-Hydroxy-7-azabenzotriazole \\
\hline HOBt & 1-Hydroxybenzotriazole \\
\hline HPLC & High Performance Liquid Chromatography \\
\hline HRMS & High Resolution Mass Spectroscopy \\
\hline HMG & High mobility group \\
\hline IHF & Integration host factor \\
\hline IMPACT & Intein Mediated Purification with an Affinity Chitin-Binding Domain \\
\hline IPL & Intein mediated protein ligation \\
\hline IPTG & isopropyl-beta-D-thiogalactopyranoside \\
\hline IRTG & International Research Training Group \\
\hline J & coupling constant \\
\hline $\mathrm{L}$ & Liter \\
\hline
\end{tabular}




\begin{tabular}{|c|c|}
\hline LB & luria broth \\
\hline $\mathrm{m}$ & multiplet \\
\hline $\mathrm{MeCN} / \mathrm{ACN}$ & Acetonitrile \\
\hline $\mathrm{MeOH}$ & Methanol \\
\hline MESNA & sodium 2-mercaptoethanesulfonate \\
\hline $\mathrm{mg}$ & milligram \\
\hline $\mathrm{MHz}$ & megahertz \\
\hline $\min$ & minute \\
\hline $\mathrm{mL}$ & millilitre \\
\hline $\mathrm{mM}$ & millimolar \\
\hline$\mu \mathrm{M}$ & micromolar \\
\hline MMR & mismatch repair pathway \\
\hline NaAsc & sodium ascorbate \\
\hline $\mathrm{NCL}$ & Native Chemical Ligation \\
\hline NER & Nucleotide excision repair \\
\hline $\mathrm{nm}$ & nanometer \\
\hline $\mathrm{nM}$ & nanomolar \\
\hline NMM & $N$-Methylmorpholine \\
\hline NMP & $N$-Methyl-2-pyrrolidone \\
\hline NMR & Nuclear Magnetic Resonance \\
\hline $\mathrm{NCL}$ & native chemical ligation \\
\hline
\end{tabular}




\begin{tabular}{|c|c|}
\hline PAGE & Polyacrylamide Gel Electrophoresis \\
\hline $\mathrm{Pbf}$ & $2,2,4,6,7$-Pentamethyldihydrobenzofuran-5-sulfonyl protecting group \\
\hline $\mathrm{Pd} / \mathrm{C}$ & Activated Palladium Carbon \\
\hline PE & polyethylene \\
\hline PG & protecting group \\
\hline PIDA & (diacetoxyiodo)benzene \\
\hline ppm & parts per million \\
\hline q & Quartet \\
\hline$r_{f}$ & ratio of the peptide to DNA \\
\hline $\mathrm{R}_{\mathrm{f}}$ & retention Factor \\
\hline RNA & Ribonucleic acid \\
\hline $\mathrm{RP}$ & reverse phase \\
\hline $\mathrm{rpm}$ & rotations per minute \\
\hline r.t. & room temperature \\
\hline s & singlet \\
\hline $\mathrm{sec}$ & seconds \\
\hline SPPS & Solid Phase Peptide Synthesis \\
\hline ss & singlestrand \\
\hline $\mathrm{t}$ & triplet \\
\hline $\mathrm{T}$ & Thymine \\
\hline Tacn & Triazacyclononane \\
\hline
\end{tabular}




\begin{tabular}{|c|c|}
\hline${ }^{t} \mathrm{Boc}$ & tert-butoxycarbonyl \\
\hline TCEP & tris(carboxyethyl)phosphine \\
\hline TEMED & $N, N, N^{\prime}, N^{\prime}$-Tetramethylethylenediamine \\
\hline TFA & Trifluoroacetic acid \\
\hline THF & tetrahydrofuran \\
\hline TIS & Triisopropylsilane \\
\hline TLC & Thin Layer Chromatography \\
\hline$T_{m}$ & Melting Temperature \\
\hline TMS & trimethylsilyl \\
\hline TosCl & Tosylchloride \\
\hline$t_{R}$ & retention time \\
\hline Trt & trityl protecting group \\
\hline UV & Ultra-Violet \\
\hline $\mathrm{V}$ & Volt \\
\hline$v / v$ & volume by volume \\
\hline W & Watt \\
\hline$w t \%$ & weight percentage \\
\hline $\mathrm{Zf}$ & zinc finger domain \\
\hline ZFN & zinc finger nuclease \\
\hline
\end{tabular}




\section{Acknowledgements}

First and foremost, I would like to thank my supervisor Prof. Ulf Diederichsen for accepting me as a PhD student in his group and giving an opportunity to work on scientifically stimulating research topics. I am grateful for his support, guidance and freedom of research during the entire course of my PhD work.

I would like to thank him and other thesis committee members Prof. Franc Meyer and Prof. Sofi Elmroth for having me as a part of the very international graduate programme IRTG 1442 as well as for reviewing my thesis. Special thanks to Prof. Elmroth for inviting me to her group in Lund University and collaborating on the IHF topic. I thank her and her PhD student Alak Alsheikh for their valuable suggestions to improvise the work overall.

I am grateful for the financial support from Deutsche Forschungsgemeinschaft within the framework of "International Research Training Group 1422 - Metal sites in biomolecules".

I thank all the fellow members of the graduate programme for maintaining a very friendly environment and for organizing events together. I have really enjoyed attending seminars, courses, excursions, workshops and what not with you all.

I would like to thank Prof. Ivo Feussner and his group members Florian Brodhun and Julia Newie for collaborating on the zinc finger topic. I am also grateful to Prof. Claudia Höbartner and her group members Katarzyna Warzyniak, Lea Büttner and Biswajit Samanta for being very kind in extending support in times of need $(-)$.

I thank all the members of AK Diederichsen for a very friendly, good working atmosphere and for always being eager to help and share their knowledge. I am thankful to Aoife Neville for helping out with all the paper work and German to English translations :-)

I thank the members of lab 130 Christine Hansen, Swantje Nawratil, Martin Börsken, Amartya Banerjee, Stephen Middel, Spyros Markos, Eike Sachs and Stefan Müller for making every moment spent in lab truly memorable. 
I am deeply grateful to have the met the most wonderful bunch of people who have been truly my support system and gave me courage to endure as well as enjoy this phase my life. I will always cherish your friendship and the time that I spent with you all. I thank my lab colleagues Barbara Hübrich, Swantje Nawratil, Amartya Banerjee, Christine Hänsen, Meike Junius, Pawan Kumar and my sister Yamini for proof reading my thesis. Especial thanks to Franziska for her valuable suggestions and improvisations.

I thank you Debashis if not anything else but for just being there and tolerating me at all times. You know how tedious the task could be sometimes $(-)$.

Lastly, I convey my deepest and heartfelt gratitude to my family for their understanding, encouragement and blessings without which I would not be able to accomplish this work. My dearest sister Yamini I thank you for your positivity and motivational speeches $(:)$ 


\section{Curriculum Vitae}

\section{PERSONAL INFORMATION}

$\begin{array}{ll}\text { Name: } & \text { Harita Rao } \\ \text { Place and Date of Birth: } & \text { Andhra Pradesh, India | } 10 \text { March } 1987 \\ \text { Nationality: } & \text { Indian } \\ \text { E-mail: } & \text { hrao@gwdg.de, harita1987@gmail.com }\end{array}$

EDUCATION

PhD thesis in the group of Prof. Ulf Diederichsen,

IOBC, Georg-August-Universität Göttingen

$09 / 2011-11 / 2015$

“Metal Containing Peptides as Specific DNA Binders"

Master Thesis in the group of Dr. S. G. Srivatsan,

Indian Institute of Science Education \& Research - Pune $\quad$ 08/2010 - 06/2011

"Synthesis and Enzymatic Incorporation of an Azide

Modified Uridine Triphosphate"

Bachelor (B.S.) and Master (M.S.) in Chemistry

Indian Institute of Science Education \& Research - Pune $\quad$ 08/2006 - 06/2011

Higher \& Senior Secondary School Certificate (HSC \& SSC)

Central Board of Secondary Education (CBSE) 04/2002 - 03/2005

Modern Senior Secondary School - Kota, India. 
English: Fluent

Telugu: Native
Hindi: Fluent

German: Beginner

\section{EXPERIENCE}

Teaching Assistant in Advanced Organic Chemistry

$10 / 2014-02 / 2015$

Practical Course

Teaching Assistant in Basic Organic Chemistry

$05 / 2014-07 / 2014$

Practical Course

Teaching Assistant in Advanced Organic Chemistry

$10 / 2013-02 / 2014$

Practical Course

Training Bachelor Students

$04 / 2012-08 / 2012$

$04 / 2014-08 / 2014$

ACHIEVEMENTS \& AWARDS

PhD. Scholarship position in framework of IRTG-1422

$09 / 2011-10 / 2014$

"Metal Sites in Biomolecules"

INSPIRE Scholarship from the Government of India

$08 / 2008-04 / 2011$

DAAD-Wise fellowship for summer internship in group of

$05 / 2010-07 / 2010$

Prof. Alexander Heckel, University of Frankfurt 


\section{PUBLICATIONS}

Rao, H., Damian, M.S., Alsheikh, A., Elmroth, S.K.C., Diederichsen, U. Design, synthesis and DNA interaction of chimera between a platinum complex and an IHF mimicking peptide. Org. Biomol. Chem. 13, 11704-11713 (2015).

Rao, H., Tanpure, A.A., Sawant, A.A. \& Srivatsan, S.G. Post-transcriptional chemical functionalization of azide-modified oligoribonucleotides by bioorthogonal click and Staudinger reactions. Chem. Commun. 48, 498-500 (2012).

Rao, H., Sawant, A.A., Tanpure, A.A. \& Srivatsan, S.G. Enzymatic incorporation of an azide-modified UTP analog into oligonucleotides for post-transcriptional chemical functionalization. Nat. Protoc. 7, 1097-1112 (2012). 